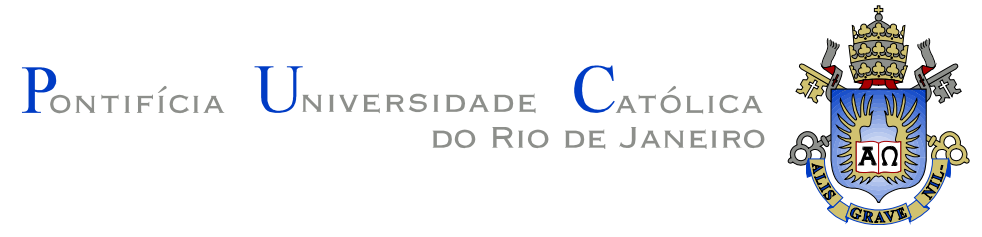

Matheus José Pinheiro Guerra

\title{
Planejamento de experimentos para otimização de critérios de aceitação da calibração de instrumentos de medição
}

Dissertação de Mestrado

Dissertação apresentada como requisito parcial para obtenção do grau de Mestre pelo Programa de PósGraduação em Metrologia (Área de concentração: Metrologia para Qualidade e Inovação) da PUC-Rio.

Orientador: Prof. Mauricio Nogueira Frota (PósMQI/PUC-Rio) Co-orientador: Dr. Elcio Cruz de Oliveira (PETROBRAS) 
Matheus José Pinheiro Guerra

\section{Planejamento de experimentos para otimização de critérios de aceitação da calibração de instrumentos de medição}

Dissertação de Mestrado

Dissertação apresentada como requisito parcial para obtenção do grau de Mestre pelo Programa de PósGraduação em Metrologia (Área de concentração: Metrologia para Qualidade e Inovação) da PUC-Rio. Aprovada pela Comissão Examinadora abaixo assinada.

Prof. Mauricio Nogueira Frota Orientador Programa de Pós-Graduação em Metrologia - PUC-Rio

Dr. Elcio Cruz de Oliveira Co-orientador PETROBRAS S.A.

Prof. Carlos Roberto Hall Barbosa Programa de Pós-Graduação em Metrologia - PUC-Rio

Profa. Veronica Maria de Araujo Calado Universidade Federal do Rio de Janeiro - UFRJ

Prof. Marcio da Silveira Carvalho Coordenador Setorial de Pós-Graduação do

Centro Técnico Científico - PUC-Rio 
Todos os direitos reservados. É proibida a reprodução total ou parcial do trabalho sem autorização da universidade, do autor e do orientador.

Matheus José Pinheiro Guerra

Formado em Engenharia Civil pela Universidade Federal do Espírito Santo, em 2010. Trabalha na Petrobras, desde 2006, em atividade de suporte técnico em metrologia e medição de fluidos.

Ficha Catalográfica

Guerra, Matheus José Pinheiro

Planejamento de experimentos para otimização de critérios de aceitação da calibração de instrumentos de medição / Matheus José Pinheiro Guerra; orientador: Mauricio Nogueira Frota; co-orientador: Elcio Cruz de Oliveira. - 2015.

138 f. : il. (color.) ; $30 \mathrm{~cm}$

Dissertação (mestrado) - Pontifícia Universidade Católica do Rio de Janeiro, Programa de PósGraduação em Metrologia. Área de concentração: Metrologia para Qualidade e Inovação, 2015.

Inclui bibliografia

1. Metrologia - Teses. 2. Planejamento de experimentos. 3. Metodologia de superfície de resposta. 4. Otimização. 5. Medição por placa de orifício. I. Frota, Mauricio Nogueira. II. Oliveira, Elcio Cruz de. III. Pontifícia Universidade Católica do Rio de Janeiro. Programa de Pós-Graduação em Metrologia. Área de concentração: Metrologia para Qualidade e Inovação. IV. Título. 
A Deus, pelas oportunidades e sucessos alcançados. Aos meus pais, que não mediram esforços em apoiar-me e incentivar-me pela formação acadêmica e pessoal. À minha esposa, pelo apoio incondicional para a conclusão deste trabalho 


\section{Agradecimentos}

A Deus por todas conquistas alcançadas.

Ao meu orientador, Professor Ph.D. Mauricio Nogueira Frota, pela paciência, dedicação, orientação e persistência pelo melhor desenvolvimento desta dissertação.

A meu co-orientador, Dr. Elcio Cruz de Oliveira, pela dedicação em engajar-me na difusão da metodologia de otimização a partir do desenvolvimento desta dissertação, pela paciência e horas empenhadas nas revisões e desenvolvimento deste estudo.

À Petrobras, principalmente aos meus superiores, José Luiz Marcuso, Luiz Robério, João Luiz Seder e Renato Dias pela oportunidade de participar deste projeto.

Aos meus pais, pelo amor incondicional e sacrifícios pelos filhos.

A minha amada esposa, pelo estímulo, carinho e dedicação. Mesmo tendo que cuidar do nosso recém-chegado João Pedro, soube me incentivar e apoiar para a conclusão deste trabalho.

Aos professores do Programa de pós-graduação em Metrologia, pelos conhecimentos transmitidos.

Aos amigos do mestrado, em particular o Fagner, entusiasta da metrologia, pela amizade e apoio.

Aos amigos do trabalho, em especial a Leonardo pelo incentivo, Andreatta e Milena, pelo companheirismo e apoio.

E a todos aqueles que de alguma forma contribuíram para o desenvolvimento e a realização deste trabalho. 


\section{Resumo}

Guerra, Matheus José Pinheiro; Frota, Mauricio Nogueira; Oliveira, Elcio Cruz de. Planejamento de experimentos para otimização de critérios de aceitação da calibração de instrumentos de medição. Rio de Janeiro, 2015. 138p. Dissertação de Mestrado - Programa de Pós-Graduação em Metrologia (Área de concentração: Metrologia para Qualidade e Inovação), Pontifícia Universidade Católica do Rio de Janeiro.

O objetivo desta dissertação é propor critérios de aceitação da calibração individual de transmissores secundários de pressão estática, pressão diferencial e temperatura como dados de entrada da calibração final do sistema de medição de vazão de gás natural por placa de orifício. A motivação que norteou o desenvolvimento deste trabalho resultou do fato de o recém-introduzido Regulamento Técnico de Medição de Petróleo e Gás Natural (RTM) não definir as tolerâncias aplicáveis aos instrumentos associados a este tipo de sistema de medição, deixando esta decisão a cargo do usuário. Nesse sentido, o trabalho visa contribuir para a melhoria do controle metrológico do medidor de vazão por placa de orifício vis-à-vis o que determina o RTM, i.e.: incerteza expandida limitada a $1,5 \%$ em medições fiscais e $2 \%$ em medições de apropriação. A metodologia utilizada é a do planejamento experimental e de superfície de resposta, que permitiu otimizar os critérios de aceitação da incerteza associada a cada um dos três instrumentos que interferem no sistema de medição. Os resultados obtidos definem valores critérios-limites para a calibração de cada um dos transmissores secundários, de pressão estática, pressão diferencial e temperatura. Dentre as conclusões destaca-se a validação da metodologia proposta, que permitiu definir os critérios de aceitação da calibração pela análise da calibração individual de cada instrumento que integra o sistema global do medidor por placa de orifício. Finalizando, o trabalho encaminha recomendações para a melhoria da estrutura laboratorial da Unidade Operacional da Petrobras, no Espírito Santo (UO-ES), visando assegurar atendimento aos requisitos do regulamento técnico de medição de petróleo e gás natural.

\section{Palavras-chave}

Metrologia; planejamento de experimentos; metodologia de superfície de resposta; otimização; medição por placa de orifício. 


\section{Abstract}

Guerra, Matheus José Pinheiro; Frota, Mauricio Nogueira (Advisor); Oliveira, Elcio Cruz de (Co-Advisor). Design of experiments for optimizing acceptance criteria of measuring instruments calibration. Rio de Janeiro, 2015. 138p. MSc. Dissertation - Programa de Pós-Graduação em Metrologia (Área de concentração: Metrologia para Qualidade e Inovação), Pontifícia Universidade Católica do Rio de Janeiro.

The aim of this dissertation is to propose individual acceptance criteria calibration of secondary transmitters of static pressure, differential pressure and temperature as the final calibration input data of the natural gas flow measurement system by orifice plate. The motivation that guided the development of this work resulted from the fact that the newly introduced technical regulation of Petroleum and Natural Gas measurement (RTM) does not define the applicable tolerances to associated instruments with this type of measurement system, leaving this decision in charge of user. In this sense, the work aims to contribute to the improvement of the metrological control of the flowmeter by orifice plate vis-à-vis what determines the RTM, e.g.: expanded uncertainty limited to $1.5 \%$ on fiscal measurements and $2 \%$ on measurements appropriation. The methodology used is the experimental design and response surface witch allowed to optimize the acceptance criteria of uncertainty associated each of the three instruments that interfere in the measurement system. The obtained results define the limits criteria values for each calibration of secondary transmitters, static pressure, differential pressure and temperature. Among the conclusions stands out the validation of proposal methodology, which allowed to define the acceptance criteria of calibration for analysis of individual calibration of each instrument that integrates global system for measuring orifice plate. Finally, the work forward recommendations for the improvement of laboratory structure of Petrobras Operation, in the Espírito Santo (UO-ES) in order to ensure compliance with the requirements of the technical regulation of oil and natural gas measurement.

\section{Keywords}

Metrology; experimental design; response surface methodology; optimization; square-edged orifice meters. 


\section{Sumário}

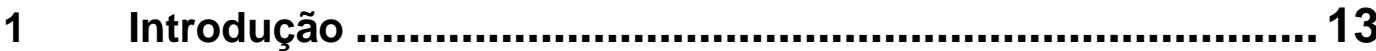

$\begin{array}{lll}1.1 & \text { Definição do problema de pesquisa }\end{array}$

1.2 Objetivos: geral e específicos 16

$\begin{array}{lll}1.3 & 16\end{array}$

$\begin{array}{lll}1.4 & \text { Estrutura da dissertação } & 17\end{array}$

2 Fundamentação teórica .................................................... 18

$2.1 \quad$ Preceitos da metrologia legal 18

2.2 O regulamento técnico de medição de petróleo e gás natural 19

$\begin{array}{lll}2.3 & \text { Sistema de gestão da medição } & 21\end{array}$

2.4 Medição de gás natural por placa de orifício 23

2.4.1 O gás natural 23

2.4.2 A medição do gás natural à luz do RTM 23

3 Uso do planejamento de experimentos para definição de critérios de aceitação de instrumentos ...................................... 27

3.1 Planejamento de experimentos 27

3.2 Planejamento fatorial $2^{\mathrm{k}} \quad 29$

3.3 Explorando uma superfície de resposta 32

3.4 Planejamento composto central (Central Composite Design -

CCD) 35

$4 \quad$ Medição de vazão por placa de orifício ............................. 38

4.1 Instrumentos utilizados nas estações de medição de gás Natural

4.2 Transmissores de pressão e seus princípios de funcionamento 39

4.2.1 Sensores capacitivos de pressão 39

4.2.2 Sensores de pressão piezorresistivos 41

4.2.3 Sensores de pressão piezoelétricos 42

4.2.4 Sensores de silício ressonante 42 
$5 \quad$ Resultados e discussão 46

5.1 As estações de medição de gás natural estudadas 46

5.2 Condições de contorno adotadas nos experimentos 47

5.3 Planejamento do experimento e superfície de resposta 49

5.3.1 Estação $A$ - estação de medição fiscal 50

5.3.2 Compilação dos valores limites de incerteza das EMEDs estudadas

6 Conclusões e recomendações

62

6.1 Conclusões 62

6.2 Recomendações para desdobramento futuros desta dissertação

7 Referência Bibliográfca 64

APÊNDICE A 67

A.1 Estação B - estação de medição fiscal 67

A.2 Estação C - estação de medição para apropriação 72

A.3 Estação D - estação de medição fiscal 78

A.4 Estação E1 - estação de medição para apropriação 83

A.5 Estação E2 - estação de medição para apropriação 89

A.6 Estação F1 - estação de medição para apropriação 94

A.7 Estação F2 - estação de medição fiscal 100

A.8 Estação G1 - estação de medição fiscal 105

A.9 Estação G2 - estação de medição para apropriação 111

A.10 Estação $\mathrm{H}$ - estação de medição fiscal 116

A.11 Estação I - estação de medição fiscal 122

A.12 Estação J1 - estação de medição fiscal 127

$\begin{array}{ll}\text { A.13 Estação J2 - estação de medição fiscal } & 133\end{array}$ 


\section{Lista de Figuras}

Figura 1 - Arquitetura típica de um sistema de medição por placa de orifício

Figura 2 - skid de um sistema de medição por placa de orifício 25

Figura 3 - Esquema do processo de planejamento experimental 28

Figura 4 - Planejamento fatorial $2^{3} \quad 31$

Figura 5 - Superfície de resposta $\eta=f(P ; T)$

Figura 6 - Planejamentos compostos centrais. 36

Figura 7 - Esquema construtivo de um sensor capacitivo 40

Figura 8 - Diafragma com sensores de pressão piezorresistivos 41

Figura 9 - Transdutor de silício ressonante 43

Figura 10 - Exemplos de termorresistências utilizadas 44

Figura 11 - Gráfico de Pareto em função dos valores da estatística de teste $\mathrm{t}$

Figura 12 - Resíduos versus estimativas de y (EMED A - nível:

$1 \%$ f.e. e $\left.1{ }^{\circ} \mathrm{C}\right)$.

Figura 13 - Superfície de resposta (EMED A) dado uP e uDP (1\% f.e.) 54

Figura 14 - Curva de nível (EMED A) dado uP e uDP (1\% f.e.) 54

Figura 15 - Superfície de resposta (EMED A) dado uP ( $1 \%$ f.e.) e Ut $\left( \pm 1^{\circ} \mathrm{C}\right)$

Figura 16 - Curva de nível (EMED A) dado uP ( $1 \%$ f.e.) e uT $\left( \pm 1^{\circ} \mathrm{C}\right) \quad 55$

Figura 17 - Superfície de resposta (EMED A) dado uDP ( $1 \%$ f.e.) e Ut $\left( \pm 1^{\circ} \mathrm{C}\right)$

Figura 18 - Curva de nível (EMED A) dado uDP (1\% f.e.) e uT $\left( \pm 1^{\circ} \mathrm{C}\right)$

Figura 19 - Superfície de resposta (EMED E1) dado uP e uDP (0,75\% f.e.)

Figura 20 - Superfície de resposta (EMED E2) dado uP e Udp $(0,75 \%$ f.e. $)$

Figura 21 - Superfície de resposta (EMED F1) dado uP e uDP $(1 \%$ f.e.) 60

Figura 22 - Curva de nível (EMED F1) dado uP e uDP ( 1 \% f.e.)

Figura 23 - Superfície de resposta (EMED F2) dado UP e UDP (1\% f.e.)

Figura 24 - Curva de nível (EMED F2) dado uP e u $\Delta \mathrm{P}$ (1 \% f.e.) 


\section{Lista de Tabelas}

Tabela 1 - Erro máximo admissível de sistemas de medição

Tabela 2 - Erro máximo admissível dos instrumentos associados

Tabela 3 - Representações alternativas para um planejamento fatorial $2^{3}$

Tabela 4 - Matriz dos coeficientes de contrastes num Planejamento fatorial $2^{3}$

Tabela 5 - Matriz do Planejamento composto central com três variáveis

Tabela 6 - *Características dos instrumentos instalados nas EMEDs 38

Tabela 7 - Características das estações de medição 46

Tabela 8 - Matriz de planejamento experimental 47

Tabela 9 - Matriz de planejamento experimental da EMED A 50

Tabela 10 - Tabela de ANOVA do planejamento de experimentos da EMED A

Tabela 11 - Matriz das incertezas estimadas da vazão (EMED A) 53

Tabela 12 - Valores limites das grandezas de influência das respectivas EMEDs

Tabela 13 - Equações das superfícies de resposta das EMEDs 


\title{
Lista de Siglas
}

\author{
Símbolo \\ Descrição \\ ABNT \\ Associação brasileira de normas técnicas \\ AGA \\ American gas association \\ ANP \\ ANSI \\ Agência nacional de petróleo, gás natural e biocombustíveis \\ API \\ American National Standards Institute \\ BSW \\ American Petroleum Institute \\ CMC \\ Percentual de água e sedimentos no fluido medido \\ Capacidade de medição e calibração \\ CONMETRO Conselho Nacional de Metrologia, Normalização e Qualidade Industrial \\ EMA \\ Erro máximo admissível \\ EMED \\ Estação de medição de fluidos \\ $E \& P$ \\ Exploração e produção \\ IAAC \\ InterAmerican Accreditation Cooperation \\ IEC \\ International Electrotechnical Commission \\ ILAC \\ International Laboratoratory Accreditation Cooperation \\ INMETRO \\ Instituto Nacional de Metrologia, Qualidade e Tecnologia \\ ISO \\ International Organization for Standardization \\ ITU \\ International Telecommunication Union \\ MSR \\ Metodologia de Superfície de Resposta \\ OIML \\ Organização Internacional de Metrologia Legal \\ PCC \\ Planejamento composto central \\ PRT \\ Platinum Resistance Thermometer \\ RTD \\ Resistance Temperature Detectors \\ RTM \\ Regulamento técnico de medição de Petróleo e Gás \\ SGM \\ Sistema de gestão da medição \\ UO-ES \\ Unidade de operação da Petrobras no Espírito Santo
}

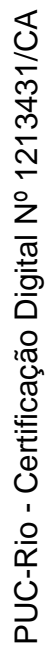




\section{Introdução}

A necessidade da medição da vazão de um líquido surgiu há muitos séculos com a percepção pela administração pública de ao taxar a vazão de água potável canalizada para o consumo doméstico ter-se-ia uma razoável fonte de arrecadação (DELMÉE, 2003). Foi, entretanto, somente a partir do século XX que medir a vazão de fluidos diversos tornou-se premente em decorrência do crescimento da aplicação dos processos contínuos na indústria, em substituição aos processos em batelada. $\mathrm{O}$ século XX foi marcado pela realização de inúmeros eventos técnico-científicos reunindo especialistas de empresas, universidades e institutos de pesquisas, assim impulsionando a indústria de instrumentos e a criação de organismos nacionais e internacionais de normalização (e.g.: a IEC, em 1906; a ABNT, em 1945; a ISO e a ITU, em 1947) responsáveis pelo desenvolvimento de normas técnicas que, incontestavelmente, possuem um papel fundamental na melhoria da qualidade e da confiabilidade desses instrumentos de medição.

Nesse mesmo século, surgiram inúmeros avanços no campo da ciência, aplicações industriais e da Meteorologia (SANTANA, GUIMARÃES, THOMAZ Jr, \& E ARLINO, 2008). No contexto do desenvolvimento tecnológico, a Metrologia experimentou expressivos avanços, contribuindo para a consolidação de unidades de medida mais estáveis e adequadamente caracterizadas em conformidade às normas aplicáveis.

A Metrologia Legal, por sua vez, originada da necessidade de assegurar um comércio justo, é responsável pela proteção do consumidor enquanto comprador de produtos e serviços medidos, e do vendedor, enquanto fornecedor destes (INMETRO, 2013). Os regulamentos técnicos, as portarias e outros dispositivos legais impostos pela regulação e pelo controle do Estado constituem-se em documentos legais fundamentais para garantir qualquer operação comercial.

No domínio das operações que envolvem a exploração, produção e comercialização de petróleo e gás natural, tais documentos regulam as ações das atividades econômicas da indústria do petróleo com a União. Notadamente, dentre as empresas que atuam nesse setor, tem-se como exemplo a Petrobras.

Em 2000, após a quebra do monopólio para a exploração do petróleo e gás natural no Brasil, foi publicada a Portaria Conjunta ANP/INMETRO $n^{\circ} 1$, que instituiu o Regulamento Técnico de Medição de Petróleo e Gás Natural (RTM ${ }^{1}$ ). Com a promulgação deste regulamento, na última década, as atividades de exploração e produção de petróleo e gás natural no Brasil passaram por um acelerado processo de reestruturação organizacional e de adequação das instalações de medição para atender ao RTM (CARVALHO, 2011).

\footnotetext{
${ }^{1}$ Este regulamento estabelece as condições e requisitos mínimos que os sistemas de medição de petróleo e gás natural devem observar, com vistas a garantir resultados completos e com uma determinada exatidão de medida.
} 
Em dezembro de 2013, entrou em vigor a resolução conjunta ANP/INMETRO $n^{\circ} 1$, que institui o novo regulamento técnico de medição de petróleo e gás natural em substituição ao então RTM vigente. Este novo RTM busca a garantia da credibilidade dos resultados de medição. Mostra-se mais detalhado e organizado que o anterior, pois destaca o seu papel em especificar requisitos técnicos, construtivos e metrológicos mínimos que os sistemas de medição deverão atender, conceitos esses inexistentes no RTM anterior.

Similarmente à revolução introduzida pelo RTM de 2000, a sua revisão recentemente aprovada certamente impõe novos desafios e responsabilidades aos diferentes atores que operam no setor.

Dentre estes novos desafios, pode-se destacar a obrigatoriedade em utilizar laboratórios acreditados por organismos de acreditação que sejam signatários de Acordo de Reconhecimento Mútuo da ILAC (International Laboratoratory Accreditation Cooperation) ou da IAAC (InterAmerican Accreditation Cooperation) para as calibrações dos instrumentos de medição ou para as inspeções dimensionais.

Tal obrigação pode se mostrar como um fator complicador quanto ao atendimento ao requisito da nova resolução conjunta pois, apesar do prazo estipulado para a aquisição de serviços de calibração acreditados ser de 24 meses após a vigência da nova resolução, o mercado brasileiro de calibração não registrou crescimento substancial para ofertar este serviço nos escopos e capacidade de medição e calibração (CMC) para atendimento da demanda. Por exemplo, poucas são as empresas que possuem acreditação em todos os escopos necessários para inspeção dos trechos retos de medição.

Ainda sobre os novos desafios, pode-se destacar a obrigatoriedade das empresas exploradoras e produtoras de petróleo e gás natural adotarem um sistema de gestão da medição (SGM) similar ao previsto na NBR ISO 10012, sem obrigálas a tal sistema ser certificado.

Com a compulsoriedade da implantação de um SGM, observa-se a disposição da ANP em melhorar a credibilidade dos resultados das medições, haja visto que a implantação de um SGM envolve a mudança de cultura de uma empresa pois, para garantir a qualidade metrológica, deverá ser buscada a melhoria contínua dos processos gerindo as informações relacionadas à atividade de medição, aos sistemas de medição, aos equipamentos de medição e aos sistemas de controle de processo. Com isso, em um primeiro momento, a implantação deste tipo de sistema de gestão, aparentemente, pode apresentar-se trabalhosa e custosa.

Contrapondo-se às situações negativas da implantação e manutenção de um SGM, tem-se a possibilidade de ganhos econômicos para a empresa pois, em determinados sistemas de medição que por ventura tiverem desvios desfavoráveis às empresas, os mesmos poderão ser identificados, conhecidos e corrigidos. $\mathrm{E}$, com isso, poder-se-á reduzir pagamentos de royalties, participações, impostos ou compromissos contratuais indevidos por conta de erros de medição.

Não obstante à atualização do RTM, este, e tampouco sua versão anterior, não definem critérios metrológicos para os instrumentos de medição associados ao sistema de medição de gás. Este RTM apresenta apenas a classe de exatidão para a qual um determinado sistema deve ser projetado, instalado e calibrado. Apesar 
disso, o INMETRO ainda não publicou uma portaria que defina os erros máximos admissíveis definidos para os sistemas de medição de gás, similar ao que a portaria do INMETRO/MDIC $\mathrm{n}^{\circ} 64$ de abril de 2003 apresenta para os instrumentos de sistemas de medição de petróleo, seus derivados líquidos, álcool anidro e álcool hidratado carburante.

Assim sendo, para suprir esta carência da definição das tolerâncias a serem adotadas para cada instrumento de medição associado ao sistema de medição de gás, adota-se a recomendação OIML R 140 - Measuring systems for gaseous fuel (Sistemas de medição para combustíveis gasosos). Este documento sugere valores de erros máximos admissíveis para sistemas de medição e instrumentos a eles associados.

Atrelados a essa inexistência de critério metrológico para os instrumentos de

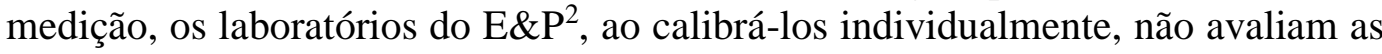
suas incertezas de medição, de forma global. Consequentemente, a decisão por ajustes nesses instrumentos a fim de garantir o atendimento à incerteza máxima do sistema de medição de gás acaba não se realizando de forma racional e otimizada ainda no laboratório.

Objetivando preencher essas lacunas, esta pesquisa de mestrado se propõe a identificar os possíveis critérios de incerteza a serem adotados na calibração dos instrumentos de medição de pressão estática, pressão diferencial e temperatura para sistemas de medição de gás por placa de orifício. Espera-se, assim, que ao incorporar exigências de calibração no sistema global de medição de vazão, seja possível atender ao critério de 1,5\% na incerteza associada à medição fiscal de gás e de $2 \%$ na incerteza associada à medição de gás para apropriação, conforme especificadas na edição vigente do RTM.

\section{1 \\ Definição do problema de pesquisa}

No contexto da Metrologia Legal, que requer comprovação metrológica com frequência predeterminada dos instrumentos de pressão diferencial, pressão estática e temperatura do fluido em escoamento utilizados na medição de vazão, o RTM define condições para assegurar níveis mínimos de incerteza associada à medição de vazão. Em sintonia com esse preceito, esta pesquisa de mestrado propõe-se a responder à seguinte questão:

"Quais são os máximos valores de incerteza expandida da medição a serem adotados como critérios de aceitação nas calibrações dos transmissores de pressão estática, de pressão diferencial e de temperatura para assegurar que a incerteza expandida da medição de vazão de gás natural, por placa de orifício, atenda aos requisitos do RTM aplicável nas medições fiscais e de apropriação?"

Para responder essa questão principal da pesquisa, as seguintes questões específicas foram formuladas:

\footnotetext{
2 O setor de Exploração e Produção da Petrobras é o órgão de sua estrutura responsável pela pesquisa, localização, identificação, desenvolvimento, produção e incorporação de reservas de óleo e gás natural dentro do território nacional (PETROLEO, 2009 Apud MARCHETI, 2010).
} 
Quais são os critérios-limites para o uso dos instrumentos de medição de pressão estática, pressão diferencial e temperatura utilizados nos sistemas de medição de gás natural por placa de orifício?

Qual é a influência da contribuição da calibração dos instrumentos de medição de pressão estática, pressão diferencial e temperatura no cômputo da incerteza global associada ao sistema de medição?

Qual é a capacidade mínima necessária de um laboratório para assegurar que a calibração dos instrumentos de medição associados seja realizada em conformidade aos critérios de aceitação identificados?

\section{2}

\section{Objetivos: geral e específicos}

Com base no exposto, o objetivo geral deste trabalho é avaliar e identificar os possíveis critérios de aceitação a serem utilizados na calibração dos transmissores secundários de pressão estática, pressão diferencial e temperatura do gás. Mais especificamente, assegurar que a incerteza expandida associada à medição de vazão de gás por placa de orifício atenda ao RTM aplicável, ou seja, não ultrapasse 1,5\% para as medições fiscais e $2 \%$ nas medições de apropriação.

Em consonância com este objetivo central, definem-se os seguintes objetivos específicos:

- Identificar os critérios-limites para o uso dos instrumentos de medição de pressão estática, pressão diferencial e temperatura utilizados nos sistemas de medição de gás natural;

- Verificar a influência dos critérios de aceitação na incerteza global do sistema de medição de pressão estática, pressão diferencial e temperatura utilizando-se como metodologia o planejamento fatorial;

- $\quad$ Propor uma capacidade de medição laboratorial mínima que possibilite a realização da calibração dos instrumentos de medição associados em conformidade aos critérios de aceitação da calibração dos instrumentos identificados.

\section{3}

\section{Motivação}

Este trabalho foi motivado pela observação de que a resolução conjunta ANP/INMETRO n $^{\text {1 }}$ 1, de junho de 2013, (RTM aplicável à medição de vazão de petróleo e gás), não define os limites aceitáveis de incerteza associados à calibração dos instrumentos de medição secundários requeridos para a medição de vazão ${ }^{3}$ de gás. Assim, a escolha desses valores máximos admissíveis fica a cargo do usuário, a quem compete a responsabilidade de assegurar que a incerteza expandida associada à medição de vazão de gás esteja em conformidade aos requisitos do RTM. O desconhecimento desta incerteza suscita, portanto, dúvidas sobre os

\footnotetext{
${ }^{3}$ Entende-se por instrumentos de medição associados os sensores e transmissores de pressão estática, pressão diferencial e temperatura.
} 
critérios adotados, o que pode levar o usuário a, desnecessariamente, desqualificar o uso dos instrumentos acessórios de medição das grandezas de influência (pressão estática, pressão diferencial e temperatura do gás) mesmo em situações em que tais medições atendam aos requisitos do RTM. Com isso, fazendo uso do método de superfície de resposta (ferramenta muito utilizada na otimização de processos), buscou-se identificar os critérios de aceitação adequados que poderiam ser adotados nas calibrações dos instrumentos de medição; em particular, daqueles utilizados nos sistemas de medição fiscal e de apropriação de gás por placa de orifício das estações de medição (EMED) de interesse.

Acredita-se que a introdução de critérios inteligentes de aceitação a serem adotados na calibração dos instrumentos secundários de medição seja capaz de evitar o descarte prematuro de instrumentos secundários que, embora não estejam em conformidade com requisitos da norma vigente ainda se encontram em condições adequadas para outro uso. Espera-se, também, contribuir para a difusão do uso da metodologia de planejamento fatorial ao se avaliar a adequação e os limites de uso de um determinado instrumento secundário nas estações de medição selecionadas para estudo neste trabalho.

\section{4}

\section{Estrutura da dissertação}

A dissertação estrutura-se em seis capítulos, incluindo esta introdução.

O capítulo 2 discorre sobre a base conceitual de Metrologia Legal, identifica as principais mudanças no Regulamento Técnico de Medição de Petróleo e Gás Natural, destaca a importância da adoção de sistemas de gestão da medição e a referência que o RTM faz à NBR ISO 10012 e, por fim, discorre brevemente sobre a medição de gás natural por placa de orifício a luz do RTM.

O capítulo 3 revê a base conceitual relacionada ao planejamento experimental fatorial e o uso da metodologia de superfície de resposta para identificar os limites máximos de cada fator.

O capítulo 4 caracteriza as estações de medição da Unidade de Operações de Exploração e Produção do Espírito Santo (UO-ES) e discorre sobre os instrumentos de medição de temperatura, pressão estática e pressão diferencial do gás natural, de forma a caracterizá-los metrologicamente.

O capítulo 5 descreve o planejamento experimental realizado para as EMED escolhidas da UO-ES e apresenta a revisão dos critérios adotados para cada instrumento, considerando as três grandezas físicas (temperatura, pressão estática e pressão diferencial) e os três níveis atribuídos a cada fator.

Concluindo o trabalho, o capítulo 6 apresenta as conclusões da pesquisa e encaminha recomendações para a melhoria da estrutura laboratorial da UO-ES, visando assegurar atendimento aos requisitos do regulamento técnico de medição de petróleo e gás natural. Inclui, também, sugestões para futuros estudos como desdobramentos naturais deste trabalho. 


\section{2 \\ Fundamentação teórica}

A Metrologia é uma ciência estratégica para o desenvolvimento econômico e social do País, pois a aplicação de seus conceitos nos processos produtivos é parte integrante da infraestrutura básica de apoio à competitividade das empresas, à preservação da saúde, da segurança, do meio ambiente, à proteção do consumidor e prevenção de práticas enganosas de comércio (resolução $n^{\circ} 1$ de 2013 do CONMETRO $^{4}$ ).

\section{1}

\section{Preceitos da metrologia legal}

Em particular, a metrologia legal estabelece as exigências legais, técnicas e administrativas referentes às unidades de medida, aos métodos e instrumentos de medição, com o propósito de proteger o consumidor. Compete, portanto, à metrologia legal assegurar que transações comerciais sejam realizadas em absoluta observância das unidades de medida, dos métodos e sistemas de medição.

A metrologia legal compreende as seguintes atividades (SILVA, 2009):

- $\quad$ Estabelecimento de exigências legais;

- Promoção da infraestrutura necessária para a rastreabilidade das medições e dos instrumentos de medição regulamentados;

- Supervisão dos produtos/instrumentos regulamentados e das atividades regulamentadas; e

- Controle/avaliação da conformidade de produtos regulamentados e atividades regulamentadas.

No âmbito da metrologia legal, entende-se como controle metrológico legal o controle efetuado pelo Estado sobre os instrumentos (ou sistemas) de medição ou medidas materializadas, notadamente aquelas utilizadas nas atividades comerciais, na saúde, na segurança e no meio ambiente. Esse controle legal, por sua vez, combina todas as atividades de metrologia legal em prol da garantia metrológica.

Desta forma, o INMETRO, no uso de suas atribuições, endossa e dissemina regulamentos consubstanciados nas recomendações da Organização Internacional de Metrologia Legal (OIML) e das contribuições dos diversos setores da sociedade brasileira diretamente interessados no objeto da regulamentação.

O Regulamento técnico de medição de petróleo e gás natural (RTM), elaborado conjuntamente pelo INMETRO e pela Agência Nacional do Petróleo, Gás Natural e Biocombustíveis (ANP), se constitui em um exemplo de controle metrológico de grande impacto para o setor petroquímico.

\footnotetext{
${ }^{4}$ CONMETRO - Conselho Nacional de Metrologia, Normalização e Qualidade Industrial. Dispõe sobre a aprovação do documento "Diretrizes Estratégicas para a Metrologia Brasileira 2013-2017". Resolução no 01, de 10 de abril de 2013.
} 
Considerando que a metrologia legal é a parte da metrologia relacionada às atividades resultantes de exigências obrigatórias, referentes às medições, unidades de medida, instrumentos de medição e métodos de medição (SILVA, 2009). No ramo de exploração e produção de petróleo e gás natural, a metrologia legal deve ser considerada como parte fundamental na garantia dos interesses da União, da empresa produtora e dos proprietários de terras sobre jazidas em produção. Com isso, pode-se dizer que o RTM, à luz da metrologia legal, mostra-se como um instrumento regulador dos métodos de medição do petróleo e gás natural no Brasil e, mais do que isso, mostra-se como um instrumento garantidor da credibilidade dos resultados de medição.

\section{2 \\ O regulamento técnico de medição de petróleo e gás natural}

Por se tratar de um instrumento regulatório de controle legal, o RTM estabelece as condições e os requisitos técnicos, construtivos e metrológicos mínimos que os sistemas de medição de petróleo e gás natural devem atender.

Como apresentado anteriormente, o RTM é um dispositivo regulatório que visa assegurar uma transação comercial justa para as partes envolvidas, pela imposição de exigências que assegurem a confiabilidade da medição na exploração e produção de petróleo e gás natural.

Este regulamento aplica-se ao projeto, instalação, operação, teste e à manutenção em condições normais de operação dos seguintes sistemas de medição: (i) volumétrica fiscal do petróleo ou do gás natural produzido nos campos; (ii) volumétrica de apropriação do petróleo ou do gás natural produzido; (iii) volumétrica do petróleo ou do gás natural para controle dos volumes produzidos, consumidos, injetados, transferidos e transportados; (iv) volumétrica do petróleo ou do gás natural para controle dos volumes importados e exportados em pontos de aduana; (v) volumétrica de transferência de custódia do petróleo ou do gás natural; e (vi) volumétrica de água para controle operacional dos volumes produzidos, captados, transferidos, injetados e descartados.

Esta nova edição revisada do RTM (já aplicável aos novos sistemas de medição que adotam o sistema de partilha de produção) define novos prazos de calibração dos instrumentos de medição, com uma frequência reduzida em relação aos prazos da versão anterior do RTM. Esta mudança representa um grande ganho para os agentes regulados, pois a realização de calibrações em curtos períodos de tempo mostrava-se desnecessária tecnicamente devido à qualidade metrológica dos instrumentos disponíveis no mercado, uma vez que os mesmos apresentavam baixas derivas temporais, corroborando com a manutenção da qualidade da medição, mesmo após várias calibrações.

Com o advento da nova edição do RTM, as empresas produtoras de petróleo e gás natural são obrigadas a implantar um sistema de gestão da medição (SGM) a fim de garantir a eficácia e a adequação do sistema ao uso pretendido; são obrigadas a calibrar seus medidores e instrumentos de medição em laboratórios acreditados por organismos signatários de acordos de reconhecimentos mútuo da ILAC (International Laboratory Accreditation Cooperation) ou da IAAC (InterAmerican Accreditation Cooperation); e são obrigadas a utilizar medidores e computadores de vazão com aprovação de modelo, por exemplo. 
Para que um laboratório seja acreditado, este deve atender aos requisitos da ABNT NBR ISO/IEC 17025: 2005 e aos requisitos do organismo de acreditação; ou seja, o laboratório deve possuir equipamentos controlados e rastreados ao SI; deve possuir um sistema de gestão da qualidade do laboratório, documentando suas políticas, sistemas, programas, procedimentos e instruções, na extensão necessária para assegurar a qualidade dos resultados de ensaios e/ou calibrações; deve participar de comparações interlaboratoriais; deve ser auditada periodicamente pelo organismo de acreditação; entre outros.

A obrigatoriedade do uso de um sistema de gestão de medição (SGM), tomando-se como referência a norma NBR ISO 10012 - Sistemas de gestão de medição - Requisitos para os processos de medição e equipamento de medição, e a obrigatoriedade do uso de laboratórios acreditados demonstram a importância dada pelo agente regulador à qualidade do resultado de uma medição. A partir do novo RTM, nota-se um amadurecimento nas questões metrológicas cobradas pelos agentes reguladores e nas questões metrológicas garantidas pelos agentes regulados, ou seja, não basta que o agente regulado realize as calibrações de seus instrumentos e apresente o certificado em auditorias. Os mesmos devem gerenciar seus sistemas de medição de forma a evitar que produzam resultados de medições incorretos.

Não obstante às obrigações impostas pelo RTM aos agentes regulados, as disponibilidades de serviços metrológicos de qualidade no Brasil têm-se mostrado insuficientes e ineficientes, tornando-se um risco para as atividades de produção e exploração de petróleo e gás natural à luz do controle metrológico legal.

No desempenho de sua função oficial de responsável pelo sistema metrológico brasileiro, no curso desses últimos quinze anos de vigência do regulamento técnico de medição, o INMETRO, no que tange à regulamentação dos sistemas de medição de vazão de gás, apresentou para consulta pública, apenas em março de 2015 , a portaria $n^{\circ} 182$, que aprovou o regulamento técnico metrológico visando estabelecer os requisitos metrológicos e técnicos, mínimos e necessários, aplicáveis aos instrumentos de medição de vazão de gás natural dos sistemas de medição fiscal e transferência de custódia. Porém, ainda assim, os sistemas de medidores deprimogênios não são contemplados na portaria supra.

Com isso, o item 6.4.6 da nova edição do RTM torna-se impraticável, pois não existe definição dos erros máximos admissíveis para as classes de exatidão 0.5 e 1.5 para sistemas de medição de gás no arcabouço de normas técnicas e outras instruções brasileiras aplicáveis. Uma alternativa para contornar essa vulnerabilidade é adotar a recomendação OIML R 140 - Measuring systems for gaseous fuel (Sistemas de medição para combustíveis gasosos). Nesta recomendação internacional são definidas três classes de exatidão (A, B e C) aplicadas às aprovações e verificações iniciais de sistemas de medição de combustíveis gasosos. Tais classes definem os erros máximos admissíveis (EMA ${ }^{5}$ ) para os sistemas de medição e instrumentos de medição associados ao sistema, conforme apresentados nas tabelas 1 e 2 , os quais poderiam ser adotados para o

5 Valor extremo do erro de medição, com respeito a um valor de referência conhecido, admitido por especificações ou regulamentos para uma dada medição, instrumento de medição ou sistema de medição. 
atendimento do item 6.4.6 do RTM até que se tenha uma regulamentação brasileira sobre o assunto.

As Tabela 1 e Tabela 2, a seguir, definem, respectivamente, por classe de exatidão, os erros máximos admissíveis dos sistemas de medição e de seus instrumentos associados.

Tabela 1 - Erro máximo admissível de sistemas de medição

\begin{tabular}{c|ccc}
\hline $\begin{array}{c}\text { Erro máximo admissível } \\
(\text { EMA) }\end{array}$ & $\begin{array}{c}\text { Classe de exatidão } \\
A\end{array}$ & $\begin{array}{c}\text { Classe de exatidão B } \\
\text { exatidão C }\end{array}$ & $\begin{array}{c}\text { Classe de } \\
\text { Volume convertido }\end{array}$ \\
\hline
\end{tabular}

Fonte: Adaptado da (OIML R 140, 2007)

Tabela 2 - Erro máximo admissível dos instrumentos associados

\begin{tabular}{c|ccc}
\hline $\begin{array}{c}\text { Erro máximo admissivel } \\
\text { (EMA) }\end{array}$ & $\begin{array}{c}\text { Classe de exatidão } \\
A\end{array}$ & Classe de exatidão B & $\begin{array}{c}\text { Classe de } \\
\text { exatidão C }\end{array}$ \\
\hline Temperatura & $\pm 0,5{ }^{\circ} \mathrm{C}$ & $\pm 0,5{ }^{\circ} \mathrm{C}$ & $\pm 1{ }^{\circ} \mathrm{C}$ \\
Pressão & $\pm 0,2 \%$ f.e.* & $\pm 0,5 \%$ f.e. & $\pm 1 \%$ f.e. \\
\hline
\end{tabular}

Fonte: Adaptado da (OIML R 140, 2007) * f.e.: Fundo de escala

Da mesma forma, por limitações internas, o INMETRO, nas suas atribuições quanto às atividades de metrologia legal, tem como desafio introduzir portarias de aprovação de modelo com a premência requerida pelo mercado; não consegue garantir o atendimento às solicitações de arqueação de tanque no cronograma apresentado pelos agentes regulados por indisponibilidade técnica em alguns estados, bem como não consegue agilizar, em muitos dos casos, o processo de acreditação e/ou de extensão de escopo de laboratórios de calibração. Essas dificuldades vivenciadas pelos órgãos reguladores e fiscalizadores denotam um risco para o atendimento da garantia metrológica hoje requerida pelo RTM.

\section{3}

\section{Sistema de gestão da medição}

Conforme a ABNT NBR ISO 10012, o sistema de gestão de medição (SGM) é definido pelo conjunto de elementos inter-relacionados e interativos, necessários à comprovação metrológica e ao controle contínuo dos processos de medição. $\mathrm{Ou}$ seja, permite assegurar que o equipamento de medição e os processos de medição estejam adequados para o uso pretendido, caracterizando a função de um SGM.

Para descrever o comportamento e as especificações de sistemas de medição, é comum a utilização de um conjunto de características metrológicas. (ALBERTAZZI \& SOUZA, 2008) destacam que as principais características metrológicas são classificadas quanto: à faixa de utilização; à indicação; à relação entre estímulo e resposta (sensibilidade); e aos erros de medição. 
Os erros de medição sempre estão presentes em sistemas de medição. Apresentam-se em maior ou menor grau, podendo ser originários do próprio sistema de medição ou decorrentes da ação de grandezas de influência externas.

Por isso, apesar da implementação de um sistema de gestão da medição requerer mudanças de cultura organizacional, o uso de um SGM proporciona mais benefícios para a corporação do que transtornos.

O objetivo central de um SGM é gerenciar o risco de que o equipamento de medição e os processos de medição possam produzir resultados incorretos de forma a influenciar na qualidade do produto.

Isto posto, o desempenho de um sistema de medição deve ser verificado periodicamente para manter a confiabilidade dos resultados de medições, uma vez que a validade dos resultados de medição é altamente dependente das propriedades metrológicas do instrumento, determinadas pela sua calibração.

O RTM determina as periodicidades mínimas para os medidores e os instrumentos de medição associados de acordo com cada aplicação, bem como determina que as incertezas de medição atendam aos requisitos metrológicos de suas aplicações e seus cálculos sejam atualizados após cada calibração de um instrumento ou alteração significativa nas condições de medição.

Todavia, para a implantação de um SGM, baseado na NBR ISO 10012, fazse necessária a identificação dos requisitos de medição do cliente, convertê-los em requisitos metrológicos e, por conseguinte, comprovar os instrumentos de medição considerados no SGM à luz dos preceitos básicos da metrologia.

No contexto das atividades de Exploração e Produção (E\&P) de Petróleo e Gás no Brasil, entende-se por clientes aqueles atores envolvidos na exploração e produção de petróleo e gás natural que tenham interesse nos valores medidos desses fluidos (e.g.: royalties, impostos, compra ou venda).

Os requisitos metrológicos do produto são definidos no próprio RTM, por exemplo, na forma de classe de exatidão do sistema de medição, na incerteza de medição da vazão ou volume medido no sistema e nos limites máximos do percentual de água e sedimentos no fluido medido (BSW).

A partir destes requisitos, deve-se definir o erro máximo permissível, a incerteza permissível, a faixa, a estabilidade, a resolução, as condições ambientais e a habilidade do operador em instrumento integrante de cada sistema de medição. Desta forma, ao decidir o escopo e a extensão do sistema de gestão de medição, devem ser levados em consideração os riscos e as consequências de falhas no cumprimento dos requisitos metrológicos.

Considerando que a habilidade do operador deva ser um requisito metrológico, o sistema de gestão da medição deverá ser concebido para transformar as crenças e as expectativas dos indivíduos e grupos envolvidos nas atividades de um sistema de gestão da medição em normas e valores que orientem seus comportamentos e a consciência da importância da comprovação metrológica e do controle contínuos da medição. Ou seja, deverá desenvolver e consolidar a cultura metrológica de sua força de trabalho (CARVALHO, 2011). Porém, o desenvolvimento de um senso de cultura metrológica não é uma tarefa simples, requer ações de longo prazo, depende de treinamentos, do comprometimento da alta 
direção e depende da mudança de valores sobre qualidade de medição nos diversos setores das empresas e da sociedade.

\section{4 \\ Medição de gás natural por placa de orifício}

\subsection{1 \\ 0 gás natural}

O gás natural é um combustível fóssil encontrado em reservatórios do subsolo, podendo estar ou não associado ao petróleo, ou seja, o gás natural pode estar dissolvido ou formando uma camada de gás livre sobre o reservatório de óleo.

É constituído por uma mistura de hidrocarbonetos, que contém essencialmente metano, etano e propano e, em menores quantidades, hidrocarbonetos superiores, podendo, também, agregar componentes inertes (e.g.: nitrogênio, dióxido de carbono e traços de outros constituintes).

O gás natural não associado apresenta os maiores teores de metano, enquanto o gás natural associado apresenta proporções mais significativas de etano, propano, butano e hidrocarbonetos mais pesados (CARDOSO, 2005).

O RTM define gás natural como sendo todo hidrocarboneto que permaneça em estado gasoso nas condições atmosféricas normais, extraído diretamente a partir de reservatórios petrolíferos ou gaseíferos, cuja composição poderá conter gases úmidos, secos e residuais.

O gás natural é um insumo energético que apresenta diversas vantagens ao ser comparado com outras fontes de energia fóssil. Dentre estas, se destacam os menores teores de enxofre, dióxido de carbono e particulados emitidos no ar devido a uma queima mais limpa e uniforme; não requer estocagem; e necessita-se de um tratamento dos gases de combustão menos exigente.

O documento que regulamenta a especificação do gás natural, nacional ou importado, a ser comercializado em todo território nacional é o regulamento técnico da ANP n. ${ }^{\circ}$ 2/2008 da resolução ANP no 16 de 2008. Em conformidade a este regulamento, o gás natural permanece no estado gasoso sob condições de temperatura e pressão ambientes. Desta forma, ao RTM definir a classe de exatidão, a incerteza dos sistemas de medição, a periodicidade de calibração, bem como, as formas de medir o gás natural produzido e comercializado, o agente regulador prima pela credibilidade dos resultados de medição e entendimento entre as partes.

\section{4 .2}

\section{A medição do gás natural à luz do RTM}

Os sistemas de medição de gás natural devem ser constituídos de medidores de fluido compatível com os requisitos técnicos e metrológicos do RTM a fim de atender às exigências do INMETRO. As medições de gás natural nos pontos de medição da produção podem ser realizadas, por exemplo, pela técnica de placa de orifício, medidores do tipo turbina, medidores de deslocamento positivo ou 
medidores do tipo ultrassônico. Outros tipos de medidores podem ser utilizados, se previamente autorizados pela ANP.

Dentre os sistemas de medição de vazão, um dos princípios mais comumente utilizados na medição de gás natural no mundo é a placa de orifício, também conhecidos como sistemas deprimogênios (OLIVEIRA, 2006), (MARTINS, 1998) e (DELMÉE, 2003). Trata-se de uma tecnologia tradicional e bastante conhecida, objeto de normas nacionais (ABNT), internacionais (ISO) e normas de organizações estrangeiras especializadas (API e AGA). Os projetos de sistemas com placa de orifício na PETROBRAS comumente utilizam as normas $A G A$ Report $N^{o} 3$ e ISO 5167 como referências construtivas.

Apesar do rigor com a inspeção dimensional, a extensa aplicação de sistemas de medição de vazão utilizando placa de orifício é devido à simplicidade; baixo custo de construção e instalação; facilidade para realizar a manutenção e a calibração; e confiabilidade devido aos valores rigorosamente conhecidos das incertezas de medição quando devidamente projetado e instalado.

Um sistema de medição de vazão por meio de placa de orifício é constituído basicamente pela inserção de um elemento de restrição plano (placa com orifício, dotado de orifício com rigoroso controle dimensional), imerso transversalmente no escoamento do fluido. Este dispositivo causa obstrução ao escoamento, assim induzindo uma pressão diferencial (perda de carga) entre suas seções transversais a montante e a jusante da placa, que pode ser correlacionada à vazão do fluido que passa pelo orifício. A placa de orifício é usualmente instalada (de forma invasiva) no circuito do escoamento, por meio de um dispositivo porta-placa ou entre flanges ("flange de orifício").

São conhecidos como elementos primários os dispositivos responsáveis pelo condicionamento do escoamento e pela geração do sinal de pressão diferencial. Assim, são considerados como elementos primários a tomada de pressão diferencial, os trechos retos de medição, o dispositivo porta-placa ou flange de orifício e o condicionador de fluxo (quando utilizado).

Os elementos secundários, que são responsáveis pela indicação das variáveis dinâmicas do cálculo da vazão, são formados pelos sensores e transmissores de pressão estática, pressão diferencial, temperatura e, se utilizado, o cromatógrafo.

Ainda como parte integrante do sistema de medição por placa de orifício, tem-se o elemento terciário, que é composto do corretor eletrônico de volume ou computador de vazão, responsável pela conversão da vazão medida ao longo de um período de tempo em um determinado volume referido às condições básicas de pressão e temperatura do escoamento.

Com relação à comprovação metrológica dos instrumentos integrantes de um sistema de medição por placa de orifício, os instrumentos de medição de temperatura e pressão do gás são calibrados a cada 90 dias para atender à exigência regulatória dos sistemas de medição fiscal e a cada 180 dias nos sistemas de medição para apropriação e transferência de custódia. Nos sistemas de medição operacionais, as periodicidades de calibrações são definidas pelo agente regulado e esses planos de calibração devem ser aprovados pela ANP. No que concerne às características geométricas da placa (elemento sensor do medidor) e à inspeção 
dimensional de duto reto devem ser avaliados a cada 12 e 36 meses, respectivamente.

A Figura 1 ilustra uma representação usual de um sistema de medição por placa de orifício.

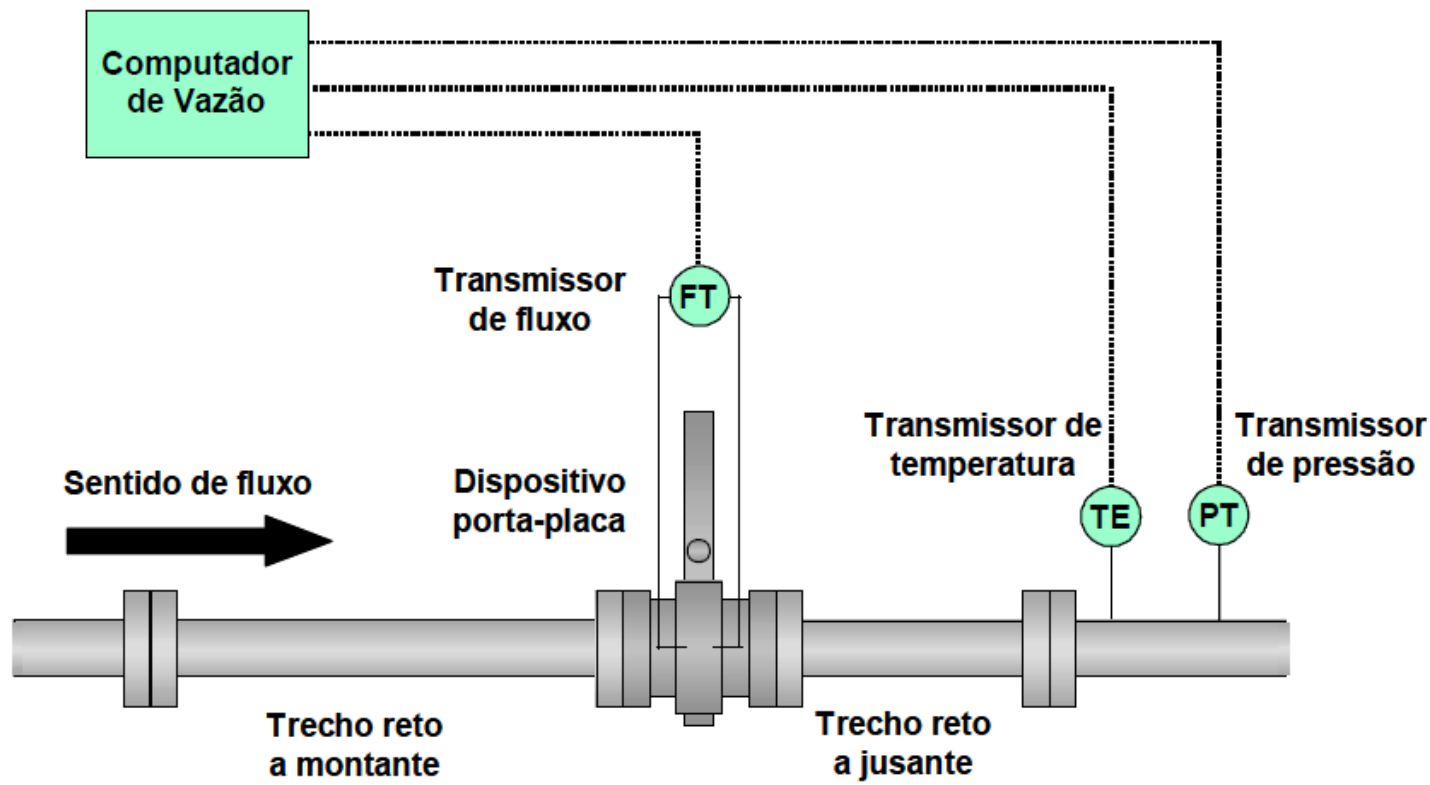

Figura 1 - Arquitetura típica de um sistema de medição por placa de orifício Fonte: (MARCHETI Jr., 2010)

A Figura 2 apresenta skid de um sistema de medição por placa de orifício com válvula porta placa.

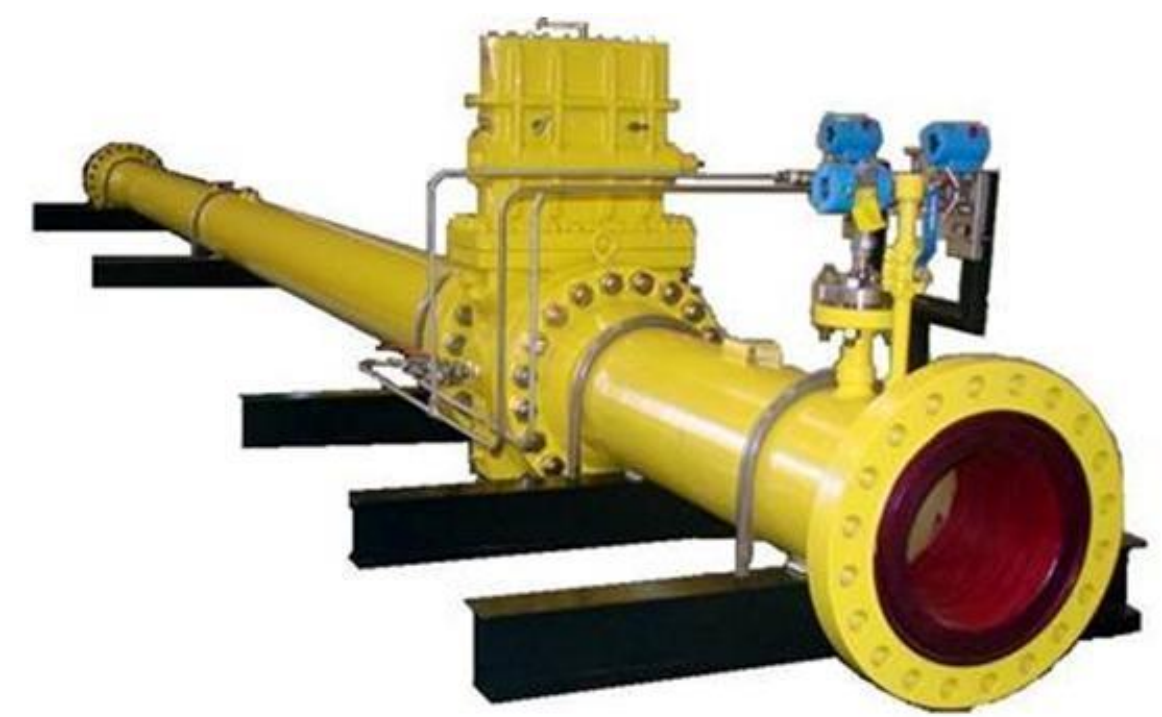

Figura 2 - skid de um sistema de medição por placa de orifício

Os sistemas de medição físcal e transferência de custódia de gás devem ser projetados, instalados e calibrados para operar dentro das classes de exatidão de 0.5 e apresentarem incerteza de medição máxima de $1,5 \%$ para a vazão ou o volume medido. 
Já os sistemas de medição de gás natural aplicados para a apropriação dos volumes medidos devem ser projetados, instalados e calibrados para operar dentro das classes de exatidão de 1.5 e apresentarem incerteza de medição máxima de 2 $\%$.

Já os sistemas de medição para queima ou ventilação de gás natural devem ser projetados para assegurar uma confiabilidade limitada a uma incerteza máxima de $5 \%$.

Os sistemas de medição de gás natural devem incluir dispositivos para compensação automática das variações de pressão estática e de temperatura. A compensação deve incluir as variações do coeficiente de compressibilidade do gás natural decorrentes das variações de pressão e temperatura. 


\section{3 \\ Uso do planejamento de experimentos para definição de critérios de aceitação de instrumentos}

\section{1}

\section{Planejamento de experimentos}

O planejamento de experimentos é uma prática comumente utilizada em ciência e tecnologia. Um dos problemas recorrentes no trabalho experimental refere-se à necessidade de determinar a influência de uma ou mais variáveis no resultado da medição. O planejamento de experimentos é uma ferramenta eficaz para melhorar e otimizar sistemas, processos e produtos (OLIVEIRA, 2006). Otimizar significa encontrar os valores para os quais as variáveis produzem a melhor resposta desejada, ou seja, encontrar as condições operacionais ótimas para o sistema.

O uso de planejamento de experimentos possibilita otimizar os experimentos, determinando modelos com elevada confiabilidade, ou seja, reduzida incerteza associada. O uso de planejamento sequencial de experimentos possibilita a redução considerável da carga experimental, pois permite concentrar esforços em regiões ótimas de experimentação; i.e., regiões em que a técnica fornece relevantes informações sobre a adequabilidade dos modelos ou sobre sua precisão paramétrica (ALBERTON, 2010).

Com os planejamentos de experimentos (design of experiments - DOE) deseja-se determinar os fatores que afetam a resposta de um determinado sistema, bem como a influência na sua resposta e a existência de interações entre os fatores de interesse.

Uma representação esquemática do processo de planejamento experimental adaptada de (MONTGOMERY \& RUNGER, 2013) é apresentada na Figura 3. Os fatores são as variáveis independentes que, ao interagirem entre si, influenciam a resposta do sistema. 


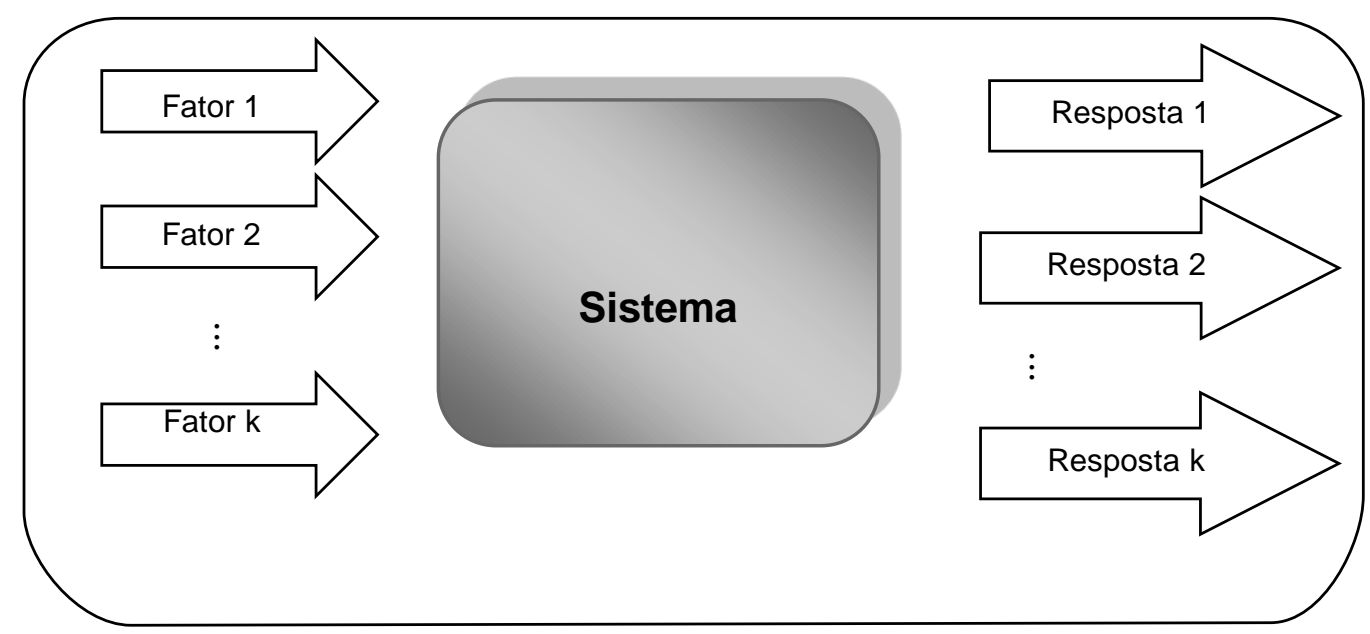

Figura 3 - Esquema do processo de planejamento experimental Fonte: Adaptação de MONTGOMERY e RUNGER (2013)

Utilizando-se o planejamento experimental baseado em princípios estatísticos, é possível, para um mínimo de experimentos, extrair do sistema em estudo o máximo de informação útil (MARINHO \& CASTRO, 2005).

Diversas são as técnicas utilizadas de planejamento experimental, dentre as quais destacam-se: o planejamento completamente aleatorizado; a comparação entre dois tratamentos de dados; a comparação de mais de dois tratamentos; a comparação de mais de dois tratamentos, com uma variável em blocos; planejamento com mais de uma variável blocada; planejamento com mais de duas variáveis blocadas; delineamento de misturas, entre outras. Essas técnicas variam em função do número e tipos de fatores considerados, bem como das condições experimentais (SILVEIRA, 2003).

Nos experimentos cujo interesse é avaliar dois ou mais fatores (variáveis experimentais) e todas as combinações dos níveis dos fatores (valores das variáveis experimentais), uma das técnicas recomendadas é o planejamento de experimentos fatorial, que alguns autores denominam de planejamento fatorial completo. Segundo este conceito, $2^{\mathrm{k}}$ experimentos equivalem a um planejamento fatorial que combina dois níveis (valores que um determinado fator pode assumir) de $k$ fatores investigados.

Em experimentos com mais de 4 fatores $(\mathrm{k}>4)$, o planejamento fatorial completo também passa a ter uma grande desvantagem devido ao elevado número de ensaios e, com isso, pode-se lançar mão do planejamento fatorial fracionário. O presente trabalho concentra-se no planejamento fatorial completo, pois permite de forma otimizada avaliar todos os efeitos dos fatores e suas interações nas respostas do sistema. Informação detalhada sobre o planejamento fatorial fracionário encontra-se descrito nos trabalhos de (BOX, HUNTER, \& HUNTER, 1978), (BARROS NETO, SCARMINIO, \& BRUNS, 2001), (LUNDSTEDT, et al., 1998), (DEAN \& VOSS, 1999), (MONTGOMERY \& RUNGER, 2013), entre outros.

Dentre os diversos tipos de planejamento experimental, o planejamento fatorial também se destaca quando comparado aos processos univariados, pois permite avaliar simultaneamente o efeito de um grande número de variáveis a partir de um número reduzido de experimentos (CUNICO, et al., 2008). 
Em experimentos cuja técnica aplicada não seja o planejamento fatorial, o experimentalista necessitará de mais experimentos e não haverá garantias de produzir resultados confiáveis devido à impossibilidade de se detectarem as interações entre as variáveis do experimento (CUNICO, et al., 2008) (MONTGOMERY \& RUNGER, 2013).

Quando o interesse recai sobre a caracterização do processo, o uso do experimento fatorial mostra-se como uma alternativa atrativa. Neste caso, o experimento é denominado experimento exploratório (screening experiment) ou estudo de triagem. Tal planejamento permite estimar a magnitude e direção dos efeitos dos fatores. Nesse sentido, o planejamento permite avaliar a influência de algumas (ou muitas) variáveis, identificando aquelas que têm maior ou menor importância e aquelas que são ou não controláveis. Além disso, os planejamentos experimentais permitem verificar a existência de uma interação entre os fatores estudados (OLIVEIRA, 2006).

(NGUTY, SALAM, DURAIRAJ, \& EKERE, 2001) utilizaram o planejamento experimental para entender como fatores físicos, químicos e ambientais, controláveis ou não controláveis, são capazes de influenciar a impressão em circuitos eletrônicos pelo uso de pasta de soldagem livre de chumbo. Estes autores aplicaram o planejamento experimental como um estudo de caracterização. (MONTGOMERY \& RUNGER, 2013) assim caracterizam a importância dessa ferramenta:

\footnotetext{
A informação proveniente desse estudo de caracterização, ou do experimento de seleção, pode ajudar a determinar as variáveis críticas do processo. Orienta, também, a definir a direção de ajuste para esses fatores, de modo a reduzir o número de defeitos e ajudar na determinação das variáveis de processo que devem ser cuidadosamente controladas durante a fabricação com o propósito de prevenir altos níveis de defeitos e desempenho errático do processo.
}

Após a realização de um experimento que permita caracterizar um determinado processo, o interesse se volta para determinar qual é a combinação dos fatores mais importantes que possibilita o melhor resultado, ou seja, uma resposta ótima para o processo de interesse. Esta resposta ótima pode ser determinada, por exemplo, pela região de menor custo em um processo fabril ou de menor incerteza na medição de um mensurando.

\section{2 \\ Planejamento fatorial $2^{k}$}

O planejamento fatorial é frequentemente utilizado em experimentos que envolvem diversos fatores e que requerem compreensão de seus efeitos combinados na resposta do sistema de medição.

O planejamento fatorial de $k$ fatores, cada um com somente dois níveis (MONTGOMERY \& RUNGER, 2013), mostra-se atrativo. Esses níveis podem ser quantitativos (e.g.: dois valores de temperatura, pressão ou tempo) ou qualitativos (e.g.: duas máquinas, dois operadores, os níveis "alto" e "baixo" de um fator, ou mesmo a presença ou ausência de um fator). Uma réplica completa de tal planejamento requer $2 \times 2 \times \ldots \times 2=2^{k}$ observações, sendo chamada de 
planejamento fatorial $2^{k}$. Neste planejamento, a base indica o número de níveis e o expoente o número de fatores de controle.

Nos planejamentos experimentais em que as variáveis são exploradas em dois níveis é comum codificá-los usando os sinais (-) e (+). A atribuição destes sinais aos níveis inferiores ou superiores é feita de forma arbitrária e não interfere na realização dos experimentos ou interpretação dos resultados, além de permitir esquematizar o planejamento na forma de matrizes de planejamento (TEÓFILO \& FERREIRA, 2006). Ainda assim, o emprego destes sinais pode ser empregado para os níveis dos fatores qualitativos.

Além dos sinais (-) e (+), existem outras duas notações que são comumente utilizadas para representar os níveis assumidos por cada fator no planejamento fatorial: letras ou 0 e 1, conforme representado na Tabela 3.

Tabela 3 - Representações alternativas para um planejamento fatorial $2^{3}$

\begin{tabular}{|c|c|c|c|c|c|c|c|}
\hline \multirow{2}{*}{ Experimentos } & \multicolumn{7}{|c|}{ Fatores } \\
\hline & Letras & $\mathrm{A}$ & B & $\mathrm{C}$ & $\mathrm{A}$ & B & $\mathrm{C}$ \\
\hline 1 & (1) & - & - & - & 0 & 0 & 0 \\
\hline 2 & $\mathrm{a}$ & + & - & - & 1 & 0 & 0 \\
\hline 3 & $\mathrm{~b}$ & - & + & - & 0 & 1 & 0 \\
\hline 4 & $\mathrm{ab}$ & + & + & - & 1 & 1 & 0 \\
\hline 5 & $\mathrm{c}$ & - & - & + & 0 & 0 & 1 \\
\hline 6 & $\mathrm{ac}$ & + & - & + & 1 & 0 & 1 \\
\hline 7 & $\mathrm{bc}$ & - & + & + & 0 & 1 & 1 \\
\hline 8 & $a b c$ & + & + & + & 1 & 1 & 1 \\
\hline
\end{tabular}

Fonte: (BOX, HUNTER, \& HUNTER, 1978)

Esta codificação das variáveis é de grande utilidade nos cálculos para determinar a influência das variáveis estudadas e de suas interações no sistema em estudo (BRASIL, 2010).

(MONTGOMERY \& RUNGER, 2013) apresentam uma notação especial usada para marcar as combinações dos tratamentos (experimentos). Utilizam uma série de letras minúsculas para representar o nível alto de um determinado fator, ou seja, se uma letra estiver presente, o fator correspondente ocorre no nível alto daquela combinação de tratamento; caso contrário, se ela estiver ausente, o fator ocorre em seu nível baixo.

A geometria do planejamento fatorial, com três fatores e dois níveis, (planejamento $2^{3}$ ) pode ser representada por um cubo cujos vértices representam os níveis dos fatores em seus valores máximos e mínimos (

Figura 4a). A presença de letras nos vértices do cubo representa o efeito de um ou mais fatores. Por conseguinte, a

Figura $4 \mathrm{~b}$ lista os oito experimentos em uma tabela, em que cada linha está associada a um dos experimentos, enquanto os sinais (-) e (+) denotam os níveis baixo e alto, respectivamente, para cada um dos três fatores. Esse conjunto de combinações (ilustrado pela 
Figura $4 b)$ é denominado de matriz de planejamento.

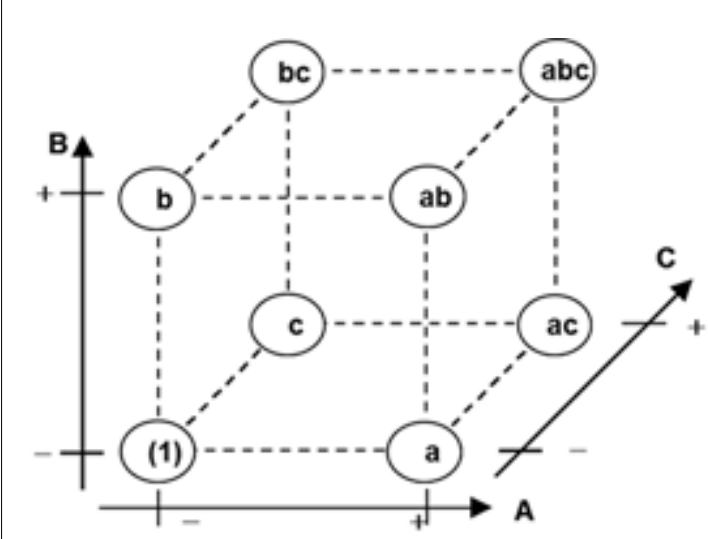

(a) Vista geométrica

\begin{tabular}{cccc}
\hline Corrida & A & B & C \\
\hline 1 & - & - & - \\
2 & + & - & - \\
3 & - & + & - \\
4 & + & + & - \\
5 & - & - & + \\
6 & + & - & + \\
7 & - & + & + \\
8 & + & + & + \\
\hline
\end{tabular}

(b) Matriz de planejamento $2^{3}$

Figura 4 - Planejamento fatorial $2^{3}$

Com o auxílio da Tabela 4 é possível determinar os contrastes a partir da soma das combinações dos tratamentos, listados na primeira coluna, multiplicadas pelos respectivos sinais da coluna do efeito fatorial de interesse. Assim, obtém-se a estimativa dos efeitos principais ou interação ao dividir os contrastes pela metade do número total de corridas no experimento.

Tabela 4 - Matriz dos coeficientes de contrastes num Planejamento fatorial $2^{3}$

\begin{tabular}{|c|c|c|c|c|c|c|c|c|}
\hline \multirow{2}{*}{$\begin{array}{l}\text { Combinação dos } \\
\text { tratamentos }\end{array}$} & \multicolumn{8}{|c|}{ Efeito Fatorial } \\
\hline & I & A & B & $\mathrm{C}$ & $\mathrm{AB}$ & $\mathrm{AC}$ & $\mathrm{BC}$ & $\mathrm{ABC}$ \\
\hline (1) & + & - & - & - & + & + & + & - \\
\hline $\mathrm{a}$ & + & + & - & - & - & - & + & + \\
\hline $\mathrm{b}$ & + & - & + & - & - & + & - & + \\
\hline$a b$ & + & + & + & - & + & - & - & - \\
\hline $\mathrm{c}$ & + & - & - & + & + & - & - & + \\
\hline ac & + & + & - & + & - & + & - & - \\
\hline bc & + & - & + & + & - & - & + & - \\
\hline$a b c$ & + & + & + & + & + & + & + & + \\
\hline
\end{tabular}

Fonte: Adaptação dos trabalhos de (TEÓFILO \& FERREIRA, 2006) e (MONTGOMERY \& RUNGER, 2013)

A partir dos efeitos estimados obtidos dos contrastes e da resposta do sistema, aplica-se o método dos mínimos quadrados para obtenção de um modelo linear do sistema em estudo. Em seguida, avalia-se a existência de falta de ajuste, isto é, se o modelo proposto é significativo.

A utilização de replicação dos experimentos é importante, pois permite a obtenção de uma estimativa direta da variabilidade do erro experimental. Entretanto, às vezes, replicações autênticas mostram-se inconvenientes ou impossibilitadas de serem realizadas. Diante disso, (NÓBREGA \& VIVACQUA, 2010) destacam que é usual a utilização dos gráficos normal ou seminormal para avaliar a significância dos efeitos dos experimentos e, assim, validar o modelo linear do sistema. Informações detalhadas sobre a utilização de gráficos normal ou seminormal encontram-se descritas nos trabalhos de (NÓBREGA, M. P., 2010), (MONTGOMERY \& RUNGER, 2013), KRANE (1963), (BARROS NETO, SCARMINIO, \& BRUNS, 2001), entre outros. 
(TEÓFILO \& FERREIRA, 2006) sugerem o emprego de um experimento no centro do planejamento, conhecido como ponto central, que seriam os valores médios dos níveis de todas as variáveis independentes, como forma, também, de se obter uma boa estimativa dos erros.

A partir de planejamentos fatoriais com pontos central, avalia-se a significância dos efeitos ou coeficientes, tanto em planejamentos exploratórios como em metodologias de superfície de resposta (TEÓFILO \& FERREIRA, 2006). Como vantagem desta aplicação, estes autores destacam que esta prática minimiza o risco de perder a relação não linear entre os intervalos e possibilita a estimativa de um modelo razoável; (BREITKREITZ, de SOUZA, \& POPPI, 2014) ressaltam que esta aplicação permite avaliar se há falta de ajuste; e (MONTGOMERY \& RUNGER, 2013) enfatizam que tal aplicação não interfere nas estimativas dos efeitos usuais em um planejamento.

\section{3}

\section{Explorando uma superfície de resposta}

A Metodologia de Superfície de Resposta (MSR) - Response Surface Methodology - é uma técnica de otimização baseada em planejamentos fatoriais que é utilizada com sucesso na modelagem de diversos processos industriais (BARROS NETO, SCARMINIO, \& BRUNS, 2001). Esta metodologia foi desenvolvida na década de 1950 por George Box motivado pela necessidade que os pesquisadores tinham em utilizar um procedimento para determinar as condições ótimas dos fatores de controle que interferem na resposta de um sistema (MYERS et al., 1989 apud GALDAMEZ, 2002).

A MSR permite explorar (modelar e deslocar) os sistemas de interesse até a sua otimização. Baseia-se na construção de modelos matemáticos empíricos que geralmente empregam, inicialmente, funções polinomiais lineares (exploratórias) que permitirão indicar as regiões onde funções polinomiais quadráticas permitirão otimizar e descrever o sistema estudado (TEÓFILO \& FERREIRA, 2006). Na MSR, normalmente os fatores (variáveis de entrada independentes) são controlados pelo pesquisador, possibilitam mais de uma resposta (SILVEIRA, 2003) e permitem prever o que acontece com a propriedade de interesse dentro de todo o domínio experimental, não se restringindo apenas aos pontos experimentados (BREITKREITZ, de SOUZA, \& POPPI, 2014). A Figura 5 apresenta um modelo de superfície de resposta otimizado em função da variação de temperatura e pressão. 


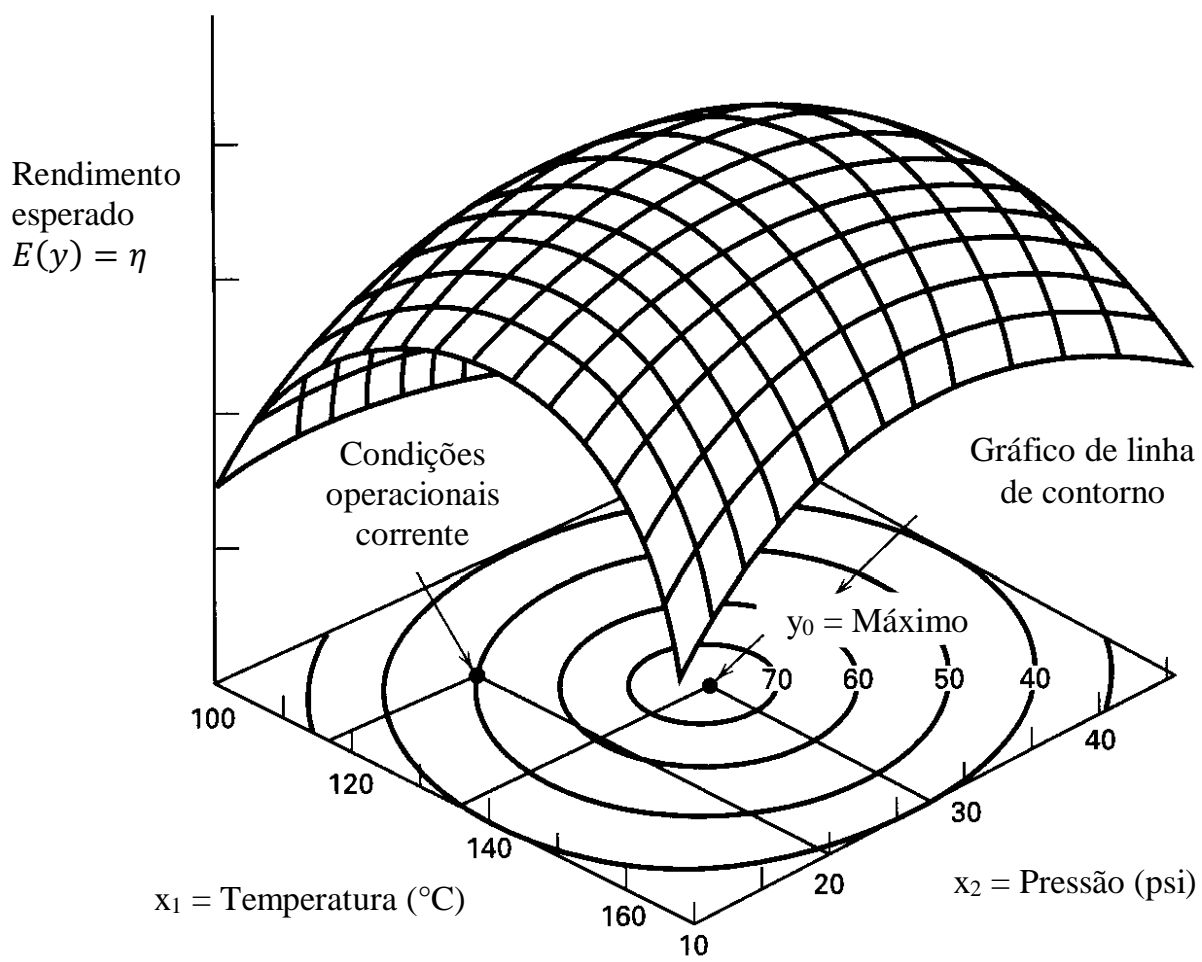

Figura 5 - Superfície de resposta $\eta=f(P ; T)$

Fonte: (MONTGOMERY, D. C., 2001)

A metodologia de superfície de resposta consiste em utilizar um grupo de técnicas utilizadas no estudo de relações empíricas entre uma ou mais respostas medidas (e.g.: rendimento, índice de cor e de viscosidade) e várias variáveis de entrada (e.g.: tempo, temperatura, pressão e concentração) (BOX, HUNTER, \& HUNTER, 1978).

Com o objetivo de atingir uma região ótima da superfície investigada, a metodologia de superfícies de resposta pode ser subdividida em duas etapas distintas denominadas modelagem e deslocamento (BARROS NETO, SCARMINIO, \& BRUNS, 2001).

Como a forma da relação entre a resposta e as variáveis independentes é geralmente desconhecida na maioria dos problemas que fazem uso da MSR, um modelo polinomial de $1^{\mathrm{a}}$ ordem pode ser uma aproximação razoável da relação funcional verdadeira sobre o espaço inteiro das variáveis independentes. A modelagem pelo emprego de um polinômio de baixo grau em alguma região das variáveis independentes resulta em uma boa aproximação inicial para regiões relativamente pequenas. Assim, o modelo ajustado de primeira ordem é dado por:

$Y=\beta_{0}+\beta_{1} x_{1}+\beta_{2} x_{2}+\cdots+\beta_{k} x_{k}+\epsilon$

em que os coeficientes $\beta_{i}$ representam os estimadores dos parâmetros do modelo, os $x_{i}$ representam as $k$ variáveis independentes e $\epsilon$ é o erro aleatório para a estimativa da resposta $Y$ do planejamento.

Para se estimar os parâmetros nas aproximações polinomiais, aplica-se o método dos mínimos quadrados ordinários. Se o ajuste for uma aproximação adequada da função verdadeira de resposta, a análise da superfície ajustada será 
aproximadamente equivalente à análise do sistema real (MONTGOMERY \& RUNGER, 2013).

A metodologia de superfície de resposta é um procedimento sequencial que pretende levar o experimentalista o mais rápido possível à região ótima. Em outras palavras, deseja-se determinar uma região do espaço fatorial em que as especificações operacionais sejam satisfeitas (TEÓFILO \& FERREIRA, 2006) e (MONTGOMERY \& RUNGER, 2013). Distante dessa região utiliza-se um modelo de primeira ordem como uma aproximação inicial da superfície verdadeira.

Para essas situações, considerando que se procuram as regiões de ponto máximo, aplica-se o chamado deslocamento a partir do método da ascendente de maior inclinação, ou seja, na direção em que $\hat{y}$ (estimativa de $y$ ) cresce mais rapidamente. Esta direção é normal aos contornos de superfície ajustada de resposta e está sobre a linha que passa pelo centro da região de interesse.

Como uma primeira aproximação da representação visual de uma superfície de resposta pode-se utilizar os gráficos dos contornos da superfície de resposta, conhecidos como gráficos da curva de nível. Nestes gráficos, as linhas de respostas constantes são desenhadas no plano $x_{1}$ e $x_{2}$.

Os experimentos são conduzidos ao longo do caminho ascendente de maior inclinação até que um aumento na resposta deixa de ser observado. Quando necessário, ajusta-se um novo modelo, determina-se uma nova direção ascendente e realizam-se novos experimentos até que o experimentalista perceba que está próximo da situação ótima.

O caminho de máxima inclinação partindo do ponto central do planejamento pode ser determinado algebricamente a partir dos coeficientes do modelo. No caso geral, em que a superfície de resposta é determinada por $k$ fatores, o caminho de máxima inclinação é proporcional aos módulos e aos sinais dos coeficientes do modelo.

Ao aproximar-se da região ótima, um modelo de segunda ordem, dos termos dos efeitos quadráticos puros, é requerido para aproximar a resposta. $\mathrm{O}$ modelo ajustado de segunda ordem é dado por:

$Y=\beta_{0}+\sum_{i=1}^{k} \beta_{i} x_{i}+\sum_{i=1}^{k} \beta_{i i} x_{i}^{2}+\cdots+\sum \sum_{i<j} \beta_{i j} x_{i} x_{j}+\epsilon$

Uma maneira de determinar o vetor de regressão $b$ é pelo método dos mínimos quadrados, definido por:

$b=\left(X^{t} X\right)^{-1} X^{t} y$

$\left(X^{t} X\right)^{-1}$ é a matriz inversa do produto da transposta da matriz $X$ com ela mesma.

Um modelo bem ajustado de segunda ordem deve ser capaz de estimar uma superfície de resposta apresentando uma baixa variância; deve possibilitar a aplicação do teste de falta de ajuste; e deve estimar de forma eficiente todos os parâmetros do modelo proposto (DEAN \& VOSS, 1999).

O uso do modelo de segunda ordem permite identificar o ponto de máxima ou mínima resposta que otimiza a combinação dos fatores de interesse. A partir da análise das raízes características (autovalores) do modelo adotado é possível 
identificar a natureza do ponto (mínimo e máximo), bem como identificar qual fator causa maior variação na variável resposta (LORENTZ, 2008).

Todavia, podem ocorrer situações nas quais os tratamentos não terão réplicas. Com isso, não é possível avaliar de forma significativa o erro experimental ajustado podendo-se levar o pesquisador a conclusões erradas. Não obstante, alguns métodos podem ser utilizados em experimentos sem réplicas para validar o modelo ajustado, ao identificar quais efeitos são significativos na análise de experimentos. Nestes casos, pode-se assumir que os erros experimentais nos valores dos efeitos são as interações de altas ordens $(\mathrm{k} \geq 3)$ ao se supor que estas interações não são significativas (TEÓFILO \& FERREIRA, 2006). Outros métodos podem ser utilizados para estimar os erros dos efeitos, tais como o método de Lenth, a análise de gráficos de probabilidade normal e half-normal, entre outros (ABOUKALAM \& AL-SHIHA, 2001), (LENTH, R. V., 1989), (LENTH, 2006) e (LI, SUDARSANAM, \& FREY, 2006).

\section{4}

\section{Planejamento composto central (Central Composite Design - CCD)}

O planejamento composto central (PCC) é uma ampliação natural do planejamento fatorial com ponto central e, portanto, permite a construção de modelos quadráticos, bem como é comumente empregado na metodologia de superfície de resposta (BREITKREITZ, de SOUZA, \& POPPI, 2014).

O planejamento composto central, por proporcionar boas estimativas para todos os coeficientes, requerer um número menor de experimentos e, por fornecer condições de avaliação dos coeficientes, é um dos tipos de planejamento mais utilizados para ajustar modelos quadráticos (TEÓFILO \& FERREIRA, 2006).

No PCC, além do ponto central, são inseridos pontos axiais que, se escolhidos adequadamente, permitirão que o planejamento composto central seja rotacionável, isto é, o desvio padrão da resposta prevista $\hat{y}$ será considerado constante em todos os pontos que estiverem à mesma distância do centro do planejamento (MONTGOMERY \& RUNGER, 2013). Assim, um planejamento é rotacionável se estiver situado sobre os eixos do sistema de coordenadas e com o espaçamento axial $\pm \alpha$ em relação à origem, onde $\alpha$ depende do número de pontos na porção fatorial, ou seja, neste caso $\alpha=\left(2^{k}\right)^{1 / 4}$, e $k$ é o número de fatores. Assim, o planejamento composto central (PCC) é constituído pelo planejamento fatorial completo; pelo ponto central, isto é, $x_{i}=0$ para todo $i$; e pontos axiais em que $x_{i}= \pm \alpha, \operatorname{com} x_{j} \neq$ $x_{i}$, e $\alpha=\sqrt[4]{2^{k}}$. Estes pontos são situados nos eixos do sistema de coordenadas com distância $\pm \alpha$ da origem e formam pontos estrela do planejamento. Em geral, um PCC com $k$ fatores requer $2^{\mathrm{k}}$ corridas fatoriais, $2 k$ corridas axiais e um ponto central com réplicas.

A Figura 6 - Planejamentos compostos centrais. ilustra os pontos experimentais no sistema de coordenadas definidas pelos eixos $x_{i}$. Na Figura $6 a$ é apresentado um planejamento $2^{2}$ e na Figura $6 \mathrm{~b}$ é apresentado um planejamento $2^{3}$. 

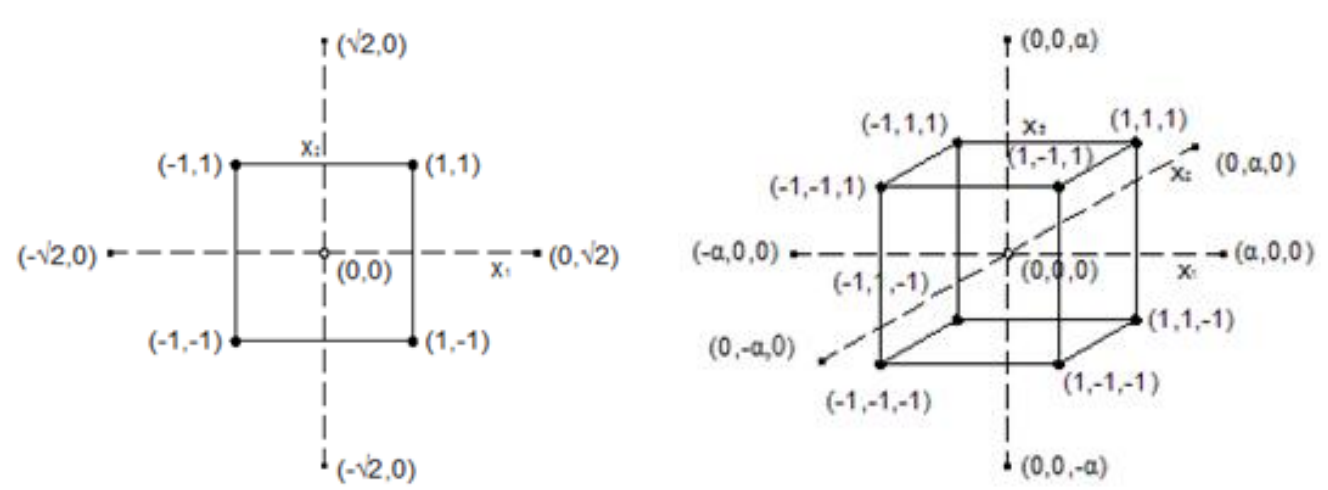

$(\bullet)$ planejamento fatorial, $(\bullet)$ pontos axiais e (०) ponto central.

Figura 6 - Planejamentos compostos centrais.

Fonte: (TEÓFILO \& FERREIRA, 2006)

A

Tabela 5 apresenta a matriz dos planejamentos compostos centrais com três variáveis.

Tabela 5 - Matriz do Planejamento composto central com três variáveis

\begin{tabular}{|c|c|c|c|}
\hline \multicolumn{4}{|c|}{ Planejamento PCC - $2^{3}$} \\
\hline A & $\mathrm{B}$ & $\mathrm{C}$ & \\
\hline- & - & - & \multirow{8}{*}{ Planejamento fatorial } \\
\hline+ & - & - & \\
\hline- & + & - & \\
\hline+ & + & - & \\
\hline- & - & + & \\
\hline+ & - & + & \\
\hline- & + & + & \\
\hline+ & + & + & \\
\hline 0 & 0 & 0 & Ponto Central \\
\hline$-\alpha$ & 0 & 0 & \multirow{6}{*}{ Pontos axiais } \\
\hline$\alpha$ & 0 & 0 & \\
\hline 0 & $-\alpha$ & 0 & \\
\hline 0 & $\alpha$ & 0 & \\
\hline 0 & 0 & $-\alpha$ & \\
\hline 0 & 0 & $\alpha$ & \\
\hline
\end{tabular}

Fonte: Adaptação do trabalho de (TEÓFILO \& FERREIRA, 2006)

(MONTGOMERY, D. C., 2001) recomenda a inclusão de três a cinco réplicas do ponto central além dos pontos axiais, enquanto, (DEAN \& VOSS, 1999) recomendam a inclusão de três a seis réplicas do ponto central e dos mesmos pontos axiais, pois tal estratégia, segundo os autores, se torna mais eficiente no ajuste de modelos de segunda ordem.

Neste tipo de planejamento, para se identificar os valores experimentais nos pontos ótimos nas unidades das variáveis, faz-se necessário decodificar os respectivos valores de $x_{i}$ no modelo estimado. Para isso, utiliza-se a equação

$x_{i}=\frac{z_{i}-\bar{z}}{\frac{\Delta z}{2}}$ 
onde, $x_{i}$ é o valor codificado do planejamento composto central (entre \pm 1$) ; z_{i}$ é o valor experimental da variável referente a $x_{i} ; \bar{z}$ é o valor médio entre os valores experimentais nos níveis baixo (-) e alto (+), que é exatamente o valor experimental no nível médio (0) e $\Delta z$ é a diferença entre os valores experimentais nos níveis alto $(+)$ e baixo (-). 


\section{4 \\ Medição de vazão por placa de orifício}

A medição de vazão por placa de orifício requer o uso de medidores auxiliares de pressão estática, pressão diferencial e temperatura do fluido de trabalho, instrumentos esses cuja confiabilidade metrológica constitui objeto de estudo deste capítulo. Antecede a discussão a análise das características técnicas reportadas pelos fabricantes desses instrumentos e considerações sobre as estações de medição de gás natural em estudo.

\section{1}

\section{Instrumentos utilizados nas estações de medição de gás natural}

A confiabilidade metrológica dos sistemas de medição de vazão de gás natural por placa de orifício é garantida por inspeções sistemáticas das características dimensionais dos elementos primários (trecho reto e placa de orifício) e pelas calibrações dos instrumentos associados que compõem o sistema de medição. Para atender a este propósito, esta seção discute o papel de cada instrumento de medição (pressão e temperatura) que integra o sistema de medição, bem como suas características geométricas e metrológicas, assim estabelecendo a base conceitual para definir a confiabilidade da medição final desejada a partir dos instrumentos assessórios utilizados.

A Tabela 6 resume informações relevantes dos instrumentos que integram o sistema de medição de vazão nas estações de medição (EMEDs) estudadas, relacionados à aplicação, fabricantes, modelos e classe de exatidão declarada pelo fabricante dos instrumentos de medição utilizados.

A classe de exatidão caracteriza o EMA (erro máximo admissível), ou seja, determina os limites especificados das características do instrumento, tais como os erros de linearidade, histerese e repetibilidade, por exemplo.

Os instrumentos de medição de pressão típicos utilizados nos sistemas de medição de gás por placa de orifício possuem faixa de operação (rangeabilidade) na proporção de 100:1, ou seja, uma relação de 100 para 1 entre os valores máximo e mínimo, lidos com a mesma confiabilidade, na escala do instrumento.

Outra característica importante desses instrumentos é a sua estabilidade (valor típico entre $0,1 \%$ e $0,2 \%$, durante uso continuado entre 1 a 5 anos, dependendo do fabricante e modelo).

Tabela 6 - *Características dos instrumentos instalados nas EMEDs

\begin{tabular}{cccc}
\hline INSTRUMENTO DE MEDIÇÃO & FABRICANTE & Modelo & $\begin{array}{c}\text { CLASSE DE EXATIDÃO } \\
\text { (fundo de escala) }\end{array}$ \\
\hline Transmissor de pressão & SMAR & LD302 & $0,075 \%$ \\
& ROSEMOUNT & $2051 \mathrm{TG}$ & $0,065 \%$ \\
& & $3051 \mathrm{CG}$ & $0,15 \%$ \\
& YOKOGAWA & EJA530A & $0,2 \%$ \\
\hline Transmissor de pressão diferencial & SMAR & LD302 & $0,075 \%$ \\
& ROSEMOUNT & 2051CD & $0,075 \%$ \\
\hline
\end{tabular}




\begin{tabular}{|c|c|c|c|}
\hline & & 3051CD & $0,15 \%$ \\
\hline \multirow[t]{5}{*}{ Transmissor de temperatura } & SMAR & TT302 & - \\
\hline & ROSEMOUNT & $3134 \mathrm{P}$ & - \\
\hline & & $3144 \mathrm{P}$ & - \\
\hline & & $644 \mathrm{H}$ & - \\
\hline & YOKOGAWA & YTA-310 & - \\
\hline \multirow[t]{3}{*}{ Sensor de temperatura } & IOPE & HX-13 & $0,30^{\circ} \mathrm{C}+0,005 \mathrm{t}^{\mathrm{a}^{* *}}$ \\
\hline & & HX-11 & $0,30^{\circ} \mathrm{C}+0,005 \mathrm{t}^{\mathrm{a}}$ \\
\hline & ECIL & CEA & $0,30^{\circ} \mathrm{C}+0,005 \mathrm{t}^{\mathrm{a}}$ \\
\hline Transmissor multivariável & ROSEMOUNT & 3095 & $0,15 \%$ \\
\hline
\end{tabular}

Com o avanço da eletrônica, os transmissores utilizados nas áreas industriais apresentam ganhos metrológicos, o que garante melhores níveis de repetibilidade, reprodutibilidade, exatidão e histerese, características essas adequadas ao uso. Outra característica a ser considerada é a estabilidade do instrumento. Os avanços da eletrônica e dos materiais resultaram, também, em melhoria da qualidade dos transmissores, em particular ganhos de estabilidade, que podem chegar a 12 anos para os sensores estudados neste trabalho. Outra vantagem desta geração de transmissores refere-se ao fato de fazerem uso de protocolos de comunicação digital, característica que certamente lhes assegura melhoria na confiabilidade metrológica, reduzindo, portanto, a ocorrência de erro de medição na transmissão.

Os valores mínimos e máximos das faixas calibradas dos instrumentos associados das EMEDs de interesse neste estudo são, no caso da pressão estática, entre 0 e $20000 \mathrm{kPa}$, da pressão diferencial entre 40 e $250 \mathrm{kPa}$ e da temperatura entre -15 e $160{ }^{\circ} \mathrm{C}$, podendo a faixa calibrada de cada instrumento variar dentro desses valores apresentados.

\section{2 \\ Transmissores de pressão e seus princípios de funcionamento}

Atualmente, os sensores de pressão com sinais de saída elétricos utilizados universalmente são dos tipos capacitivos, piezoelétricos e piezorresistivos. Estes sensores são comumente construídos na própria pastilha semicondutora, conhecidos como "sensores de estado sólido" ou dispositivos MEMS (microelectromechanical systems).

\subsection{1}

\section{Sensores capacitivos de pressão}

O princípio básico de operação dos sensores capacitivos de pressão é a variação da capacitância devido à movimentação entre as placas do capacitor quando o sensor é submetido a uma pressão.

Este sensor equivale a um capacitor de placas paralelas em que um dos eletrodos é formado por um diafragma de metal ou silício (utilizado como elemento sensor propriamente dito) enquanto o outro eletrodo, que permanece estacionário, é formado por um metal depositado sobre um substrato cerâmico ou de vidro.

A arquitetura construtiva de um sensor capacitivo de pressão diferencial apresenta um diafragma colocado entre dois eletrodos fixos constituindo-se num 
capacitor que terá a sua capacitância aumentada enquanto o outro terá a sua capacitância diminuída quando o sensor for submetido à pressão. $\mathrm{Na}$ arquitetura construtiva de sensores capacitivos com um único capacitor, a placa do capacitor é posicionada em apenas um dos lados do diafragma.

Amplamente utilizados, esses sensores são capazes de assegurar precisão da ordem de $0,01 \%$ (fundo de escala), com aplicabilidade a uma extensa faixa de pressão $\left(10^{-3} \mathrm{~Pa}\right.$ a $\left.10^{7} \mathrm{~Pa}\right)$. De um modo geral, sensores capacitivos exibem níveis de exatidão adequados para a aplicação e faixas de operação (rangeabilidade) comumente encontradas nas aplicações de interesse do setor de petróleo e gás, exibindo linearidade e velocidade de resposta (LIPTÁK, 2003) compatíveis com as necessidades dessas aplicações. Segundo (MORRIS, 2001), estes sensores possuem uma incerteza de medição típica de $0,2 \%$, avaliada para as condições de fundo de escala.

A Figura 7 ilustra um esquema construtivo de um sensor de pressão diferencial do tipo capacitivo.

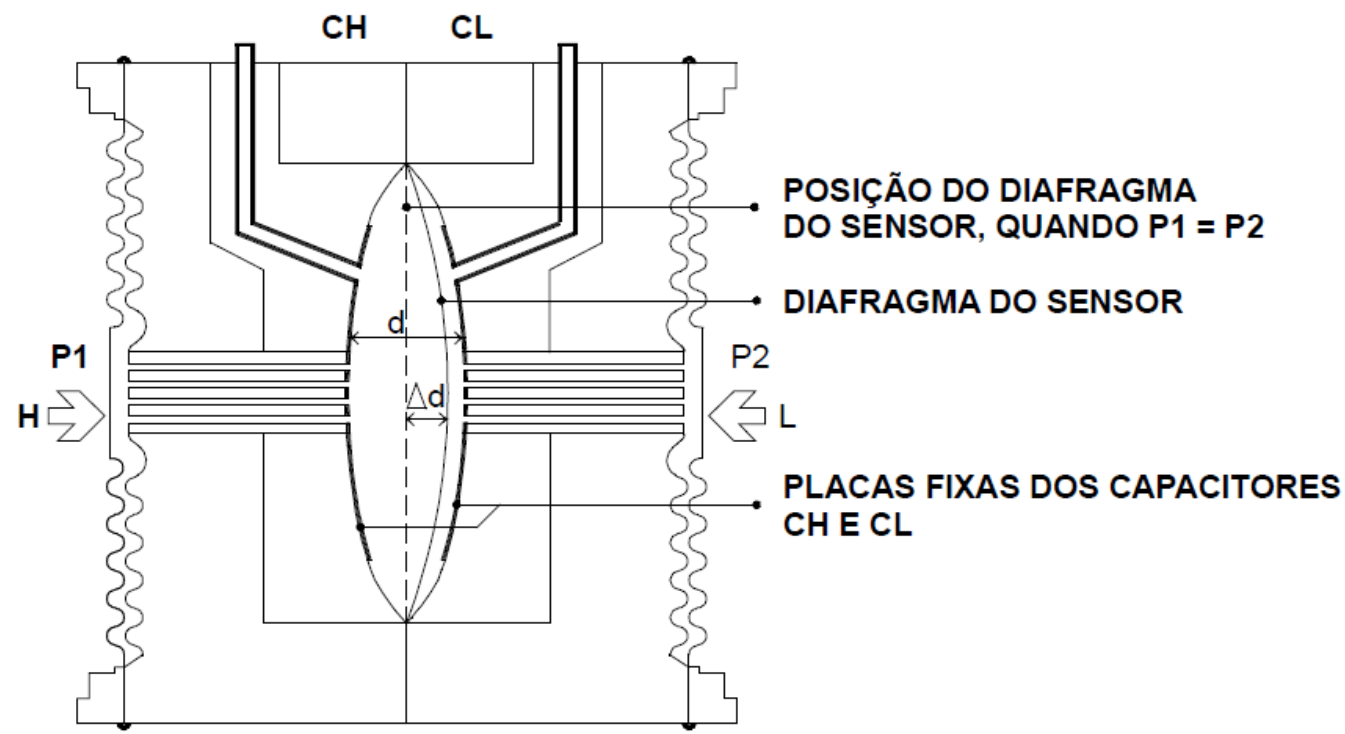

Figura 7 - Esquema construtivo de um sensor capacitivo

Fonte: (SMAR, 2014)

Nesta figura:

- P1 e P2 denotam, respectivamente, as pressões aplicadas nas câmaras H e L.

- $\mathrm{CH}$, a capacitância medida entre a placa fixa do lado de P1 e o diafragma sensor.

- CL, a capacitância medida entre a placa fixa do lado P2 e o diafragma sensor.

- $\mathrm{d}$, a distância entre as placas fixas de CH e CL.

- $\Delta \mathrm{d}$, a deflexão sofrida pelo diafragma sensor devido à aplicação da pressão diferencial $\Delta \mathrm{P}=\mathrm{P} 1-\mathrm{P} 2$. 


\subsection{2 \\ Sensores de pressão piezorresistivos}

Os sensores de pressão por efeito piezorresistivo (strain gages) mudam a resistência elétrica de elementos sensores ao serem submetidos a uma força e deformação. Os elementos piezorresistivos, o diafragma e a estrutura do sensor são construídos na mesma pastilha de silício (BALBINOT \& BRUSAMARELLO, 2011).

Para que a pastilha de silício funcione como um diafragma faz-se necessário criar uma cavidade no bloco semicondutor para que este funcione como um diafragma. Com este arranjo, uma pequena deflexão mecânica é percebida pelos extensômetros, isto é, provoca uma variação de resistência. Esta variação, por sua vez, é convertida em sinal elétrico que pode ser bastante fiel à variação de pressão que atua no diafragma. Por meio de um dispositivo eletrônico consegue-se realizar compensações de temperatura que otimizam os resultados da medição e o desempenho desse tipo de sensor (BALBINOT \& BRUSAMARELLO, 2011).

A Figura 8 ilustra um esquema construtivo de um sensor de pressão piezorresistivo em um substrato de silício.
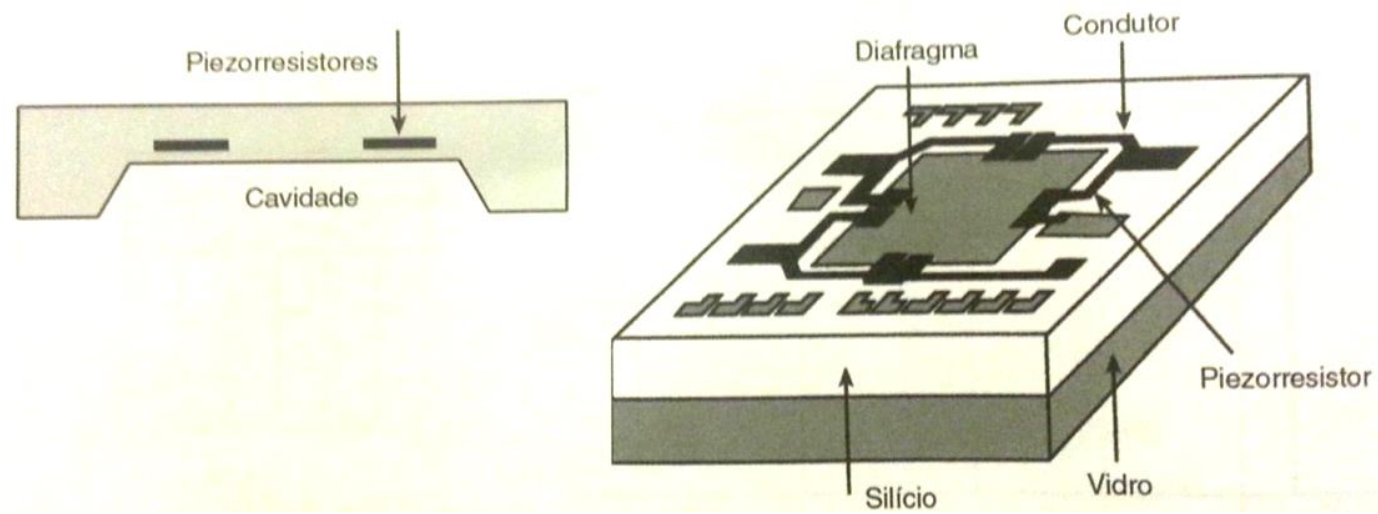

Figura 8 - Diafragma com sensores de pressão piezorresistivos Fonte: (BALBINOT \& BRUSAMARELLO, 2011)

Este tipo de sensor apresenta baixa sensibilidade às variações de temperatura e baixo nível de sinal, considerado uma desvantagem. Este inconveniente pode ser contornado pela utilização de um dispositivo eletrônico robusto, que permite compensação do "offset" antes de sua utilização.

Esses sensores possuem uma boa linearidade sob condições de temperatura constante, permitindo perceber mudanças de pressão sem, sequer, apresentarem histerese.

Devido a sua característica construtiva, quando esses sensores são submetidos a uma pressão, as suas bordas apresentam elevadas tensões mecânicas. Posicionando-se os resistores nessas áreas, obtém-se uma configuração em alta sensibilidade. Porém, com isso, o sensor perde a linearidade, o que resulta em aumento do nível de erros que resultam da variação de temperatura. Contudo, tais problemas são contornados com a utilização de condicionamentos eletrônicos adequados. 
Estes sensores exibem deriva (ao longo do tempo) e nível de histerese inferior a $0,1 \%$, em fundo de escala.

\subsection{3}

\section{Sensores de pressão piezoelétricos}

O princípio de funcionamento dos transdutores de pressão piezoelétricos resulta da diferença de potencial quando o sensor piezoelétrico é exposto a uma deformação mecânica; ou seja, o movimento ou a deformação devido à aplicação de uma pressão são transformados em sinal de tensão elétrica. Entretanto, essa diferença de potencial cessa quando o sistema entra em repouso. Assim sendo, este tipo de sensor é utilizado apenas em medições de pressão dinâmica (na presença de pulsos de pressão).

Este tipo de sensor geralmente é montado em pilha e não necessita de excitação externa, porém requer a utilização de um circuito dedicado para viabilizar o seu condicionamento.

Para simplificar o condicionamento do sinal e reduzir problemas de cabos, são utilizados alguns componentes eletrônicos que pré-amplificam a saída elétrica do sensor para um nível de tensão da ordem de milivolts com uma baixa impedância de saída.

Dependendo da capacitância e resistência do sensor, este pode apresentar uma taxa de descarga com uma constante de tempo grande, o que permitirá a sua utilização para a medição de pulsos de pressão longos, conhecida como "medição de pressão quase estática".

Dentre as vantagens dos transdutores piezoelétricos incluem-se: a sua independência de partes eletrônicas; robustez e possibilidade de medição em largas faixas de pressões com respostas rápidas. Contudo, devem ser devidamente condicionados para que não apresentem grandes variações de sensibilidade em função da temperatura.

\subsection{4}

Sensores de silício ressonante

O sensor consiste de uma capsula de silício anexada a um diafragma que vibra proporcionalmente a sua expansão/compressão, ou seja, esses sensores de silício ressonante, ao sofrerem a pressão do sistema, são comprimidos ou expandidos alterando, por sua vez, a frequência de oscilação. Alguns sensores necessitam compensações eletrônicas para minimizar os efeitos da variação de temperatura. A Figura 9 ilustra uma imagem dos sensores de silício ressonante. 


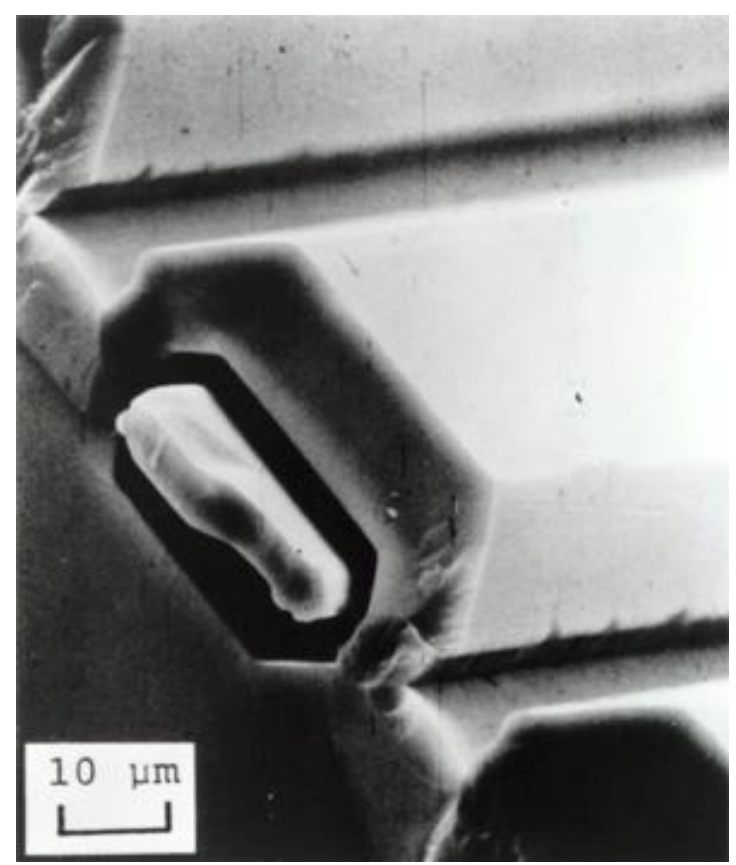

Figura 9 - Transdutor de silício ressonante

Fonte: YOKOGAWA

Estes sensores possuem longa estabilidade de zero, desvios de zero menores que $0,1 \%$ por até 7 anos, por exemplo, e ampla "rangeabilidade" ou "largura de faixa", isto é, relação de 100:1 entre o valor máximo e mínimo lido com a mesma exatidão. Devido ao seu princípio de funcionamento, a pressão é obtida a partir da medição grandeza física frequência. Em alguns casos, para a utilização desses sensores são necessárias a utilização de componentes eletrônicos intermediários para compensar a sensibilidade à variação da temperatura ambiental, choque e vibração.

\section{3 \\ Medição de temperatura por termorresistência}

Uma termorresistência ou RTD (Resistance Temperature Detectors) é um medidor de temperatura baseado na variação da resistência elétrica do elemento sensor utilizado. Estes sensores fundamentam-se no comportamento típico das resistências dos metais, ou seja, a resistência aumenta com o aumento da temperatura.

O metal mais comumente utilizado em uma termorresistência é a platina, sendo, portanto, denominado como PRT (Platinum Resistance Thermometer). Estes sensores são dispositivos praticamente lineares e, dependendo do material, são muito estáveis. São assim considerados sensores de alta exatidão e ótima repetibilidade de leitura.

Estes sensores são confeccionados com um fio metálico (cobre, platina ou níquel) com alto grau de pureza, depositado num núcleo cerâmico, vidro ou outro material isolante. A bainha ou revestimento externo visa proteger quanto a cargas mecânicas e da corrosão química. Na Figura 10, são apresentadas algumas termorresistências. 


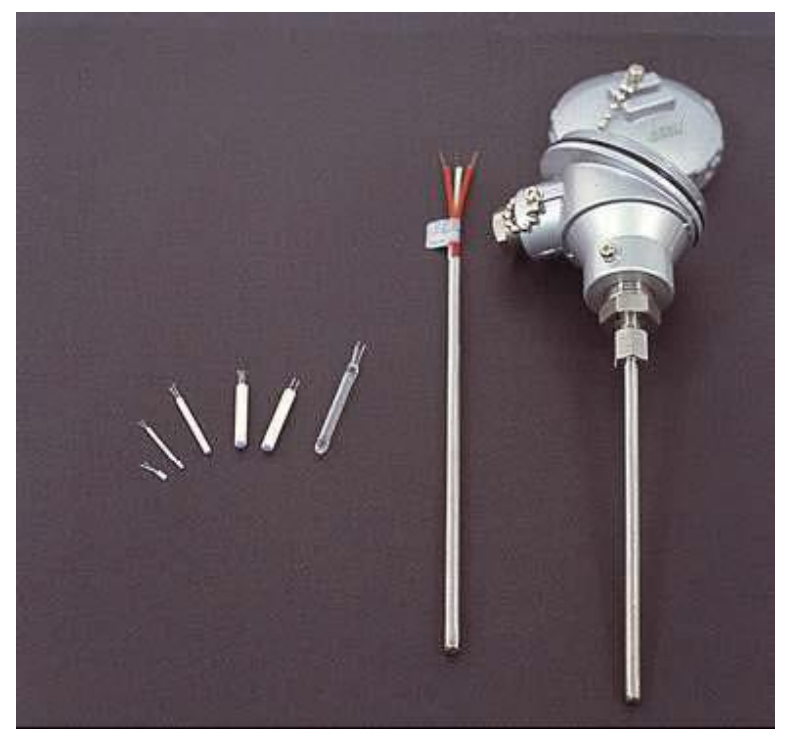

Figura 10 - Exemplos de termorresistências utilizadas

A platina é o metal usualmente utilizado na construção de RTD. Dentro de sua faixa de operação, possui uma relação resistência/temperatura razoavelmente linear, com faixa de linearidade maior quando comparada a outros metais, exibindo constância de suas características termofísicas por um longo período.

As termorresistências de platina mais comumente utilizadas são: Pt-25,5 $\Omega$, Pt-100 $\Omega$, Pt- $120 \Omega$, Pt-130 $\Omega$ e Pt-500 $\Omega$, destacando-se a Pt-100 $\Omega$ para aplicações industriais. Estas siglas representam o metal (Pt, platina) e a resistência à temperatura a $0^{\circ} \mathrm{C}$. A faixa de atuação para um RTD com filme de platina é de $50^{\circ} \mathrm{C}$ a $260^{\circ} \mathrm{C}$, enquanto que para um RTD com enrolamento de platina é de $-200^{\circ} \mathrm{C}$ a $648^{\circ} \mathrm{C}$.

A norma NBR 13773 define as classes de erro máximo A e B para as termorresistências de platina, ou seja, respectivamente: $\pm 0,15^{\circ} \mathrm{C} \mathrm{e} \pm 0,30{ }^{\circ} \mathrm{C}$ para temperaturas em torno de $0{ }^{\circ} \mathrm{C} ; \pm 0,25{ }^{\circ} \mathrm{C} \mathrm{e} \pm 0,55^{\circ} \mathrm{C}$ na temperatura em torno de $50{ }^{\circ} \mathrm{C} \mathrm{e} \pm 0,35{ }^{\circ} \mathrm{Ce} \pm 0,80{ }^{\circ} \mathrm{C}$ para temperaturas da ordem de $100{ }^{\circ} \mathrm{C}$.

$\mathrm{Na}$ aplicação de um sensor do tipo RTD, geralmente utiliza-se uma corrente de elétrica de $1 \mathrm{~mA}$ para evitar que o sensor apresente leituras com erro de autoaquecimento devido ao efeito Joule. Abaixo de $400{ }^{\circ} \mathrm{C}$, os desvios são insignificantes. Além disso, choques mecânicos, vibrações, umidade e a utilização inadequada do sensor também mudam as características do sensor e podem introduzir erros.

As equações, a seguir, permitem calcular a resistência elétrica em função da temperatura de um sensor do tipo RTD, para duas amplas faixas de temperatura (ABNT NBR ISO/IEC 13773, 2008):

para temperaturas variando na faixa de $-200^{\circ} \mathrm{C} \mathrm{a} 0^{\circ} \mathrm{C}$,

$R_{t}=R_{o}\left[1+A t+B t^{2}+C(t-100) t^{3}\right]$

para temperaturas variando na faixa de $0{ }^{\circ} \mathrm{C}$ a $850{ }^{\circ} \mathrm{C}$,

$\mathrm{R}_{\mathrm{t}}=\mathrm{R}_{\mathrm{o}}\left(1+\mathrm{At}+\mathrm{Bt}^{2}\right)$ 
Nessas expressões:

$\mathrm{R}_{\mathrm{t}}$ é a resistência na temperatura " $\mathrm{t}$ ", medida em graus Celsius, de acordo com a ITS-90;

$\mathrm{R}_{\mathrm{o}}$ é a resistência a $0{ }^{\circ} \mathrm{C}$;

$\mathrm{A}=3,9083 \times 10^{-3}{ }^{\circ} \mathrm{C}^{-1} ; \mathrm{B}=-5,775 \times 10^{-7}{ }^{\circ} \mathrm{C}^{-2}$ e $\mathrm{C}=-4,183 \times 10^{-12}{ }^{\circ} \mathrm{C}^{-4}$. 


\section{Resultados e discussão}

Este capítulo descreve e discute os resultados do planejamento de experimentos realizados para as estações de medição (EMEDs) analisadas nas instalações da Unidade Operacional da Petrobras no Espírito Santo (UO-ES). A análise considerou a combinação de critérios limítrofes para o cálculo da incerteza expandida de medição associada a cada um dos três instrumentos de medição das grandezas físicas de influência (temperatura, pressão estática e pressão diferencial) na medição de vazão de gás natural por placa de orifício, nos dois níveis atribuídos a cada fator, de forma a garantir o atendimento ao requisito do RTM; isto é: 1,5\% é a incerteza expandida aceitável para sistemas de medição fiscal e $2 \%$ para sistema de medição para fins de apropriação.

Os cálculos de incerteza das medições de vazão foram realizados a partir de um software corporativo de cálculo da incerteza baseado na metodologia proposta pela ISO 5168:2005, desenvolvido no Excel. Desta forma, foi possível montar os planejamentos propostos. A partir dos planejamentos definidos, utilizou-se o software Statistica para determinar as superfícies de respostas, as curvas de nível, a ANOVA e os gráficos de Pareto dos efeitos de cada planejamento.

\section{1}

\section{As estações de medição de gás natural estudadas}

As EMEDs estudadas referem-se aos sistemas de medição fiscal e de apropriação de gás natural por placa de orifício. Foram estudadas 11 EMEDs terrestres, das quais 8 para fins fiscais e 3 para apropriação. A Tabela 7 evidencia as características típicas das EMEDs estudadas. Os valores indicados nesta tabela referem-se a valores médios medidos de $\Delta \mathrm{P}, \mathrm{P}$ e $\mathrm{T}$.

Tabela 7 - Características das estações de medição

\begin{tabular}{|c|c|c|c|c|c|c|c|c|c|c|c|}
\hline $\begin{array}{l}\mathrm{R} \\
\mathrm{EF}\end{array}$ & $\begin{array}{l}\text { Tipo de } \\
\text { medição }\end{array}$ & $\begin{array}{l}\text { DO* } \\
{[\mathrm{mm}]}\end{array}$ & $\begin{array}{c}\mathrm{D}^{* * *} \\
{[\mathrm{~mm}]}\end{array}$ & $\begin{array}{c}\Delta \mathrm{P}^{* * *} \\
{[\mathrm{kPa}]}\end{array}$ & $\begin{array}{l}\mathrm{P} * * * * * \\
{[\mathrm{kPa}]}\end{array}$ & $\begin{array}{c}\mathrm{T}^{* * * * * * *} \\
{\left[{ }^{\circ} \mathrm{C}\right]}\end{array}$ & $\begin{array}{l}\text { vazão } \\
{\left[\mathrm{m}^{3 / d} / \mathrm{dia}\right]}\end{array}$ & $\begin{array}{c}\text { Incerteza } \\
\%\end{array}$ & $\begin{array}{l}\text { faixa } \Delta \mathrm{P} \\
{[\mathrm{kPa}]}\end{array}$ & $\begin{array}{c}\text { faixa P } \\
{[\mathrm{kPa}]}\end{array}$ & $\begin{array}{c}\text { faixa T } \\
{\left[{ }^{\circ} \mathrm{C}\right]}\end{array}$ \\
\hline A & FISCAL & 37,44 & 101,6 & 62,21 & 7098,2 & 25,98 & 213103 & 0,58 & 0 a 62,21 & 0 a 8962 & 0 a 100 \\
\hline B & FISCAL & 82,82 & 154,83 & 49,82 & 503,2 & 30,61 & 223240 & 1,16 & 0 a 49,82 & 0 a 686 & 0 a 100 \\
\hline $\mathrm{C}$ & APROPR. & 22,85 & 77,97 & 49,82 & 512,6 & 31,01 & 16133 & 1,18 & 0 a 49,82 & 0 a 686 & 0 a 100 \\
\hline D & FISCAL & 36,6 & 97,8 & 49,82 & 4980,5 & 30,28 & 142430 & 1,06 & 0 a 49,82 & 0 a 11768 & 0 a 100 \\
\hline E & APROPR. & 32,23 & 53,36 & 3,4 & 537,1 & 28,4 & 9913 & 1,24 & 0 a 24,91 & 0 a 686 & 0 a 100 \\
\hline E & APROPR. & 32,23 & 53,36 & 24,91 & 537,1 & 28,4 & 26460 & 1,19 & 0 a 24,91 & 0 a 686 & 0 a 100 \\
\hline $\mathrm{F}$ & FISCAL & 53,98 & 77,82 & 3,92 & 544,3 & 30,65 & 31714 & 1,22 & 0 a 49,82 & 0 a 686 & 0 a 100 \\
\hline $\mathrm{F}$ & FISCAL & 53,98 & 77,82 & 49,82 & 544,3 & 30,65 & 109664 & 1,22 & 0 a 49,82 & 0 a 686 & 0 a 100 \\
\hline G & FISCAL & 29,44 & 102,31 & 6,75 & 678,6 & 30,4 & 11960 & 1,50 & 0 a 29,91 & 0 a 686 & 0 a 100 \\
\hline G & FISCAL & 29,44 & 102,31 & 29,91 & 678,6 & 30,4 & 24947 & 1,15 & 0 a 29,91 & 0 a 686 & 0 a 100 \\
\hline $\mathrm{H}$ & APROPR. & 12,62 & 52,44 & 49,82 & 101,3 & 25,52 & 2301 & 1,96 & 0 a 49,82 & 0 a 558 & 0 a 100 \\
\hline I & FISCAL & 44,46 & 154,13 & 11,35 & 322,4 & 37,75 & 25081 & 1,50 & 0 a 24,91 & 0 a 558 & 0 a 100 \\
\hline $\mathrm{J}$ & FISCAL & 44,94 & 154,95 & 24,91 & 350,2 & 35,02 & 39422 & 1,27 & 0 a 24,91 & 0 a 558 & 0 a 100 \\
\hline $\mathrm{J}$ & FISCAL & 44,94 & 154,95 & 11,1 & 350,2 & 35,02 & 26553 & 1,50 & 0 a 24,91 & 0 a 558 & 0 a 100 \\
\hline $\mathrm{K}$ & FISCAL & 29,48 & 95,62 & 18,68 & 101,3 & 24,67 & 6858 & 4,32 & 0 a 18,68 & 0 a 11768 & 0 a 100 \\
\hline
\end{tabular}

* DO - diâmetro do orifício; ** D - diâmetro médio da tubulação; *** $\Delta \mathrm{P}$ - pressão diferencial média; **** $\mathrm{P}$ - pressão estática média; ***** $\mathrm{T}-$ temperatura média 


\section{2}

\section{Condições de contorno adotadas nos experimentos}

No presente trabalho, é proposto um planejamento composto central para três fatores em dois níveis, um ponto central com cinco repetições e seis pontos axiais, o que gera dezenove experimentos. Os fatores avaliados foram aqueles relacionados às grandezas físicas de influência na medição de vazão de gás por placa de orifício; i.e.: pressão diferencial, pressão estática e temperatura do gás.

Para construir a matriz experimental foi utilizada a técnica de planejamento fatorial composto central, com pontos axiais. A Tabela 8 apresenta a matriz de planejamento com os níveis de ajuste dos fatores de controle em termos de variáveis codificadas.

Tabela 8 - Matriz de planejamento experimental

\begin{tabular}{ccccc}
\hline $\begin{array}{c}\text { Experimento } \\
\#\end{array}$ & $\begin{array}{c}\text { Incerteza } \\
\text { associada a } \\
\mathbf{P}\end{array}$ & $\begin{array}{c}\text { Incerteza } \\
\text { associada a } \mathbf{\Delta P}\end{array}$ & $\begin{array}{c}\text { Incerteza } \\
\text { associada a T }\end{array}$ & $\begin{array}{c}\text { Incerteza } \\
\text { associada a } \\
\text { Vazão }\left(\mathbf{y}_{\mathbf{i}}\right)\end{array}$ \\
\hline $\mathbf{1}$ & -1 & -1 & -1 & $\mathrm{y}_{1}$ \\
$\mathbf{2}$ & +1 & -1 & -1 & $\mathrm{y}_{2}$ \\
$\mathbf{3}$ & -1 & +1 & -1 & $\mathrm{y}_{3}$ \\
$\mathbf{4}$ & +1 & +1 & -1 & $\mathrm{y}_{4}$ \\
$\mathbf{5}$ & -1 & -1 & +1 & $\mathrm{y}_{5}$ \\
$\mathbf{6}$ & +1 & -1 & +1 & $\mathrm{y}_{6}$ \\
$\mathbf{7}$ & -1 & +1 & +1 & $\mathrm{y}_{7}$ \\
$\mathbf{8}$ & +1 & +1 & +1 & $\mathrm{y}_{8}$ \\
$\mathbf{9}$ & $-1,682$ & 0 & 0 & $\mathrm{y}_{9}$ \\
$\mathbf{1 0}$ & 1,682 & 0 & 0 & $\mathrm{y}_{10}$ \\
$\mathbf{1 1}$ & 0 & $-1,682$ & 0 & $\mathrm{y}_{11}$ \\
$\mathbf{1 2}$ & 0 & 1,682 & 0 & $\mathrm{y}_{12}$ \\
$\mathbf{1 3}$ & 0 & 0 & $-1,682$ & $\mathrm{y}_{13}$ \\
$\mathbf{1 4}$ & 0 & 0 & 1,682 & $\mathrm{y}_{14}$ \\
$\mathbf{1 5}$ & 0 & 0 & 0 & $\mathrm{y}_{15}$ \\
$\mathbf{1 6}$ & 0 & 0 & 0 & $\mathrm{y}_{16}$ \\
$\mathbf{1 7}$ & 0 & 0 & 0 & $\mathrm{y}_{17}$ \\
$\mathbf{1 8}$ & 0 & 0 & 0 & $\mathrm{y}_{18}$ \\
$\mathbf{1 9}$ & 0 & 0 & 0 & $\mathrm{y}_{19}$ \\
\hline
\end{tabular}

Para o ponto central, nível médio, a incerteza de medição das grandezas de influência foi considerada como uma perturbação aleatória em torno de zero para os cincos pontos de repetição. Já para os níveis alto (+1) e baixo (-1) das grandezas pressão estática $(P)$ e pressão diferencial $(\Delta P)$, a incerteza de medição foi avaliada para quatro cenários: $1 \%, 0,75 \%, 0,50 \%$ e $0,25 \%$ das respectivas faixas de medição dos transmissores de pressão diferencial e estática. Esta hipótese considerada resulta nos seguintes valores de incerteza expandida associada à medição da vazão: 1,5 \% para medição fiscal e $2 \%$ para medição de apropriação. Para os mesmos níveis +1 e -1 , incertezas de $1{ }^{\circ} \mathrm{C}$ foram consideradas para as medições de temperatura, resultando em um valor de incerteza expandida associada à medição da vazão que varia na faixa de $1,5 \%$ de medição fiscal e $2,0 \%$ para medição de apropriação.

Como o interesse neste estudo é identificar os valores ótimos (pontos máximos) para a incerteza associada à medição da vazão, os modelos que se ajustam 
ao sistema real é a equação de $2^{a}$ ordem dos fatores, pois possibilitam estimar uma superfície curvilínea e, portanto, valores com uma maior aproximação à superfície de resposta real.

Foram previstas réplicas para cálculo do ponto central com o intuito de fornecer informações sobre o erro associado à determinação dos coeficientes. (BARROS NETO, SCARMINIO, \& BRUNS, 2001) sugerem uma regra prática: realizar de 3 a 5 réplicas do ponto central, quanto mais próximo $\alpha$ (espaçamento axial em relação à origem) estiver de $\sqrt{n_{f}}$, sendo $\mathrm{n}_{\mathrm{f}} \mathrm{o}$ número de pontos fatoriais, $\mathrm{e}$ somente 1 ou 2 réplicas, quando $\alpha$ se aproximar do valor unitário 1.

O efeito médio resultante da repetição dos últimos efeitos apresentados na Tabela 8 corresponde a uma estimativa da resposta no ponto central, ou seja, ao coeficiente linear de um modelo matemático do tipo

$\mathrm{y}=\beta_{0}+\beta_{1} x_{1}+\beta_{2} x_{2}+\beta_{3} x_{3}+\beta_{4} x_{1} x_{2}+\beta_{5} x_{1} x_{3}+\beta_{6} x_{2} x_{3}+\beta_{7} x_{1} x_{2} x_{3}+$ $\beta_{8} x_{1}^{2}+\beta_{9} x_{2}^{2}+\beta_{10} x_{3}^{2}$

Sendo $x_{1}$ o "nível" da incerteza padrão combinada associada à medição de $P$, $x_{2} \mathrm{o}$ "nível" da incerteza padrão combinada associada à medição de $\Delta P$ e $x_{3} \mathrm{o}$ "nível" da incerteza padrão combinada associada à medição de $T$, obtém-se

$$
\begin{aligned}
& \mathrm{y}=\beta_{0}+\beta_{1} \mathrm{P}+\beta_{2} \Delta \mathrm{P}+\beta_{3} \mathrm{~T}+\beta_{4} \mathrm{P} \cdot \Delta \mathrm{P}+\beta_{5} \mathrm{P} \cdot \mathrm{T}+\beta_{6} \Delta \mathrm{P} \cdot \mathrm{T}+\beta_{7} \mathrm{P} \cdot \Delta \mathrm{P} \cdot \\
& \mathrm{T}+\beta_{8} \mathrm{P}^{2}+\beta_{9} \Delta \mathrm{P}^{2}+\beta_{10} \mathrm{~T}^{2}
\end{aligned}
$$

As variáveis de entrada são as incertezas padrão combinadas associadas às grandezas de influência $P, \Delta P$ e $T$ e a variável de saída $y$ é a incerteza expandida associada à medição da vazão volumétrica de gás, calculada de acordo com a metodologia proposta pela ISO 5168:2005.

A Equação (8) pode ser decomposta nas seguintes matrizes

$$
y=\left[\begin{array}{l}
y_{1} \\
y_{2} \\
y_{3} \\
y_{4} \\
y_{5} \\
y_{6} \\
y_{7} \\
y_{8} \\
y_{9} \\
y_{10} \\
y_{11} \\
y_{12} \\
y_{13} \\
y_{14} \\
y_{15} \\
y_{16} \\
y_{17} \\
y_{18} \\
y_{19}
\end{array}\right](9), \beta=\left[\begin{array}{l}
\beta_{1} \\
\beta_{2} \\
\beta_{3} \\
\beta_{4} \\
\beta_{5} \\
\beta_{6} \\
\beta_{7} \\
\beta_{8} \\
\beta_{9} \\
\beta_{10} \\
\beta_{11} \\
\beta_{12} \\
\beta_{13} \\
\beta_{14} \\
\beta_{15} \\
\beta_{16} \\
\beta_{17} \\
\beta_{18} \\
\beta_{19}
\end{array}\right](10) \mathrm{e}
$$




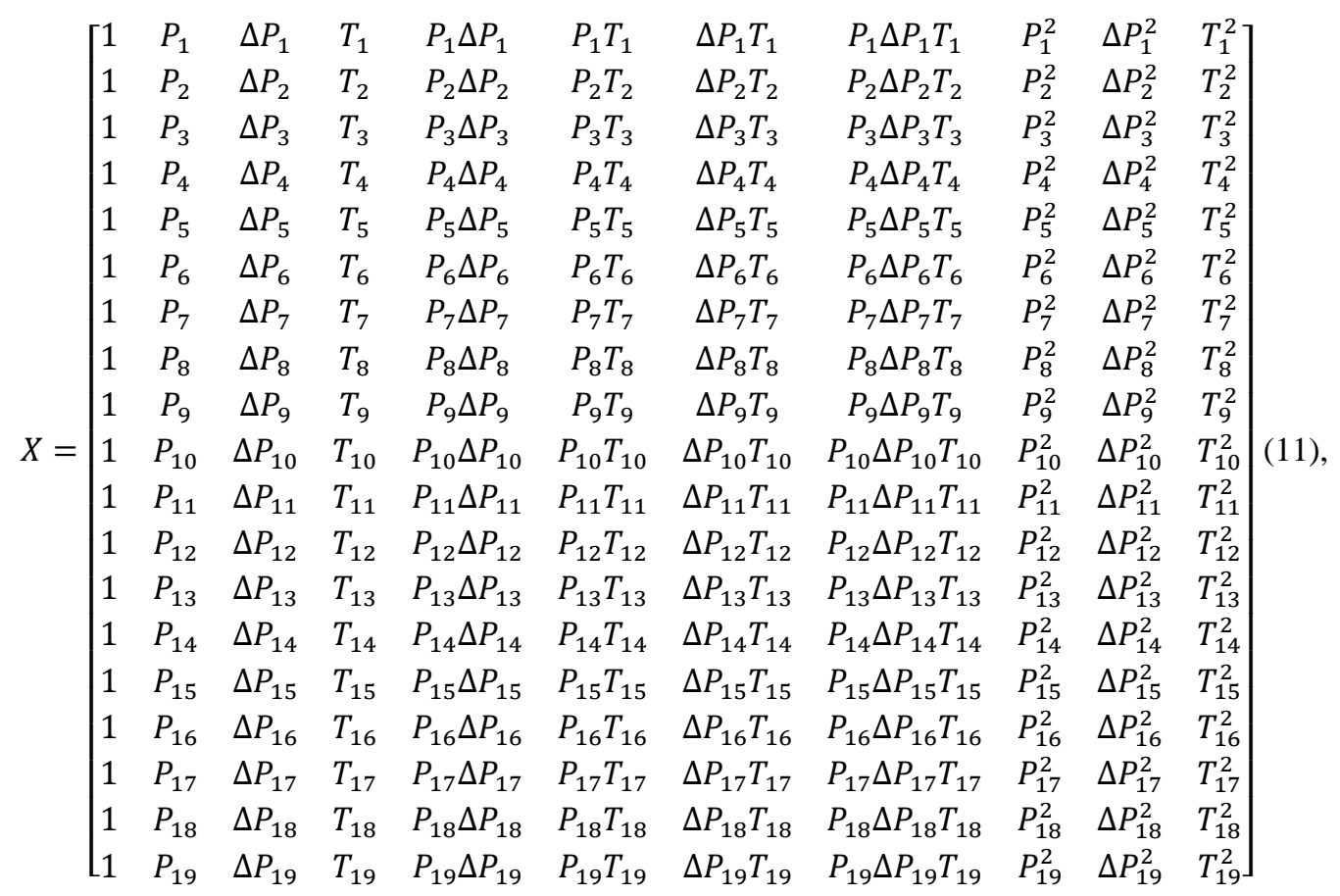

e os coeficientes $\beta$ podem ser calculados pela Equação (3).

As representações gráficas do modelo proposto pela Equação (8) geradas neste trabalho são superfícies de resposta tridimensionais tendo como eixos $x_{1}$ e $x_{2}$, respectivamente, os níveis dos fatores $P$ e $\Delta P$ e como eixo $z$ a resposta $y$, isto é, o resultado analítico obtido pela própria Equação (8). Para possibilitar, também, a avaliação dos níveis da grandeza de influência temperatura, ao serem gerados esses tais gráficos de superfície de resposta contemplando $P$ e $\Delta P$, estes são gerados para cada um nível da grandeza temperatura de $1{ }^{\circ} \mathrm{C}$.

Os valores decodificados dos pontos ótimos na unidade das grandezas de interesse serão os valores dos critérios-limites para aceitação da calibração de transmissores de cada grandeza de influência que atendem aos requisitos impostos pelo RTM para cada sistema de medição de vazão de gás.

\section{3}

\section{Planejamento do experimento e superfície de resposta}

Com a definição do planejamento de experimento apresentada na Tabela 8, foram calculados os 19 valores de incerteza associada à medição de vazão referente a cada experimento, para cada uma das EMED estudadas. Em seguida, pelo método dos mínimos quadrados foi obtido um polinômio de segunda ordem do tipo apresentado na equação (8) que permitiu estimar a incerteza associada ao sistema de medição de vazão de gás para cada EMED na região delimitada pelos níveis de cada grandeza. Este processo foi efetuado considerando o nível das grandezas como sendo $1 \%$ das respectivas faixas de medição dos transmissores de pressão diferencial e estática de cada EMED.

O uso desses polinômios de segunda ordem permite construir uma superfície de resposta para os planejamentos propostos com os seguintes eixos: pressão estática $\left(\mathrm{x}_{1}\right)$ e diferencial $\left(\mathrm{x}_{2}\right)$. A superfície representa graficamente a variação da 
incerteza de medição expandida associada à medição de vazão de gás (y) face à interação de $\mathrm{x}_{1}$ e $\mathrm{x}_{2}$ considerando o nível da temperatura igual a $1{ }^{\circ} \mathrm{C}$.

\subsection{1}

\section{Estação A - estação de medição fiscal}

A Tabela 9 apresenta a matriz de planejamento de experimentos da EMED A, com os níveis adotados para cada grandeza: $1 \%$ do fundo de escala (f.e.) de cada instrumento de pressão estática e diferencial, bem como uma variação de de $1{ }^{\circ} \mathrm{C}$ no instrumento de medição de temperatura. Com a aplicação dos mínimos quadrados realizada a partir dos dados do planejamento de experimento, foi possível a obtenção da Equação (12), que determina a superfície de resposta das incertezas expandidas estimadas na medição de vazão.

Tabela 9 - Matriz de planejamento experimental da EMED A

\begin{tabular}{|c|c|c|c|c|c|c|c|}
\hline \multirow{2}{*}{ Experimento \# } & \multicolumn{6}{|c|}{ Matriz do modelo } & \multirow{2}{*}{$\begin{array}{l}\text { Incerteza de medição } \\
\text { associada à vazão }\end{array}$} \\
\hline & $\mathrm{x} 1$ & $\mathrm{x} 2$ & $\mathrm{x} 3$ & $\mathrm{P}$ & $\Delta \mathrm{P}$ & $\mathrm{T}$ & \\
\hline 1 & -1 & -1 & -1 & $-89,62$ & $-0,6221$ & -1 & 2,09 \\
\hline 2 & 1 & -1 & -1 & 89,62 & $-0,6221$ & -1 & 2,09 \\
\hline 3 & -1 & 1 & -1 & $-89,62$ & 0,6221 & -1 & 2,09 \\
\hline 4 & 1 & 1 & -1 & 89,62 & 0,6221 & -1 & 2,09 \\
\hline 5 & -1 & -1 & 1 & $-89,62$ & $-0,6221$ & 1 & 2,09 \\
\hline 6 & 1 & -1 & 1 & 89,62 & $-0,6221$ & 1 & 2,09 \\
\hline 7 & -1 & 1 & 1 & $-89,62$ & 0,6221 & 1 & 2,09 \\
\hline 8 & 1 & 1 & 1 & 89,62 & 0,6221 & 1 & 2,09 \\
\hline 9 & $-1,682$ & 0 & 0 & $-150,74$ & 0 & 0 & 3,30 \\
\hline 10 & 1,682 & 0 & 0 & 150,74 & 0 & 0 & 3,30 \\
\hline 11 & 0 & $-1,682$ & 0 & 0 & $-1,0464$ & 0 & 1,95 \\
\hline 12 & 0 & 1,682 & 0 & 0 & 1,0464 & 0 & 1,95 \\
\hline 13 & 0 & 0 & $-1,682$ & 0 & 0 & $-1,682$ & 1,22 \\
\hline 14 & 0 & 0 & 1,682 & 0 & 0 & 1,682 & 1,22 \\
\hline 15 & 0 & 0 & 0 & 0 & 0 & 0 & 1,05 \\
\hline 16 & 0 & 0 & 0 & 0,36 & 0,0013 & 0,014 & 1,05 \\
\hline 17 & 0 & 0 & 0 & 0,34 & 0,0012 & 0,0090 & 1,05 \\
\hline 18 & 0 & 0 & 0 & 0,12 & 0,0033 & 0,0088 & 1,05 \\
\hline 19 & 0 & 0 & 0 & 0,40 & 0,0034 & 0,0085 & 1,05 \\
\hline
\end{tabular}

$Y=1,06+0,77 X_{1}^{2}+0,29 X_{2}^{2}+0,03 X_{3}^{2}$

Pode-se notar a partir da Tabela 10 e pela Figura 11 que, para os níveis observados, somente os termos quadráticos de $u(P)$ e $u(D P)$ são estatisticamente significativo enquanto que o termo quadrático de $u(T)$ é marginalmente significativo. Os demais termos são irrelevantes estatisticamente.

Tabela 10 - Tabela de ANOVA do planejamento de experimentos da EMED A

\begin{tabular}{|c|c|c|c|c|c|}
\hline \multirow{2}{*}{ Fonte de variação } & \multicolumn{5}{|c|}{ ANOVA; Var.:Y [\%]; R²=,99347; $\mathrm{R}^{2} \mathrm{a}: 98695$} \\
\cline { 2 - 6 } & 3 fatores, 1 Bloco, 19 Experimentos; Média Quadrática Residual =,0062959 \\
\cline { 2 - 6 } & $\begin{array}{c}\text { Soma de } \\
\text { Quadrados }\end{array}$ & $\begin{array}{c}\text { Graus de } \\
\text { liberdade }\end{array}$ & $\begin{array}{c}\text { Quadrados } \\
\text { médios }\end{array}$ & Teste F & $\mathrm{p}$ \\
\hline$(1) \mathrm{u}(\mathrm{P})[\mathrm{kPa}](\mathrm{L})$ & 0,000000 & 1 & 0,000000 & 0,000 & 0,999815 \\
\hline $\mathrm{u}(\mathrm{P})[\mathrm{kPa}](\mathrm{Q})$ & 8,029735 & 1 & 8,029735 & 1275,389 & 0,000000 \\
\hline$(2) \mathrm{u}(\mathrm{DP})[\mathrm{kPa}](\mathrm{L})$ & 0,000000 & 1 & 0,000000 & 0,000 & 0,999796 \\
\hline
\end{tabular}




\begin{tabular}{|c|c|c|c|c|c|}
\hline $\mathrm{u}(\mathrm{DP})[\mathrm{kPa}](\mathrm{Q})$ & 1,155254 & 1 & 1,155254 & 183,493 & 0,000000 \\
\hline$(3) \mathrm{u}(\mathrm{T})\left[{ }^{\circ} \mathrm{C}\right](\mathrm{L})$ & 0,000000 & 1 & 0,000000 & 0,000 & 0,999458 \\
\hline $\mathrm{u}(\mathrm{T})\left[{ }^{\circ} \mathrm{C}\right](\mathrm{Q})$ & 0,013536 & 1 & 0,013536 & 2,150 & 0,176623 \\
\hline $1 \mathrm{~L} \times 2 \mathrm{~L}$ & 0,000000 & 1 & 0,000000 & 0,000 & 0,999999 \\
\hline $1 \mathrm{~L} \times 3 \mathrm{~L}$ & 0,000000 & 1 & 0,000000 & 0,000 & 0,999998 \\
\hline $2 \mathrm{~L} \times 3 \mathrm{~L}$ & 0,000000 & 1 & 0,000000 & 0,000 & 0,999998 \\
\hline Erro & 0,056663 & 9 & 0,006296 & & \\
\hline Total SQ & 8,683122 & 18 & & & \\
\hline
\end{tabular}

Como não é finalidade deste trabalho aprofundar na teoria estatística, para que o leitor obtenha uma boa fundamentação teórica sobre a análise de variância para a análise da tabela supra, recomenda-se a consulta a autores como (MONTGOMERY \& RUNGER, 2013), (DEVORE, 2006), (WALPOLE, MYERS, MYERS, \& YE, 2011), entre outros.

Gráfico de Pareto dos Efeitos; Variável: Y [\%] - EMED A

3 fatores, 1 Bloco, 19 Experimentos; Média Quadrática Residual =,0062959

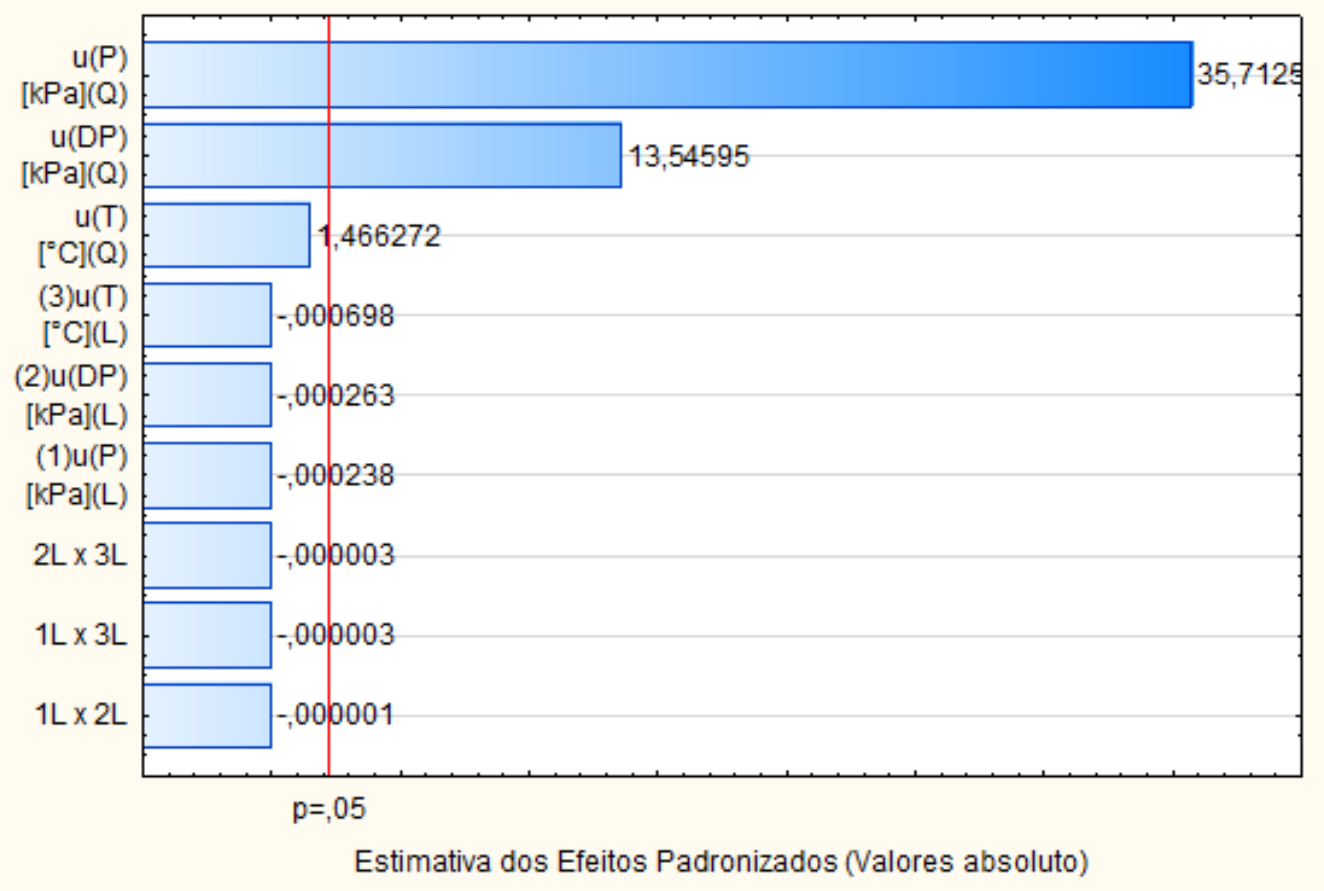

Figura 11 - Gráfico de Pareto em função dos valores da estatística de teste t

Ao avaliar a Figura 12, que apresenta o gráfico dos resíduos deste planejamento de experimento, verifica-se visualmente uma dispersão aleatória em torno do eixo de x. Com isso, sugere-se que o modelo proposto pela equação 12 pode ser adequado para um nível de $1 \%$ do f.e. e $1{ }^{\circ} \mathrm{C}$. Outro dado que corrobora com a adequabilidade do modelo é que o valor de $\mathrm{R}^{2}$ desta regressão é dado por 0,9935 . Além disso, verifica-se visualmente apenas 5 pontos destacados. Isso ocorre, pois, os demais pontos estão sobrepostos por se tratar de um planejamento rotacionável, ou seja, o desvio-padrão da resposta prevista para $\hat{y}$ é constante em todos os pontos que estão à mesma distância do centro do planejamento. 


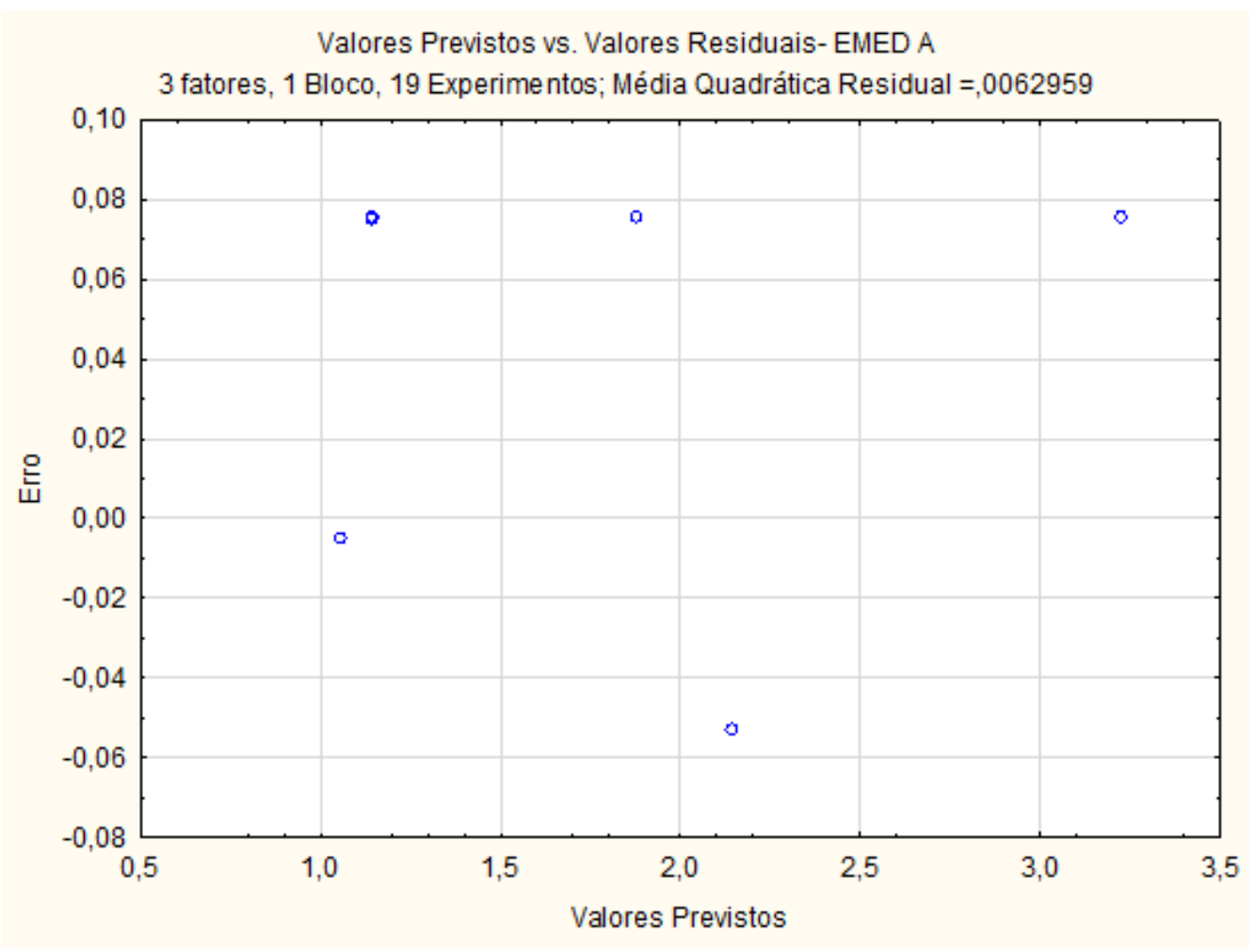

Figura 12 - Resíduos versus estimativas de y (EMED A - nível: $1 \%$ f.e. e $1^{\circ} \mathrm{C}$ ).

Com a mesma analogia empregada no desenvolvimento da equação 12 , as equações 13, 14 e 15 foram obtidas para níveis de incerteza de $0,75 \%, 0,50 \%$ e $0,25 \%$ do fundo de escala dos instrumentos de medição de pressão e $1^{\circ} \mathrm{C}$ para os instrumentos de medição de temperatura.

$Y=1,05+0,48 X_{1}^{2}+0,18 X_{2}^{2}+0,01 X_{3}^{2}$

$Y=1,05+0,22 X_{1}^{2}+0,095 X_{2}^{2}+0,009 X_{3}^{2}$

$Y=1,05+0,053 X_{1}^{2}+0,027 X_{2}^{2}+0,003 X_{3}^{2}$

No caso da EMED A, verificou-se que os critérios-limites da incerteza das grandezas pressão estática e diferencial são superiores a $0,50 \%$ do fundo de escala dos respectivos instrumentos de medições ao se adotar $1{ }^{\circ} \mathrm{C}$, pois todas as interações para a estimativa da incerteza de medição da vazão, neste caso, resultam em valores dentro dos limites estabelecidos pelo RTM, ou seja, menores que $1,5 \%$ da vazão de gás.

A Tabela 11 apresenta as incertezas estimadas da medição de vazão a partir da equação (12) dado $\mathrm{x}_{3}(\mathrm{~T})$ igual a 1 e $\mathrm{x}_{1}(\mathrm{P})$ e $\mathrm{x}_{2}(\Delta \mathrm{P})$ variando entre os seus respectivos níveis baixo, alto e frações. As células com fundo branco representam aqueles valores de incerteza da medição de vazão estimados que atendem ao requisito do RTM para medição fiscal de 1,5\%. 
Tabela 11 - Matriz das incertezas estimadas da vazão (EMED A)

(dado $\mathrm{x}_{3}(\mathrm{~T})$ igual a 1 e $\mathrm{x}_{1}$ e $\mathrm{x}_{2}$ variando do nível baixo ao nível alto)

\begin{tabular}{|c|c|c|c|c|c|c|c|c|c|c|c|}
\multicolumn{1}{c|}{} & \multicolumn{10}{c|}{$\mathbf{1} 1$} \\
\cline { 2 - 12 } & -1 & $-0,8$ & $-0,6$ & $-0,4$ & $-0,2$ & 0 & 0,2 & 0,4 & 0,6 & 0,8 & 1 \\
\hline-1 & 2,14 & 1,87 & 1,65 & 1,50 & 1,41 & 1,38 & 1,41 & 1,50 & 1,65 & 1,87 & 2,14 \\
\hline$-0,8$ & 2,04 & 1,76 & 1,55 & 1,40 & 1,30 & 1,27 & 1,30 & 1,40 & 1,55 & 1,76 & 2,04 \\
\hline$-0,6$ & 1,96 & 1,68 & $\mathbf{1 , 4 7}$ & 1,31 & 1,22 & 1,19 & 1,22 & 1,31 & $\mathbf{1 , 4 7}$ & 1,68 & 1,96 \\
\hline$-0,4$ & 1,90 & 1,62 & 1,41 & 1,26 & 1,16 & 1,13 & 1,16 & 1,26 & 1,41 & 1,62 & 1,90 \\
\hline$-0,2$ & 1,87 & 1,59 & 1,37 & 1,22 & 1,13 & 1,10 & 1,13 & 1,22 & 1,37 & 1,59 & 1,87 \\
\hline 0 & 1,85 & 1,58 & 1,36 & 1,21 & 1,12 & 1,09 & 1,12 & 1,21 & 1,36 & 1,58 & 1,85 \\
\hline 0,2 & 1,87 & 1,59 & 1,37 & 1,22 & 1,13 & 1,10 & 1,13 & 1,22 & 1,37 & 1,59 & 1,87 \\
\hline 0,4 & 1,90 & 1,62 & 1,41 & 1,26 & 1,16 & 1,13 & 1,16 & 1,26 & 1,41 & 1,62 & 1,90 \\
\hline 0,6 & 1,96 & 1,68 & $\mathbf{1 , 4 7}$ & 1,31 & 1,22 & 1,19 & 1,22 & 1,31 & $\mathbf{1 , 4 7}$ & 1,68 & 1,96 \\
\hline 0,8 & 2,04 & 1,76 & 1,55 & 1,40 & 1,30 & 1,27 & 1,30 & 1,40 & 1,55 & 1,76 & 2,04 \\
\hline 1 & 2,14 & 1,87 & 1,65 & 1,50 & 1,41 & 1,38 & 1,41 & 1,50 & 1,65 & 1,87 & 2,14 \\
\hline
\end{tabular}

A análise dos dados da Tabela 11 permite mostrar que para a combinação de $x_{1}= \pm 0,6 \operatorname{com} x_{2}= \pm 0,6$ é obtida a máxima incerteza da vazão $(1,47 \%)$ que atende aos limites (1,5\%) do sistema. Utilizando-se a Equação (4) para decodificar tais valores para a unidade da própria variável obtêm-se os seguintes valores:

$P=89,62 \times 0,60= \pm 53,77 \mathrm{kPa} ; \quad \Delta P=0,6221 \times 0,6= \pm 0,37 \mathrm{kPa} ; \quad T=$ $\pm 1^{\circ} \mathrm{C}$

As Figura 13 e Figura 14 ilustram, respectivamente, as superfícies de resposta e a curva de nível da incerteza estimada para a temperatura no nível \pm 1 . Ao analisar a Figura 13, nota-se que para todos os valores de $\mathrm{x}_{1}$ e $\mathrm{x}_{2}$ dentro da região verde escuro a incerteza estimada é menor que $1,5 \%$ de incerteza.

Além disso, pela curva de nível mostrada na Figura 14, verifica-se que a variável $\mathrm{x}_{1}$ apresenta o maior efeito na estimativa da incerteza de medição da vazão da EMED A dadas as condições de contorno. 
Superficie de Resposta; Variảvel: $Y$ [\%] = UP X uDP - EMED A

3 fatores, 1 Bloco, 19 Experimentos; Média Quadrática Residual $=, 0062959$

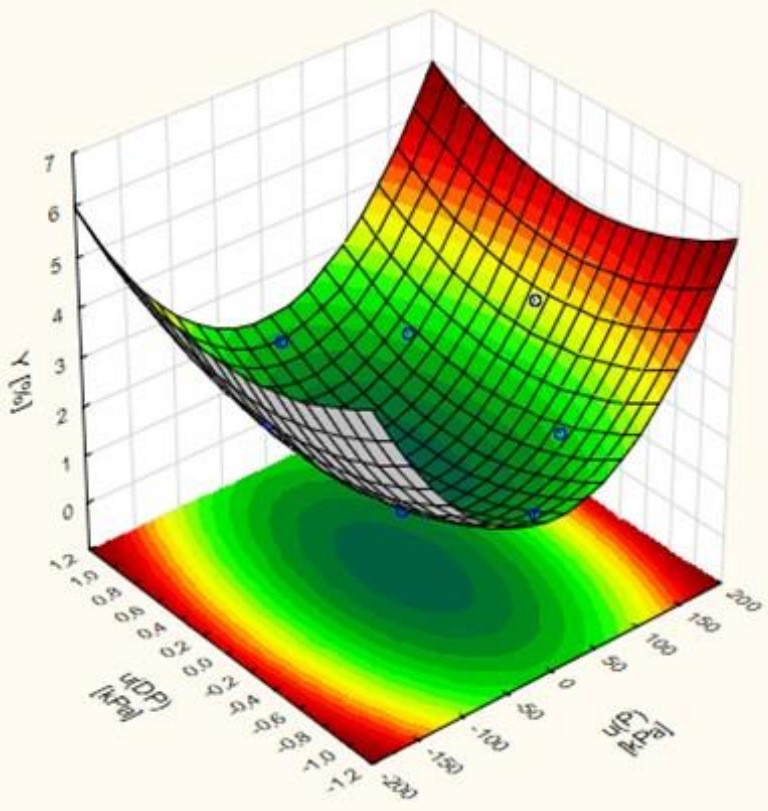

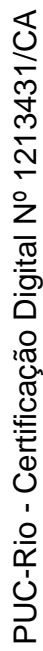

Figura 13 - Superfície de resposta (EMED A) dado uP e uDP (1 \% f.e.)

Curva de nivel; Variável: $Y[\%]=u P \times$ uDP - EMED A

3 fatores, 1 Bloco, 19 Experimentos; Média Quadrática Residual $=, 0062959$

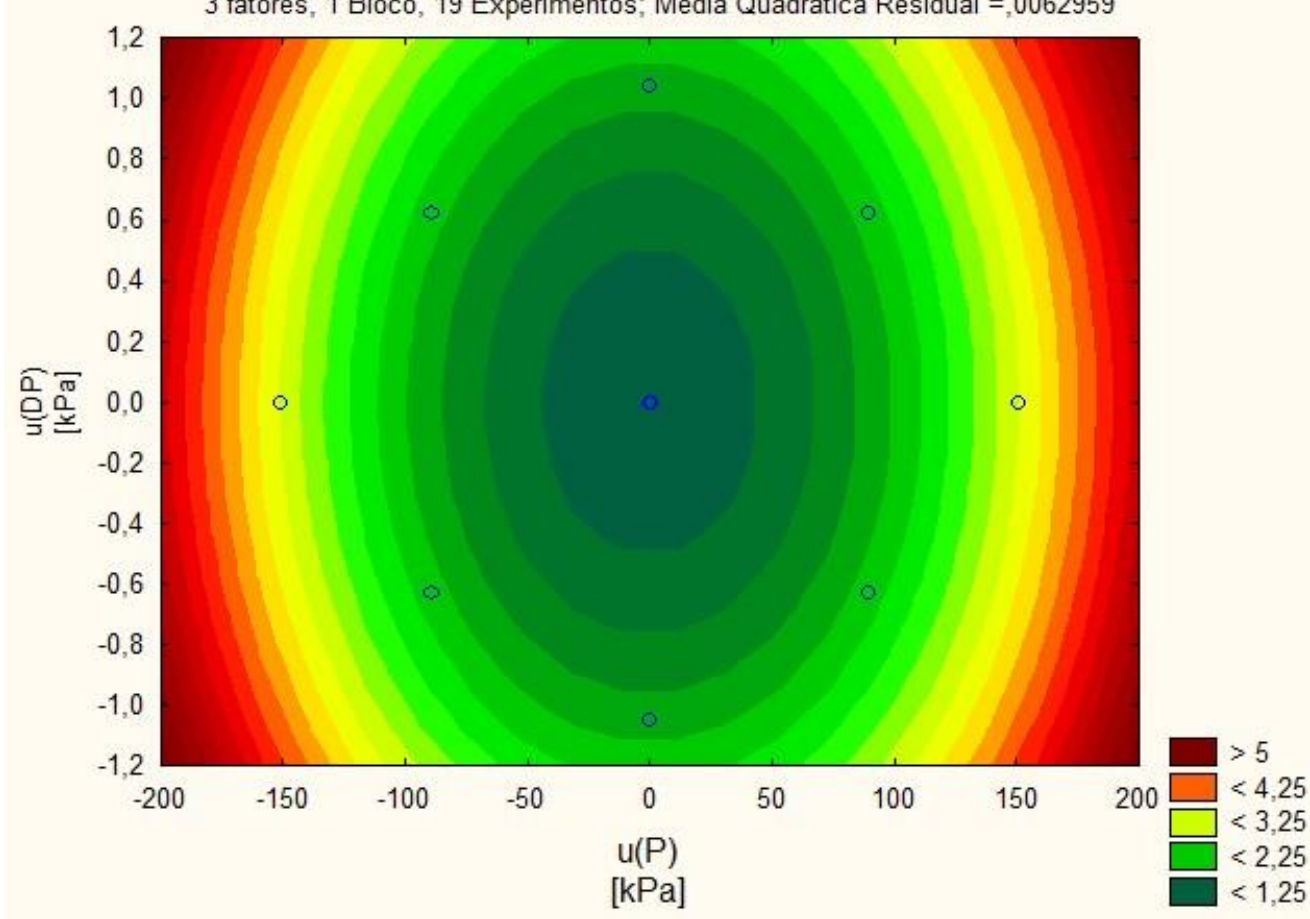

Figura 14 - Curva de nível (EMED A) dado uP e uDP (1\% f.e.) 
As Figura 15 e Figura 16 ilustram, respectivamente, as superfícies de resposta e a curva de nível da incerteza estimada para as combinações entre uP e uT. Ao analisar a Figura 15, observa-se que a pressão estática exerce maior influência na variável dependente que a temperatura.

Superficie de Resposta; Variável: Y [\%] = UP x UT - EMED A

3 fatores, 1 Bloco, 19 Experimentos; Média Quadrática Residual $=, 0062959$

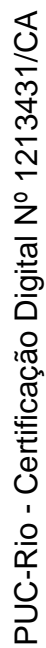

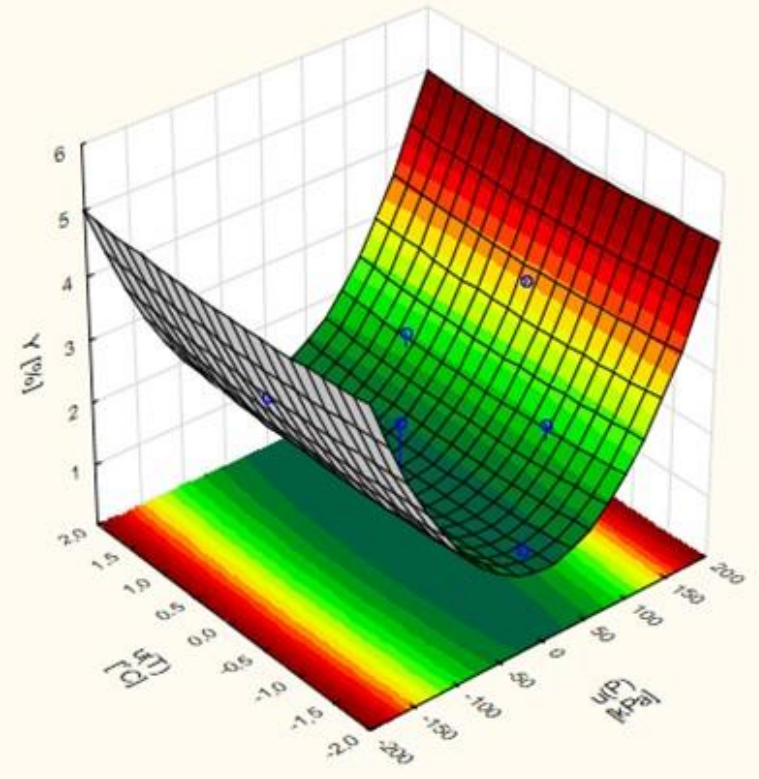

Figura 15 - Superfície de resposta (EMED A) dado uP $(1 \%$ f.e. $)$ e uT $\left( \pm 1{ }^{\circ} \mathrm{C}\right)$

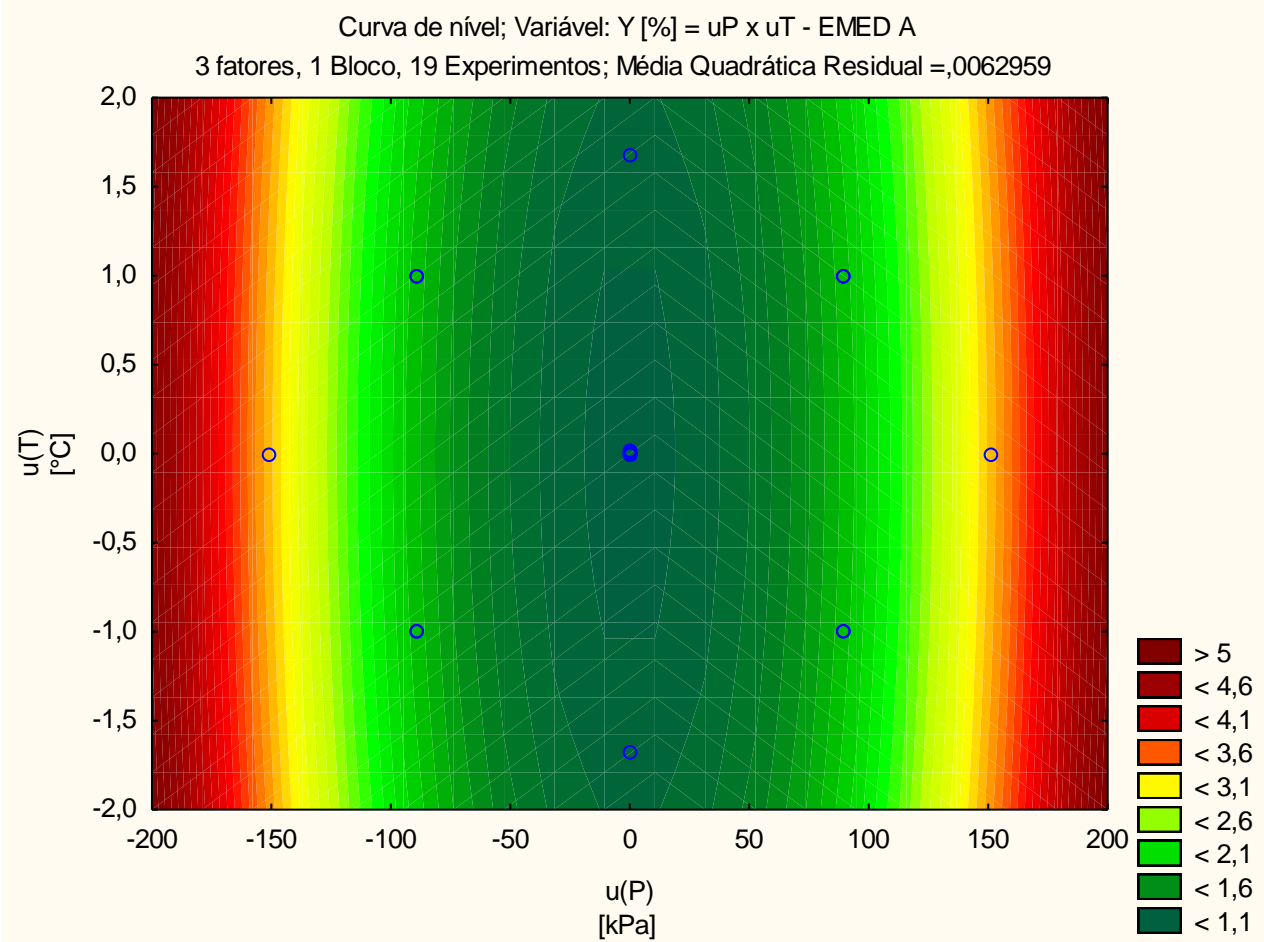

Figura 16 - Curva de nível (EMED A) dado uP ( $1 \%$ f.e. $)$ e uT $\left( \pm 1{ }^{\circ} \mathrm{C}\right)$ 
As Figura 17 e Figura 18 ilustram, respectivamente, as superfícies de resposta e a curva de nível da incerteza estimada para as combinações entre uDP e uT. Ao analisar a Figura 17, observa-se que a pressão diferencial exerce maior influência na variável dependente que a temperatura.

Superficie de Resposta; Variável: $Y$ [\%] = uP x uDP - EMED A 3 fatores, 1 Bloco, 19 Experimentos; Média Quadrática Residual $=, 0062959$

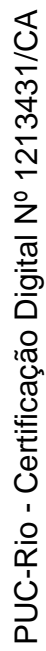

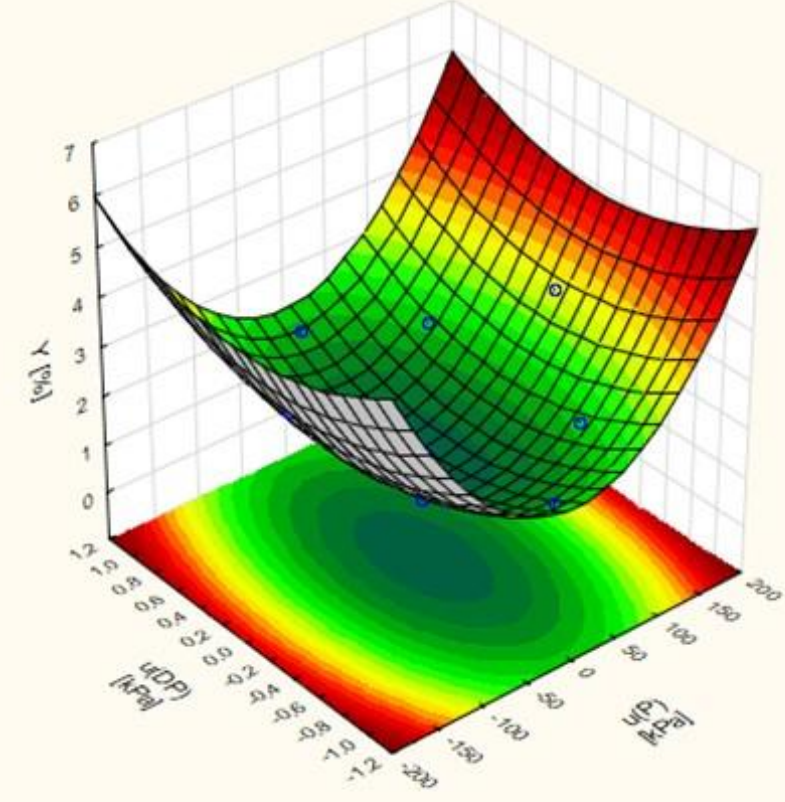

Figura 17 - Superfície de resposta (EMED A) dado uDP $\left(1 \%\right.$ f.e.) e uT $\left( \pm 1{ }^{\circ} \mathrm{C}\right)$

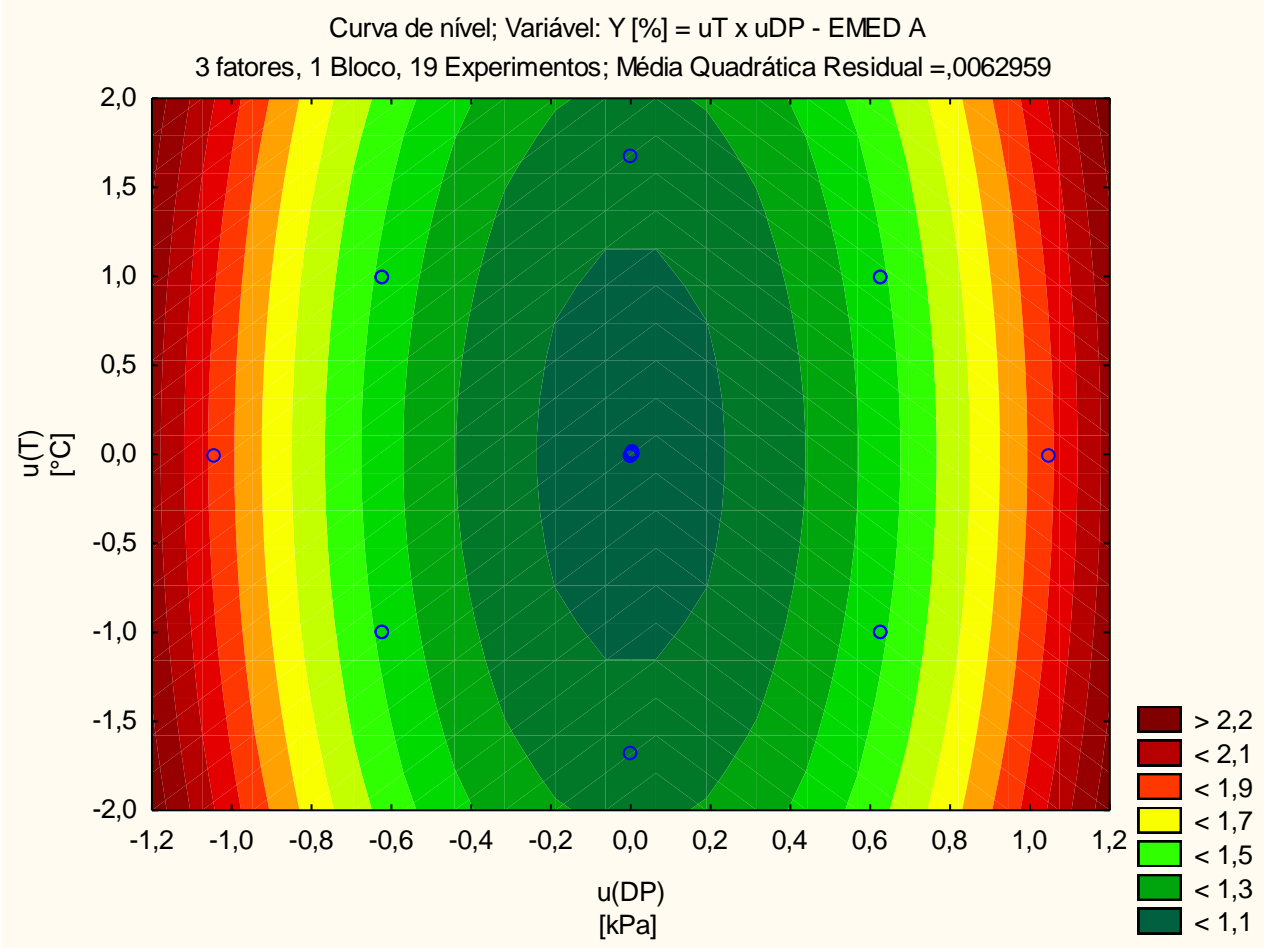

Figura 18 - Curva de nível (EMED A) dado uDP (1\% f.e.) e uT $\left( \pm 1^{\circ} \mathrm{C}\right)$ 
As matrizes de planejamento, os gráficos dos resíduos, as matrizes das incertezas estimadas, as superfícies de respostas e as curvas de nível de todas as EMED podem ser consultadas no Apêndice A.

\section{3 .2}

\section{Compilação dos valores limites de incerteza das EMEDs estudadas}

Na Tabela 12 são apresentados os valores limites das grandezas de influência que otimizam a incerteza de medição da vazão de gás das EMED estudadas. Observa-se que os menores valores encontrados para a incerteza da pressão estática $\left(\mathrm{x}_{1}\right)$ são $0,05 \%$ e $0,20 \%$ do fundo de escala. Estes valores ocorrem em três das 14 avaliações. Do mesmo modo, ao analisar os dados de incerteza para a pressão diferencial $\left(\mathrm{x}_{2}\right)$, observa-se que os menores valores encontrados são $0,15 \%$, e 0,20 $\%$ do fundo de escala e que estes valores ocorrem em três das 14 avaliações.

Tabela 12 - Valores limites das grandezas de influência das respectivas EMEDs

\begin{tabular}{|c|c|c|c|c|c|c|c|c|}
\hline EMED & $\begin{array}{c}\text { Nível } \\
{[\% \text { f.e. }]}\end{array}$ & $\begin{array}{c}\text { Nível } \\
\text { Temp }\end{array}$ & $\begin{array}{c}\text { Nível } \\
\text { Limite } \\
\mathrm{x}_{1}\end{array}$ & $\begin{array}{c}\text { Nível } \\
\text { Limite } \\
\mathrm{x}_{2}\end{array}$ & $\begin{array}{c}\text { Incerteza } \\
\mathrm{x}_{1}[\%]\end{array}$ & $\begin{array}{c}\text { Incerteza } \\
\mathrm{x}_{2}[\%]\end{array}$ & $\begin{array}{c}\text { Incerteza } \\
\mathrm{x}_{1}[\mathrm{kPa}]\end{array}$ & $\begin{array}{c}\text { Incerteza } \\
\mathrm{x}_{2}[\mathrm{kPa}]\end{array}$ \\
\hline $\mathrm{A}$ & 1 & $1{ }^{\circ} \mathrm{C}$ & 0,6 & 0,6 & 0,60 & 0,60 & 53,8 & 0,37 \\
\hline $\mathrm{B}$ & 0,75 & $1{ }^{\circ} \mathrm{C}$ & 0,6 & 0,8 & 0,45 & 0,60 & 3,09 & 0,30 \\
\hline $\mathrm{C}$ & 1 & $1{ }^{\circ} \mathrm{C}$ & 0,8 & 1 & 0,80 & 1,00 & 5,49 & 0,50 \\
\hline $\mathrm{D}$ & 0,75 & $1{ }^{\circ} \mathrm{C}$ & 0,6 & 1 & 0,45 & 0,75 & 52,96 & 0,37 \\
\hline $\mathrm{E} 1$ & 0,75 & $1{ }^{\circ} \mathrm{C}$ & 0,6 & 0,8 & 0,45 & 0,60 & 3,09 & 0,15 \\
\hline $\mathrm{E} 2$ & 0,75 & $1{ }^{\circ} \mathrm{C}$ & 0,6 & 0,2 & 0,45 & 0,15 & 3,09 & 0,04 \\
\hline $\mathrm{F} 1$ & 1 & $1{ }^{\circ} \mathrm{C}$ & 0,4 & 0,6 & 0,40 & 0,60 & 2,74 & 0,30 \\
\hline $\mathrm{F} 2$ & 0,75 & $1{ }^{\circ} \mathrm{C}$ & 0,2 & 0,2 & 0,60 & 0,15 & 1,03 & 0,07 \\
\hline $\mathrm{G} 1$ & 1 & $1{ }^{\circ} \mathrm{C}$ & 0,2 & 1 & 0,20 & 1,00 & 1,37 & 0,30 \\
\hline $\mathrm{G} 2$ & 0,75 & $1{ }^{\circ} \mathrm{C}$ & 0,6 & 0,2 & 0,45 & 0,15 & 3,09 & 0,04 \\
\hline $\mathrm{H}$ & 0,25 & $1{ }^{\circ} \mathrm{C}$ & 0,2 & 1 & 0,05 & 0,25 & 0,28 & 0,12 \\
\hline $\mathrm{I}$ & 0,5 & $1{ }^{\circ} \mathrm{C}$ & 0,4 & 0,8 & 0,20 & 0,40 & 1,12 & 0,10 \\
\hline $\mathrm{J} 1$ & 0,75 & $-1{ }^{\circ} \mathrm{C}$ & 0,6 & 0,4 & 0,45 & 0,30 & 2,51 & 0,07 \\
\hline $\mathrm{J} 2$ & 1 & $1{ }^{\circ} \mathrm{C}$ & 0,4 & 0,8 & 0,40 & 0,80 & 2,74 & 0,20 \\
\hline
\end{tabular}

Como é possível observar na Tabela 12 , os valores calculados para $\mathrm{x}_{1} \mathrm{e} / \mathrm{ou} \mathrm{x}_{2}$ das EMEDs E2, F2, G1, G2, H e I mostram-se restritivos quando comparados ao limite definido pela OIML R 140 (0,2 \% f.e.). A EMED H apresentou valores limite para $\mathrm{x}_{1}$ e $\mathrm{x}_{2}$ muito menores que $0,2 \%$ do f.e. ao utilizar a metodologia proposta neste estudo.

Pode-se observar, também, que os menores valores limites para $\mathrm{x}_{1}$ e $\mathrm{x}_{2}$ ocorreram nas simulações das EMEDs que apresentaram as menores vazões de gás, ou seja, EMED E2, F2, G1, G2, H e I.

$\mathrm{Na}$ Tabela 13 são apresentados os polinômios de $2^{\mathrm{a}}$ ordem que definem as superfícies de resposta aplicáveis às combinações dos níveis das grandezas de influência $(1 \%, 0,75 \%, 0,5 \%$ e $0,25 \%$ f.e.). 
Tabela 13 - Equações das superfícies de resposta das EMEDs (aplicáveis aos valores limites das grandezas de influência)

\begin{tabular}{c|cc}
\hline EMED & EQUAÇÃO & $\begin{array}{c}\text { VALOR DO NÍVEL } \\
\text { [\% f.e.] }\end{array}$ \\
\hline A & $Y=1,06+0,77 X_{1}^{2}+0,29 X_{2}^{2}+0,03 X_{3}^{2}$ & 1 \\
B & $Y=1,16+0,48 X_{1}^{2}+0,18 X_{2}^{2}+0,03 X_{3}^{2}$ & 0,75 \\
C & $Y=1,18+0,80 X_{1}^{2}+0,26 X_{2}^{2}+0,04 X_{3}^{2}$ & 1 \\
D & $Y=1,06+1,41 X_{1}^{2}+0,20 X_{2}^{2}+0,04 X_{3}^{2}$ & 0,75 \\
E1 & $Y=1,19+0,44 X_{1}^{2}+0,17 X_{2}^{2}+0,02 X_{3}^{2}$ & 0,75 \\
E2 & $Y=1,07+1,13 X_{1}^{2}+6,68 X_{2}^{2}+0,72 X_{3}^{2}$ & 0,75 \\
F1 & $Y=1,23+0,66 X_{1}^{2}+0,27 X_{2}^{2}+0,05 X_{3}^{2}$ & 1 \\
F2 & $Y=1,07+1,46 X_{1}^{2}+7,76 X_{2}^{2}+0,84 X_{3}^{2}$ & 1 \\
G1 & $Y=1,13+0,51 X_{1}^{2}+0,28 X_{2}^{2}+0,04 X_{3}^{2}$ & 1 \\
G2 & $Y=1,10+0,41 X_{1}^{2}+1,69 X_{2}^{2}+0,14 X_{3}^{2}$ & 0,75 \\
H & $Y=1,96+0,54 X_{1}^{2}+0,01 X_{2}^{2}-0,01 X_{3}^{2}$ & 0,25 \\
I & $Y=1,19+0,07 X_{1}^{2}+0,11 X_{2}^{2}+0,0044 X_{3}^{2}$ & 0,5 \\
J1 & $Y=1,20+1,00 X_{1}^{2}+0,28 X_{2}^{2}+0,06 X_{3}^{2}$ & 1 \\
J2 & $Y=0,89+1,09 X_{1}^{2}+1,02 X_{2}^{2}+0,15 X_{3}^{2}$ & 1 \\
\hline
\end{tabular}

A partir da análise das Figura 19 e Figura 20 percebe-se a ocorrência de uma variação da influência dos efeitos das grandezas uP e uDP ao ser modificada a vazão daquela EMED, neste caso, a EMED E. A Figura 19 apresenta a superfície de resposta para a vazão máxima da EMED E, onde se verifica certa simetria entre os efeitos gerados pelas variáveis uP e uDP. Já na Figura 20, apresenta-se a superfície de resposta para a vazão mínima da mesma EMED. Neste caso, nota-se que os efeitos das variáveis se alteraram, passaram de simétrica para assimétrica, tendo a variável uDP um maior efeito sobre a estimativa da incerteza da vazão frente à variável uP, como pode ser observado na Figura 20. 
Superficie de Resposta; Variável: $Y[\%]=$ UT $x$ uDP - EMED E1

3 fatores, 1 Bloco, 19 Experimentos; Média Quadrática Residual $=, 0019976$

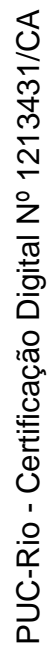

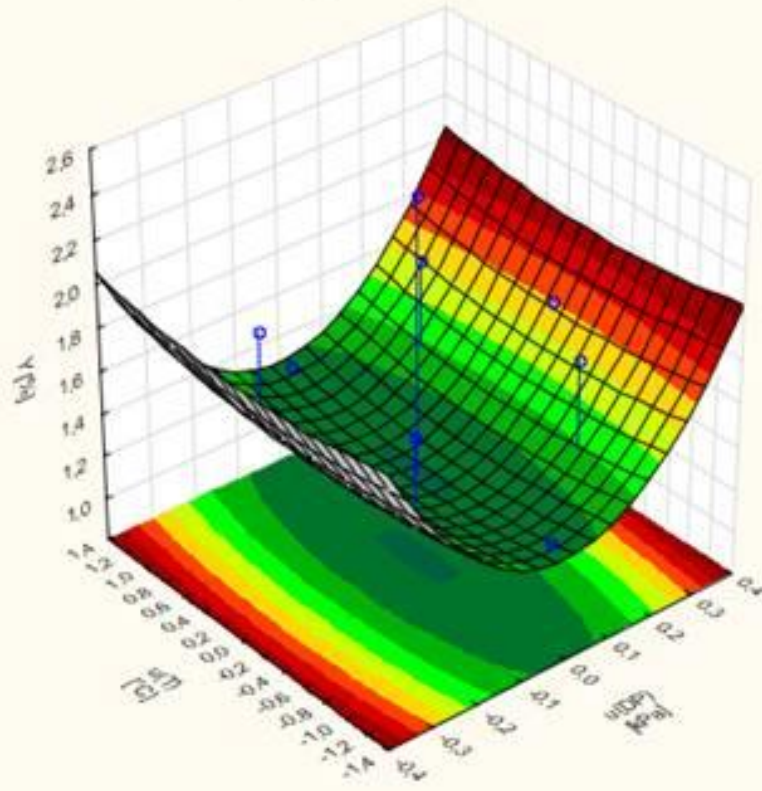

Figura 19 - Superfície de resposta (EMED E1) dado uP e uDP (0,75 \% f.e.)

Superficie de Resposta; Variável: Y [\%] = uP x uDP - EMED E2

3 fatores, 1 Bloco, 19 Experimentos; Média Quadrática Residual $=3,647921$
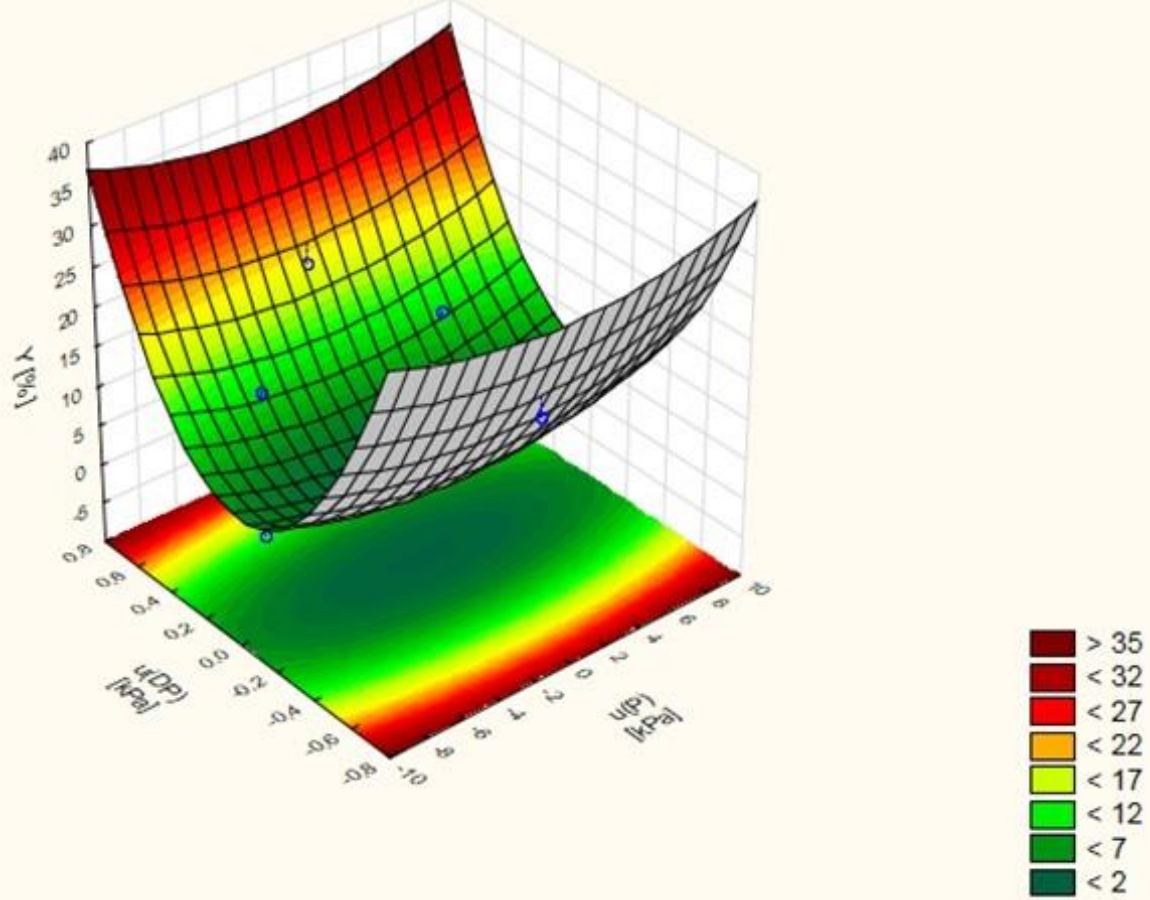

Figura 20 - Superfície de resposta (EMED E2) dado uP e uDP (0,75 \% f.e.)

Da mesma forma, ao analisar as Figura 21, Figura 22, Figura 23 e Figura 24, observa-se visualmente uma mudança do comportamento dos efeitos das grandezas de influência ( $\mathrm{x}_{1}$ e $\left.\mathrm{x}_{2}\right)$ na incerteza da medição da vazão da EMED $\mathrm{F}$ apenas pela mudança na vazão medida, ou seja, na Figura 21 e na Figura 22, observa-se uma 
certa simetria entre os efeitos. Já nas Figura 23 e Figura 24, os efeitos são assimétricos, com preponderância da variável x2.

Superfície de Resposta; Variável: $Y$ [\%] = uP x uDP - EMED F1

3 fatores, $1 \mathrm{Bloco}, 19$ Experimentos; Média Quadrática Residual $=, 0036339$

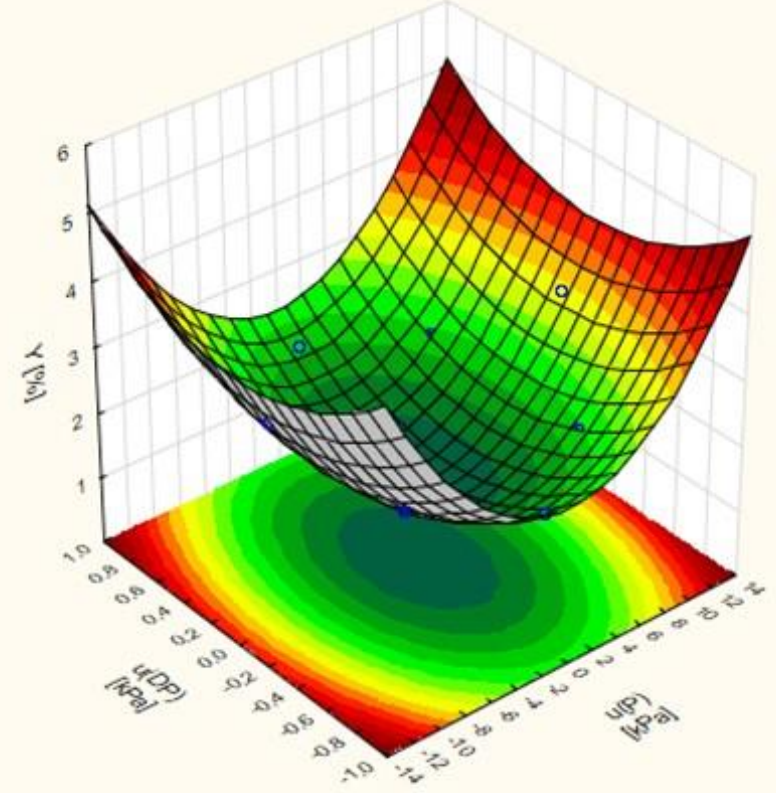

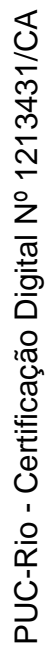

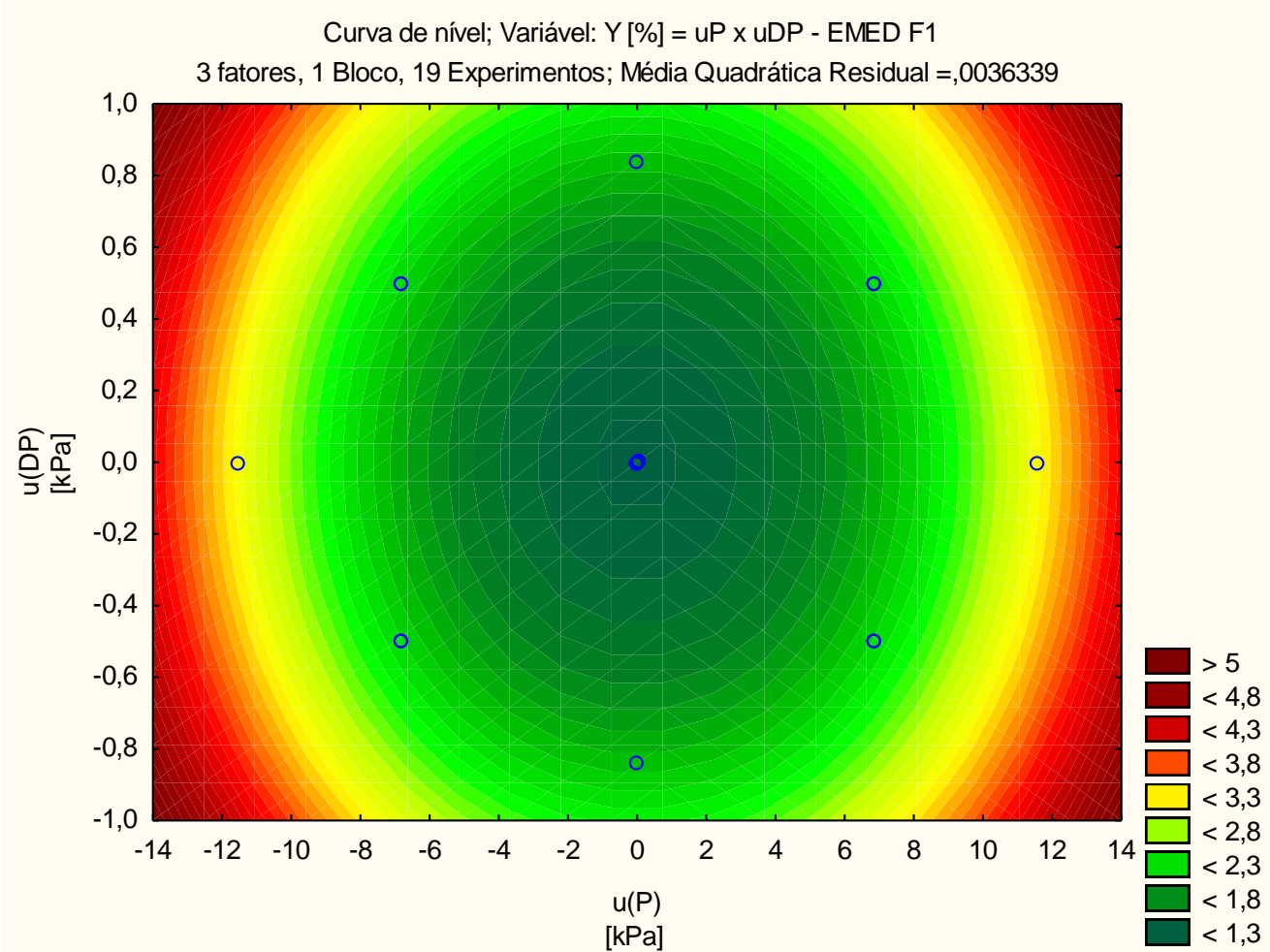

Figura 22 - Curva de nível (EMED F1) dado uP e uDP (1\% f.e.) 
Superficie de Resposta; Variável: Y [\%] = uP x uDP - EMED F2

3 fatores, 1 Bloco, 19 Experimentos; Média Quadrática Residual $=4,669477$

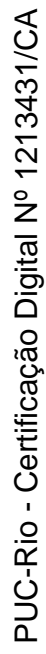

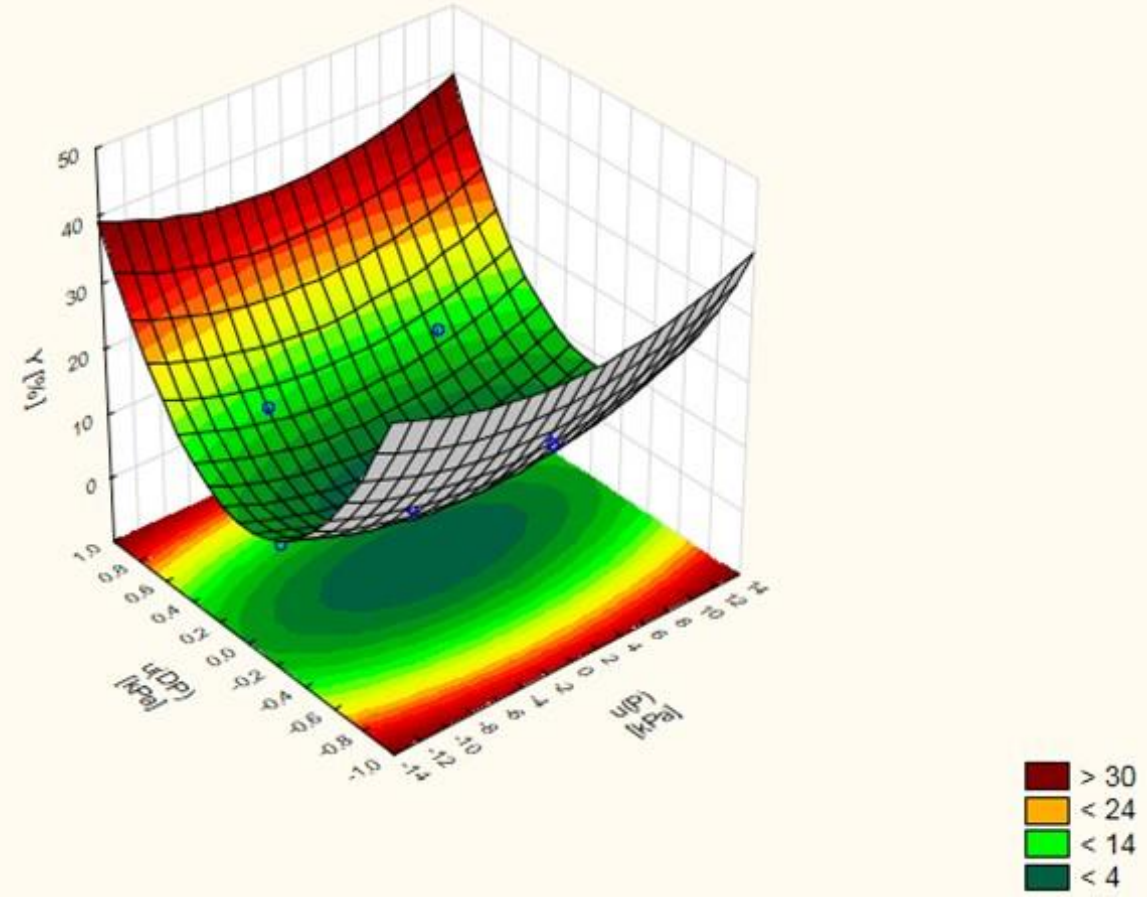

Figura 23 - Superfície de resposta (EMED F2) dado uP e uDP (1 \% f.e.)

Curva de nível; Variável: Y [\%] = uP x uDP - EMED F2

3 fatores, 1 Bloco, 19 Experimentos; Média Quadrática Residual =4,669477

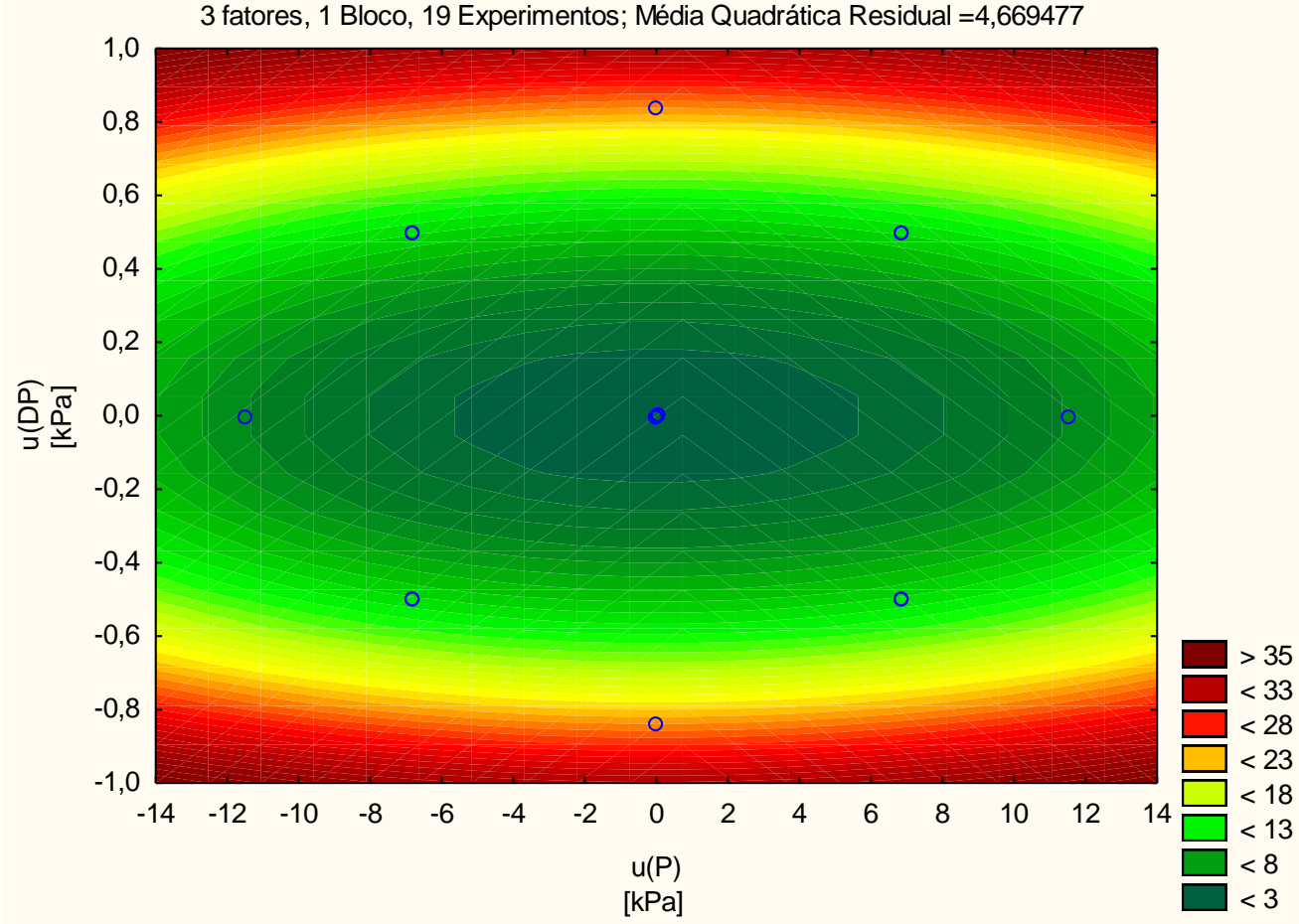

Figura 24 - Curva de nível (EMED F2) dado uP e u $\Delta \mathrm{P}$ (1 \% f.e.)

Do mesmo modo, se forem registradas graficamente as superfícies de resposta para a EMED G para a vazão máxima e mínima, perceber-se-ia o mesmo comportamento de mudança dos efeitos. 


\section{6 \\ Conclusões e recomendações}

Alinhado com os objetivos descritos na seção introdutória deste trabalho, este capítulo concentra-se nas suas conclusões e encaminha recomendações para desdobramentos futuros da pesquisa desenvolvida.

Ao definir critérios de aceitação de calibração e propor recomendações, o trabalho contribui para a melhoria da confiabilidade metrológica em processos críticos de medição de gás natural. Inquestionavelmente todos esses processos geram expressivos impactos econômicos dados os vultosos volumes de gás transportado diariamente na extensa rede que integra a malha de distribuição em todo o território nacional.

\section{1 \\ Conclusões}

No que concerne o objetivo central do trabalho - i.e.: definir critérios de aceitação para a calibração de grandezas de influência na calibração de medição de vazão por placa de orifício - o estudo mostrou que os objetivos da pesquisa foram plenamente alcançados. Em particular, permitiu: (i) mostrar que o uso da metodologia de superfície de resposta de fato contribui para conhecer os efeitos das interações na incerteza expandida associada à medição de vazão de gás por placa de orifício e (ii) identificar quais são os critérios que atendem ao RTM aplicável, ou seja, não ultrapassa o limite de 1,5\% para medições de natureza fiscal e $2 \%$ naquelas para fins de apropriação. Dentre todas as EMEDs estudadas, em três $(\mathrm{H}$, E2 e G2) foi possível constatar que o uso da metodologia proposta permite definir valores limites inferiores ao patamar de $0,20 \%$ da leitura de fundo de escala.

No que concernem os objetivos específicos, a aplicação da técnica do planejamento fatorial do experimento permitiu:

- Constatar que os limites de incerteza atualmente adotados para uso dos instrumentos de medição das grandezas de influência na medição de vazão de gás natural por placa de orifício (pressão estática, pressão diferencial e temperatura) são mais restritivos que aqueles obtidos pela adoção do método proposto neste estudo. Embora a OIML R 140 defina $0,2 \%$ do f.e. como valor limite, para as estações com vazão máxima, a aplicação da MSR resulta em valores limites de $0,4 \%$ a $0,8 \%$ na medição de pressão estática e de $0,45 \%$ a $1 \%$ na medição de pressão diferencial, percentuais esses referenciados ao fundo de escala. Ou seja, os critérios de aceitação devem ser definidos individualmente para cada EMED. Por outro lado, a escolha dos critérios de aceitação das estações com vazões mínimas de gás deve ser mais criteriosa, pois, para essa condição, a maioria dos resultados obtidos foram mais restritivos, ou seja, de $0,05 \%$ a $0,6 \%$ para medição de pressão estática e de $0,15 \%$ a $0,6 \%$ para medição de pressão diferencial, igualmente referenciados ao fundo de escala. Já para essa condição, o critério da OIML R 140 mostrase adequado. 
- Avaliar a influência dos critérios de aceitação na incerteza global do sistema de medição. Isto é, a MSR permite avaliar (visualmente) o efeito que cada grandeza de influência consegue induzir na incerteza expandida de medição. A partir dessa avaliação visual foi possível constatar que as EMEDs G1, I e J2 são as mais simétricas no que diz respeito aos efeitos que resultam das grandezas de influência pressão estática e diferencial. Os resultados obtidos permitiram, também, constatar (visualmente) a relevância que resulta dos efeitos da pressão diferencial nas EMEDs E2, F2 e G2.

- Propor uma capacidade de medição mínima capaz de atender aos valores limites para a calibração dos instrumentos de medição das grandezas de influência requeridas para a medição de vazão de gás natural por placa de orifício nas EMEDs estudadas. Constatação essa materializada em estrita conformidade aos critérios de aceitação da calibração dos instrumentos identificados. Desta forma, os valores aceitáveis são, respectivamente, 0,05 \% para os calibradores de pressão diferencial e $0,01 \%$ do f.e para a pressão estática. Entretanto, para evitar a necessidade de aquisição de um padrão com uma classe muito baixa para as calibrações da pressão estática, pode-se revisar o projeto da EMED $\mathrm{H}$ e utilizar um transmissor dual range, ou seja, um para a faixa de medição alta e outro para a faixa de medição baixa.

\section{2 \\ Recomendações para desdobramento futuros desta dissertação}

Com base na experiência aprendida que resultou do desenvolvimento desta pesquisa de mestrado, e com o propósito de avançar o conhecimento na área, recomenda-se:

- Elaborar uma solução automática que permita ao laboratório alimentar os dados oriundos da EMED, assim convergindo para a solução que define os valores otimizados como critério aceitável para cada instrumento acessório durante a calibração final do medidor de vazão;

- Realizar o mesmo estudo para as demais EMEDs da UO-ES de forma a gerar um subsídio para o laboratório da unidade operacional da Petrobras, o que racionaliza a medição, reduz custos e agiliza a operação;

- Avaliar as demais superfícies de respostas considerando a variação da temperatura versus pressão estática; e temperatura versus pressão diferencial;

Como demonstrado, a presente pesquisa de mestrado contribuiu para o controle metrológico das medições realizadas nas EMEDs, contribuindo, também, para a difusão da metodologia de planejamento fatorial e superfície de resposta, comprovada neste trabalho como ferramenta eficiente na otimização dos critérios de aceitação das incertezas de medição das grandezas de influência na medição de vazão em associados às EMEDs para atendimento aos requisitos do RTM. 


\section{7 \\ Referência Bibliográfca}

ABNT NBR ISO/IEC 13773. Termorresistência industrial de platina - Requisitos e ensaio. Associação Brasileira de Normas Técnicas. International Organization for Standardization. ABNT. 2008.

ABNT NBR ISO/IEC 17025. Requisitos gerais para a competência de laboratórios de ensaio e calibração. Associação Brasileira de Normas Técnicas. International Organization for Standardization. ABNT. 2005.

ABNT, NBR ISO 10012. Sistemas de gestão de medição: requisitos para os processis de medição e equipamento de medição. Associação Brasileira de Normas Técnicas - International Organization for Standardization. ABNT. 2004.

ABOUKALAM, M., \& AL-SHIHA, A. A robust analysis for unreplicated factorial experiments. Computational Statistics \& Data Analysis 36, pp. 31-46. 2001.

ALBERTAZZI, A., \& SOUZA, A. R. Fundamentos de metrologia científica e industrial. Barueri, SP: Manole. 2008.

ALBERTON, A. L. Estimação de parâmetros e planejamento de experimentos: estudo de incertezas e funções de informação. Tese de doutorado do programa de Engenharia Química da COPPE. Rio de Janeiro, RJ: UFRJ. 2010.

BALBINOT, A., \& BRUSAMARELLO, V. J.. Instrumentação e fundamentos de medidas (2 ${ }^{\mathrm{a}}$ ed., Vol. Vol. 2). Rio de Janeiro, RJ: LTC. 2011.

BARROS NETO, B. d., SCARMINIO, I. S., \& BRUNS, R. E.. Como fazer experimentos: pesquisa e desenvolvimento na ciência e na indústria. Campinas: UNICAMP. 2001.

BOX, G. E., HUNTER, W. G., \& HUNTER, J. S.. Statistics for experimenters: an introduction to design, data analysis and model building. New YorK: John Wiley \& Sons. 1978.

BRASIL, J. d.. Uso de planejamento estatístico de experimentos aplicados a sistemas de adsorção. Tese de doutorado do programa de Pós-Graduação em Química. Porto Alegre, RS: UFRGS. 2010.

BREITKREITZ, M. C., de SOUZA, A. M., \& POPPI, R. J.. Experimento de quimiometria para planejamento de experimentos: avaliação das condições experimentais na determinação espectrofotométrica de ferro II com o-Fenantrolina. Um tutorial, parte III. Química Nova, Vol. 37, $n^{o}$ 3, 564-573. 2014.

CARDOSO, L. C.. Petróleo: do poço ao posto. Rio de Janeiro: Qualitymark. 2005.

CARVALHO, L. S.. Gestão da função metrológica em uma unidade de exploração e produção de óleo e gás natural: desafios e oportunidades. Rio de Janeiro, RJ: PUCRJ. 2011.

CUNICO, M. W., CUNICO, M. M., MIGUEL, O. G., ZAWADZKI, S. F., PERALTA-ZAMORA, P., \& VOLPATO, N.. Planejamento fatorial: uma 
ferramenta estatística valiosa para a definição de parâmetros experimentais empregados na pesquisa científica. Visão Acadêmica. Jan a Jun de 2008.

DEAN, A. M., \& VOSS, D. T.. Design and analysis of experiments. New York: SPRINGER. 1999.

DELMÉE, G. J.. Manual de medição de vazão ( $3^{\mathrm{a}}$ edição ed.). São Paulo: Edgard Blucher. 2003.

DEVORE, J. L.. Probabilidade e estatística para engenharia e ciências (Tradução da $6^{\text {a }}$ edição ed.). São Paulo: Pioneira Thomson Learning. 2006.

INMETRO. www.inmetro.gov.br. Fonte: Instituto Nacional de Metrologia, Qualidade e Tecnologia: http://www.inmetro.gov.br/metlegal/definicao.asp. Acesso em 23 de março de 2013.

ISO 5168. Measurement of fluid flow - Procedures for the evaluation of uncertainties. International Organization for Standardization. Genebra: ISO. 2005.

LENTH, R. V.. Quick and easy analysis of unreplicated factorials. Technometrics, Vol. $31, N^{o} 4$.

LENTH, R. V. (2006). Lenth's Method for the Analysis of Unreplicated Experiments. 1989.

LI, X., SUDARSANAM, N., \& FREY, D. D.. Regularities in data from factorial experiments. Wiley Peiodicals, INC., Vol 11, $N^{o}$ 5, 32-45. 2006.

LIPTÁK, B. G.. Instrument engineers' - Handbook. Process measurement and analysis. Vol. I. 4th Edition. . Florida: CRC Press. 2003.

LORENTZ, L. H.. Relação entre estatísticas do planejamento experimental e tamanho da parcela para pimentão em estufa plástica. Tese de doutorado do programa de Pós-graduação em Agronomia. Rio Grande do Sul: UFSM. 2008.

LUNDSTEDT, T., SEIFERT, E., ABRAMO, L., THELIN, B., NUSTRÖM, A., PETTERSEN, J., \& BERGMAN, R.. Experimental design and optimization. Chemometrics and Intelligent Laboratory Systems 42. May,1998.

MARCHETI Jr., C.. Utilização de medidores ultrassônico para medição fiscal de vazão de gás natural. Dissertação de mestrado do programa de Pós-Graduação MQI. Rio de Janeiro, RJ: PUCRJ. 2010.

MARINHO, M. R., \& CASTRO, W. B.. PLANEJAMENTO FATORIAL: UMA FERRAMENTA PODEROSA PARA OS PESQUISADORES. XXXIII Congresso Brasileiro de Ensino de Engenharia. Campinas Grande, PB: COBENGE. 2005.

MARTINS, N.. Manual de medição de vazão: através de placas de orifício, bocais e venturis. Rio de Janeiro: Interciência. 1998.

MONTGOMERY, D. C.. Design and analysis of experiments. Arizona: JOHN WILEY \& SONS, INC. $5^{\text {a }}$ Ed. 2001.

MONTGOMERY, D. C., \& RUNGER, G. R.. Estatística aplicada e probabilidade para engenheiros ( $5^{\mathrm{a}}$ ed.). Rio de Janeiro, RJ: LTC. 2013. 
MORRIS, A. S.. Measurement and Instrumentation Principles. Woburn, MA: Butterworth-Heinemann. $1^{\text {a }}$ Ed. 2001.

MYERS, R. H., KHURI, A. I., \& CARTER JR., W. H.. Response surface methodology: 1966-1988. Technometrics, ol. 31, no 2, p. 137-157. Apud E. V. GALDAMEZ, Aplicação das técnicas de planejamento e análise de experimentos na melhoria da qualidade de um processo de fabricação de produtos plásticos. São Carlos: Dissertação do programa de mestrado de Engenharia de Produção. USP. 2002.

NGUTY, T. A., SALAM, B., DURAIRAJ, R., \& EKERE, N. N.. Understanding the Process Window for Printing Lead-Free Solder Pastes. IEEE transactions on electronics packaging manufacturing, vol. 24, no. 4. outubro, 2001.

NÓBREGA, M. P.. Estudo comparativo Estudo comparativo de gráficos de probabilidade normal para analise de experimentos fatoriais não replicados. Dissertação do programa de Pós-graduação em Matemática Aplicada e Estatística. Natal, RN: UFRN. 2010.

NÓBREGA, M. P., \& VIVACQUA, C. A.. Estudo comparativo de gráficos de probabilidade normal para analise de experimentos fatoriais não replicados. $19^{\circ}$ SINAPE - Simpósio Nacional de Probabilidade e Estatística. São Pedro, SP: ABE. 2010.

OIML R 140.. Measuring systems for gaseous fuel. International organization of legal metrology. Paris: OIML. BIML. 2007.

OLIVEIRA, E. C.. Otimização do critério de aceitação na calibração de instrumentos para medição de transferência de custódia de gás natural. São Paulo, SP: REMESP. ENQUALAB. 2006.

SANTANA, M. A., GUIMARÃES, P. L., THOMAZ Jr, J. C., \& E ARLINO, P. R. Rastreabilidade metrológica e os critérios de aceitação para a instrumentação meteorológica/ambiental. São Paulo, SP: EQUALAB, REMESP. 2008.

SILVA, L. G.. A busca da garantia metrológica em prol do desenvilvimento dos instrumentos de medição. V Congresso Brasileiro de Metrologia, p. 4.9 a 13 de novembro de 2009

SILVA, M. E. da.. Garantia metrológica na medição de volume:uma praposta de metodologia de atuação. Dissertação do programa de mestrado profissional em sistemas de gestão. Niterói, RJ: UFF. 2004.

SILVEIRA, Z. d.. Análise Estatística e Otimização de Parâmetros de Projeto em Componentes de Sistemas Mecânicos. Tese do programa de doutorado da Faculdade de Engenharia Mecânica. Campinas, SP: UNICAMP. 2003.

SMAR.. Manual de instrução, manutenção e operação - Transmissor de pressão Fieldbus. Sertãozinho: SMAR. 2014.

TEÓFILO, R. F., \& FERREIRA, M. M.. Quimiometria II: planilhas eletrônicas para cálculos de planejamentos experimentais, um tutorial. Quimica Nova, Vol. 29, N ${ }^{\circ}$ 2, 338-350. 2006.

WALPOLE, R. E., MYERS, R. H., MYERS, S. L., \& YE, K.. Probability \& Statistics for Engineers \& Scientists (9 $9^{\mathrm{a}}$ ed.). Pearson. 2011. 


\section{APÊNDICE A}

\section{A.1}

\section{Estação B - estação de medição fiscal}

Tabela A.1 - Matriz de planejamento experimental da EMED B

\begin{tabular}{|c|c|c|c|c|c|c|c|}
\hline \multirow[b]{2}{*}{ Exp } & \multicolumn{6}{|c|}{ Matriz do modelo } & \multirow{2}{*}{$\begin{array}{c}\text { Incerteza de } \\
\text { medição da } \\
\text { vazão } \\
\mathrm{y}(\%) \\
\end{array}$} \\
\hline & $\mathrm{x} 1$ & $\mathrm{x} 2$ & $\mathrm{x} 3$ & $\begin{array}{c}\mathrm{u}(\mathrm{P}) \\
{[\mathrm{kPa}]}\end{array}$ & $\begin{array}{l}\mathrm{u}(\Delta \mathrm{P}) \\
{[\mathrm{kPa}]}\end{array}$ & $\begin{array}{l}\mathrm{u}(\mathrm{T}) \\
{\left[{ }^{\circ} \mathrm{C}\right]}\end{array}$ & \\
\hline 1 & -1 & -1 & -1 & $-6,86$ & $-0,4982$ & -1 & 2,24 \\
\hline 2 & 1 & -1 & -1 & 6,86 & $-0,4982$ & -1 & 2,24 \\
\hline 3 & -1 & 1 & -1 & $-6,86$ & 0,4982 & -1 & 2,24 \\
\hline 4 & 1 & 1 & -1 & 6,86 & 0,4982 & -1 & 2,24 \\
\hline 5 & -1 & -1 & 1 & $-6,86$ & $-0,4982$ & 1 & 2,24 \\
\hline 6 & 1 & -1 & 1 & 6,86 & $-0,4982$ & 1 & 2,24 \\
\hline 7 & -1 & 1 & 1 & $-6,86$ & 0,4982 & 1 & 2,24 \\
\hline 8 & 1 & 1 & 1 & 6,86 & 0,4982 & 1 & 2,24 \\
\hline 9 & $-1,682$ & 0 & 0 & $-11,54$ & 0 & 0 & 3,58 \\
\hline 10 & 1,682 & 0 & 0 & 11,54 & 0 & 0 & 3,58 \\
\hline 11 & 0 & $-1,682$ & 0 & 0 & $-0,8380$ & 0 & 2,02 \\
\hline 12 & 0 & 1,682 & 0 & 0 & 0,8380 & 0 & 2,02 \\
\hline 13 & 0 & 0 & $-1,682$ & 0 & 0 & $-1,682$ & 1,37 \\
\hline 14 & 0 & 0 & 1,682 & 0 & 0 & 1,682 & 1,37 \\
\hline 15 & 0 & 0 & 0 & 0 & 0 & 0 & 1,16 \\
\hline 16 & 0 & 0 & 0 & 0,016 & 0,0029 & 0,015 & 1,16 \\
\hline 17 & 0 & 0 & 0 & 0,015 & 0,0008 & 0,003 & 1,16 \\
\hline 18 & 0 & 0 & 0 & 0,019 & 0,0016 & 0,002 & 1,16 \\
\hline 19 & 0 & 0 & 0 & 0,014 & 0,0029 & 0,003 & 1,16 \\
\hline
\end{tabular}

Tabela A.2 - Tabela de ANOVA do planejamento de experimentos da EMED B

\begin{tabular}{|c|c|c|c|c|c|}
\hline \multirow[b]{2}{*}{ Fonte de variação } & \multicolumn{5}{|c|}{$\begin{array}{c}\text { ANOVA; Var.:Y [\%]; } \mathrm{R}^{2}=, 99217 ; \mathrm{R}_{\mathrm{a}}^{2}:, 98434 \\
3 \text { fatores, 1 Bloco, 19 Experimentos; Média Quadrática Residual =,00849 }\end{array}$} \\
\hline & $\begin{array}{c}\text { Soma de } \\
\text { Quadrados }\end{array}$ & $\begin{array}{l}\text { Graus de } \\
\text { liberdade }\end{array}$ & $\begin{array}{l}\text { Quadrados } \\
\text { médios }\end{array}$ & Teste F & $\mathrm{p}$ \\
\hline$(1) \mathrm{u}(\mathrm{P})[\mathrm{kPa}](\mathrm{L})$ & 0,000000 & 1 & 0,000000 & 0,000 & 0,999872 \\
\hline $\mathrm{u}(\mathrm{P})[\mathrm{kPa}](\mathrm{Q})$ & 9,237599 & 1 & 9,237599 & 1088,052 & 0,000000 \\
\hline$(2) \mathrm{u}(\mathrm{DP})[\mathrm{kPa}](\mathrm{I}$ & 0,000000 & 1 & 0,000000 & 0,000 & 0,999779 \\
\hline $\mathrm{u}(\mathrm{DP})[\mathrm{kPa}](\mathrm{Q})$ & 0,987879 & 1 & 0,987879 & 116,357 & 0,000002 \\
\hline$(3) \mathrm{u}(\mathrm{T})\left[{ }^{\circ} \mathrm{C}\right](\mathrm{L})$ & 0,000000 & 1 & 0,000000 & 0,000 & 0,999698 \\
\hline $\mathrm{u}(\mathrm{T})\left[{ }^{\circ} \mathrm{C}\right](\mathrm{Q})$ & 0,023641 & 1 & 0,023641 & 2,785 & 0,129520 \\
\hline $1 \mathrm{~L} \times 2 \mathrm{~L}$ & 0,000000 & 1 & 0,000000 & 0,000 & 0,999999 \\
\hline $1 \mathrm{~L} \times 3 \mathrm{~L}$ & 0,000000 & 1 & 0,000000 & 0,000 & 0,999999 \\
\hline $2 \mathrm{~L} \times 3 \mathrm{~L}$ & 0,000000 & 1 & 0,000000 & 0,000 & 0,999998 \\
\hline Erro & 0,076410 & 9 & 0,008490 & & \\
\hline Total SQ & 9,757093 & 18 & & & \\
\hline
\end{tabular}


Gráfico de Pareto dos Efeitos; Variável: Y[\%] - EMED B

3 fatores, 1 Bloco, 19 Experimentos; Média Quadrática Residual $=, 00849$

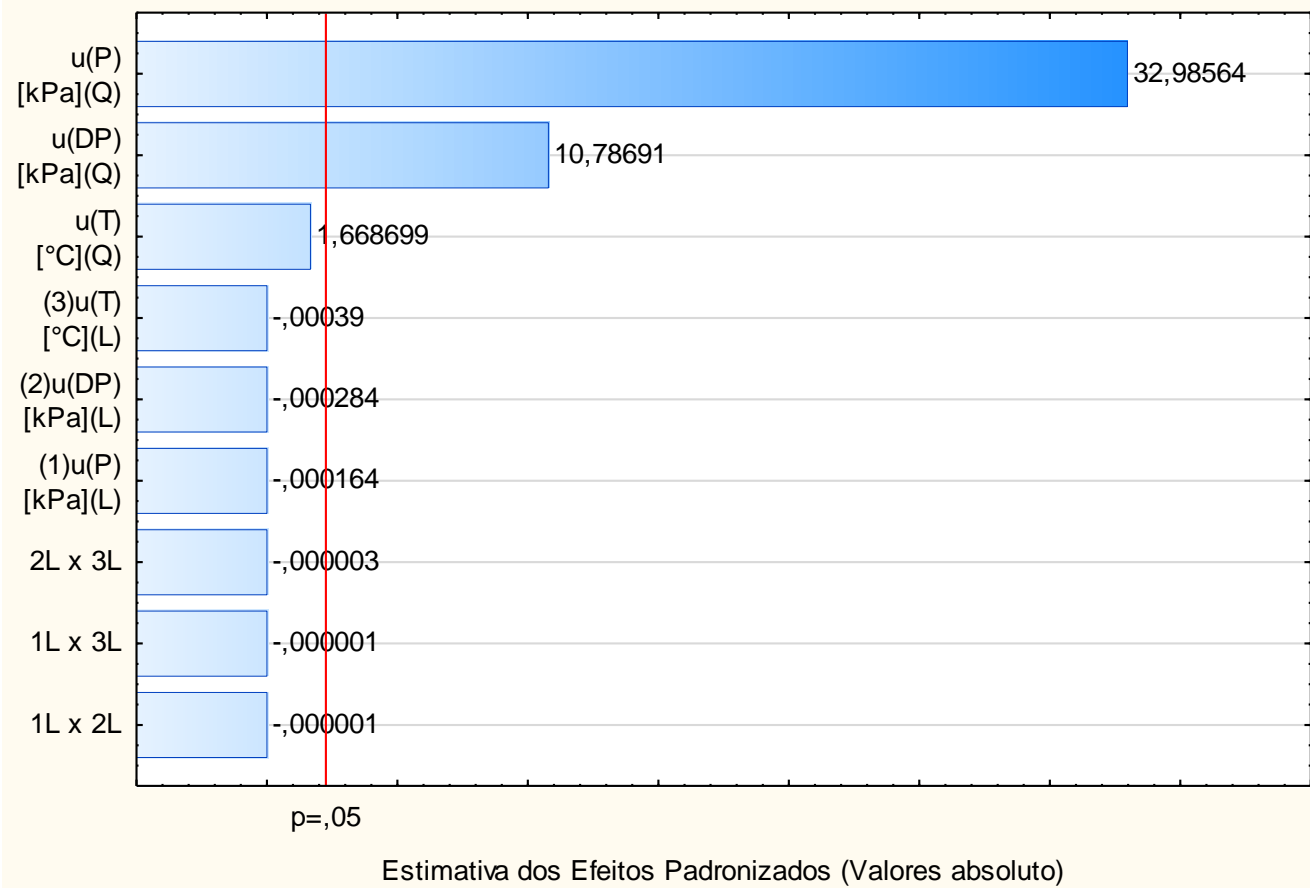

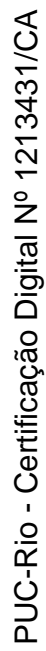

Figura A.1 - Gráfico de Pareto em função dos valores da estatística de teste $\mathrm{t}$

Valores Previstos vs. Valores Residuais- EMED B

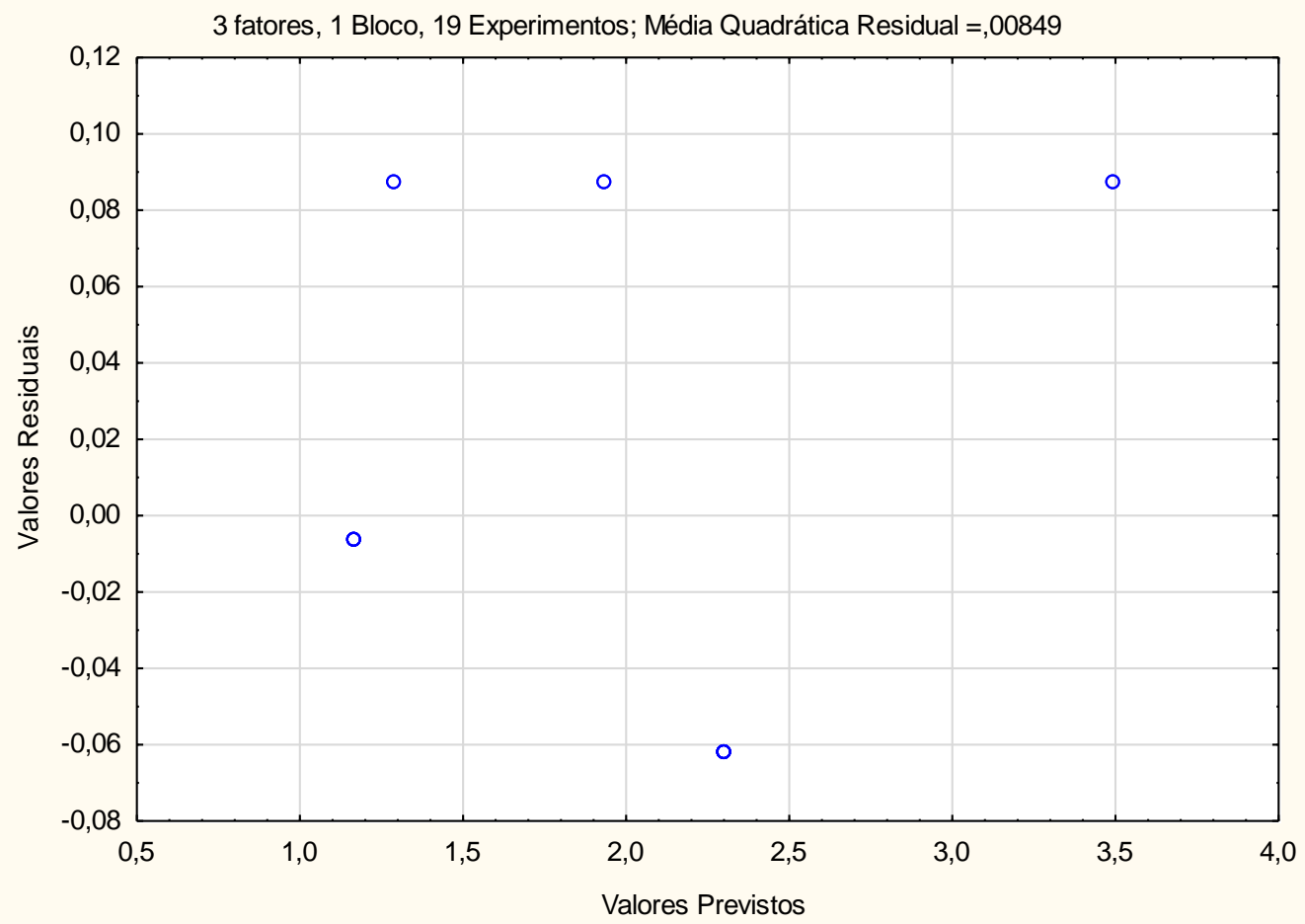

Figura A.2 - Resíduos versus estimativas de y (EMED B - nível: $1 \%$ f.e. e $1^{\circ} \mathrm{C}$ ) 
Tabela A.3 - Matriz das incertezas estimadas da vazão (EMED B)

(dado $\mathrm{x}_{3}(\mathrm{~T})$ igual a 1 e $\mathrm{x}_{1}$ e $\mathrm{x}_{2}$ variando do nível baixo ao nível alto)

\begin{tabular}{|c|c|c|c|c|c|c|c|c|c|c|c|}
\multicolumn{1}{c|}{} & -1 & $-0,8$ & $-0,6$ & $-0,4$ & $-0,2$ & 0 & 0,2 & 0,4 & 0,6 & 0,8 & 1 \\
\hline-1 & 2,30 & 2,00 & 1,77 & 1,61 & 1,51 & $\mathbf{1 , 4 8}$ & 1,51 & 1,61 & 1,77 & 2,00 & 2,30 \\
\hline$-0,8$ & 2,20 & 1,91 & 1,68 & 1,51 & 1,41 & 1,38 & 1,41 & 1,51 & 1,68 & 1,91 & 2,20 \\
\hline$-0,6$ & 2,13 & 1,83 & 1,60 & $\mathbf{1 , 4 4}$ & 1,34 & 1,31 & 1,34 & $\mathbf{1 , 4 4}$ & 1,60 & 1,83 & 2,13 \\
\hline$-0,4$ & 2,07 & 1,78 & 1,55 & 1,38 & 1,28 & 1,25 & 1,28 & 1,38 & 1,55 & 1,78 & 2,07 \\
\hline$-0,2$ & 2,04 & 1,75 & 1,52 & 1,35 & 1,25 & 1,22 & 1,25 & 1,35 & 1,52 & 1,75 & 2,04 \\
\hline 0 & 2,03 & 1,74 & 1,50 & 1,34 & 1,24 & 1,21 & 1,24 & 1,34 & 1,50 & 1,74 & 2,03 \\
\hline 0,2 & 2,04 & 1,75 & 1,52 & 1,35 & 1,25 & 1,22 & 1,25 & 1,35 & 1,52 & 1,75 & 2,04 \\
\hline 0,4 & 2,07 & 1,78 & 1,55 & 1,38 & 1,28 & 1,25 & 1,28 & 1,38 & 1,55 & 1,78 & 2,07 \\
\hline 0,6 & 2,13 & 1,83 & 1,60 & $\mathbf{1 , 4 4}$ & 1,34 & 1,31 & 1,34 & $\mathbf{1 , 4 4}$ & 1,60 & 1,83 & 2,13 \\
\hline 0,8 & 2,20 & 1,91 & 1,68 & 1,51 & 1,41 & 1,38 & 1,41 & 1,51 & 1,68 & 1,91 & 2,20 \\
\hline 1 & 2,30 & 2,00 & 1,77 & 1,61 & 1,51 & $\mathbf{1 , 4 8}$ & 1,51 & 1,61 & 1,77 & 2,00 & 2,30 \\
\hline
\end{tabular}

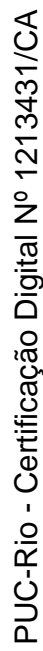

Superficie de Resposta; Variável: Y [\%] = uP x uDP - EMED B

3 fatores, 1 Bloco, 19 Experimentos; Média Quadrática Residual $=, 00849$

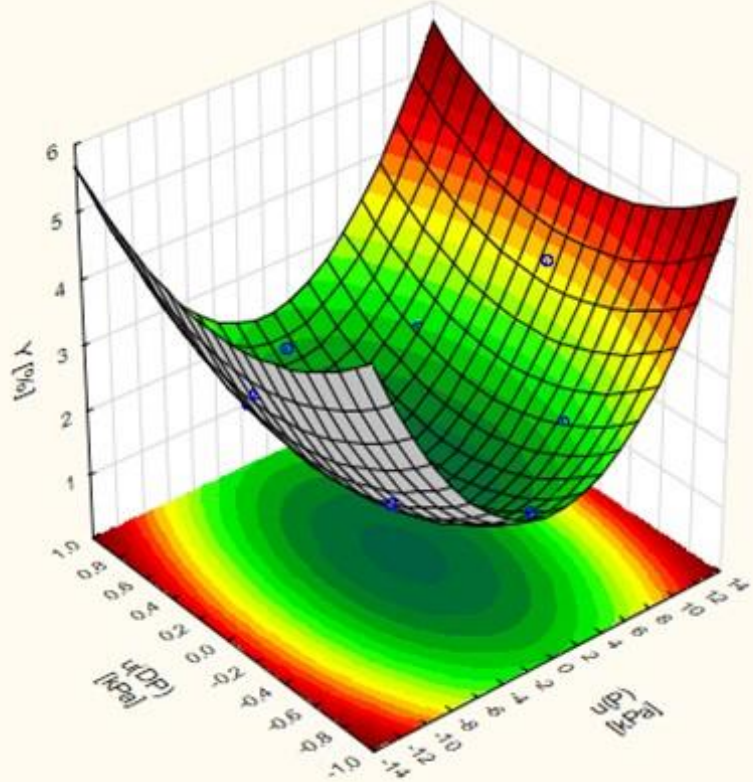

Figura A.3 - Superfície de resposta (EMED B) dado uP e uDP (1 \% f.e.) 
Curva de nível; Variável: $Y[\%]$ = uP x uDP - EMED B

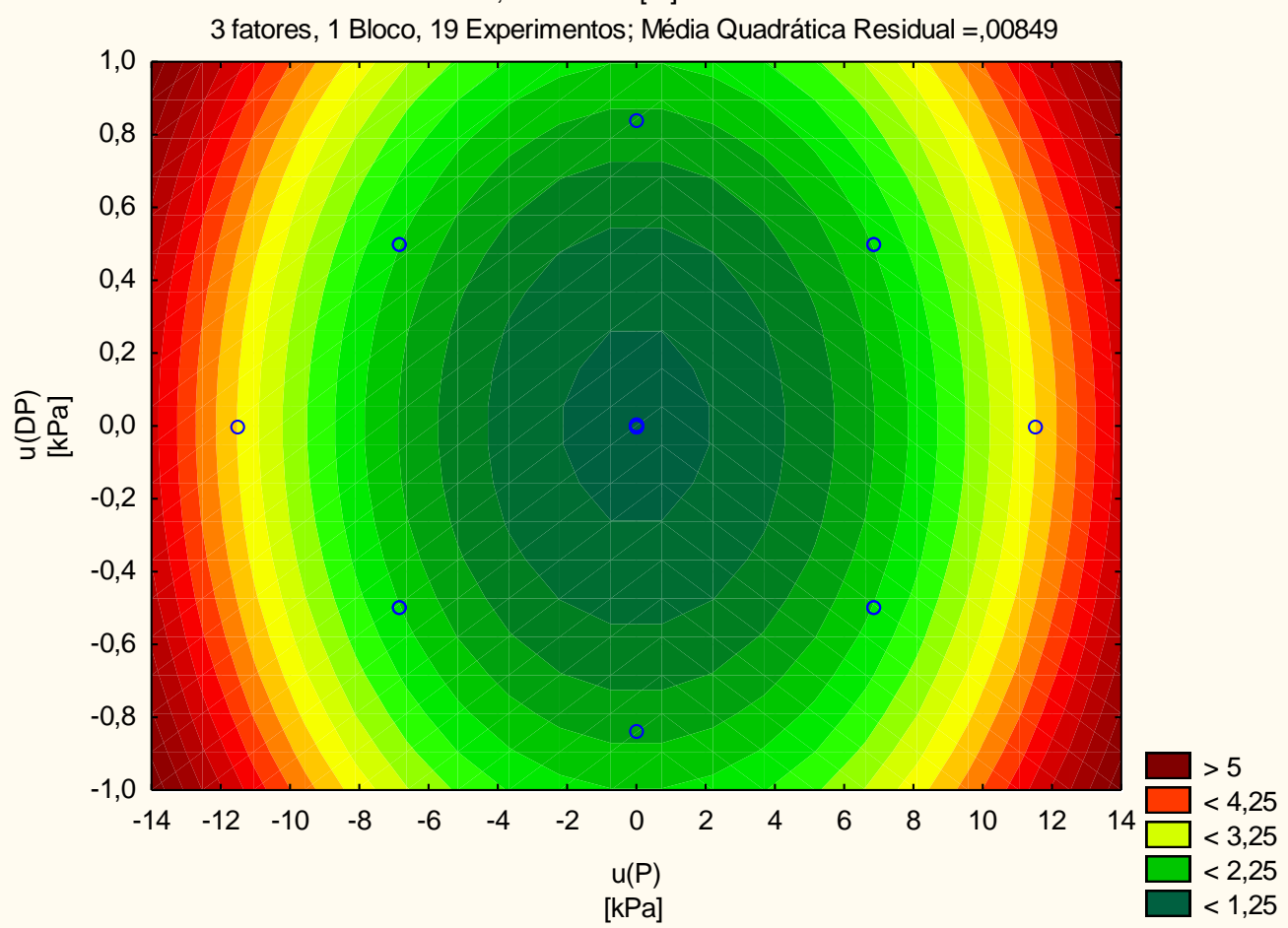

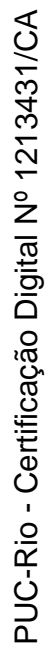

Figura A.4 - Curva de nível (EMED B) dado uP e uDP (1 \% f.e.)

Superficie de Resposta; Variável: $Y$ [\%] = UP X UT - EMED B

3 fatores, $1 \mathrm{Bloco}, 19$ Experimentos; Média Quadrática Residual $=, 00849$

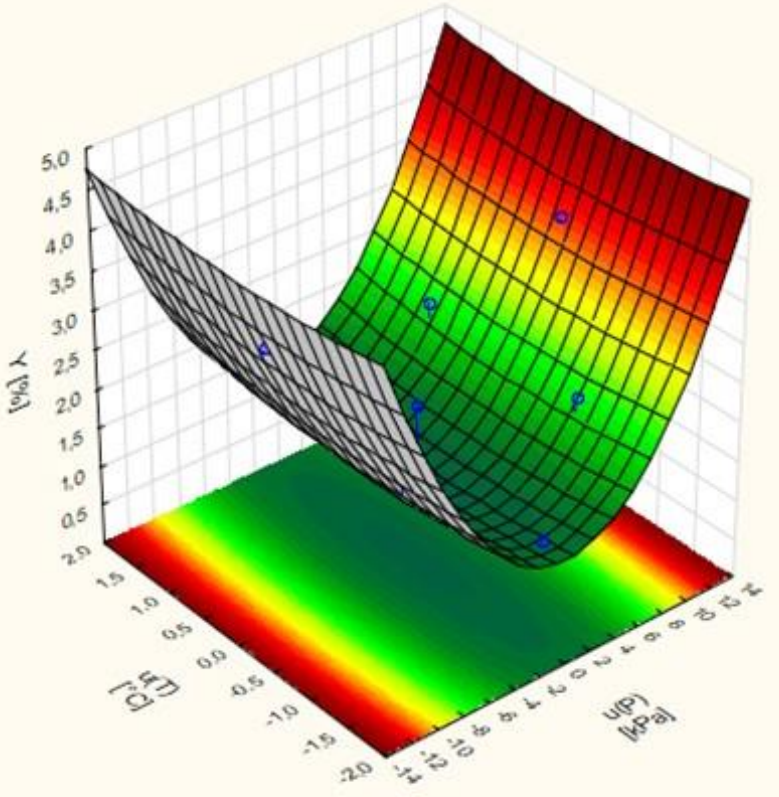

Figura A.5 - Superfície de resposta (EMED B) dado uT $\left( \pm 1{ }^{\circ} \mathrm{C}\right)$ e uP $(1 \%$ f.e. $)$ 
Curva de nível; Variável: Y [\%] = uP x uT - EMED B

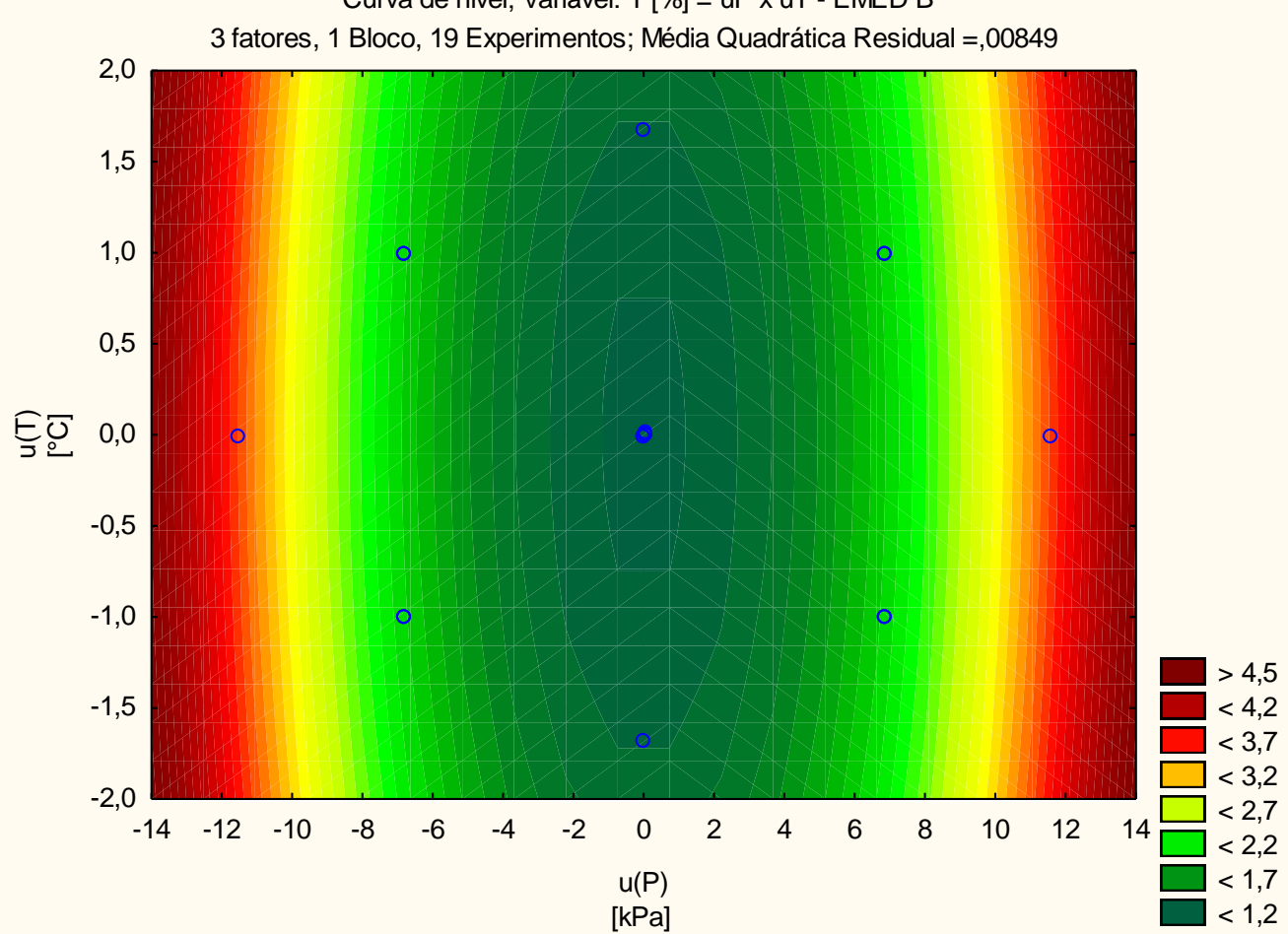

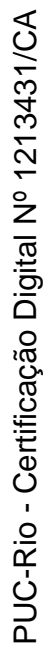

Figura A.6 - Curva de nível (EMED B) dado uP $(1 \%$ f.e. $)$ e uT $\left( \pm 1{ }^{\circ} \mathrm{C}\right)$

Superficie de Resposta; Variável: $Y[\%]=U T \times$ uDP - EMED B

3 fatores, 1 Bloco, 19 Experimentos; Média Quadrática Residual $=, 00849$

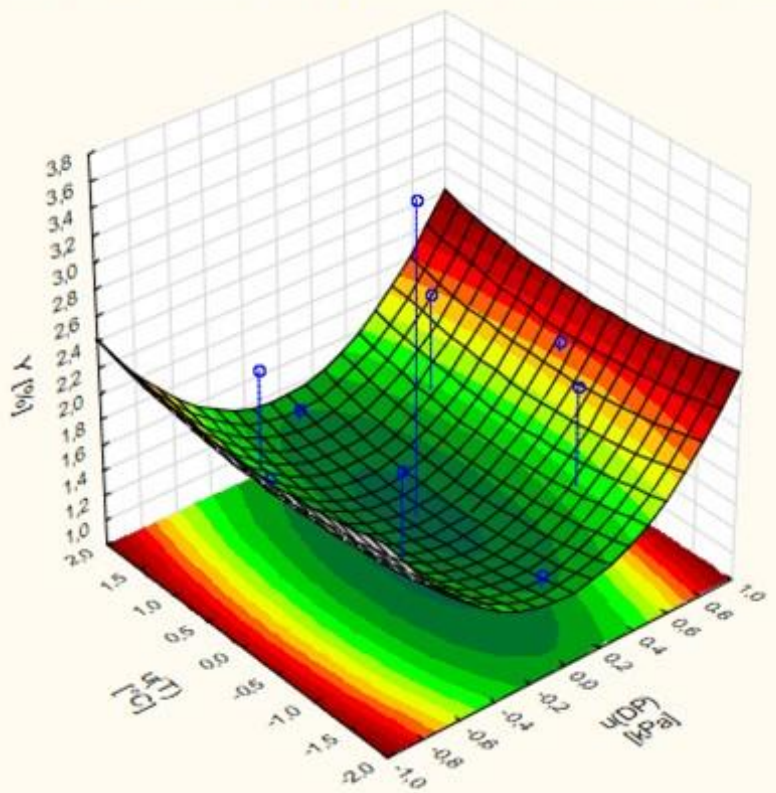

$>2,4$

Figura A.7 - Superfície de resposta (EMED B) dado uT $\left( \pm 1^{\circ} \mathrm{C}\right)$ e uDP $(1 \%$ f.e. $)$ 


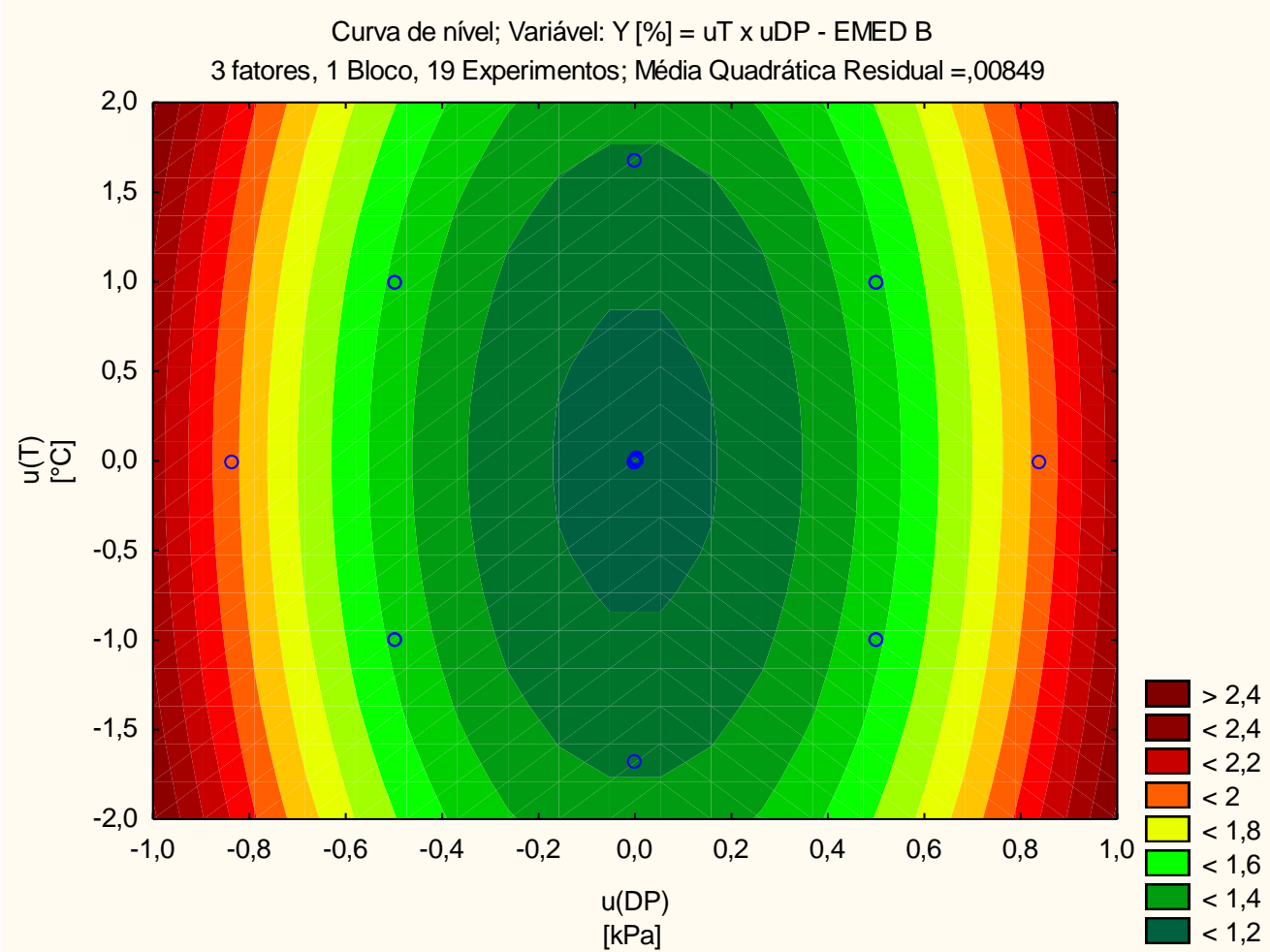

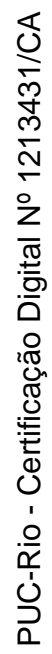

Figura A.8 - Curva de nível (EMED B) dado uDP ( $1 \%$ f.e.) e uT $\left( \pm 1^{\circ} \mathrm{C}\right)$

\section{A.2}

\section{Estação C - estação de medição para apropriação}

Tabela A.4 - Matriz de planejamento experimental da EMED C

\begin{tabular}{|c|c|c|c|c|c|c|c|}
\hline \multicolumn{7}{|c|}{ Matriz do planejamento } & Incerteza da vazão \\
\hline Exp & $\mathrm{x} 1$ & $\mathrm{x} 2$ & $\mathrm{x} 3$ & $\begin{array}{c}\mathrm{P} \\
{[\mathrm{kPa}]}\end{array}$ & $\mathrm{DP}[\mathrm{kPa}]$ & $\begin{array}{c}\mathrm{T} \\
{\left[{ }^{\circ} \mathrm{C}\right]}\end{array}$ & $\mathrm{y}(\%)$ \\
\hline 1 & -1 & -1 & -1 & $-6,86$ & $-0,4982$ & -1 & 2,22 \\
2 & 1 & -1 & -1 & 6,86 & $-0,4982$ & -1 & 2,22 \\
3 & -1 & 1 & -1 & $-6,86$ & 0,4982 & -1 & 2,22 \\
4 & 1 & 1 & -1 & 6,86 & 0,4982 & -1 & 2,22 \\
5 & -1 & -1 & 1 & $-6,86$ & $-0,4982$ & 1 & 2,22 \\
6 & 1 & -1 & 1 & 6,86 & $-0,4982$ & 1 & 2,22 \\
7 & -1 & 1 & 1 & $-6,86$ & 0,4982 & 1 & 2,22 \\
8 & 1 & 1 & 1 & 6,86 & 0,4982 & 1 & 2,22 \\
9 & $-1,682$ & 0 & 0 & $-11,5385$ & 0 & 0 & 3,54 \\
10 & 1,682 & 0 & 0 & 11,5385 & 0 & 0 & 3,54 \\
11 & 0 & $-1,682$ & 0 & 0 & $-0,8380$ & 0 & 2,02 \\
12 & 0 & 1,682 & 0 & 0 & 0,8380 & 0 & 2,02 \\
13 & 0 & 0 & $-1,682$ & 0 & 0 & $-1,6820$ & 1,38 \\
14 & 0 & 0 & 1,682 & 0 & 0 & 1,6820 & 1,38 \\
15 & 0 & 0 & 0 & 0 & 0 & 0 & 1,18 \\
16 & 0 & 0 & 0 & 0,0130 & 0,0020 & 0,0096 & 1,18 \\
17 & 0 & 0 & 0 & 0,0197 & 0,0012 & 0,0086 & 1,18 \\
18 & 0 & 0 & 0 & 0,0014 & 0,0002 & 0,0079 & 1,18 \\
19 & 0 & 0 & 0 & 0,0196 & 0,0018 & 0,0090 & 1,18 \\
\hline
\end{tabular}


Tabela A.5 - Tabela de ANOVA do planejamento de experimentos da EMED C

\begin{tabular}{|c|c|c|c|c|c|}
\hline \multirow[b]{2}{*}{ Fonte de variação } & \multicolumn{5}{|c|}{$\begin{array}{c}\text { ANOVA; Var.:Y [\%]; } \mathrm{R}^{2}=, 99076 ; \mathrm{R}^{2} \text { a:,98151 } \\
3 \text { fatores, 1 Bloco, 19 Experimentos; Média Quadrática Residual =,009504 }\end{array}$} \\
\hline & Soma de Quadrados & $\begin{array}{l}\text { Graus de } \\
\text { liberdade }\end{array}$ & $\begin{array}{l}\text { Quadrados } \\
\text { médios }\end{array}$ & Teste F & $\mathrm{P}$ \\
\hline$(1) \mathrm{u}(\mathrm{P})[\mathrm{kPa}](\mathrm{L})$ & 0,000000 & 1 & 0,000000 & 0,0000 & 0,999894 \\
\hline $\mathrm{u}(\mathrm{P})[\mathrm{kPa}](\mathrm{Q})$ & 8,734108 & 1 & 8,734108 & 918,9901 & 0,000000 \\
\hline$(2) \mathrm{u}(\mathrm{DP})[\mathrm{kPa}](\mathrm{L})$ & 0,000000 & 1 & 0,000000 & 0,0000 & 0,999858 \\
\hline $\mathrm{u}(\mathrm{DP})[\mathrm{kPa}](\mathrm{Q})$ & 0,944881 & 1 & 0,944881 & 99,4190 & 0,000004 \\
\hline$(3) \mathrm{u}(\mathrm{T})\left[{ }^{\circ} \mathrm{C}\right](\mathrm{L})$ & 0,000000 & 1 & 0,000000 & 0,0000 & 0,999523 \\
\hline $\mathrm{u}(\mathrm{T})\left[{ }^{\circ} \mathrm{C}\right](\mathrm{Q})$ & 0,019114 & 1 & 0,019114 & 2,0111 & 0,189835 \\
\hline $1 \mathrm{~L} \times 2 \mathrm{~L}$ & 0,000000 & 1 & 0,000000 & 0,0000 & 1,000000 \\
\hline $1 \mathrm{~L} \times 3 \mathrm{~L}$ & 0,000000 & 1 & 0,000000 & 0,0000 & 0,999999 \\
\hline $2 \mathrm{~L} \times 3 \mathrm{~L}$ & 0,000000 & 1 & 0,000000 & 0,0000 & 0,999998 \\
\hline Erro & 0,085536 & 9 & 0,009504 & & \\
\hline Total SQ & 9,253671 & 18 & & & \\
\hline
\end{tabular}

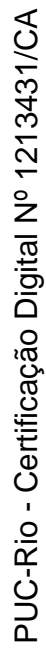

Gráfico de Pareto dos Efeitos; Variável: Y[\%] - EMED C

3 fatores, 1 Bloco, 19 Experimentos; Média Quadrática Residual =,009504 DV: $Y[\%]$

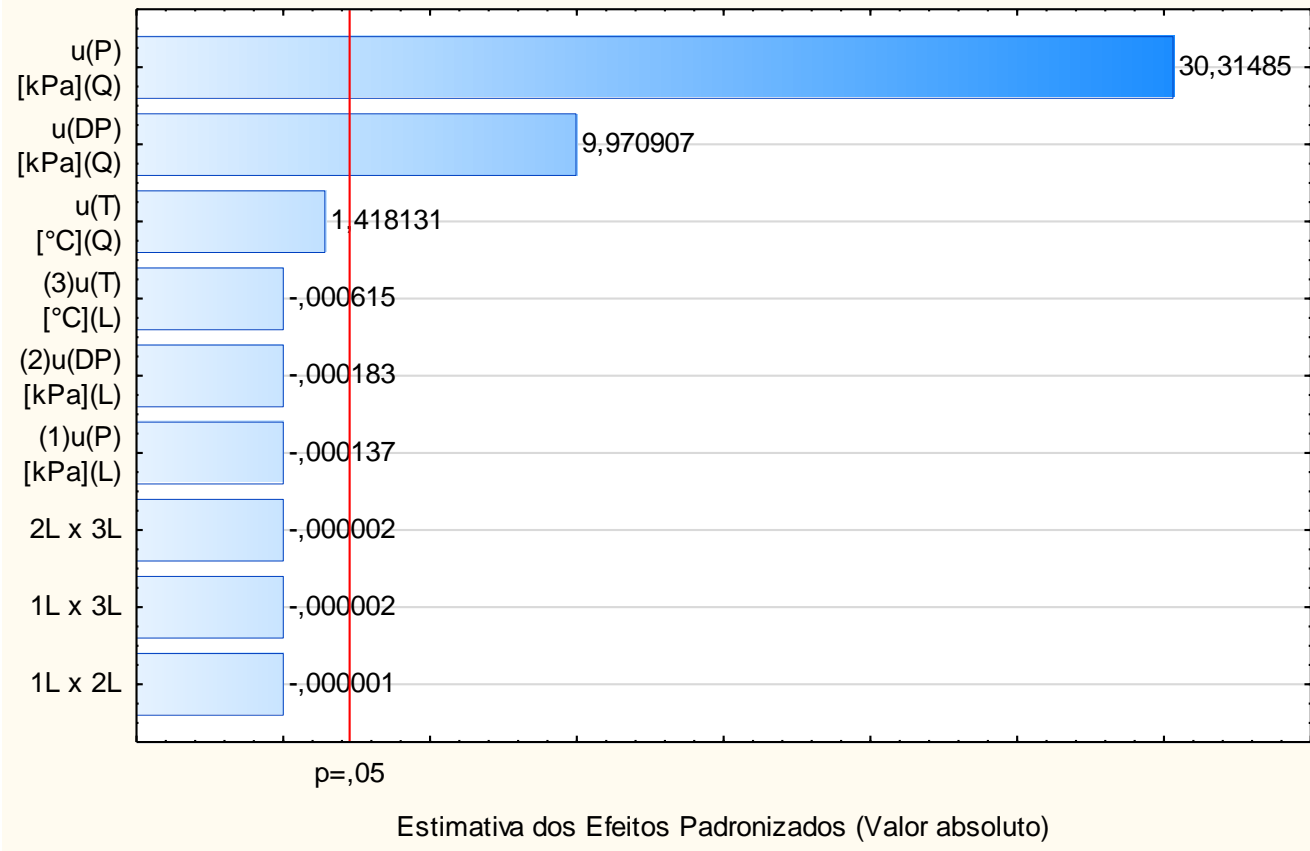

Figura A.9 - Gráfico de Pareto em função dos valores da estatística de teste t 
Valores Previstos vs. Valores Residuais - EMED C

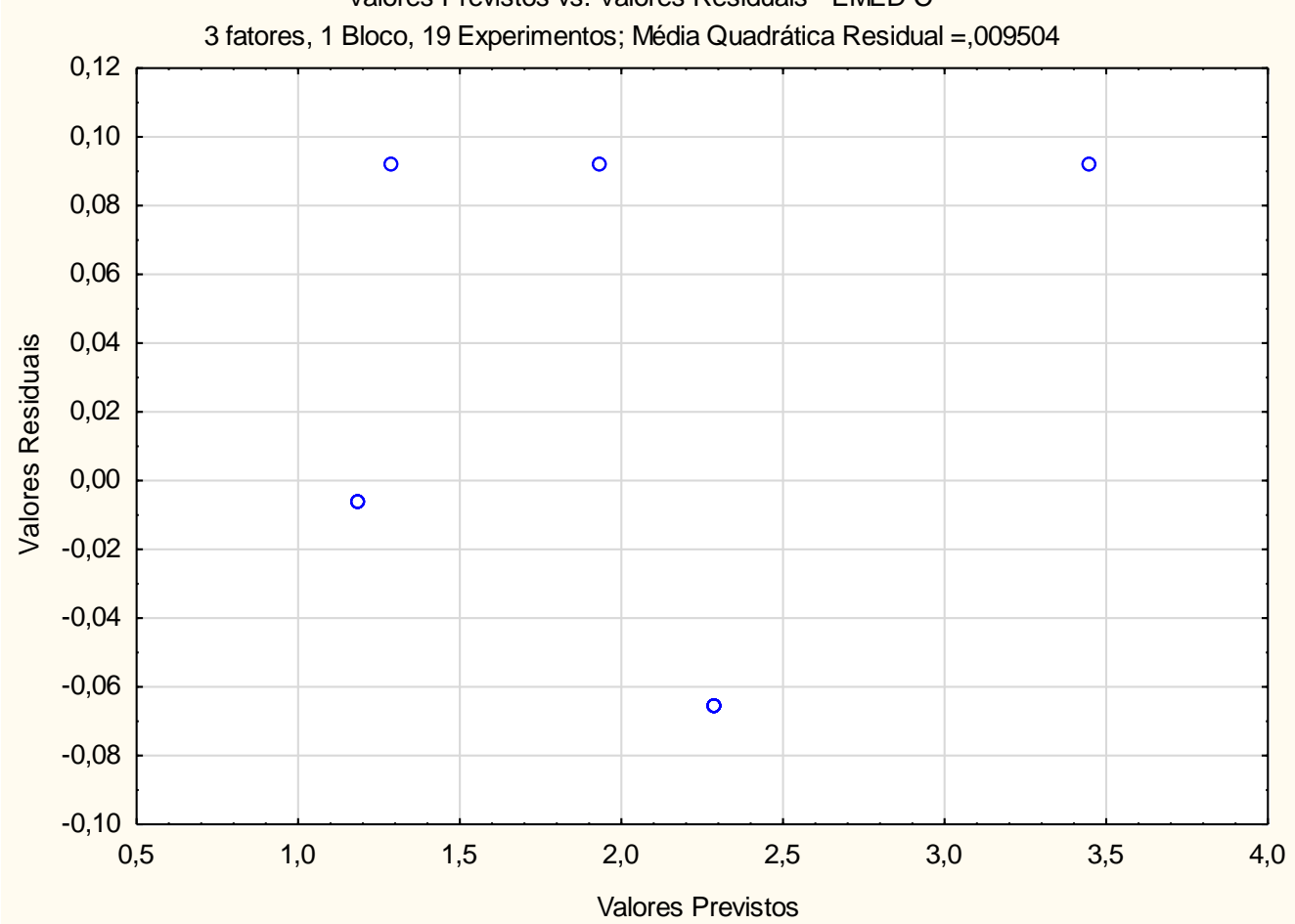

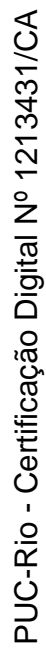

Figura A.10 - Resíduos versus estimativas de y (EMED C - nível: $1 \%$ f.e. e $1{ }^{\circ} \mathrm{C}$ )

Tabela A.6 - Matriz das incertezas estimadas da vazão (EMED C)

(dado $\mathrm{x}_{3}(\mathrm{~T})$ igual a 1 e $\mathrm{x}_{1}$ e $\mathrm{x}_{2}$ variando do nível baixo ao nível alto)

\begin{tabular}{|c|c|c|c|c|c|c|c|c|c|c|c|}
\multicolumn{1}{c|}{} & \multicolumn{10}{c|}{$\mathbf{x}_{\mathbf{1}}$} \\
\cline { 2 - 13 } & -1 & $-0,8$ & $-0,6$ & $-0,4$ & $-0,2$ & 0 & 0,2 & 0,4 & 0,6 & 0,8 & 1 \\
\hline-1 & 2,28 & $\mathbf{2 , 0 0}$ & 1,77 & 1,61 & 1,52 & 1,48 & 1,52 & 1,61 & 1,77 & $\mathbf{2 , 0 0}$ & 2,28 \\
\hline$-0,8$ & 2,19 & 1,90 & 1,68 & 1,52 & 1,42 & 1,39 & 1,42 & 1,52 & 1,68 & 1,90 & 2,19 \\
\hline$-0,6$ & 2,12 & 1,83 & 1,60 & 1,44 & 1,35 & 1,32 & 1,35 & 1,44 & 1,60 & 1,83 & 2,12 \\
\hline$-0,4$ & 2,06 & 1,78 & 1,55 & 1,39 & 1,30 & 1,26 & 1,30 & 1,39 & 1,55 & 1,78 & 2,06 \\
\hline $\mathbf{x}_{2} \mathbf{2}$ & 2,03 & 1,74 & 1,52 & 1,36 & 1,26 & 1,23 & 1,26 & 1,36 & 1,52 & 1,74 & 2,03 \\
\hline 0 & 2,02 & 1,73 & 1,51 & 1,35 & 1,25 & 1,22 & 1,25 & 1,35 & 1,51 & 1,73 & 2,02 \\
\hline 0,2 & 2,03 & 1,74 & 1,52 & 1,36 & 1,26 & 1,23 & 1,26 & 1,36 & 1,52 & 1,74 & 2,03 \\
\hline 0,4 & 2,06 & 1,78 & 1,55 & 1,39 & 1,30 & 1,26 & 1,30 & 1,39 & 1,55 & 1,78 & 2,06 \\
\hline 0,6 & 2,12 & 1,83 & 1,60 & 1,44 & 1,35 & 1,32 & 1,35 & 1,44 & 1,60 & 1,83 & 2,12 \\
\hline 0,8 & 2,19 & 1,90 & 1,68 & 1,52 & 1,42 & 1,39 & 1,42 & 1,52 & 1,68 & 1,90 & 2,19 \\
\hline 1 & 2,28 & $\mathbf{2 , 0 0}$ & 1,77 & 1,61 & 1,52 & 1,48 & 1,52 & 1,61 & 1,77 & $\mathbf{2 , 0 0}$ & 2,28 \\
\hline
\end{tabular}


Superficie de Resposta; Variável: $Y$ [\%] = uP X UDP - EMED C

3 fatores, 1 Bloco, 19 Experimentos; Média Quadrática Residual =,009504

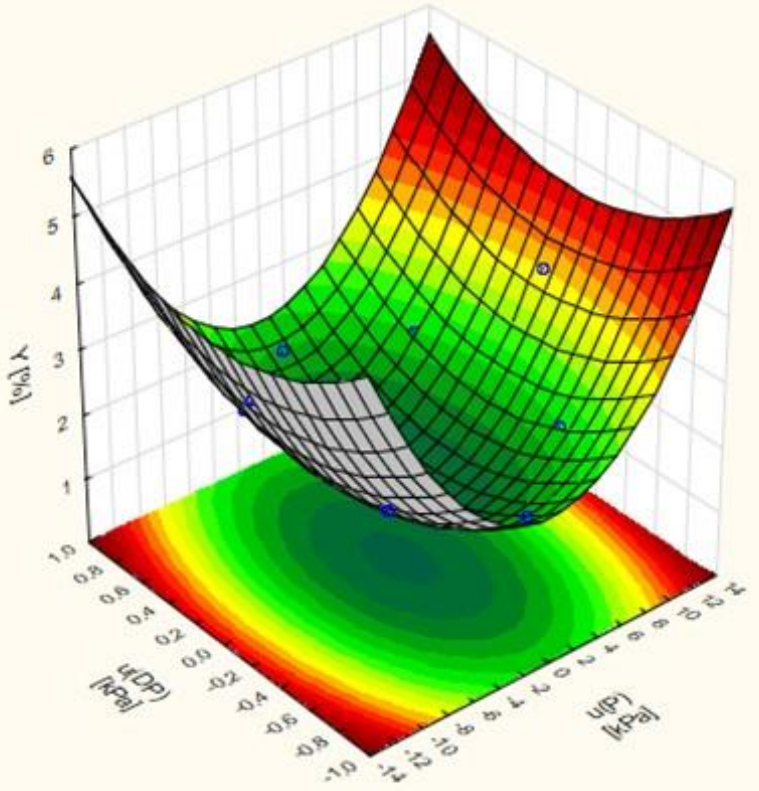

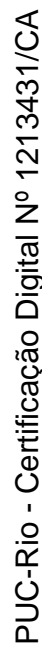

Figura A.11 - Superfície de resposta (EMED C) dado uP e uDP (1 \% f.e.)

Curva de nível; Variável: Y [\%] = uP x uDP - EMED C

3 fatores, 1 Bloco, 19 Experimentos; Média Quadrática Residual =,009504

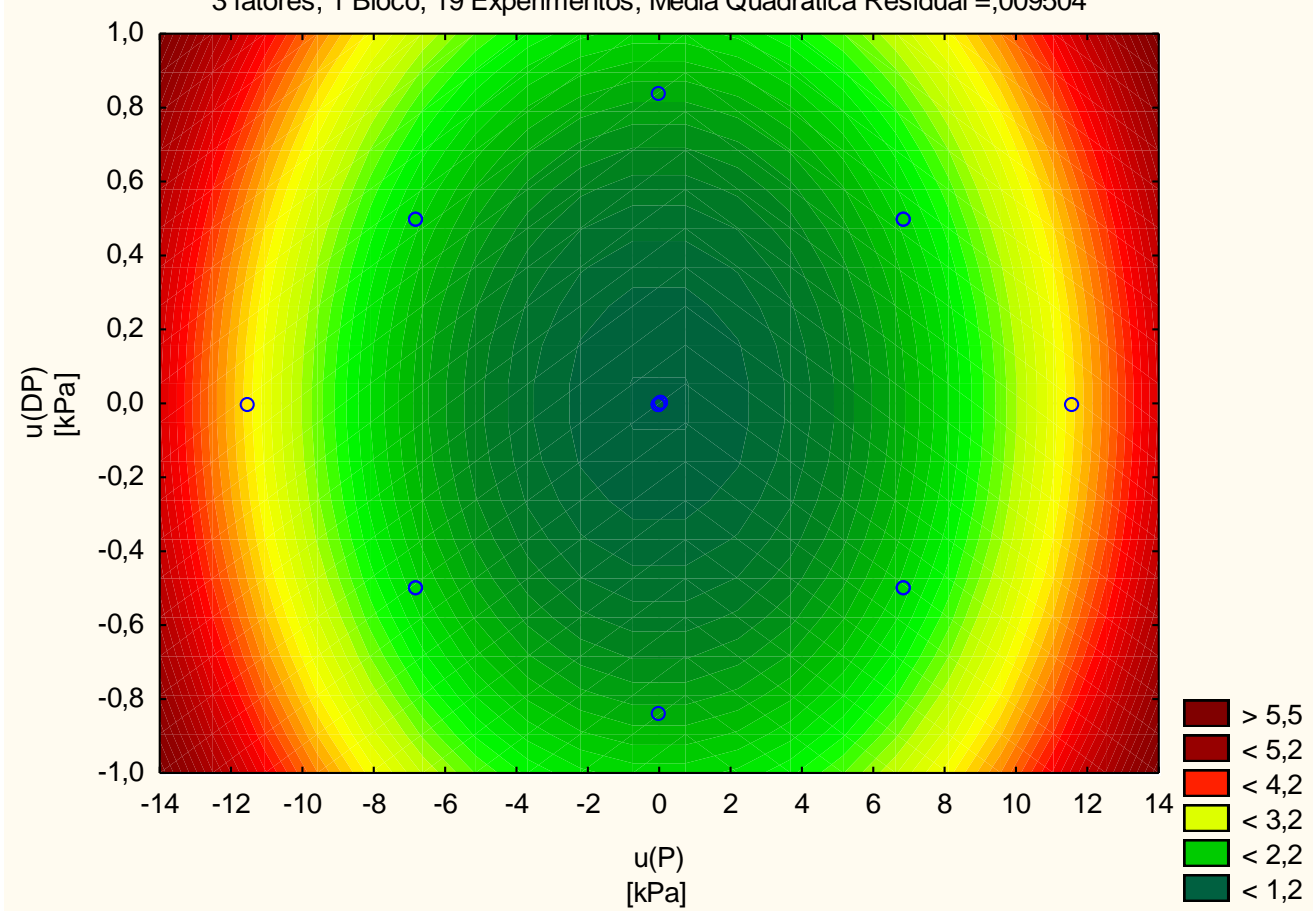

Figura A.12 - Curva de nível (EMED C) dado uP e uDP (1\% f.e.) 
Superficie de Resposta; Variável: Y [\%] = UP X UT - EMED C

3 fatores, 1 Bloco, 19 Experimentos; Média Quadrática Residual =,009504
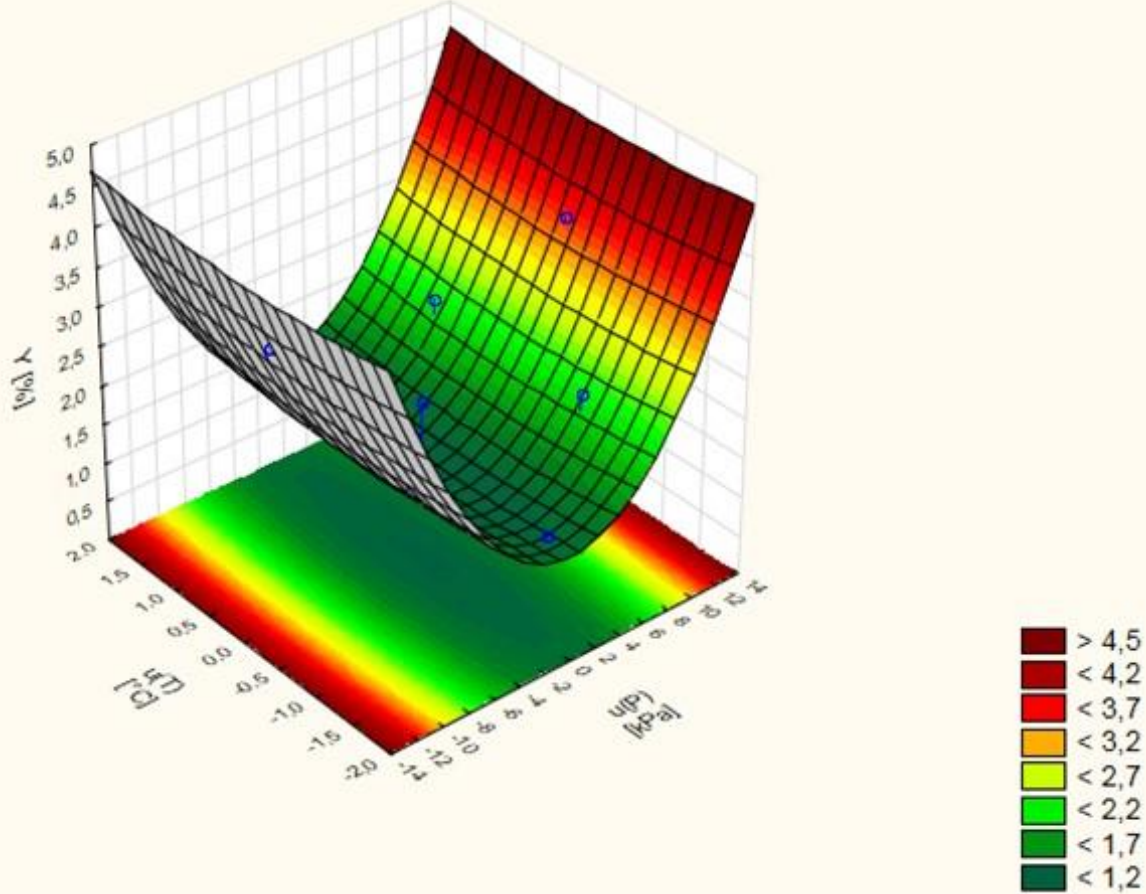

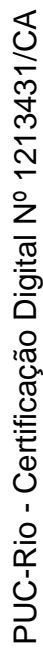

Figura A.13 - Superfície de resposta (EMED C) dado uP (1\% f.e.) e uT $\left( \pm 1^{\circ} \mathrm{C}\right)$

Curva de nível; Variável: Y [\%] = uP x uT - EMED C

3 fatores, 1 Bloco, 19 Experimentos; Média Quadrática Residual =,009504

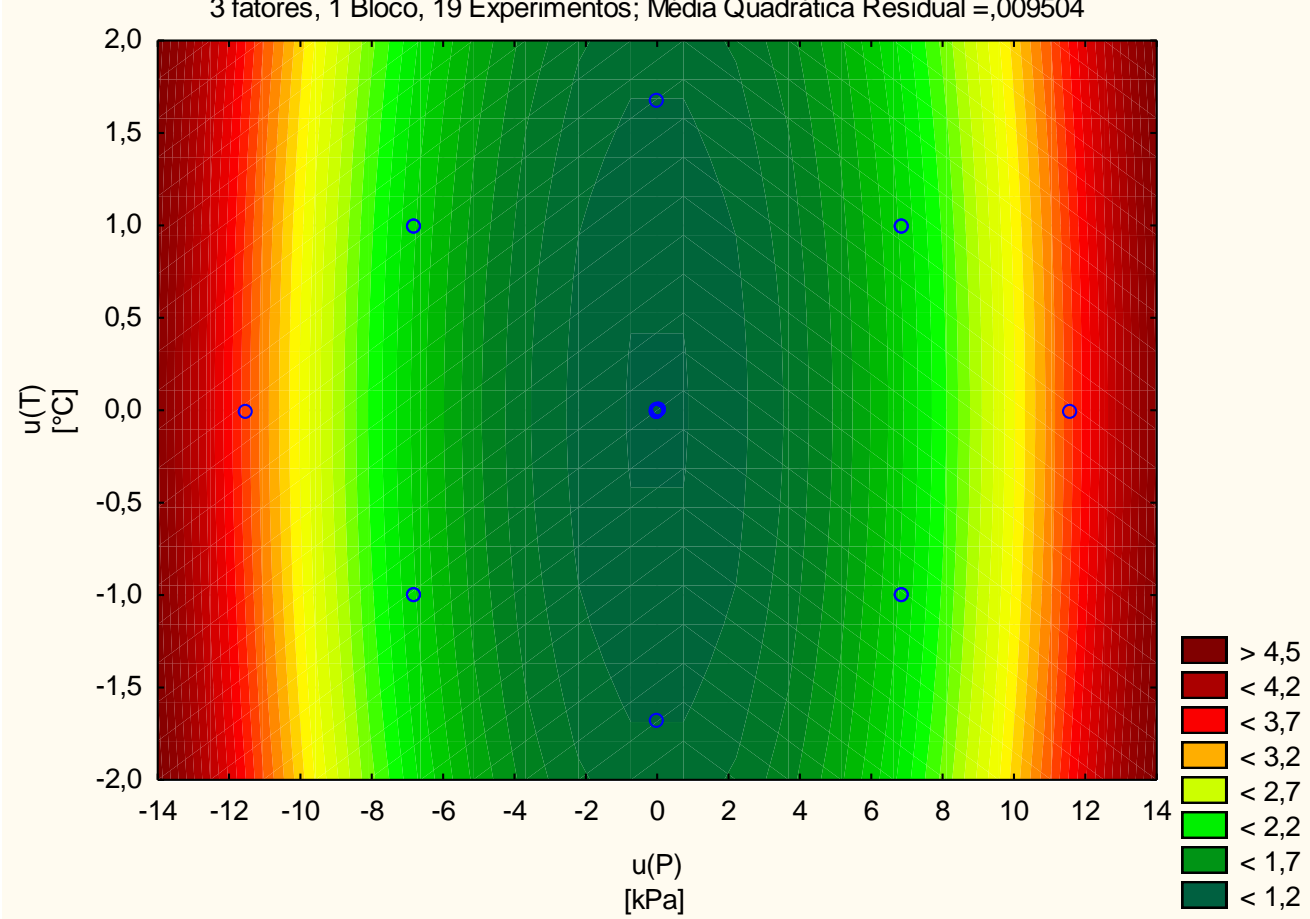

Figura A.14 - Curva de nível (EMED C) dado uP (1\% f.e.) e uT $\left( \pm 1{ }^{\circ} \mathrm{C}\right)$ 
Superficie de Resposta; Variável: $Y[\%]$ = UT X UDP - EMED C

3 fatores, 1 Bloco, 19 Experimentos; Média Quadrática Residual $=, 009504$

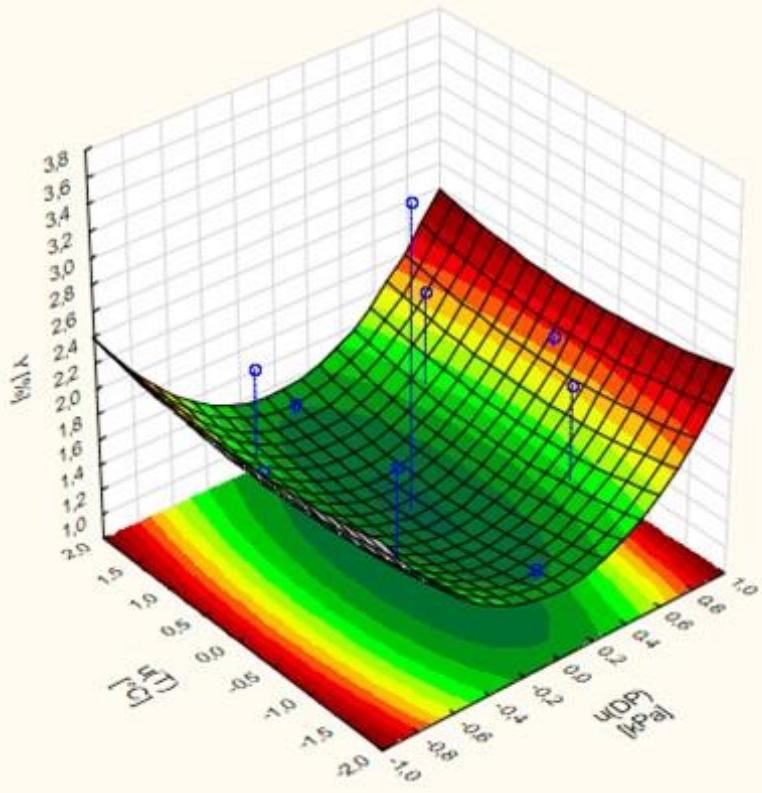

$>2,2$

$<2,2$

$<2$

$<1,8$

$<1,6$

$<1,4$

$<1,2$

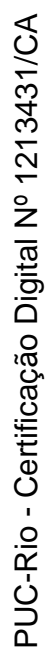

Figura A.15 - Superfície de resposta (EMED C) dado uDP $(1 \%$ f.e. $)$ e uT $\left( \pm 1^{\circ} \mathrm{C}\right)$

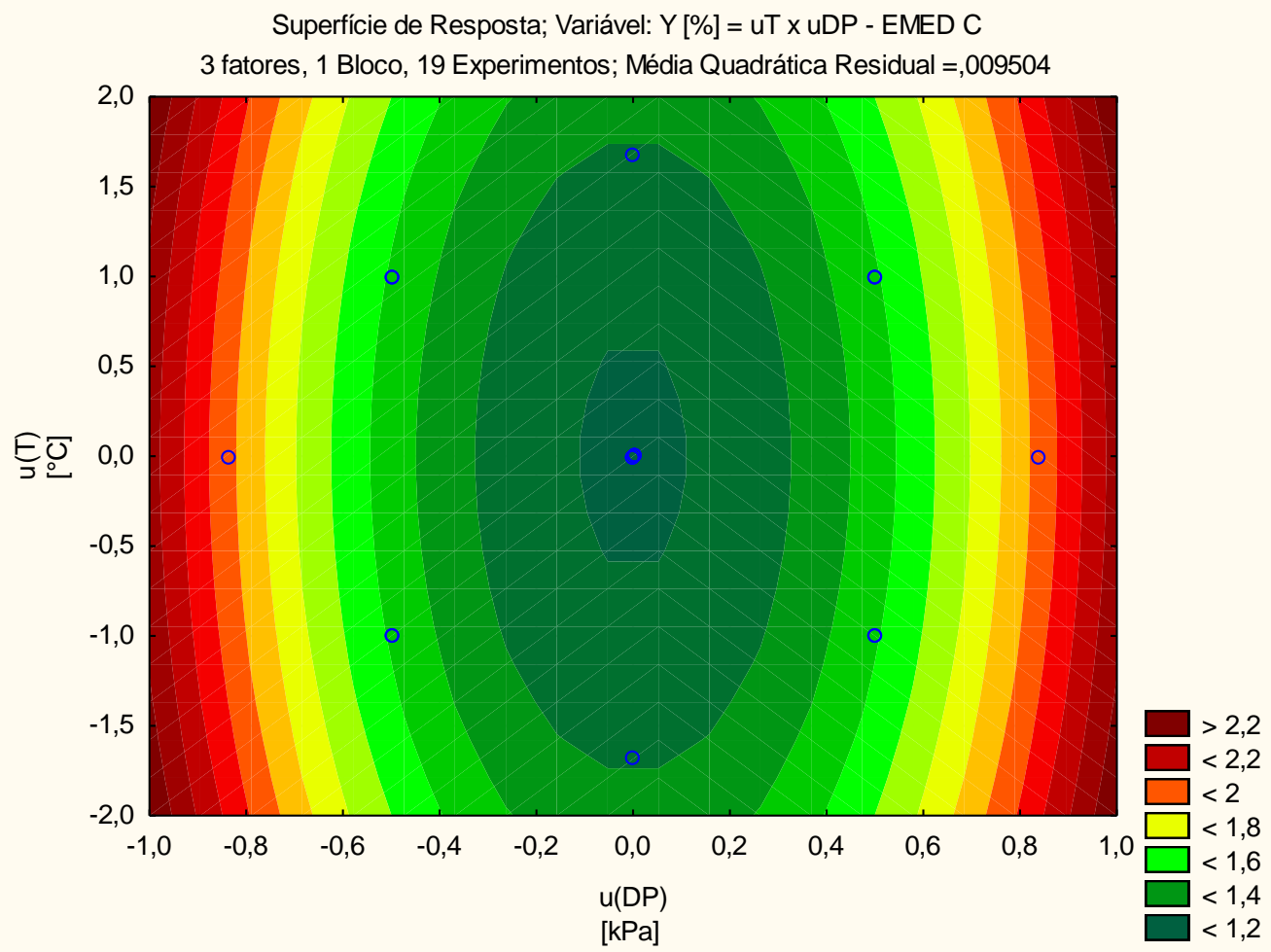

Figura A.16 - Curva de nível (EMED C) dado uDP $(1 \%$ f.e. $)$ e uT $\left( \pm 1^{\circ} \mathrm{C}\right)$ 


\section{A.3}

\section{Estação D - estação de medição fiscal}

Tabela A.7 - Matriz de planejamento experimental da EMED D

\begin{tabular}{|c|c|c|c|c|c|c|c|}
\hline \multicolumn{7}{|c|}{ Matriz do planejamento } & $\begin{array}{c}\text { Incerteza da } \\
\text { vazão }\end{array}$ \\
\hline Exp & $\mathrm{x} 1$ & $\mathrm{x} 2$ & $\mathrm{x} 3$ & $\begin{array}{c}\mathrm{P} \\
{[\mathrm{kPa}]}\end{array}$ & $\mathrm{DP}[\mathrm{kPa}]$ & $\begin{array}{c}\mathrm{T} \\
{\left[{ }^{\circ} \mathrm{C}\right]}\end{array}$ & $\mathrm{y}(\%)$ \\
\hline 1 & -1 & -1 & -1 & $-117,68$ & $-0,4982$ & -1 & 3,60 \\
2 & 1 & -1 & -1 & 117,68 & $-0,4982$ & -1 & 3,60 \\
3 & -1 & 1 & -1 & $-117,68$ & 0,4982 & -1 & 3,60 \\
4 & 1 & 1 & -1 & 117,68 & 0,4982 & -1 & 3,60 \\
5 & -1 & -1 & 1 & $-117,68$ & $-0,4982$ & 1 & 3,60 \\
6 & 1 & -1 & 1 & 117,68 & $-0,4982$ & 1 & 3,60 \\
7 & -1 & 1 & 1 & $-117,68$ & 0,4982 & 1 & 3,60 \\
8 & 1 & 1 & 1 & 117,68 & 0,4982 & 1 & 3,60 \\
9 & $-1,682$ & 0 & 0 & $-197,9378$ & 0 & 0 & 6,55 \\
10 & 1,682 & 0 & 0 & 197,9378 & 0 & 0 & 6,55 \\
11 & 0 & $-1,682$ & 0 & 0 & $-0,838$ & 0 & 1,96 \\
12 & 0 & 1,682 & 0 & 0 & 0,838 & 0 & 1,96 \\
13 & 0 & 0 & $-1,682$ & 0 & 0 & $-1,682$ & 1,22 \\
14 & 0 & 0 & 1,682 & 0 & 0 & 1,682 & 1,22 \\
15 & 0 & 0 & 0 & 0 & 0 & 0 & 1,06 \\
16 & 0 & 0 & 0 & 0,8168 & 0,0029 & 0,0148 & 1,06 \\
17 & 0 & 0 & 0 & 0,7278 & 0 & 0,0027 & 1,06 \\
18 & 0 & 0 & 0 & 0,0960 & 0,0016 & 0,0043 & 1,06 \\
19 & 0 & 0 & 0 & 0,7114 & 0,0003 & 0,0025 & 1,06 \\
\hline
\end{tabular}

Tabela A.8 - Tabela de ANOVA do planejamento de experimentos da EMED D

\begin{tabular}{|c|c|c|c|c|c|}
\hline & \multicolumn{5}{|c|}{ ANOVA; Var.:Y [\%]; $\mathbf{R}^{2}=, 99702 ; \mathrm{R}_{\mathrm{a}}^{2}:, 99404$} \\
Fonte de variação & 3 fatores, 1 Bloco, 19 Experimentos; Média Quadrática Residua =,0181658 \\
\cline { 2 - 6 } & $\begin{array}{c}\text { Soma de } \\
\text { Quadrados }\end{array}$ & $\begin{array}{c}\text { Graus de } \\
\text { liberdade }\end{array}$ & $\begin{array}{c}\text { Quadrados } \\
\text { médios }\end{array}$ & Teste F & $\mathrm{P}$ \\
\hline$(1) \mathrm{u}(\mathrm{P})[\mathrm{kPa}](\mathrm{L})$ & 0,00000 & 1 & 0,00000 & 0,000 & 0,999729 \\
\hline $\mathrm{u}(\mathrm{P})[\mathrm{kPa}](\mathrm{Q})$ & 54,08356 & 1 & 54,08356 & 2977,211 & 0,000000 \\
\hline$(2) \mathrm{u}(\mathrm{DP})[\mathrm{kPa}](\mathrm{L})$ & 0,00000 & 1 & 0,00000 & 0,000 & 0,999870 \\
\hline $\mathrm{u}(\mathrm{DP})[\mathrm{kPa}](\mathrm{Q})$ & 1,83065 & 1 & 1,83065 & 100,774 & 0,000003 \\
\hline$(3) \mathrm{u}(\mathrm{T})\left[{ }^{\circ} \mathrm{C}\right](\mathrm{L})$ & 0,00000 & 1 & 0,00000 & 0,000 & 0,999670 \\
\hline $\mathrm{u}(\mathrm{T})\left[{ }^{\circ} \mathrm{C}\right](\mathrm{Q})$ & 0,15506 & 1 & 0,15506 & 8,536 & 0,016987 \\
\hline $1 \mathrm{~L} \times 2 \mathrm{~L}$ & 0,00000 & 1 & 0,00000 & 0,000 & 0,999999 \\
\hline $1 \mathrm{~L} \times 3 \mathrm{~L}$ & 0,00000 & 1 & 0,00000 & 0,000 & 0,999998 \\
\hline $2 \mathrm{~L} \times 3 \mathrm{~L}$ & 0,00000 & 1 & 0,00000 & 0,000 & 0,999998 \\
\hline Erro & 0,16349 & 9 & 0,01817 & & \\
\hline Total SQ & 54,86490 & 18 & & & \\
\hline
\end{tabular}


Gráfico de Pareto dos Efeitos; Variável: Y[\%] - EMED D

3 fatores, 1 Bloco, 19 Experimentos; Média Quadrática Residual =, 0181658

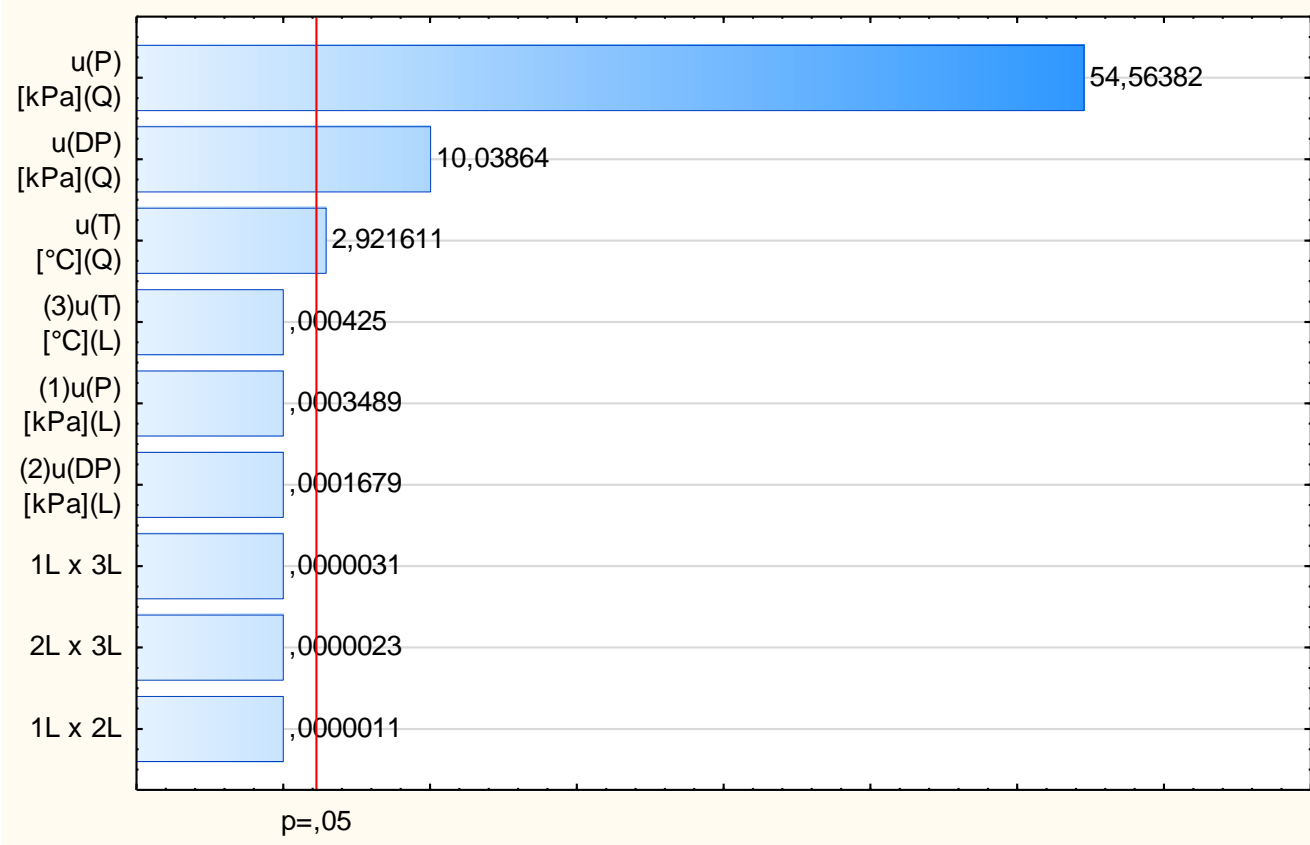

Estimativa dos Efeitos Padronizados (Valor absoluto)

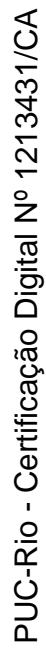

Figura A.17 - Gráfico de Pareto em função dos valores da estatística de teste t

Valores Previstos vs. Valores Residuais- EMED D

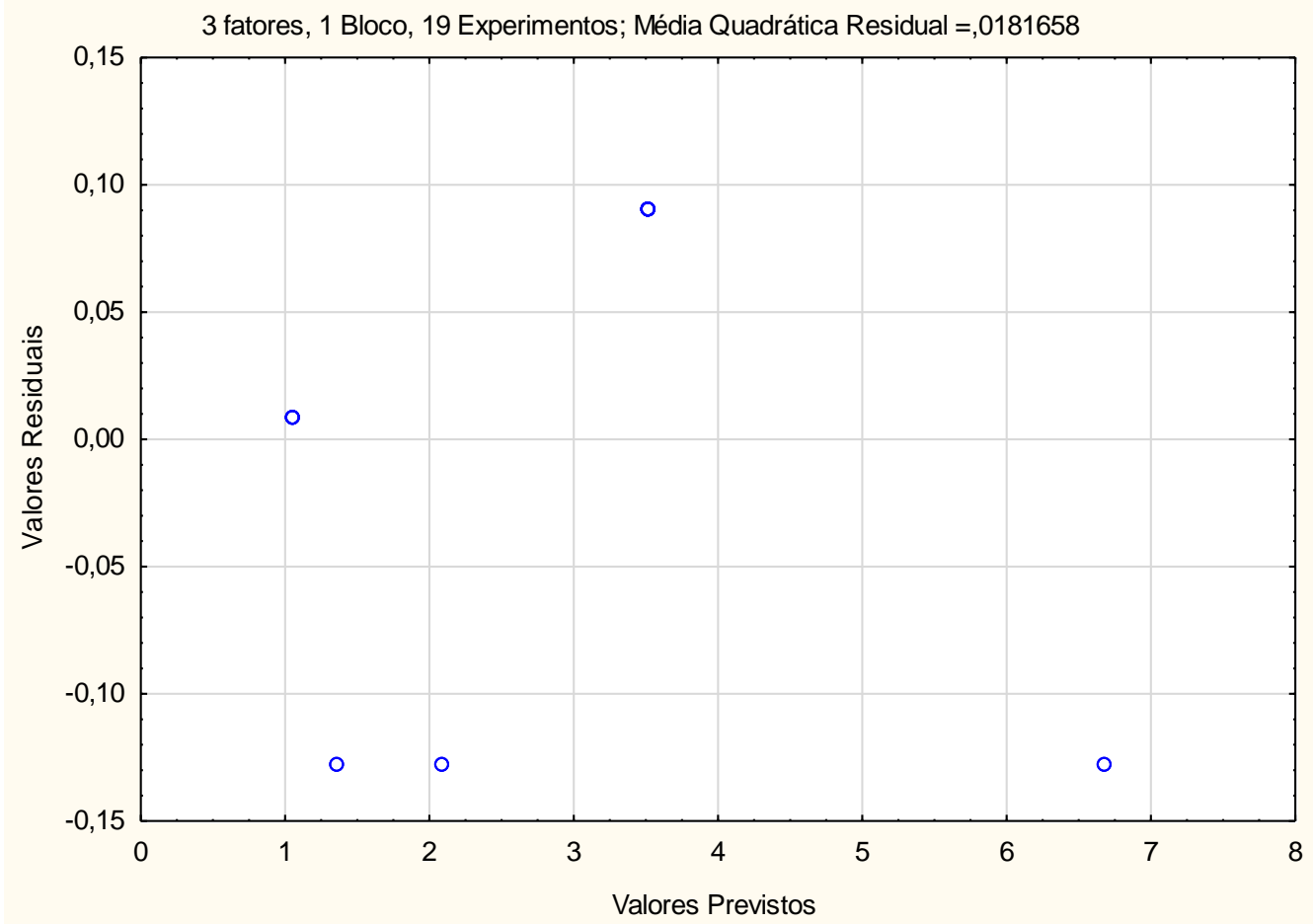

Figura A.18 - Resíduos versus estimativas de y (EMED D - nível: $1 \%$ f.e. e $1^{\circ} \mathrm{C}$ ) 
Tabela A.9 - Matriz das incertezas estimadas da vazão (EMED D)

(dado $x_{3}(T)$ igual a 1 e $x_{1}$ e $x_{2}$ variando do nível baixo ao nível alto)

\begin{tabular}{|c|c|c|c|c|c|c|c|c|c|c|c|}
\multicolumn{1}{c|}{} & \multicolumn{10}{c|}{$\mathbf{x}_{\mathbf{1}}$} \\
\cline { 2 - 14 } & -1 & $-0,8$ & $-0,6$ & $-0,4$ & $-0,2$ & 0 & 0,2 & 0,4 & 0,6 & 0,8 & 1 \\
\hline-1 & 3,51 & 2,80 & 2,24 & 1,84 & 1,60 & 1,52 & 1,60 & 1,84 & 2,24 & 2,80 & 3,51 \\
\hline$-0,8$ & 3,38 & 2,66 & 2,11 & 1,71 & 1,47 & 1,39 & 1,47 & 1,71 & 2,11 & 2,66 & 3,38 \\
\hline$-0,6$ & 3,28 & 2,56 & 2,00 & 1,61 & 1,37 & 1,29 & 1,37 & 1,61 & 2,00 & 2,56 & 3,28 \\
\hline$-0,4$ & 3,20 & 2,49 & 1,93 & 1,53 & 1,29 & 1,21 & 1,29 & 1,53 & 1,93 & 2,49 & 3,20 \\
\hline$-0,2$ & 3,16 & 2,44 & 1,89 & $\mathbf{1 , 4 9}$ & 1,25 & 1,17 & 1,25 & $\mathbf{1 , 4 9}$ & 1,89 & 2,44 & 3,16 \\
\hline 0 & 3,15 & 2,43 & 1,87 & 1,47 & 1,23 & 1,16 & 1,23 & 1,47 & 1,87 & 2,43 & 3,15 \\
\hline 0,2 & 3,16 & 2,44 & 1,89 & $\mathbf{1 , 4 9}$ & 1,25 & 1,17 & 1,25 & $\mathbf{1 , 4 9}$ & 1,89 & 2,44 & 3,16 \\
\hline 0,4 & 3,20 & 2,49 & 1,93 & 1,53 & 1,29 & 1,21 & 1,29 & 1,53 & 1,93 & 2,49 & 3,20 \\
\hline 0,6 & 3,28 & 2,56 & 2,00 & 1,61 & 1,37 & 1,29 & 1,37 & 1,61 & 2,00 & 2,56 & 3,28 \\
\hline 0,8 & 3,38 & 2,66 & 2,11 & 1,71 & 1,47 & 1,39 & 1,47 & 1,71 & 2,11 & 2,66 & 3,38 \\
\hline 1 & 3,51 & 2,80 & 2,24 & 1,84 & 1,60 & 1,52 & 1,60 & 1,84 & 2,24 & 2,80 & 3,51 \\
\hline
\end{tabular}

Superficie de Resposta; Variável: $Y$ [\%] = UP x uDP - EMED D

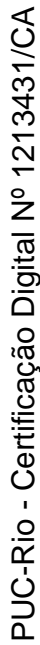
3 fatores, 1 Bloco, 19 Experimentos; Média Quadrática Residual $=, 0181658$

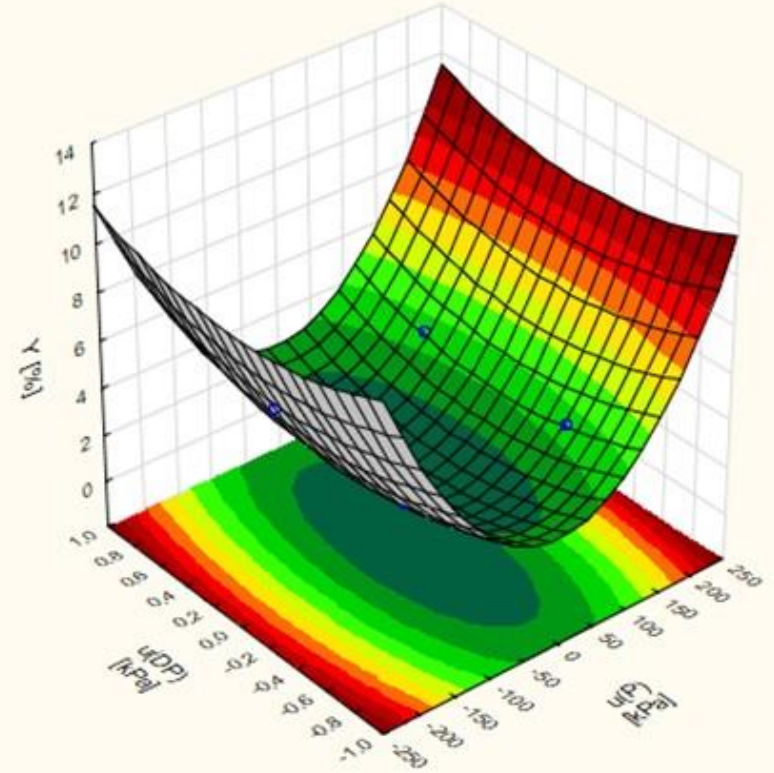

Figura A.19 - Superfície de resposta (EMED D) dado uP e uDP (1 \% f.e.) 
Curva de nível; Variável: Y [\%] = UP x UDP - EMED D

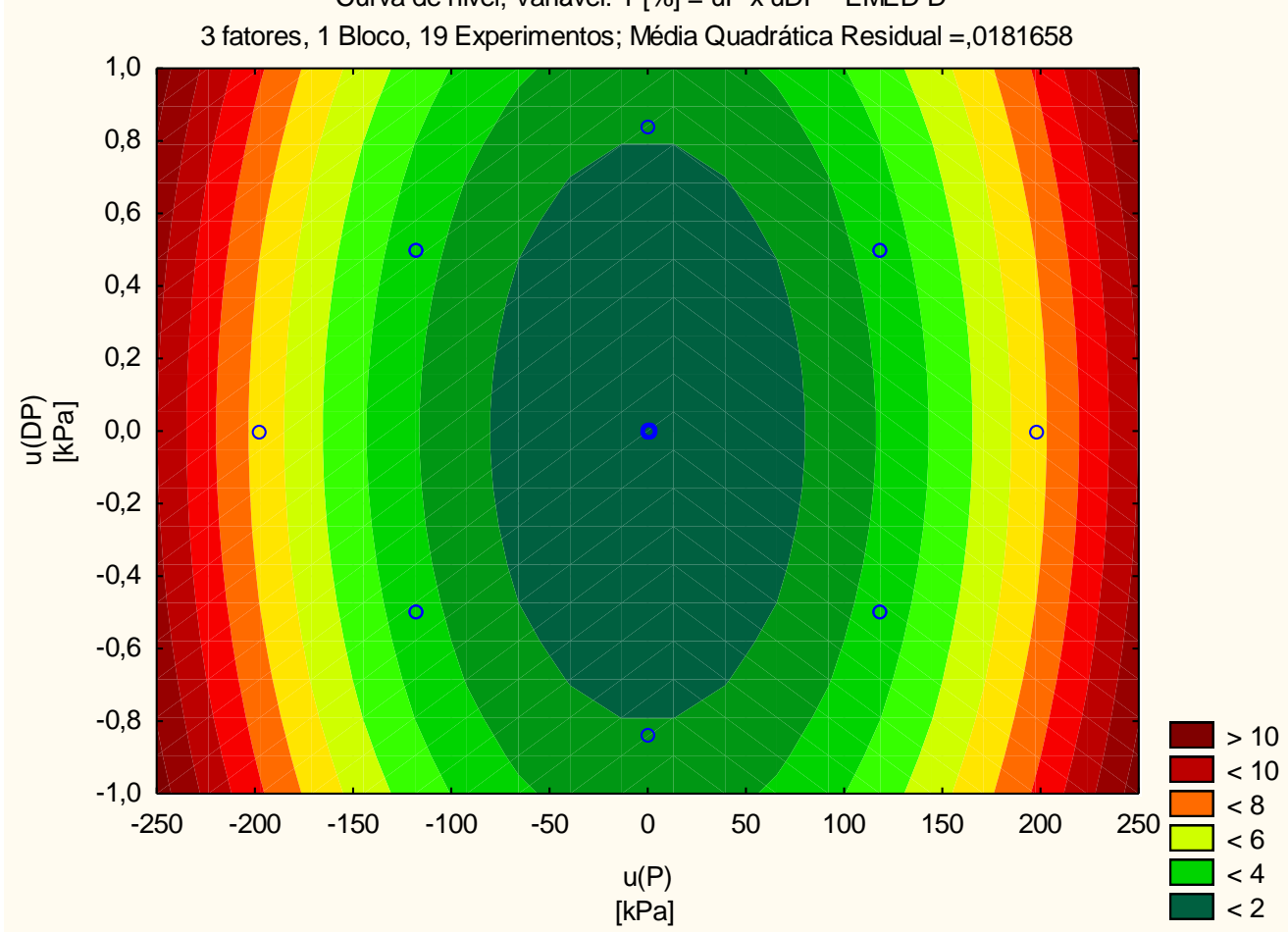

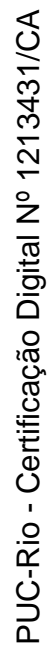

Figura A.20 - Curva de nível (EMED D) dado uP e uDP (1\% f.e.)

Superficie de Resposta; Variável: Y [\%] = uP x UT - EMED D

3 fatores, 1 Bloco, 19 Experimentos; Média Quadrática Residual =, 0181658

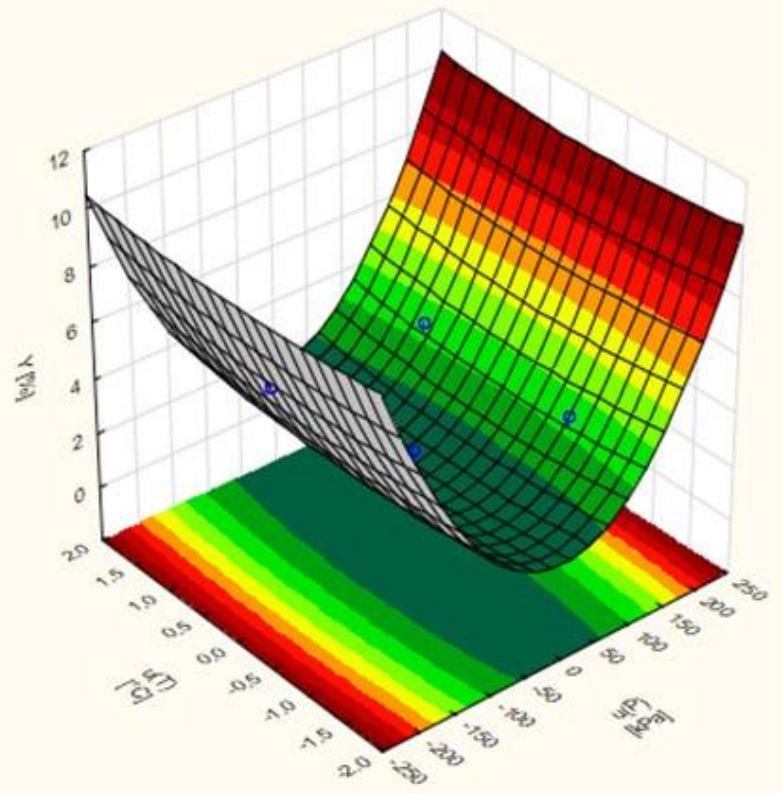

Figura A.21 - Superfície de resposta (EMED D) dado uP ( $1 \%$ f.e. $)$ e uT $\left( \pm 1{ }^{\circ} \mathrm{C}\right)$ 


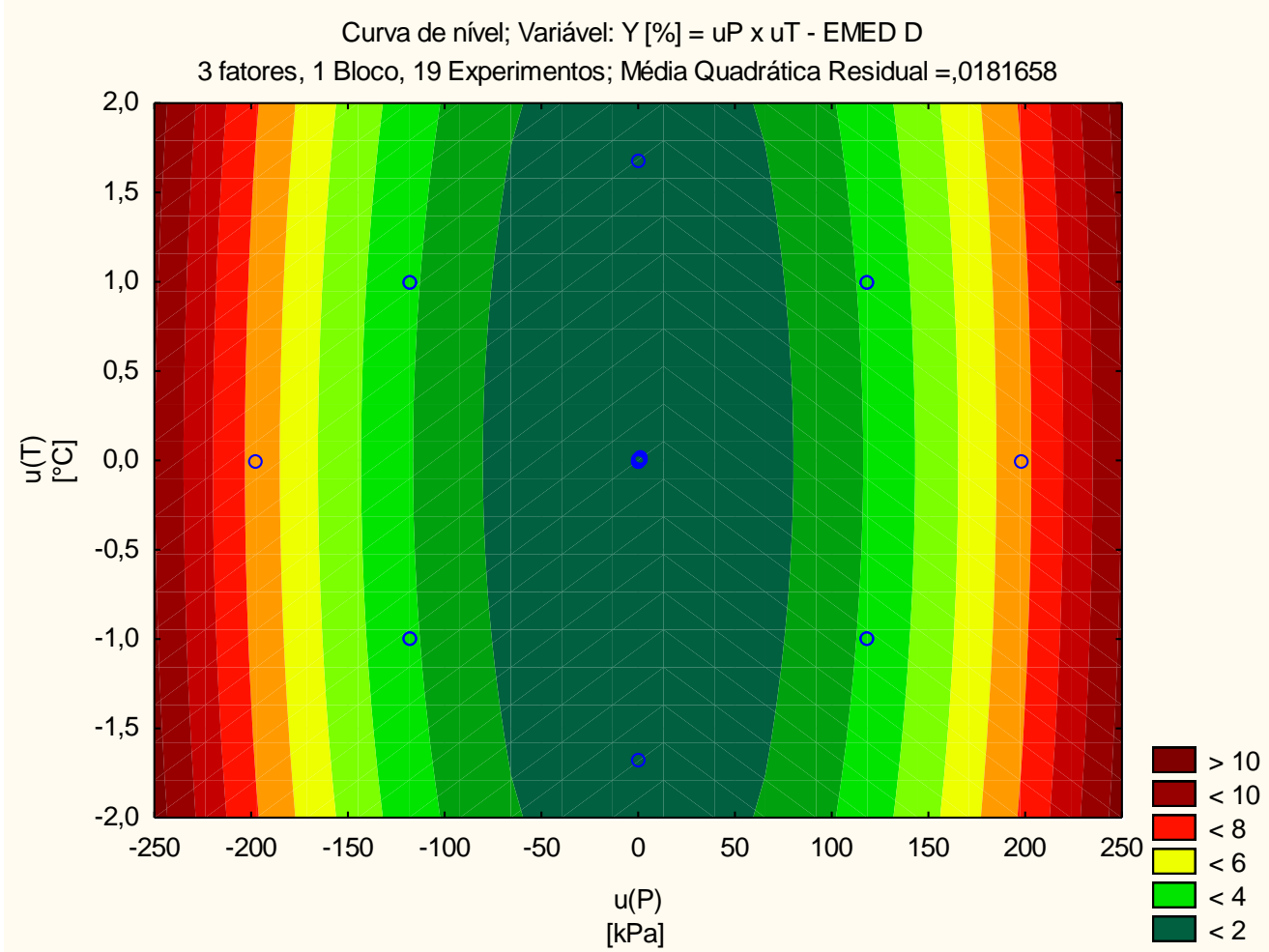

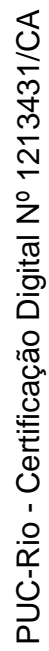

Figura A.22 - Curva de nível (EMED D) dado uP (1\% f.e.) e uT $\left( \pm 1{ }^{\circ} \mathrm{C}\right)$

Superficie de Resposta; Variável: $Y[\%]=$ UT x uDP - EMED D

3 fatores, 1 Bloco, 19 Experimentos; Média Quadrática Residual =, 0181658

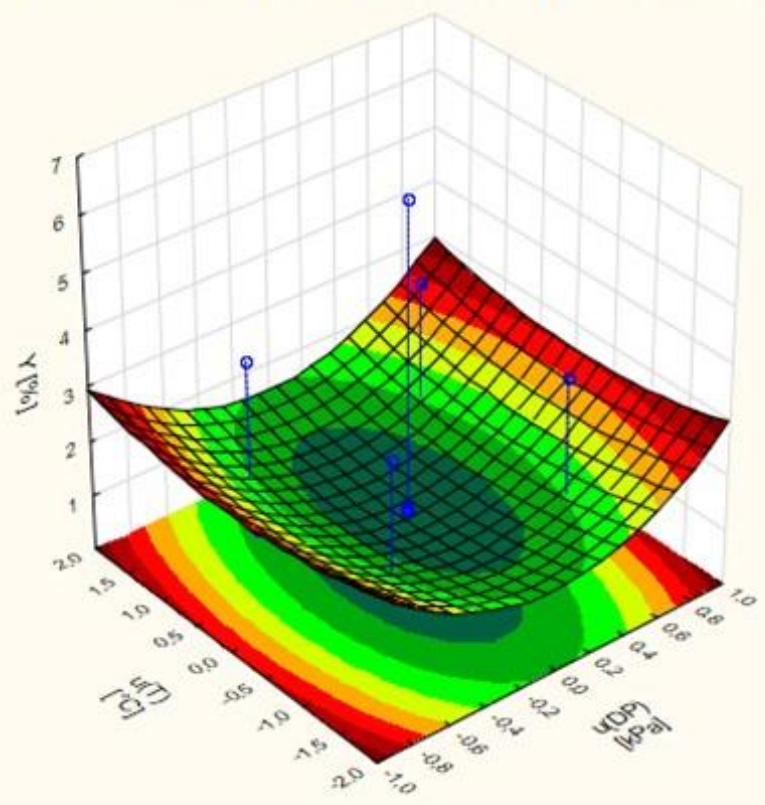

Figura A.23 - Superfície de resposta (EMED D) dado uDP $(1 \%$ f.e. $)$ e uT $\left( \pm 1{ }^{\circ} \mathrm{C}\right)$ 


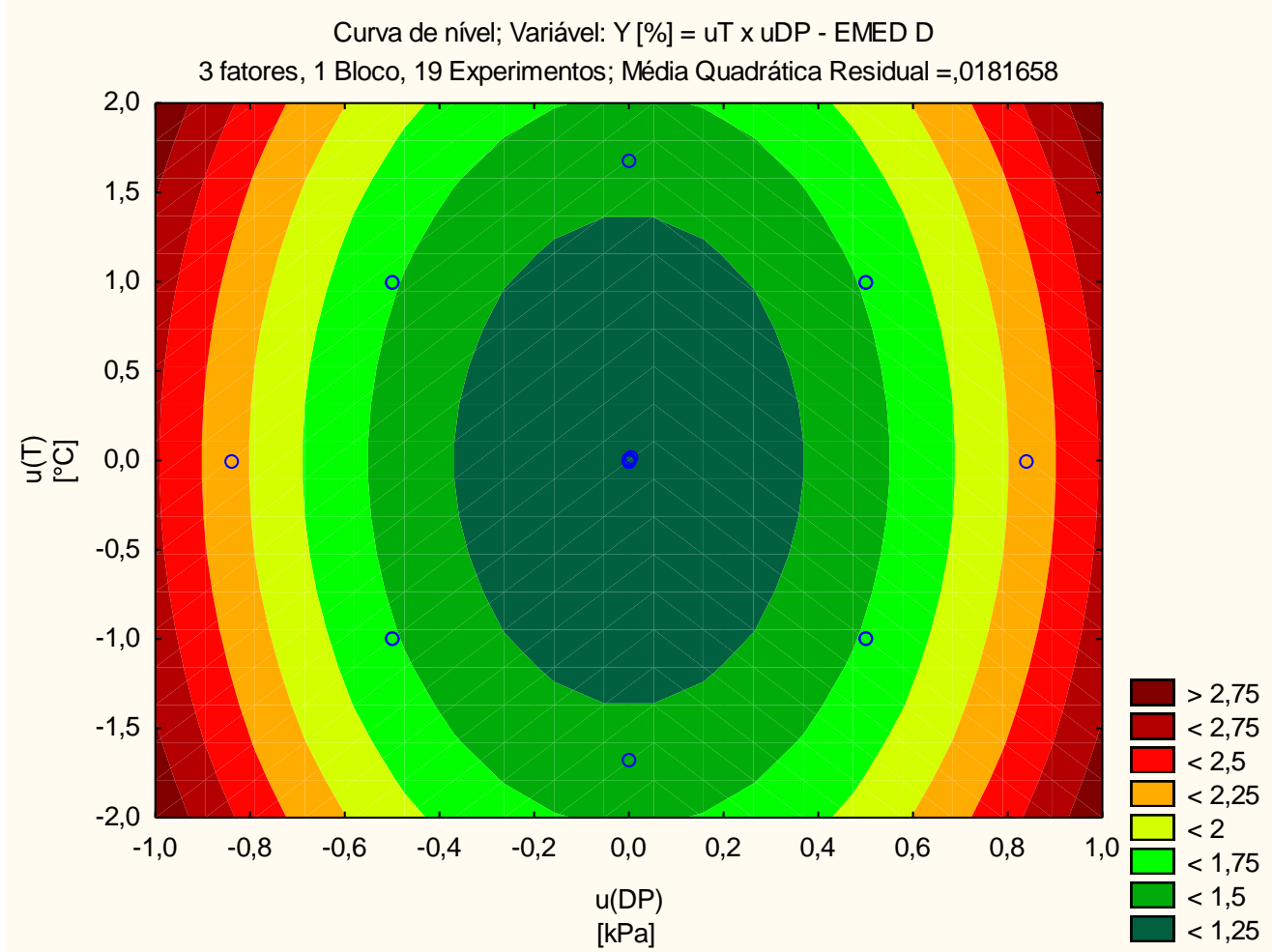

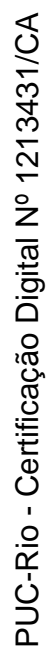

Figura A.24 - Curva de nível (EMED D) dado uDP (1\% f.e.) e uT $\left( \pm 1{ }^{\circ} \mathrm{C}\right)$

\section{A.4 \\ Estação E1 - estação de medição para apropriação}

Tabela A.10 - Matriz de planejamento experimental da EMED E1

\begin{tabular}{|c|c|c|c|c|c|c|c|}
\hline \multicolumn{7}{|c|}{ Matriz do planejamento } & $\begin{array}{c}\text { Incerteza da } \\
\text { vazão }\end{array}$ \\
\hline Exp & $\mathrm{x} 1$ & $\mathrm{x} 2$ & $\mathrm{x} 3$ & $\begin{array}{c}\mathrm{P} \\
{[\mathrm{kPa}]}\end{array}$ & $\mathrm{DP}[\mathrm{kPa}]$ & $\begin{array}{c}\mathrm{T} \\
{\left[{ }^{\circ} \mathrm{C}\right]}\end{array}$ & $\mathrm{y}(\%)$ \\
\hline 1 & -1 & -1 & -1 & $-6,86$ & $-0,2491$ & -1 & 2,17 \\
2 & 1 & -1 & -1 & 6,86 & $-0,2491$ & -1 & 2,17 \\
3 & -1 & 1 & -1 & $-6,86$ & 0,2491 & -1 & 2,17 \\
4 & 1 & 1 & -1 & 6,86 & 0,2491 & -1 & 2,17 \\
5 & -1 & -1 & 1 & $-6,86$ & $-0,2491$ & 1 & 2,17 \\
6 & 1 & -1 & 1 & 6,86 & $-0,2491$ & 1 & 2,17 \\
7 & -1 & 1 & 1 & $-6,86$ & 0,2491 & 1 & 2,17 \\
8 & 1 & 1 & 1 & 6,86 & 0,2491 & 1 & 2,17 \\
9 & $-1,682$ & 0 & 0 & $-11,5385$ & 0 & 0 & 3,17 \\
10 & 1,682 & 0 & 0 & 11,5385 & 0 & 0 & 3,17 \\
11 & 0 & $-1,682$ & 0 & 0 & $-0,4190$ & 0 & 2,03 \\
12 & 0 & 1,682 & 0 & 0 & 0,4190 & 0 & 2,03 \\
13 & 0 & 0 & $-1,682$ & 0 & 0 & $-1,682$ & 1,39 \\
14 & 0 & 0 & 1,682 & 0 & 0 & 1,682 & 1,39 \\
15 & 0 & 0 & 0 & 0 & 0 & 0 & 1,19 \\
16 & 0 & 0 & 0 & 0,0163 & 0,0029 & 0,0148 & 1,19 \\
17 & 0 & 0 & 0 & 0,0146 & 0 & 0,0027 & 1,19 \\
18 & 0 & 0 & 0 & 0,0192 & 0,0016 & 0,0043 & 1,19 \\
19 & 0 & 0 & 0 & 0,0142 & 0,0003 & 0,0025 & 1,19 \\
\hline
\end{tabular}


Tabela A.11 - Tabela de ANOVA do planejamento de experimentos da EMED E1

\begin{tabular}{|c|c|c|c|c|c|}
\hline \multirow{2}{*}{ Fonte de variação } & \multicolumn{5}{|c|}{ ANOVA; Var.: $[\%] ; \mathrm{R}^{2}=, 9958 ; \mathrm{R}^{2} \mathrm{a}:, 99159$} \\
\cline { 2 - 6 } & 3 fatores, 1 Bloco, 19 Experimentos; Média Quadrática Residual =,0031995 \\
\hline $\begin{array}{c}\text { Soma de } \\
\text { Quadrados }\end{array}$ & $\begin{array}{c}\text { Graus de } \\
\text { liberdade }\end{array}$ & $\begin{array}{c}\text { Quadrados } \\
\text { médios }\end{array}$ & Teste F & $\mathrm{P}$ \\
\hline $\mathrm{u}(\mathrm{P})[\mathrm{kPa}](\mathrm{Q})$ & 0,000000 & 1 & 0,000000 & 0,000 & 0,999872 \\
\hline$(2) \mathrm{u}(\mathrm{DP})[\mathrm{kPa}](\mathrm{L})$ & 0,308934 & 1 & 6,308934 & 1971,846 & 0,000000 \\
\hline $\mathrm{u}(\mathrm{DP})[\mathrm{kPa}](\mathrm{Q})$ & 1,000000 & 1 & 0,000000 & 0,000 & 0,999737 \\
\hline$(3) \mathrm{u}(\mathrm{T})\left[{ }^{\circ} \mathrm{C}\right](\mathrm{L})$ & 0,000000 & 1 & 0,000000 & 0,000 & 0,999667 \\
\hline $\mathrm{u}(\mathrm{T})\left[{ }^{\circ} \mathrm{C}\right](\mathrm{Q})$ & 0,036780 & 1 & 0,036780 & 11,496 & 0,007993 \\
\hline $1 \mathrm{~L} \times 2 \mathrm{~L}$ & 0,000000 & 1 & 0,000000 & 0,000 & 0,9999999 \\
\hline $1 \mathrm{~L} \times 3 \mathrm{~L}$ & 0,000000 & 1 & 0,000000 & 0,000 & 0,999999 \\
\hline $2 \mathrm{~L} \times 3 \mathrm{~L}$ & 0,000000 & 1 & 0,000000 & 0,000 & 0,999996 \\
\hline Erro & 0,028796 & 9 & 0,003200 & & \\
\hline Total SQ & 6,849751 & 18 & & & \\
\hline
\end{tabular}

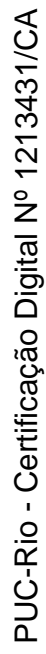

Gráfico de Pareto dos Efeitos; Variável: Y[\%] - EMED E1

3 fatores, 1 Bloco, 19 Experimentos; Média Quadrática Residual =,0031995

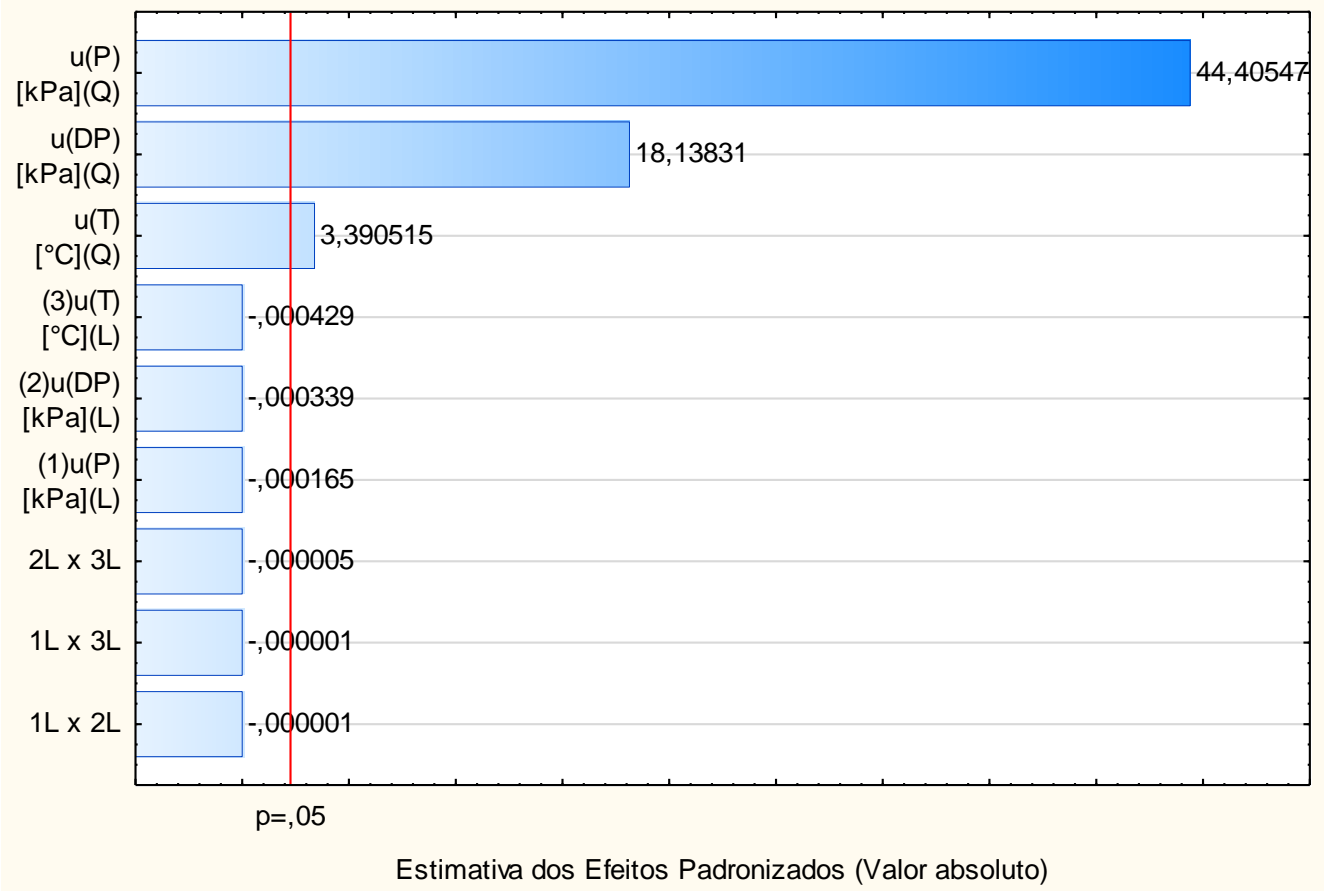

Figura A.25 - Gráfico de Pareto em função dos valores da estatística de teste $\mathrm{t}$ 
Valores Previstos vs. Valores Residuais- EMED E1

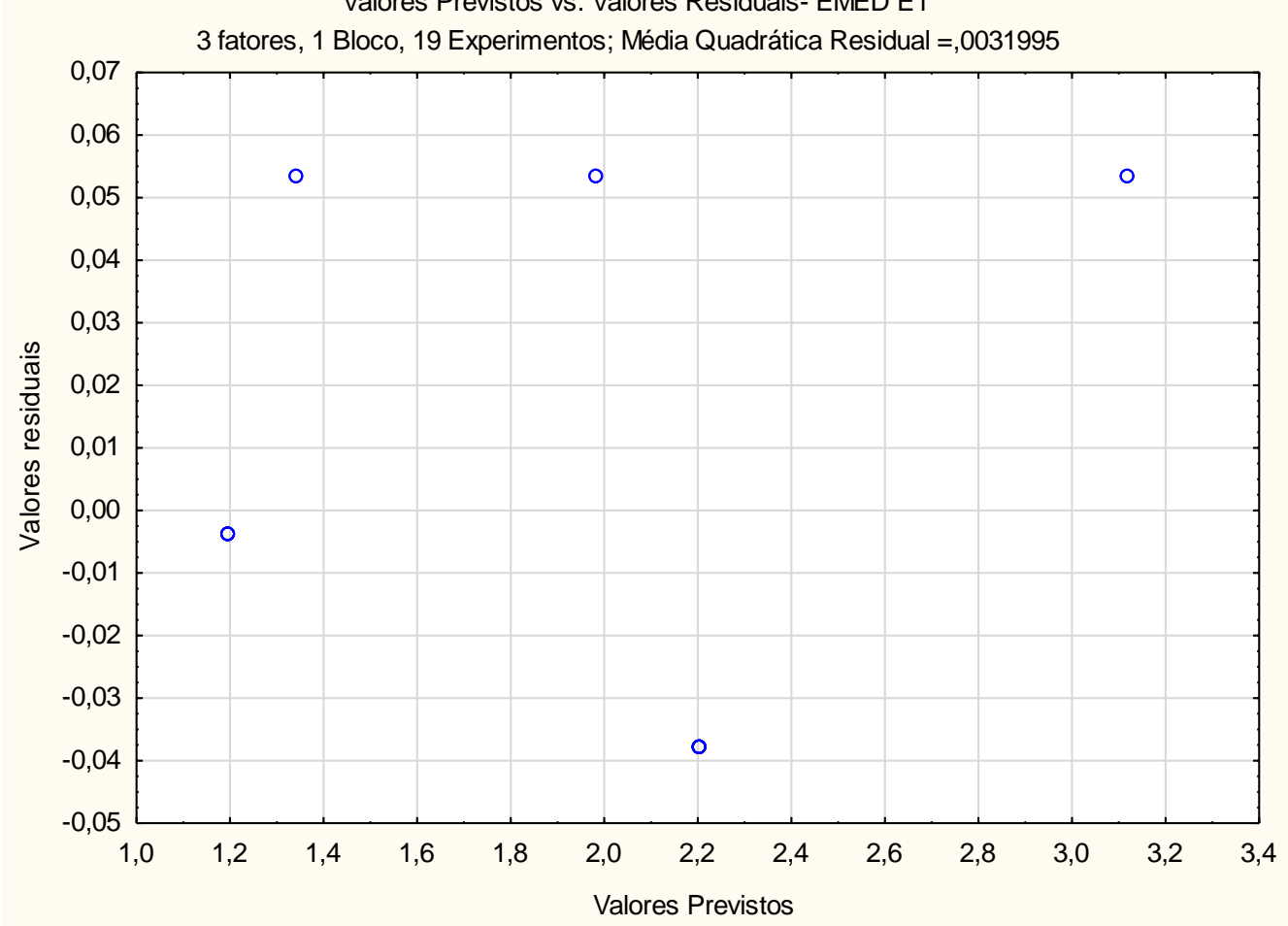

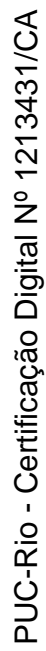

Figura A.26 - Resíduos versus estimativas de y (EMED E1 - nível: $1 \%$ f.e. e $1{ }^{\circ} \mathrm{C}$ )

Tabela A.12 - Matriz das incertezas estimadas da vazão (EMED E1)

(dado $x_{3}(T)$ igual a 1 e $x_{1}$ e $x_{2}$ variando do nível baixo ao nível alto)

\begin{tabular}{|c|c|c|c|c|c|c|c|c|c|c|c|c|}
\hline & \multicolumn{11}{|c|}{$\mathbf{x}_{1}$} \\
\hline & & -1 & $-0,8$ & $-0,6$ & $-0,4$ & $-0,2$ & 0 & 0,2 & 0,4 & 0,6 & 0,8 & 1 \\
\hline \multirow{11}{*}{$\mathbf{x}_{2}$} & -1 & 2,20 & 1,96 & 1,77 & 1,63 & 1,55 & 1,52 & 1,55 & 1,63 & 1,77 & 1,96 & 2,20 \\
\hline & $-0,8$ & 2,10 & 1,86 & 1,67 & 1,53 & 1,45 & 1,42 & 1,45 & 1,53 & 1,67 & 1,86 & 2,10 \\
\hline & $-0,6$ & 2,03 & 1,78 & 1,59 & 1,45 & 1,37 & 1,35 & 1,37 & $\mathbf{1 , 4 5}$ & 1,59 & 1,78 & 2,03 \\
\hline & $-0,4$ & 1,97 & 1,73 & 1,54 & 1,40 & 1,32 & 1,29 & 1,32 & 1,40 & 1,54 & 1,73 & 1,97 \\
\hline & $-0,2$ & 1,94 & 1,69 & 1,50 & 1,37 & 1,28 & 1,26 & 1,28 & 1,37 & 1,50 & 1,69 & 1,94 \\
\hline & 0 & 1,93 & 1,68 & 1,49 & 1,35 & 1,27 & 1,25 & 1,27 & 1,35 & 1,49 & 1,68 & 1,93 \\
\hline & 0,2 & 1,94 & 1,69 & 1,50 & 1,37 & 1,28 & 1,26 & 1,28 & 1,37 & 1,50 & 1,69 & 1,94 \\
\hline & 0,4 & 1,97 & 1,73 & 1,54 & 1,40 & 1,32 & 1,29 & 1,32 & 1,40 & 1,54 & 1,73 & 1,97 \\
\hline & 0,6 & 2,03 & 1,78 & 1,59 & 1,45 & 1,37 & 1,35 & 1,37 & 1,45 & 1,59 & 1,78 & 2,03 \\
\hline & 0,8 & 2,10 & 1,86 & 1,67 & 1,53 & 1,45 & 1,42 & 1,45 & 1,53 & 1,67 & 1,86 & 2,10 \\
\hline & 1 & 2,20 & 1,96 & 1,77 & 1,63 & 1,55 & 1,52 & 1,55 & 1,63 & 1,77 & 1,96 & 2,20 \\
\hline
\end{tabular}


Superficie de Resposta; Variável: Y [\%] = uP x uDP - EMED E1

3 fatores, 1 Bloco, 19 Experimentos; Média Quadrática Residual $=, 0031995$

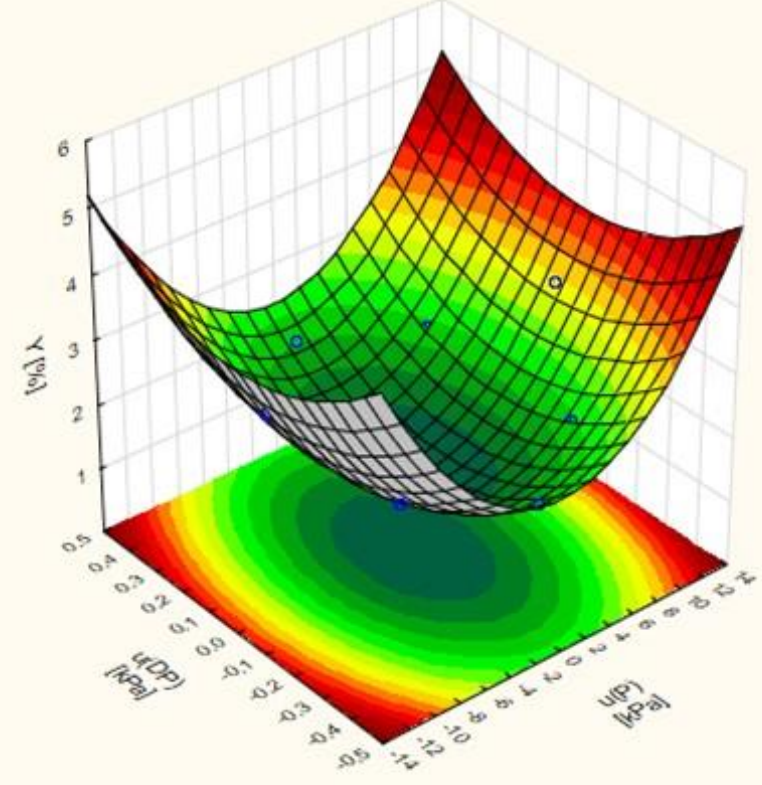

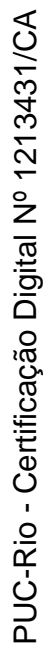

Figura A.27 - Superfície de resposta (EMED E1) dado uP e uDP (1\% f.e.)

Curva de nível; Variável: Y [\%] = uP x uDP - EMED E1

3 fatores, 1 Bloco, 19 Experimentos; Média Quadrática Residual =,0031995

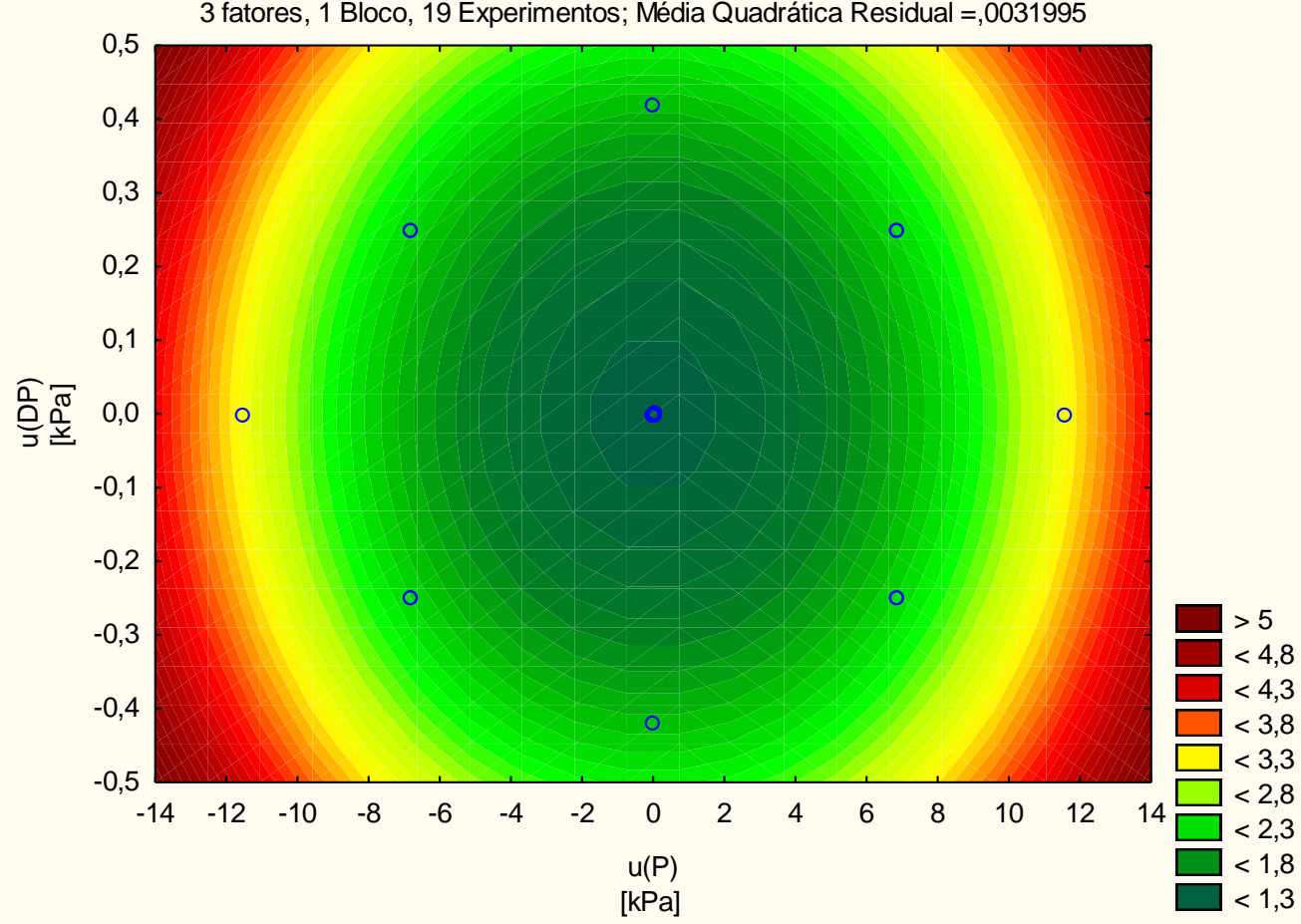

Figura A.28 - Curva de nível (EMED E1) dado uP e uDP (1 \% f.e.) 
Superficie de Resposta; Variável: Y [\%] = uP X UT - EMED E1

3 fatores, 1 Bloco, 19 Experimentos; Média Quadrática Residual $=, 0031995$

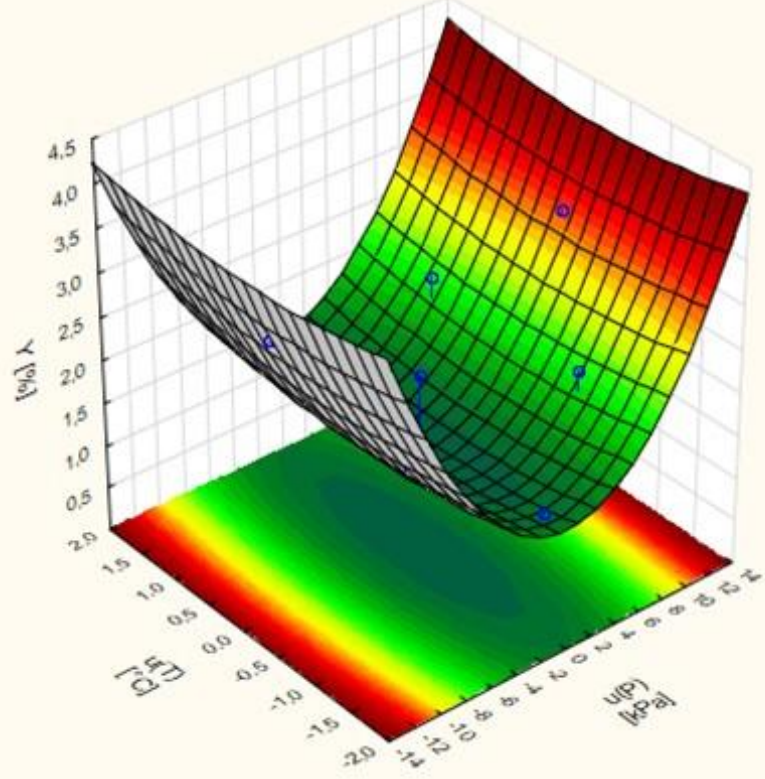

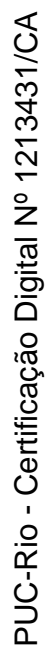

Figura A.29 - Superfície de resposta (EMED E1) dado uP ( $1 \%$ f.e.) e uT $\left( \pm 1{ }^{\circ} \mathrm{C}\right)$

Curva de nível; Variável: $\mathrm{Y}[\%]=$ uP $\times$ uT - EMED E1

3 fatores, 1 Bloco, 19 Experimentos; Média Quadrática Residual =,0031995

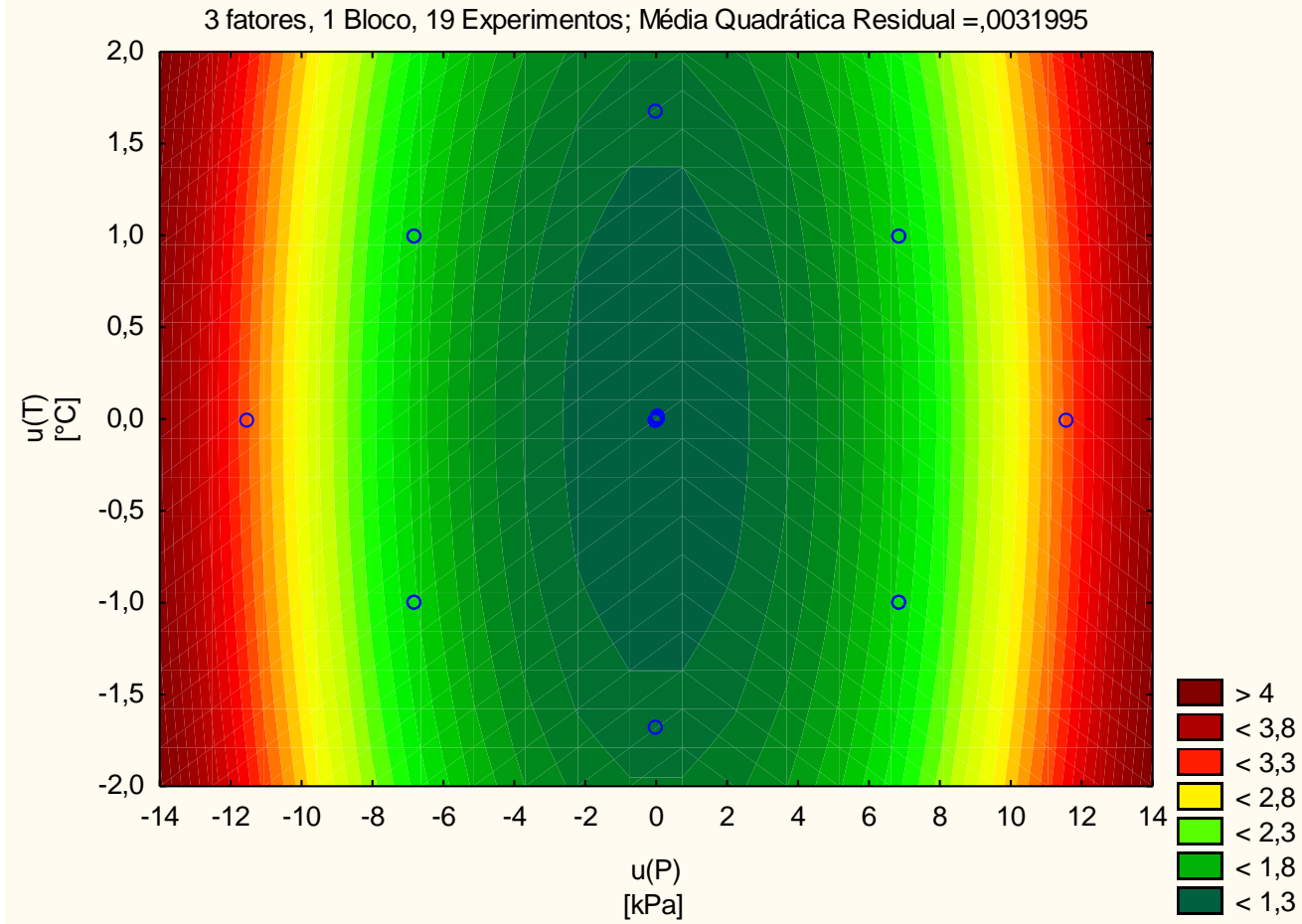

Figura A.30 - Curva de nível (EMED E1) dado uP (1\% f.e.) e uT $\left( \pm 1{ }^{\circ} \mathrm{C}\right)$ 
Superficie de Resposta; Variável: Y [\%] = UT x UDP - EMED E1

3 fatores, 1 Bloco, 19 Experimentos; Média Quadrática Residual $=, 0031995$
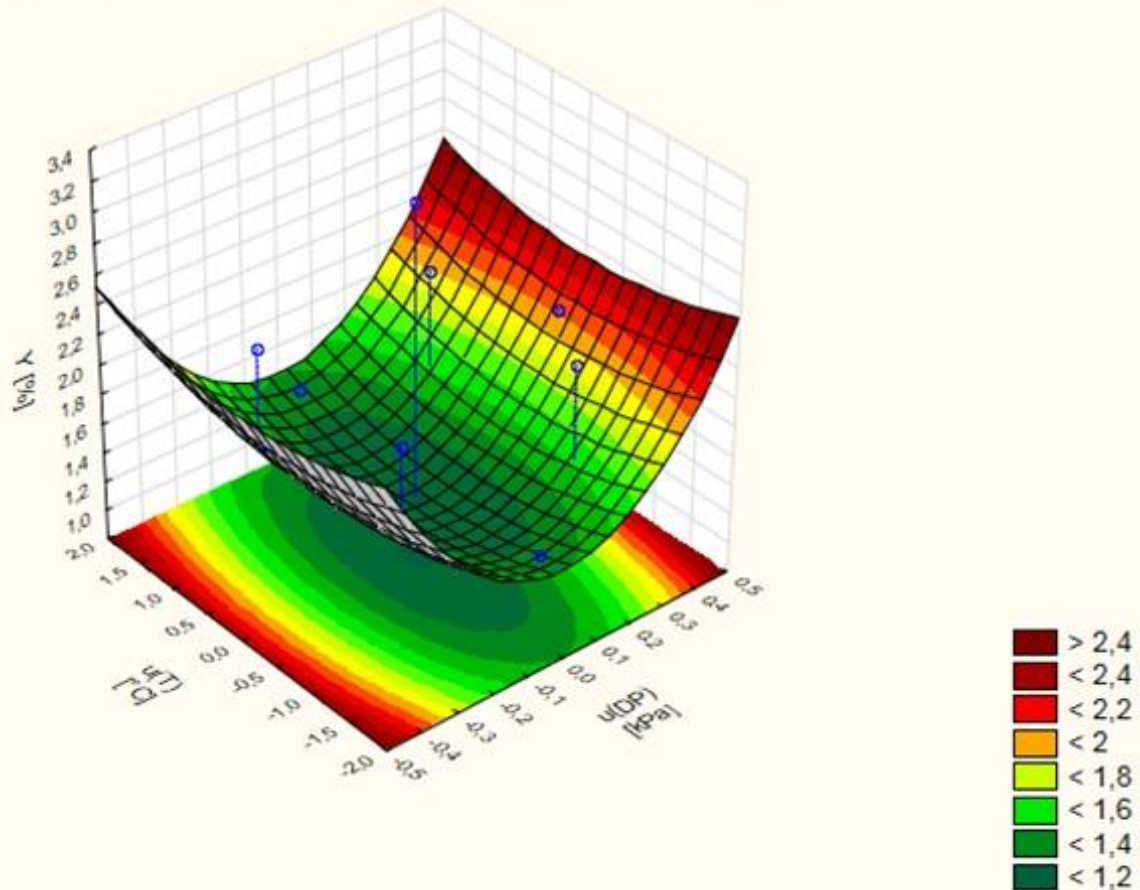

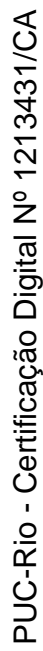

Figura A.31 - Superfície de resposta (EMED E1) dado uDP $(1 \%$ f.e. $)$ e uT $\left( \pm 1{ }^{\circ} \mathrm{C}\right)$

Curva de nível; Variável: Y [\%] = UT x uDP - EMED E1

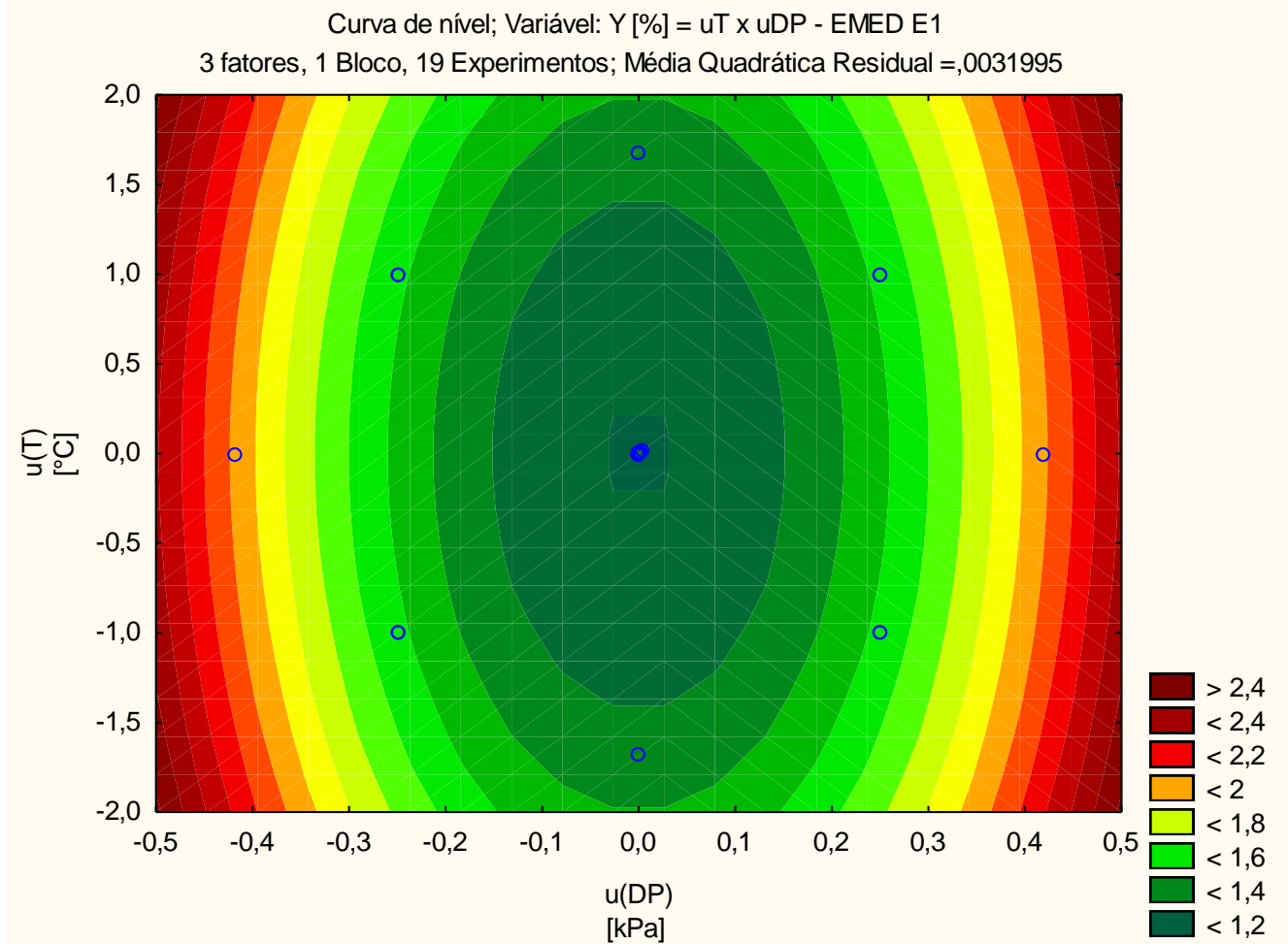

Figura A.32 - Curva de nível (EMED E1) dado uDP (1\% f.e.) e uT $\left( \pm 1^{\circ} \mathrm{C}\right)$ 


\section{A.5}

\section{Estação E2 - estação de medição para apropriação}

Tabela A.13 - Matriz de planejamento experimental da EMED E2

\begin{tabular}{|c|c|c|c|c|c|c|c|}
\hline \multicolumn{7}{|c|}{ Matriz do planejamento } & $\begin{array}{c}\text { Incerteza da } \\
\text { vazão }\end{array}$ \\
\hline Exp & $\mathrm{x} 1$ & $\mathrm{x} 2$ & $\mathrm{x} 3$ & $\begin{array}{c}\mathrm{P} \\
{[\mathrm{kPa}]}\end{array}$ & $\mathrm{DP}[\mathrm{kPa}]$ & $\begin{array}{c}\mathrm{T} \\
{\left[{ }^{\circ} \mathrm{C}\right]}\end{array}$ & $\mathrm{y}(\%)$ \\
\hline 1 & -1 & -1 & -1 & $-6,86$ & $-0,4982$ & -1 & 14,47 \\
2 & 1 & -1 & -1 & 6,86 & $-0,4982$ & -1 & 14,47 \\
3 & -1 & 1 & -1 & $-6,86$ & 0,4982 & -1 & 14,47 \\
4 & 1 & 1 & -1 & 6,86 & 0,4982 & -1 & 14,47 \\
5 & -1 & -1 & 1 & $-6,86$ & $-0,4982$ & 1 & 14,47 \\
6 & 1 & -1 & 1 & 6,86 & $-0,4982$ & 1 & 14,47 \\
7 & -1 & 1 & 1 & $-6,86$ & 0,4982 & 1 & 14,47 \\
8 & 1 & 1 & 1 & 6,86 & 0,4982 & 1 & 14,47 \\
9 & $-1,682$ & 0 & 0 & $-11,5385$ & 0 & 0 & 3,17 \\
10 & 1,682 & 0 & 0 & 11,5385 & 0 & 0 & 3,17 \\
11 & 0 & $-1,682$ & 0 & 0 & $-0,838$ & 0 & 24,19 \\
12 & 0 & 1,682 & 0 & 0 & 0,838 & 0 & 24,19 \\
13 & 0 & 0 & $-1,682$ & 0 & 0 & $-1,682$ & 1,39 \\
14 & 0 & 0 & 1,682 & 0 & 0 & 1,682 & 1,39 \\
15 & 0 & 0 & 0 & 0 & 0 & 0 & 1,19 \\
16 & 0 & 0 & 0 & 0,0163 & 0,0029 & 0,0148 & 1,19 \\
17 & 0 & 0 & 0 & 0,0146 & 0,0001 & 0,0027 & 1,19 \\
18 & 0 & 0 & 0 & 0,0192 & 0,0032 & 0,0043 & 1,19 \\
19 & 0 & 0 & 0 & 0,0142 & 0,0006 & 0,0025 & 1,19 \\
\hline
\end{tabular}

Tabela A.14 - Tabela de ANOVA do planejamento de experimentos da EMED E2

\begin{tabular}{|c|c|c|c|c|c|}
\hline \multirow[b]{2}{*}{ Fonte de variação } & \multicolumn{5}{|c|}{$\begin{array}{c}\text { ANOVA; Var.:Y [\%]; } \mathrm{R}^{2}=, 94899 ; \mathrm{R}_{\mathrm{a}}^{2}:, 89797 \\
3 \text { fatores, 1 Bloco, } 19 \text { Experimentos; Média Quadrática Residual =3,647921 }\end{array}$} \\
\hline & $\begin{array}{c}\text { Soma de } \\
\text { Quadrados }\end{array}$ & $\begin{array}{l}\text { Graus de } \\
\text { liberdade }\end{array}$ & Quadrados médios & Teste F & $\mathrm{p}$ \\
\hline$(1) \mathrm{u}(\mathrm{P})[\mathrm{kPa}](\mathrm{L})$ & 0,0000 & 1 & 0,0000 & 0,0000 & 0,999830 \\
\hline $\mathrm{u}(\mathrm{P})[\mathrm{kPa}](\mathrm{Q})$ & 17,5184 & 1 & 17,5184 & 4,8023 & 0,056121 \\
\hline$(2) \mathrm{u}(\mathrm{DP})[\mathrm{kPa}](\mathrm{L})$ & 0,0000 & 1 & 0,0000 & 0,0000 & 0,999753 \\
\hline $\mathrm{u}(\mathrm{DP})[\mathrm{kPa}](\mathrm{Q})$ & 609,3326 & 1 & 609,3326 & 167,0356 & 0,000000 \\
\hline$(3) \mathrm{u}(\mathrm{T})\left[{ }^{\circ} \mathrm{C}\right](\mathrm{L})$ & 0,0000 & 1 & 0,0000 & 0,0000 & 0,999560 \\
\hline $\mathrm{u}(\mathrm{T})\left[{ }^{\circ} \mathrm{C}\right](\mathrm{Q})$ & 7,1316 & 1 & 7,1316 & 1,9550 & 0,195549 \\
\hline $1 \mathrm{~L} \times 2 \mathrm{~L}$ & 0,0000 & 1 & 0,0000 & 0,0000 & 0,999999 \\
\hline $1 \mathrm{~L} \times 3 \mathrm{~L}$ & 0,0000 & 1 & 0,0000 & 0,0000 & 0,999998 \\
\hline $2 \mathrm{~L} \times 3 \mathrm{~L}$ & 0,0000 & 1 & 0,0000 & 0,0000 & 0,999996 \\
\hline Erro & 32,8313 & 9 & 3,6479 & & \\
\hline Total SQ & 643,5867 & 18 & & & \\
\hline
\end{tabular}


Gráfico de Pareto dos Efeitos; Variável: Y[\%] - EMED E2

3 fatores, 1 Bloco, 19 Experimentos; Média Quadrática Residual $=3,647921$

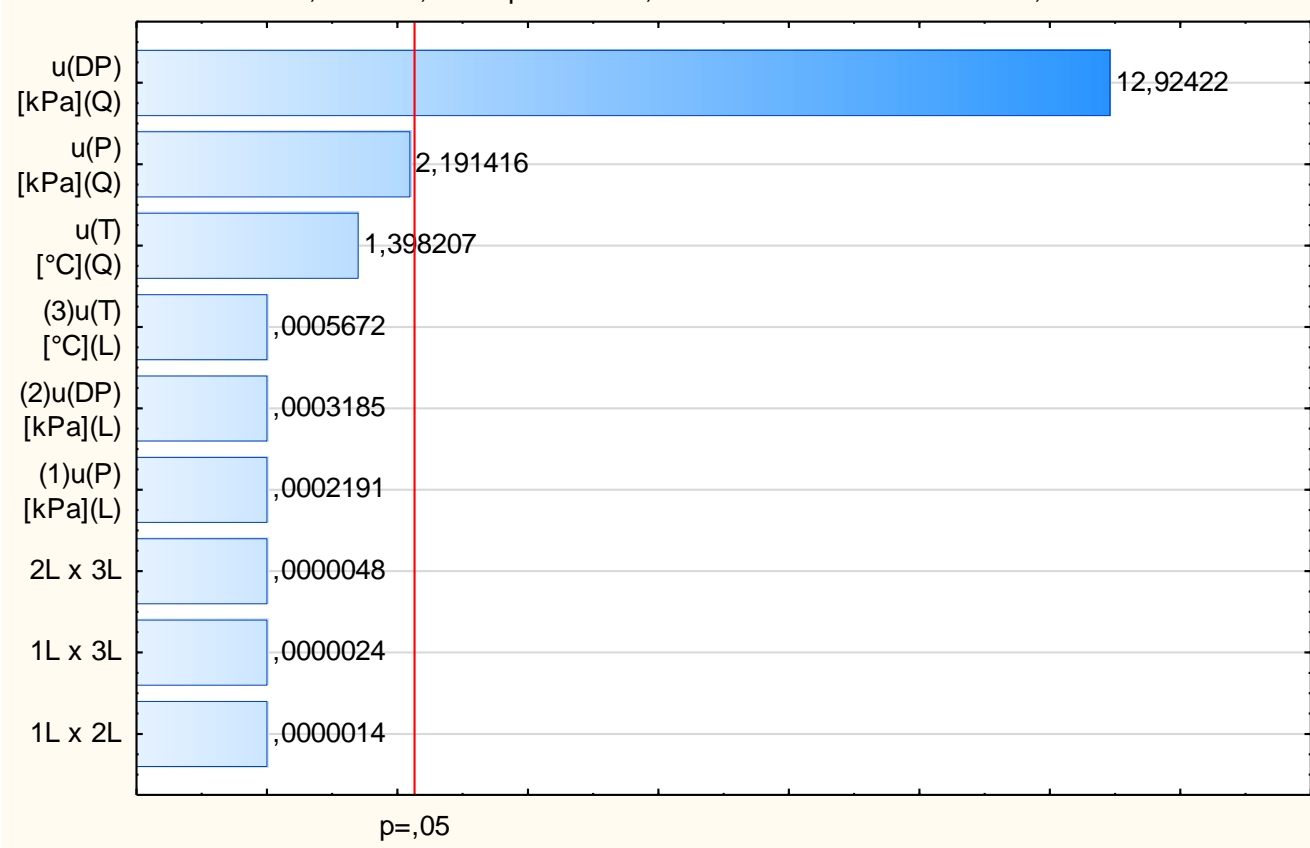

Estimativa dos Efeitos Padronizados (Valor absoluto)

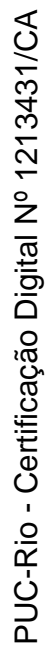

Figura A.33 - Gráfico de Pareto em função dos valores da estatística de teste t

Valores Previstos vs. Valores Residuais- EMED E2

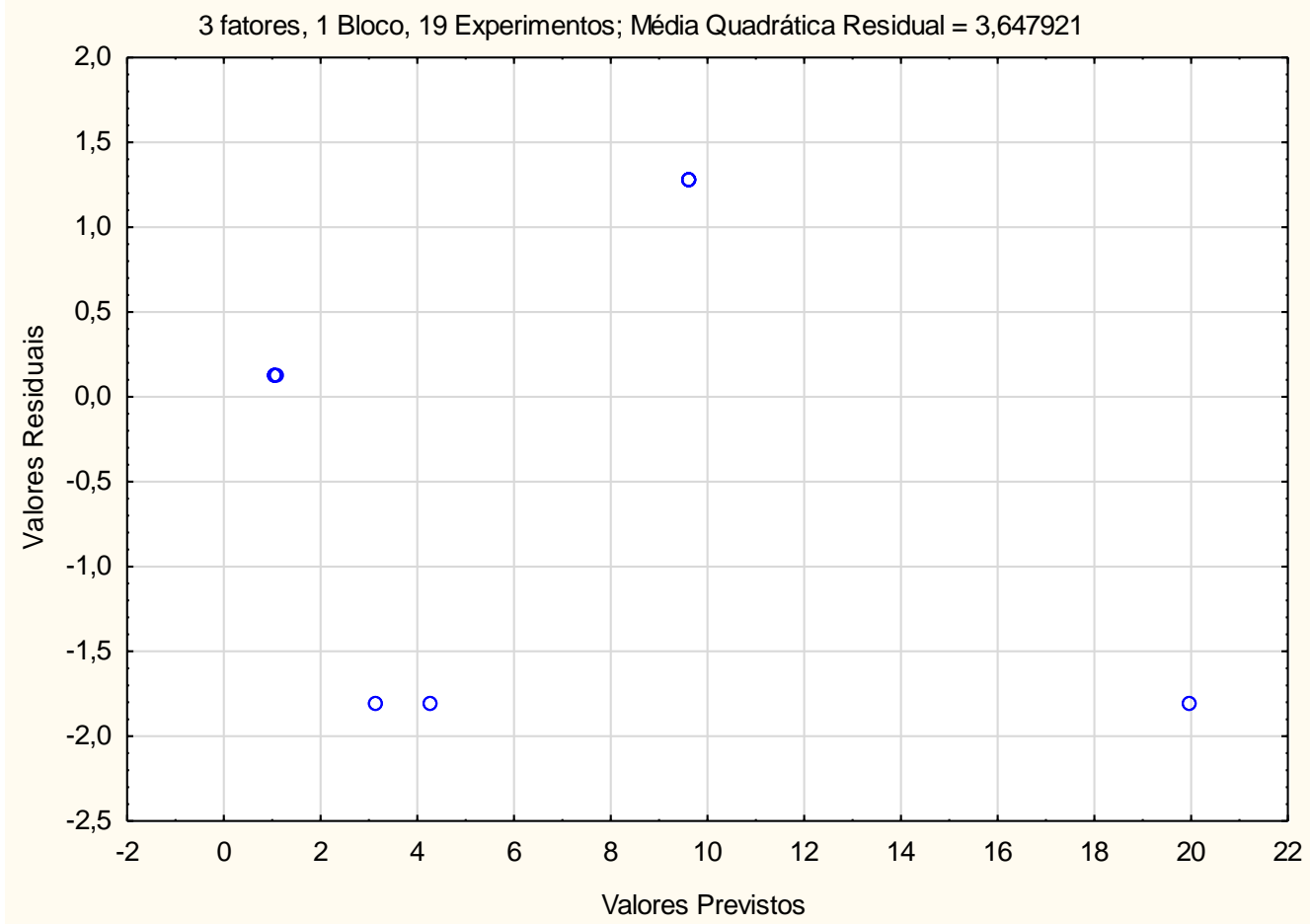

Figura A.34 - Resíduos versus estimativas de y (EMED E2 - nível: 0,75\% f.e. e $1^{\circ} \mathrm{C}$ ) 
Tabela A.15 - Matriz das incertezas estimadas da vazão (EMED E2)

(dado $x_{3}(T)$ igual a 1 e $x_{1}$ e $x_{2}$ variando em $\pm 0,75 \%$ f.e.)

\begin{tabular}{c|c|c|c|c|c|c|c|c|c|c|c|c|}
\multicolumn{1}{c|}{} & \multicolumn{10}{c|}{$\mathbf{x}_{\mathbf{1}}$} \\
\cline { 2 - 14 } & -1 & $-0,8$ & $-0,6$ & $-0,4$ & $-0,2$ & 0 & 0,2 & 0,4 & 0,6 & 0,8 & 1 \\
\hline-1 & 9,60 & 9,19 & 8,88 & 8,65 & 8,51 & 8,47 & 8,51 & 8,65 & 8,88 & 9,19 & 9,60 \\
\hline$-0,8$ & 7,20 & 6,79 & 6,47 & 6,25 & 6,11 & 6,06 & 6,11 & 6,25 & 6,47 & 6,79 & 7,20 \\
\hline$-0,6$ & 5,33 & 4,92 & 4,60 & 4,38 & 4,24 & 4,19 & 4,24 & 4,38 & 4,60 & 4,92 & 5,33 \\
\hline$-0,4$ & 3,99 & 3,58 & 3,27 & 3,04 & 2,90 & 2,86 & 2,90 & 3,04 & 3,27 & 3,58 & 3,99 \\
\hline$-0,2$ & 3,19 & 2,78 & 2,46 & 2,24 & 2,10 & 2,06 & 2,10 & 2,24 & 2,46 & 2,78 & 3,19 \\
\hline 0 & 2,92 & 2,51 & 2,20 & 1,97 & 1,83 & 1,79 & 1,83 & 1,97 & 2,20 & 2,51 & 2,92 \\
\hline 0,2 & 3,19 & 2,78 & 2,46 & 2,24 & 2,10 & 2,06 & 2,10 & 2,24 & 2,46 & 2,78 & 3,19 \\
\hline 0,4 & 3,99 & 3,58 & 3,27 & 3,04 & 2,90 & 2,86 & 2,90 & 3,04 & 3,27 & 3,58 & 3,99 \\
\hline 0,6 & 5,33 & 4,92 & 4,60 & 4,38 & 4,24 & 4,19 & 4,24 & 4,38 & 4,60 & 4,92 & 5,33 \\
\hline 0,8 & 7,20 & 6,79 & 6,47 & 6,25 & 6,11 & 6,06 & 6,11 & 6,25 & 6,47 & 6,79 & 7,20 \\
\hline 1 & 9,60 & 9,19 & 8,88 & 8,65 & 8,51 & 8,47 & 8,51 & 8,65 & 8,88 & 9,19 & 9,60 \\
\hline
\end{tabular}

Superficie de Resposta; Variável: $Y$ [\%] = UP x uDP - EMED E2

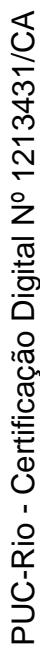
3 fatores, 1 Bloco, 19 Experimentos; Média Quadrática Residual $=3,647921$
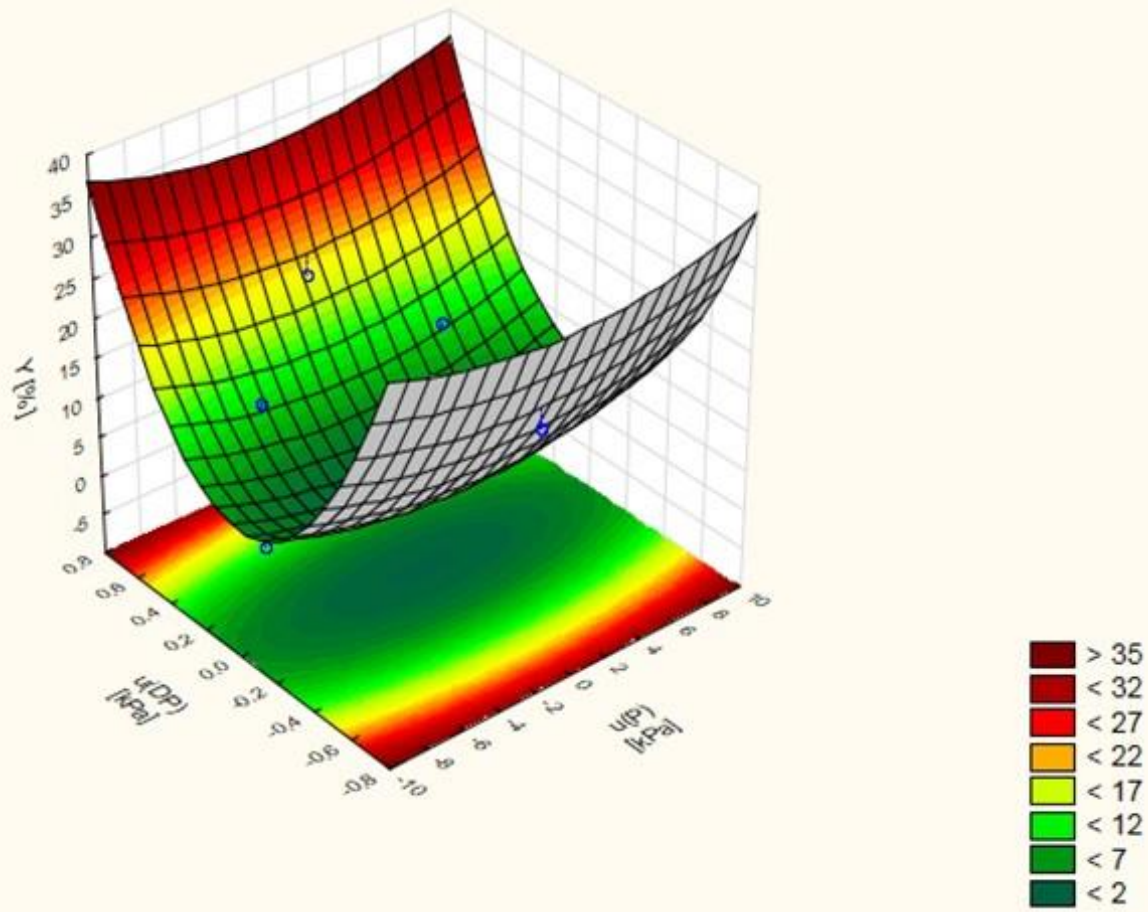

Figura A.35 - Superfície de resposta (EMED E2) dado uP e uDP (0,75 \% f.e.) 
Curva de nível; Variável: Y [\%] = uP x uDP - EMED E2

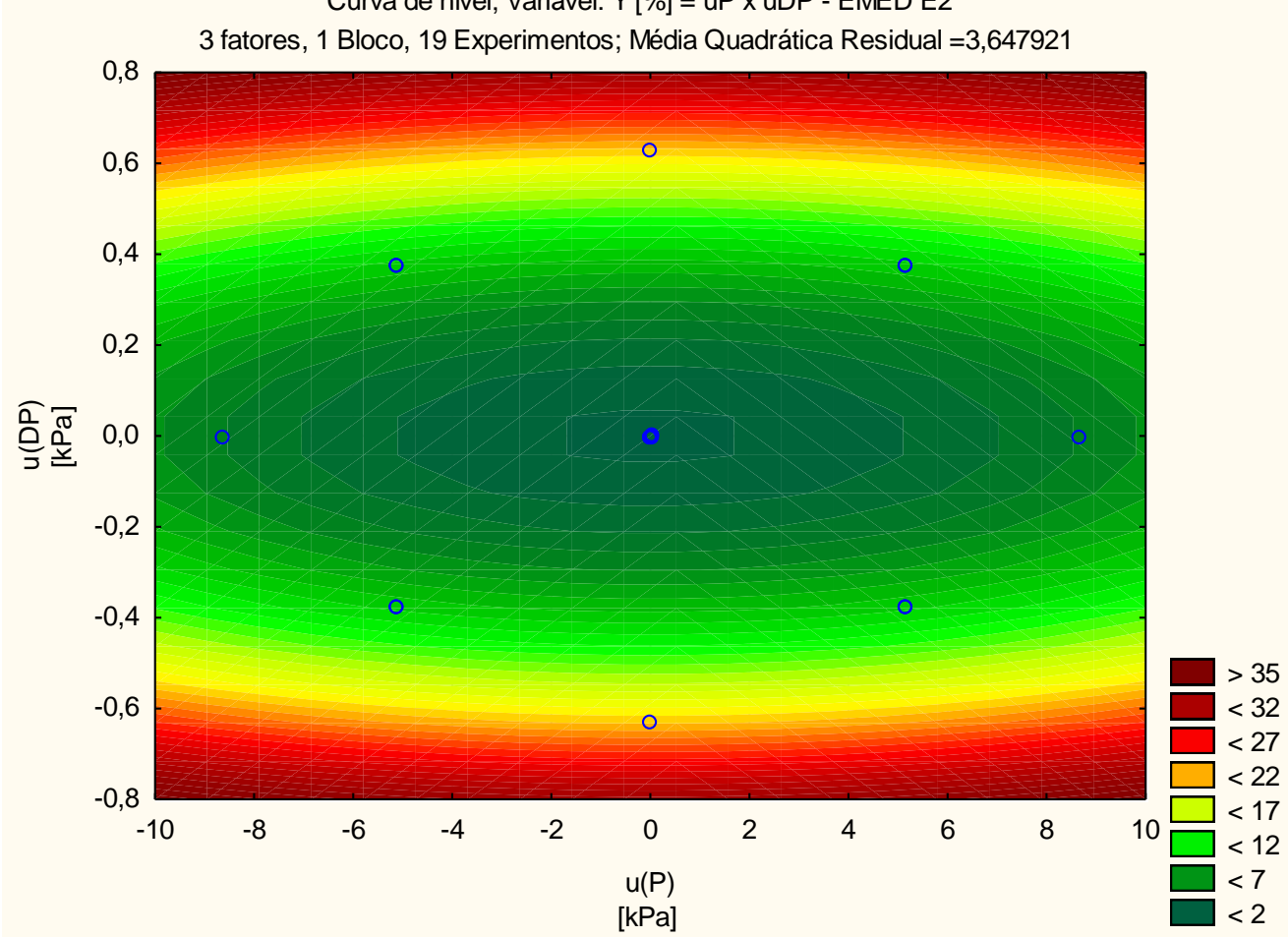

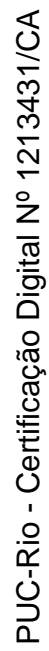

Figura A.36 - Curva de nível (EMED E2) dado uP e uDP (0,75 \% f.e.)

Superficie de Resposta; Variável: Y [\%] = uP x UT - EMED E2

3 fatores, 1 Bloco, 19 Experimentos; Média Quadrática Residual $=3,647921$

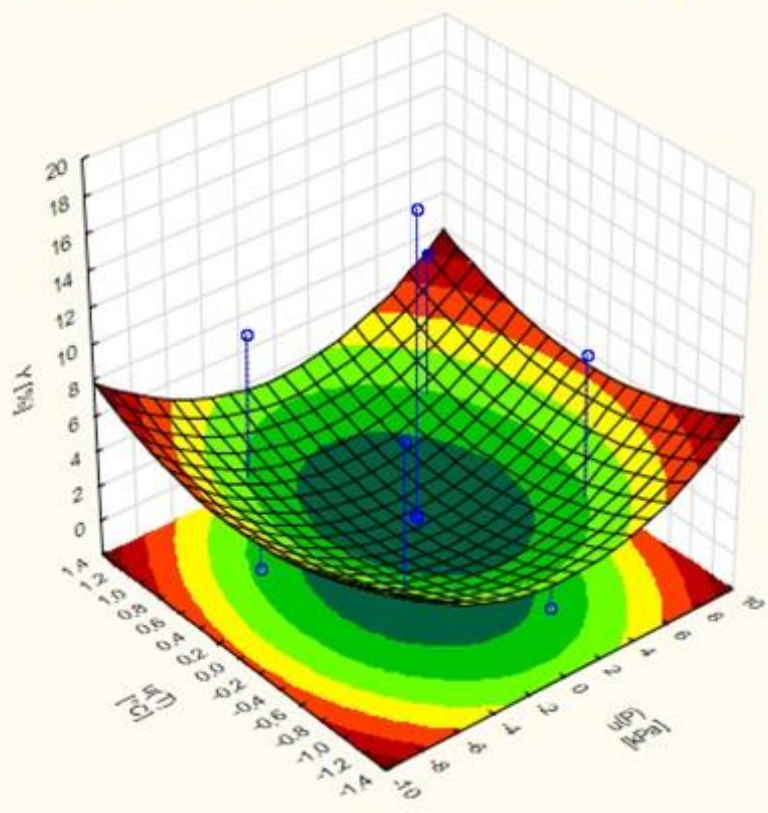

Figura A.37 - Superfície de resposta (EMED E2) dado uP $\left(0,75 \%\right.$ f.e.) e uT $\left( \pm 1^{\circ} \mathrm{C}\right)$ 
Curva de nível; Variável: Y [\%] = uP x UT - EMED E2

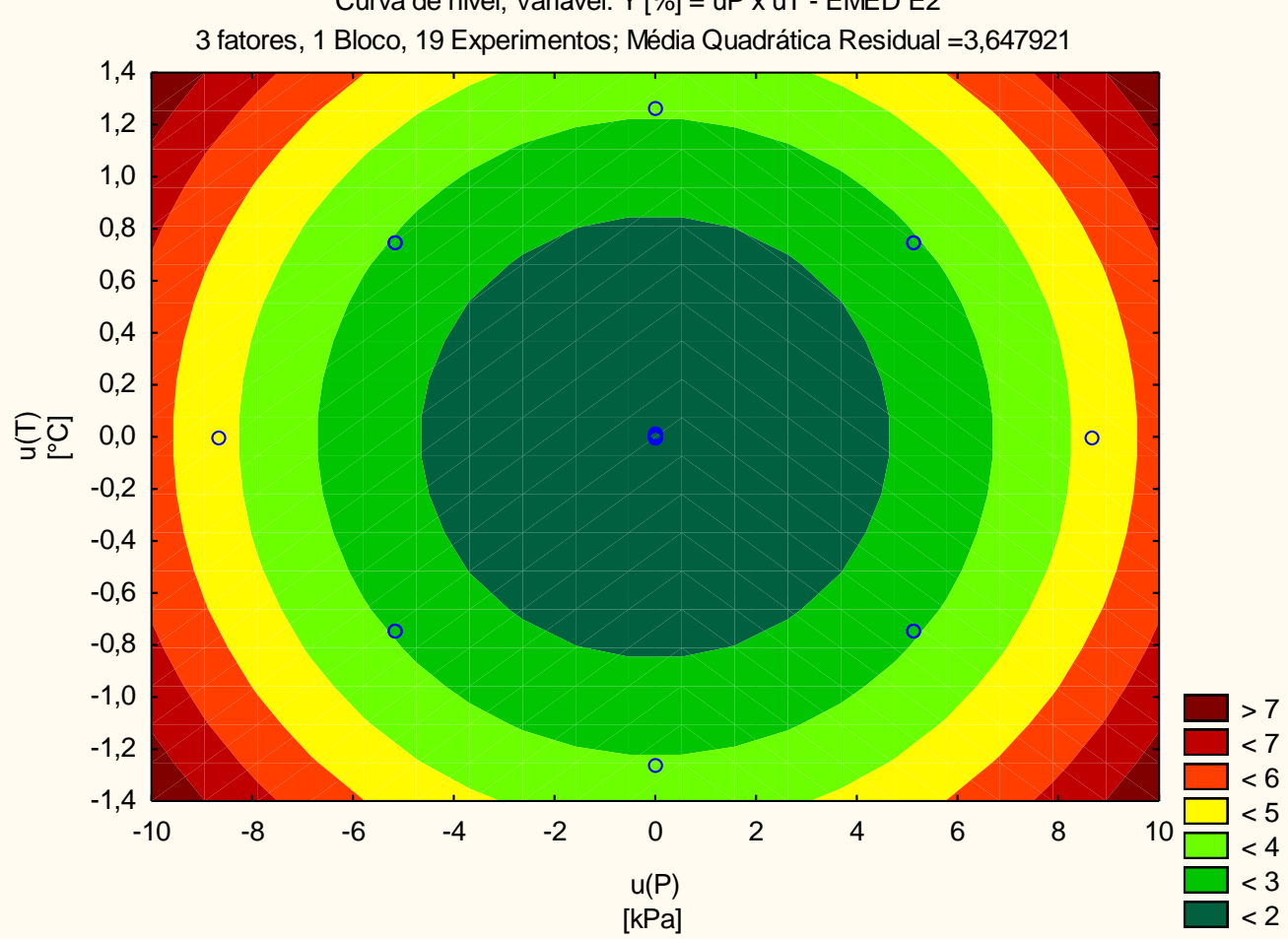

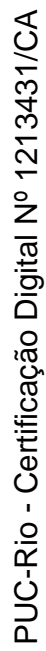

Figura A.38 - Curva de nível (EMED E2) dado uP $\left(0,75 \%\right.$ f.e.) e uT $\left( \pm 1^{\circ} \mathrm{C}\right)$

Superficie de Resposta; Variável: $Y$ [\%] = UT $x$ uDP - EMED E2

3 fatores, 1 Bloco, 19 Experimentos; Média Quadrática Residual $=3,647921$

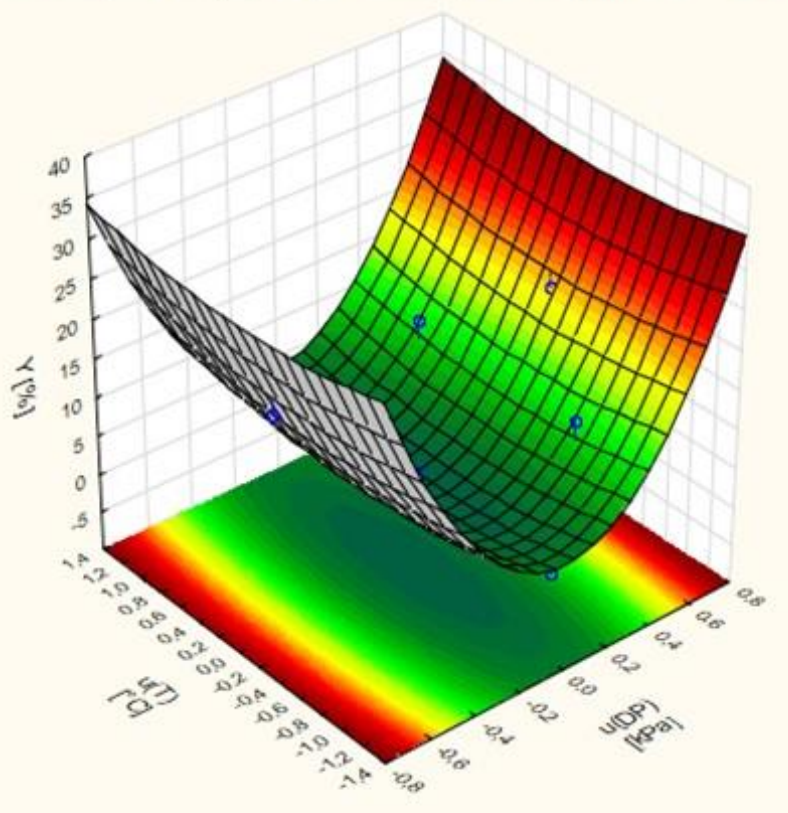

Figura A.39 - Superfície de resposta (EMED E2) dado uDP $(0,75 \%$ f.e. $)$ e uT $\left( \pm 1{ }^{\circ} \mathrm{C}\right)$ 


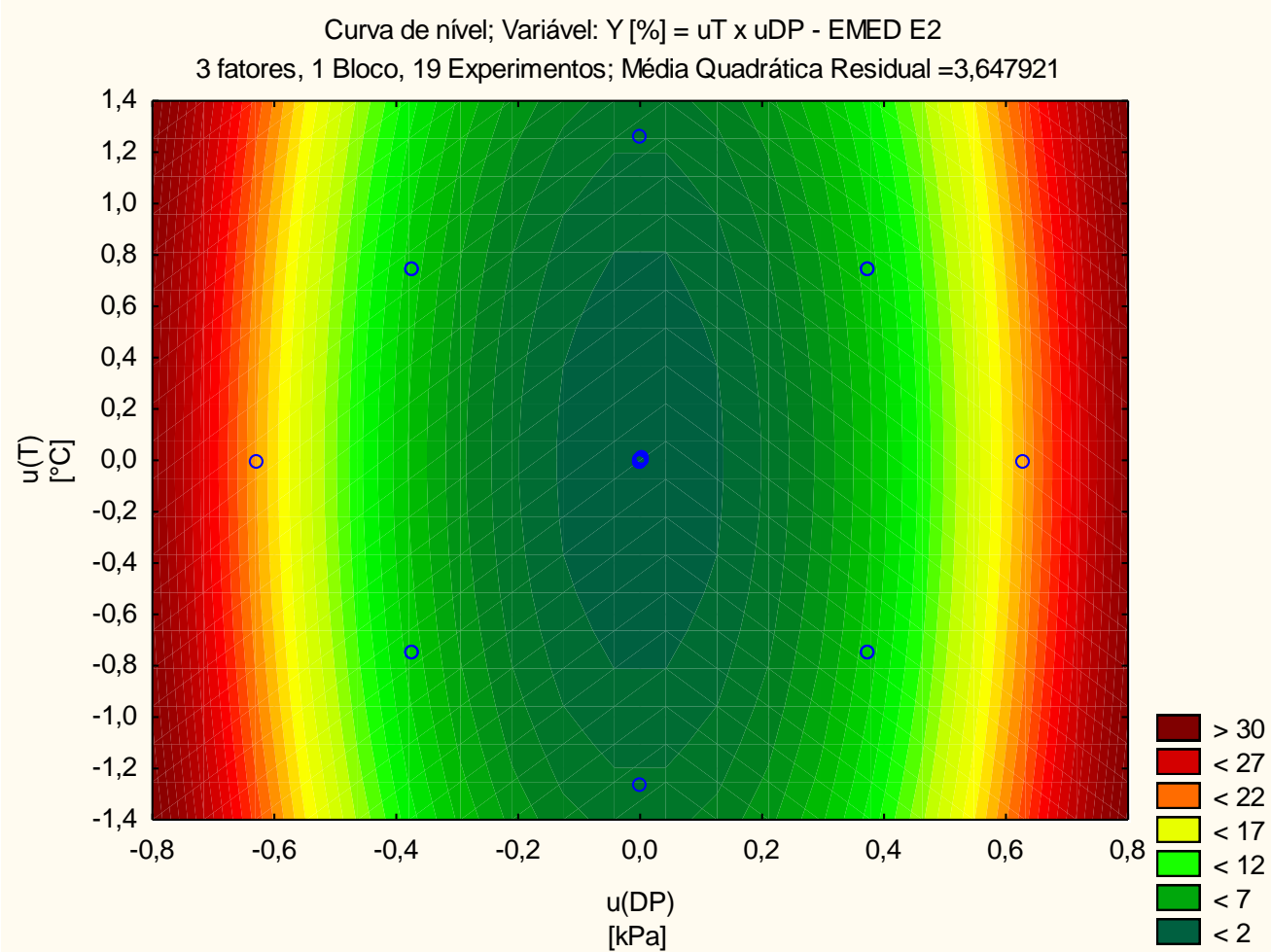

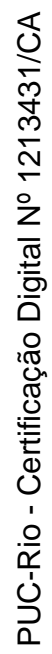

Figura A.40 - Curva de nível (EMED E2) dado uDP $(0,75 \%$ f.e. $)$ e uT $\left( \pm 1^{\circ} \mathrm{C}\right)$

\section{A.6 \\ Estação F1 - estação de medição para apropriação}

Tabela A.16 - Matriz de planejamento experimental da EMED F1

\begin{tabular}{|c|c|c|c|c|c|c|c|}
\hline \multicolumn{7}{|c|}{ Matriz do planejamento } & $\begin{array}{c}\text { Incerteza da } \\
\text { vazão }\end{array}$ \\
\hline Exp & $\mathrm{x} 1$ & $\mathrm{x} 2$ & $\mathrm{x} 3$ & $\begin{array}{c}\mathrm{P} \\
{[\mathrm{kPa}]}\end{array}$ & $\mathrm{DP}[\mathrm{kPa}]$ & $\begin{array}{c}\mathrm{T} \\
{\left[{ }^{\circ} \mathrm{C}\right]}\end{array}$ & $\mathrm{y}(\%)$ \\
\hline 1 & -1 & -1 & -1 & $-6,8600$ & $-0,4982$ & $-1,0000$ & 2,17 \\
2 & 1 & -1 & -1 & 6,8600 & $-0,4982$ & $-1,0000$ & 2,17 \\
3 & -1 & 1 & -1 & $-6,8600$ & 0,4982 & $-1,0000$ & 2,17 \\
4 & 1 & 1 & -1 & 6,8600 & 0,4982 & $-1,0000$ & 2,17 \\
5 & -1 & -1 & 1 & $-6,8600$ & $-0,4982$ & 1,0000 & 2,17 \\
6 & 1 & -1 & 1 & 6,8600 & $-0,4982$ & 1,0000 & 2,17 \\
7 & -1 & 1 & 1 & $-6,8600$ & 0,4982 & 1,0000 & 2,17 \\
8 & 1 & 1 & 1 & 6,8600 & 0,4982 & 1,0000 & 2,17 \\
9 & $-1,682$ & 0 & 0 & $-11,5385$ & 0,0000 & 0,0000 & 3,16 \\
10 & 1,682 & 0 & 0 & 11,5385 & 0,0000 & 0,0000 & 3,16 \\
11 & 0 & $-1,682$ & 0 & 0,0000 & $-0,8380$ & 0,0000 & 2,05 \\
12 & 0 & 1,682 & 0 & 0,0000 & 0,8380 & 0,0000 & 2,05 \\
13 & 0 & 0 & $-1,682$ & 0,0000 & 0,0000 & $-1,6820$ & 1,42 \\
14 & 0 & 0 & 1,682 & 0,0000 & 0,0000 & 1,6820 & 1,42 \\
15 & 0 & 0 & 0 & 0,0000 & 0,0000 & 0,0000 & 1,22 \\
16 & 0 & 0 & 0 & 0,0123 & 0,0027 & 0,0102 & 1,22 \\
17 & 0 & 0 & 0 & 0,0229 & 0,0004 & 0,0143 & 1,22 \\
18 & 0 & 0 & 0 & 0,0412 & 0,0010 & 0,0029 & 1,22 \\
19 & 0 & 0 & 0 & 0,0283 & 0,0037 & 0,0095 & 1,22 \\
\hline
\end{tabular}


Tabela A.17 - Tabela de ANOVA do planejamento de experimentos da EMED F1

\begin{tabular}{|c|c|c|c|c|c|}
\hline & \multicolumn{5}{|c|}{ ANOVA; Var.:Y [\%]; $\mathrm{R}^{2}=, 99499 ; \mathrm{R}^{2}{ }_{\mathrm{a}}: 98999$} \\
Fonte de variação & 3 fatores, 1 Bloco, 19 Experimentos; Média Quadrática Residual =,0036339 \\
\cline { 2 - 6 } & $\begin{array}{c}\text { Soma de } \\
\text { Quadrados }\end{array}$ & $\begin{array}{c}\text { Graus de } \\
\text { liberdade }\end{array}$ & $\begin{array}{c}\text { Quadrados } \\
\text { médios }\end{array}$ & Teste F & $\mathrm{p}$ \\
\hline$(1) \mathrm{u}(\mathrm{P})[\mathrm{kPa}](\mathrm{L})$ & 0,000000 & 1 & 0,000000 & 0,000 & 0,999792 \\
\hline $\mathrm{u}(\mathrm{P})[\mathrm{kPa}](\mathrm{Q})$ & 6,002447 & 1 & 6,002447 & 1651,804 & 0,000000 \\
\hline$(2) \mathrm{u}(\mathrm{DP})[\mathrm{kPa}](\mathrm{L})$ & 0,000000 & 1 & 0,000000 & 0,000 & 0,999787 \\
\hline $\mathrm{u}(\mathrm{DP})[\mathrm{kPa}](\mathrm{Q})$ & 1,005860 & 1 & 1,005860 & 276,801 & 0,000000 \\
\hline$(3) \mathrm{u}(\mathrm{T})\left[{ }^{\circ} \mathrm{C}\right](\mathrm{L})$ & 0,000000 & 1 & 0,000000 & 0,000 & 0,999498 \\
\hline $\mathrm{u}(\mathrm{T})\left[{ }^{\circ} \mathrm{C}\right](\mathrm{Q})$ & 0,029863 & 1 & 0,029863 & 8,218 & 0,018576 \\
\hline $1 \mathrm{~L} \times 2 \mathrm{~L}$ & 0,000000 & 1 & 0,000000 & 0,000 & 0,999999 \\
\hline $1 \mathrm{~L} \times 3 \mathrm{~L}$ & 0,000000 & 1 & 0,000000 & 0,000 & 0,999998 \\
\hline $2 \mathrm{~L} \times 3 \mathrm{~L}$ & 0,000000 & 1 & 0,000000 & 0,000 & 0,999997 \\
\hline Erro & 0,032705 & 9 & 0,003634 & & \\
\hline Total SQ & 6,533093 & 18 & & & \\
\hline
\end{tabular}

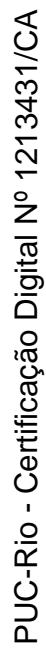

Gráfico de Pareto dos Efeitos; Variável: Y[\%] - EMED F1

3 fatores, 1 Bloco, 19 Experimentos; Média Quadrática Residual =,0036339

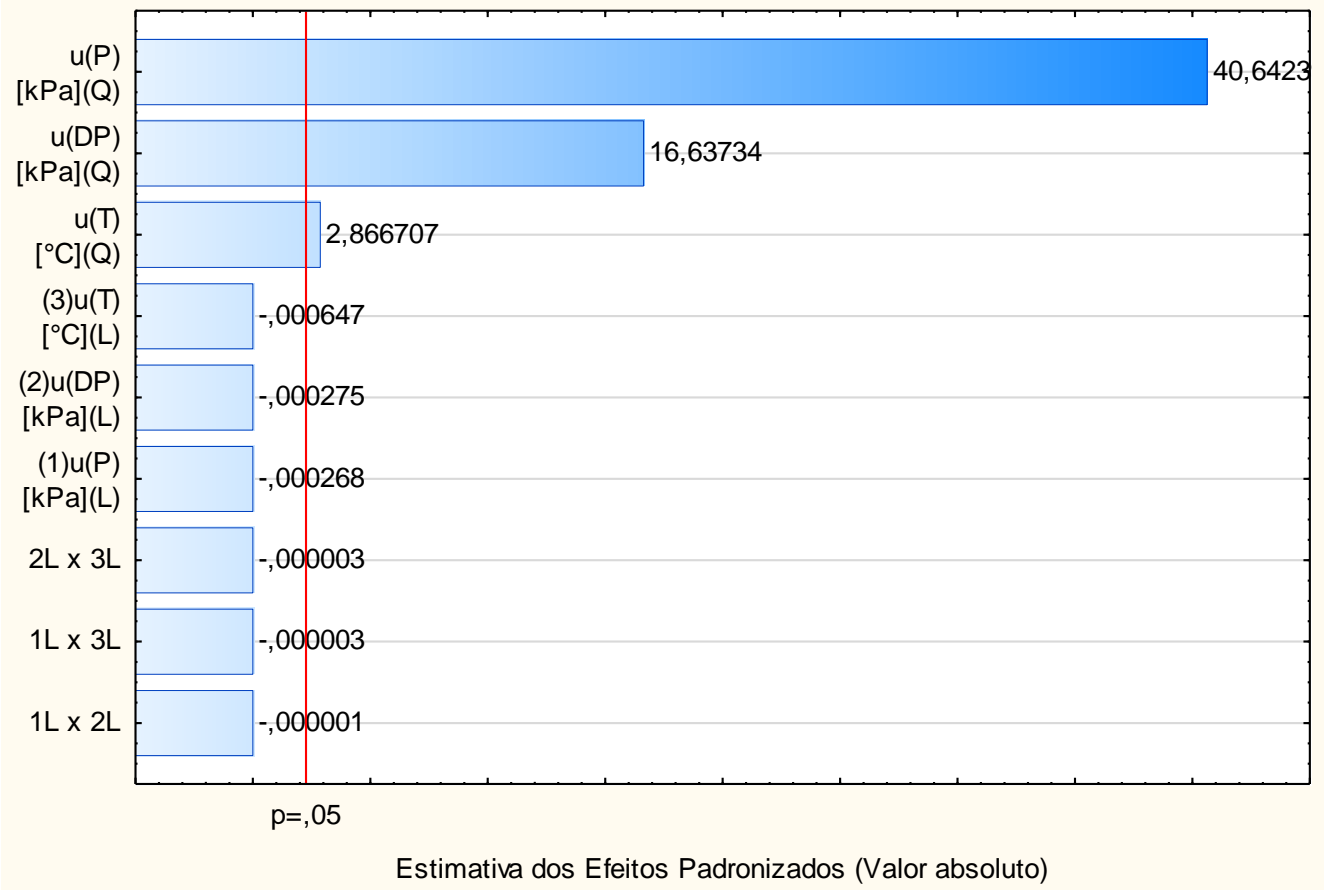

Figura A.41 - Gráfico de Pareto em função dos valores da estatística de teste t 
Valores Previstos vs. Valores Residuais - EMED F1

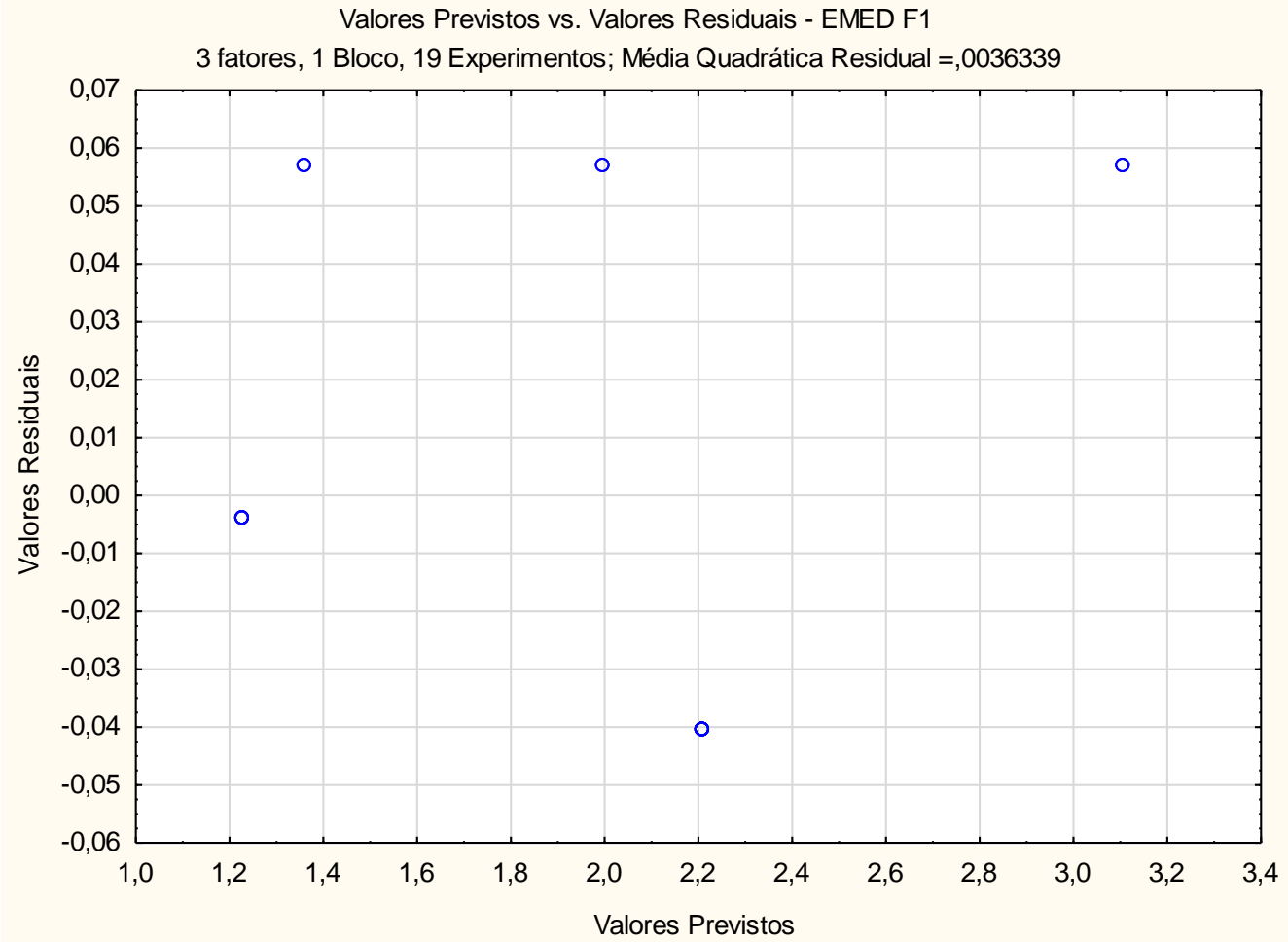

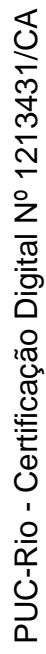

Figura A.42 - Resíduos versus estimativas de y (EMED F1 - nível: 1 \% f.e. e $1^{\circ} \mathrm{C}$ )

Tabela A.18 - Matriz das incertezas estimadas da vazão (EMED F1)

(dado $x_{3}(\mathrm{~T})$ igual a 1 e $x_{1}$ e $x_{2}$ variando do nível baixo ao nível alto)

\begin{tabular}{|c|c|c|c|c|c|c|c|c|c|c|c|}
\multicolumn{1}{c|}{} & -1 & $-0,8$ & $-0,6$ & $-0,4$ & $-0,2$ & 0 & 0,2 & 0,4 & 0,6 & 0,8 & 1 \\
\hline-1 & 2,21 & 1,97 & 1,78 & 1,65 & 1,57 & 1,55 & 1,57 & 1,65 & 1,78 & 1,97 & 2,21 \\
\hline$-0,8$ & 2,11 & 1,87 & 1,69 & 1,55 & 1,47 & 1,45 & 1,47 & 1,55 & 1,69 & 1,87 & 2,11 \\
\hline$-0,6$ & 2,04 & 1,80 & 1,61 & $\mathbf{1 , 4 8}$ & 1,40 & 1,37 & 1,40 & $\mathbf{1 , 4 8}$ & 1,61 & 1,80 & 2,04 \\
\hline$-0,4$ & 1,98 & 1,74 & 1,56 & 1,42 & 1,34 & 1,32 & 1,34 & 1,42 & 1,56 & 1,74 & 1,98 \\
\hline$-0,2$ & 1,95 & 1,71 & 1,52 & 1,39 & 1,31 & 1,29 & 1,31 & 1,39 & 1,52 & 1,71 & 1,95 \\
\hline $\mathbf{2} 2$ & 1,94 & 1,70 & 1,51 & 1,38 & 1,30 & 1,27 & 1,30 & 1,38 & 1,51 & 1,70 & 1,94 \\
\hline 0,2 & 1,95 & 1,71 & 1,52 & 1,39 & 1,31 & 1,29 & 1,31 & 1,39 & 1,52 & 1,71 & 1,95 \\
\hline 0,4 & 1,98 & 1,74 & 1,56 & 1,42 & 1,34 & 1,32 & 1,34 & 1,42 & 1,56 & 1,74 & 1,98 \\
\hline 0,6 & 2,04 & 1,80 & 1,61 & $\mathbf{1 , 4 8}$ & 1,40 & 1,37 & 1,40 & $\mathbf{1 , 4 8}$ & 1,61 & 1,80 & 2,04 \\
\hline 0,8 & 2,11 & 1,87 & 1,69 & 1,55 & 1,47 & 1,45 & 1,47 & 1,55 & 1,69 & 1,87 & 2,11 \\
\hline 1 & 2,21 & 1,97 & 1,78 & 1,65 & 1,57 & 1,55 & 1,57 & 1,65 & 1,78 & 1,97 & 2,21 \\
\hline
\end{tabular}


Superficie de Resposta; Variável: $Y$ [\%] = UP X uDP - EMED F1

3 fatores, 1 Bloco, 19 Experimentos; Média Quadrática Residual $=, 0036339$

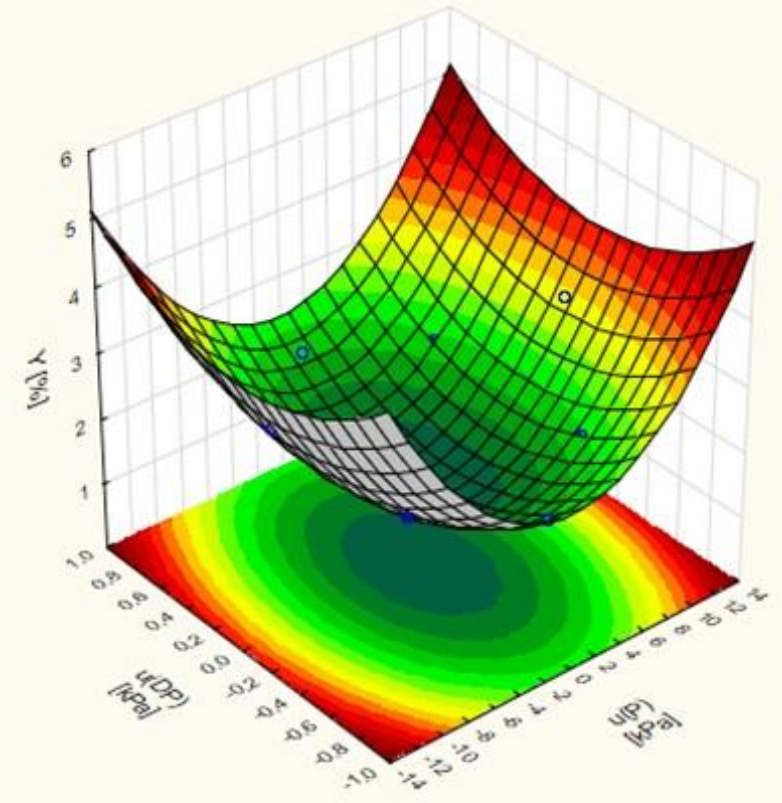

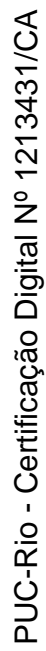

Figura A.43 - Superfície de resposta (EMED F1) dado uP e uDP (1 \% f.e.)

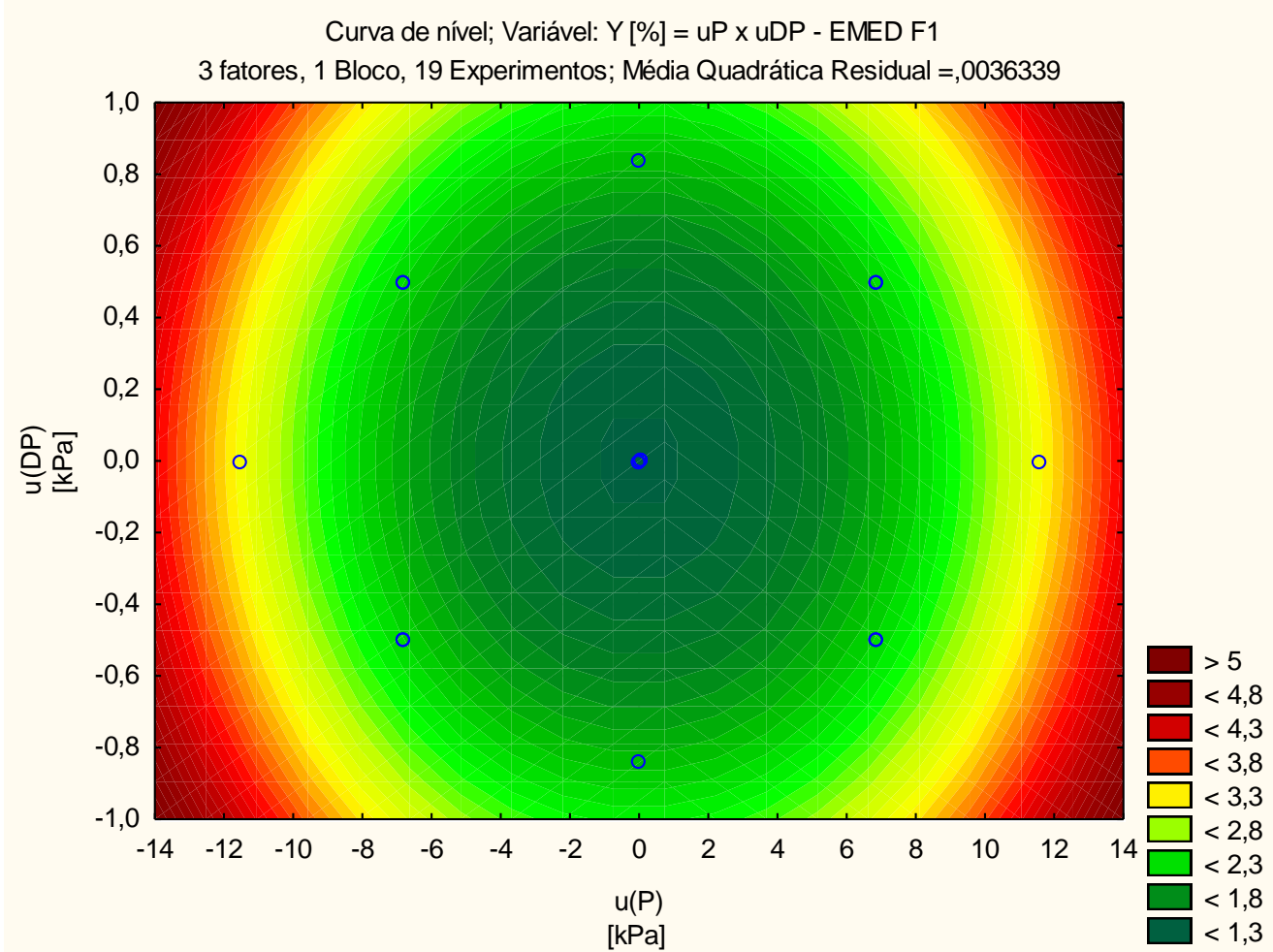

Figura A.44 - Curva de nível (EMED F21) dado uP e uDP (1 \% f.e.) 
Superficie de Resposta; Variável: Y [\%] = UP X UT - EMED F1

3 fatores, 1 Bloco, 19 Experimentos; Média Quadrática Residual $=, 0036339$

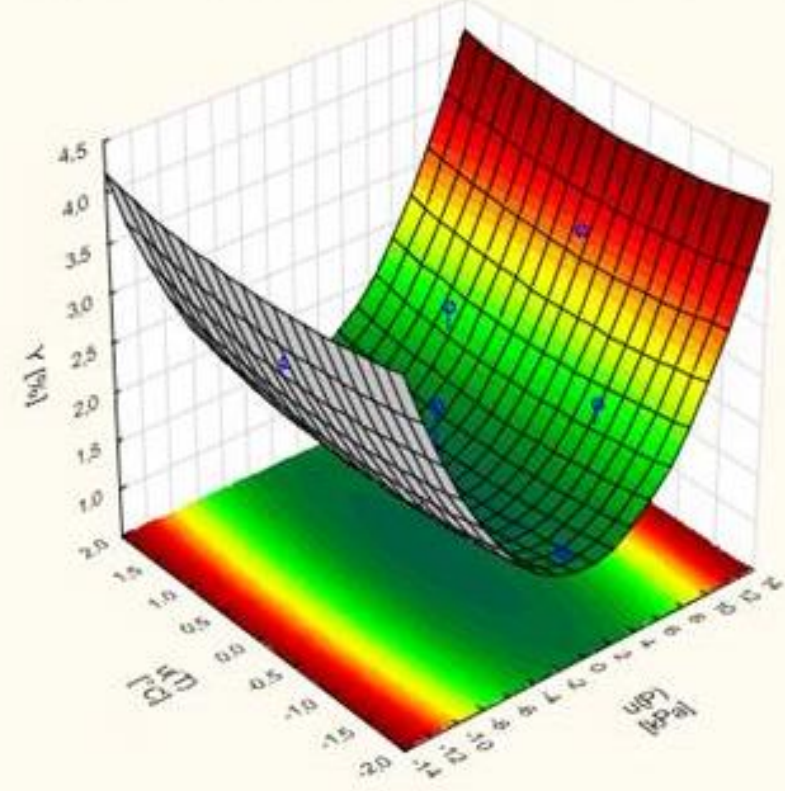

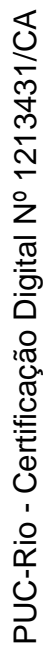

Figura A.45 - Superfície de resposta (EMED F1) dado uP (1\% f.e.) e uT $\left( \pm 1{ }^{\circ} \mathrm{C}\right)$

Curva de nivel: Variável:Y $Y \%$ l = uP X uT - EMED F1

3 fatores, 1 Bloco, 19 Experimentos; Média Quadrática Residual $=, 0036339$

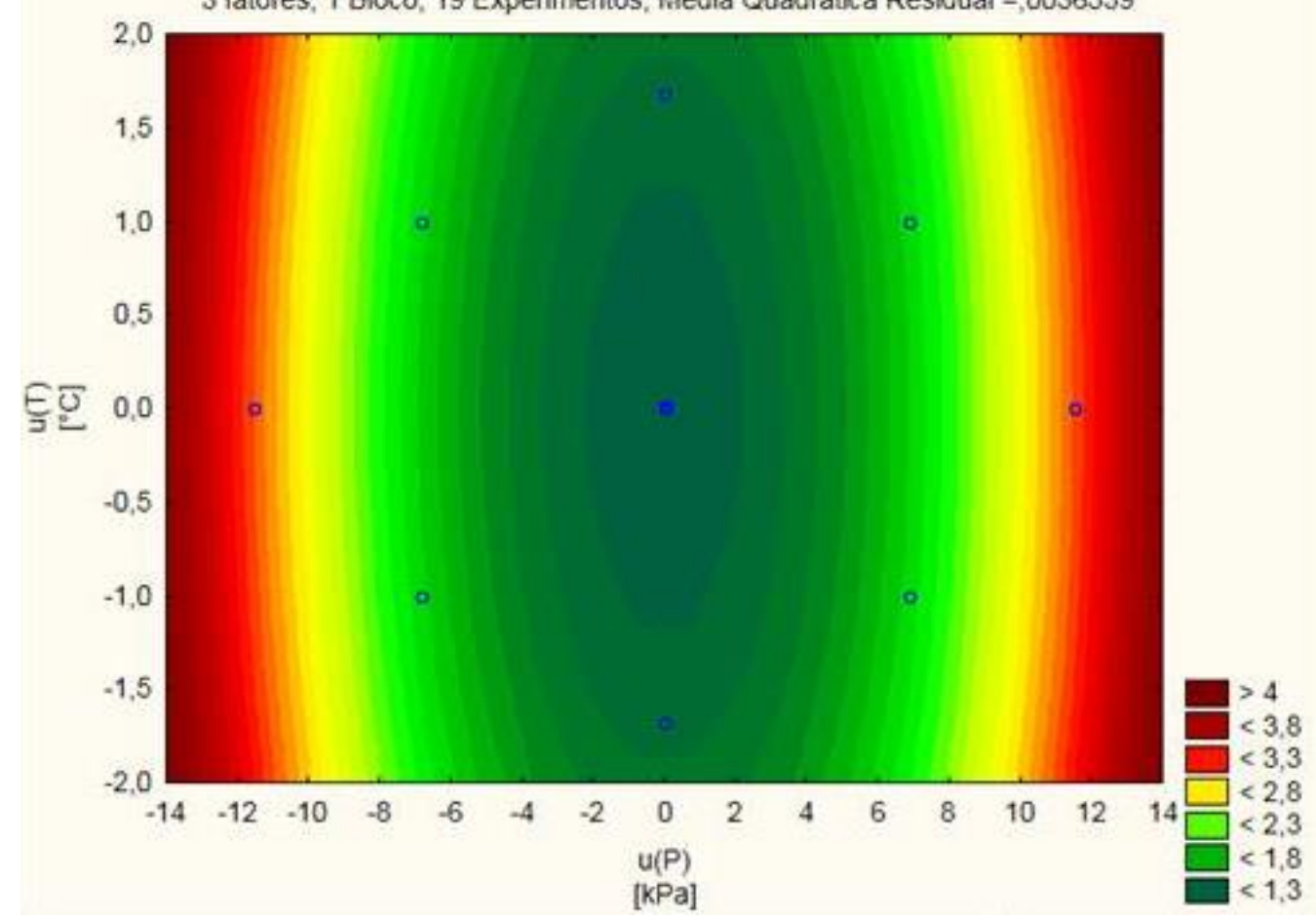

Figura A.46 - Curva de nível (EMED F1) dado uP ( $1 \%$ f.e.) e uT $\left( \pm 1^{\circ} \mathrm{C}\right)$ 
Superficie de Resposta; Variável: Y [\%] = uT x uDP - EMED F1

3 fatores, 1 Bloco, 19 Experimentos; Média Quadrática Residual $=, 0036339$

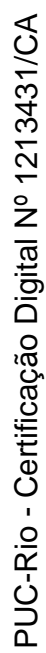

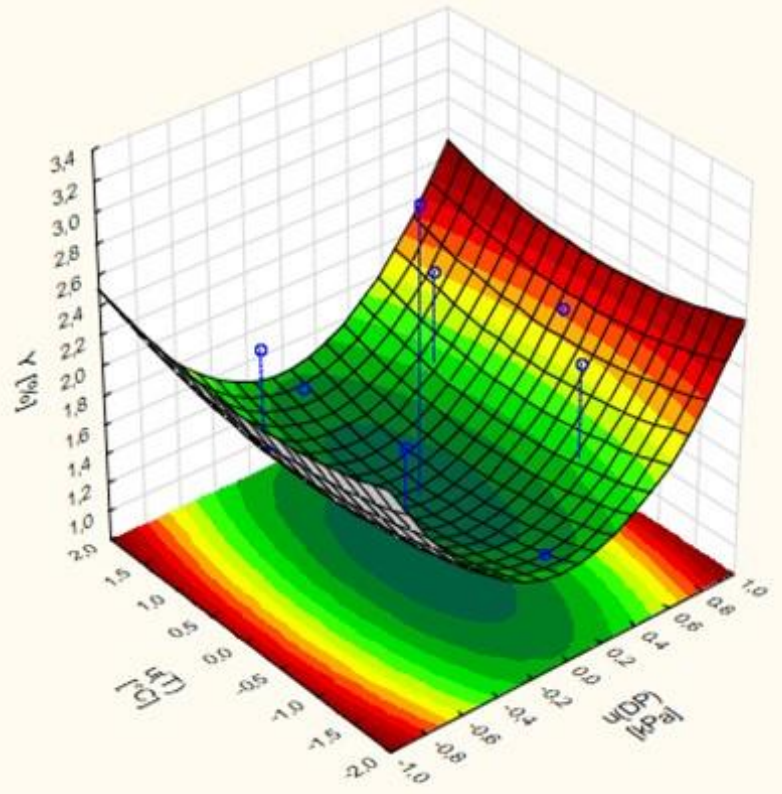

Figura A.47 - Superfície de resposta (EMED F1) dado uDP (1\% f.e.) e uT $\left( \pm 1{ }^{\circ} \mathrm{C}\right)$

Curva de nível; Variável: Y [\%] = UT x uDP - EMED F1

3 fatores, 1 Bloco, 19 Experimentos; Média Quadrática Residual =, 0036339

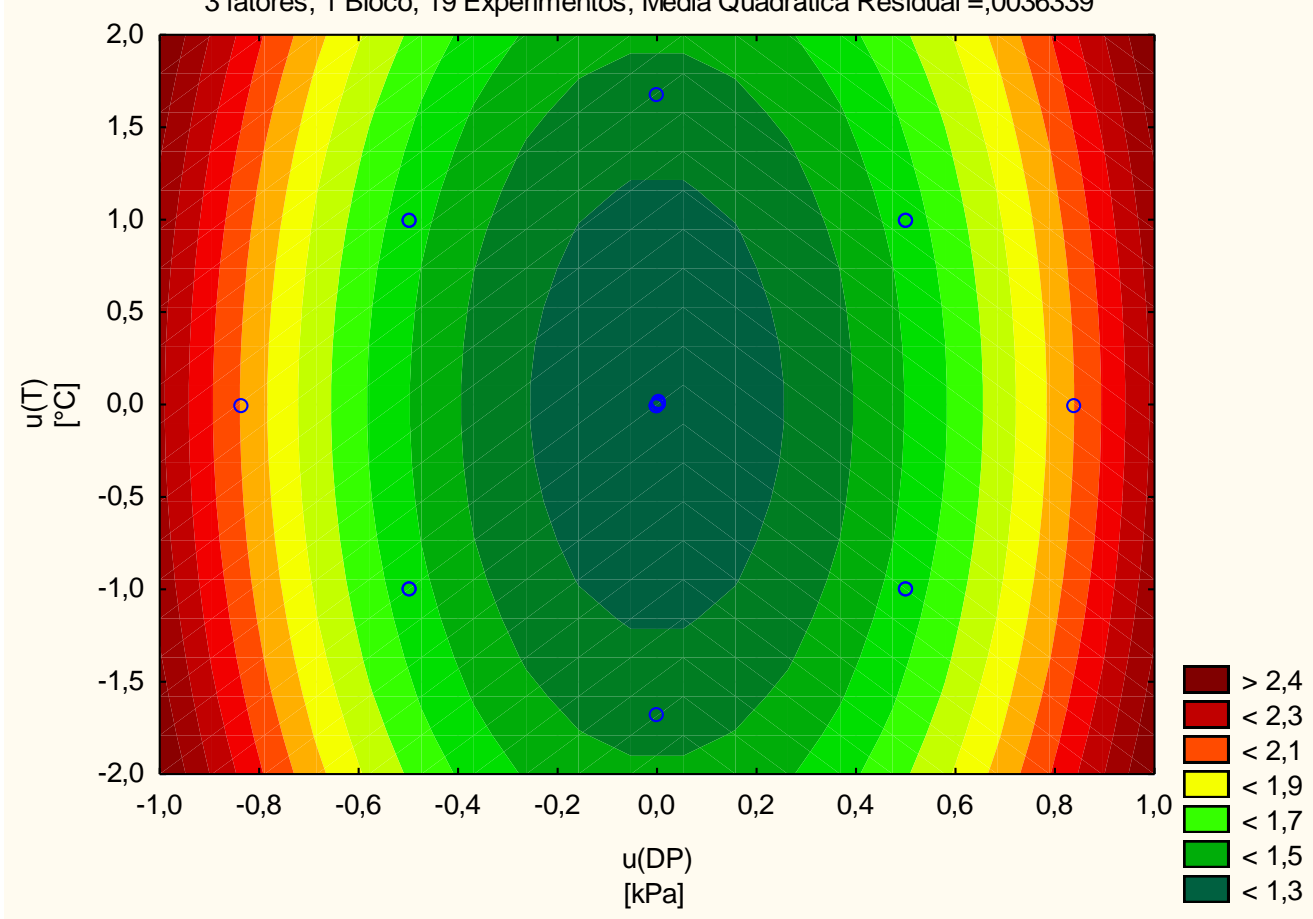

Figura A.48 - Curva de nível (EMED F1) dado uDP $(1 \%$ f.e. $)$ e uT $\left( \pm 1{ }^{\circ} \mathrm{C}\right)$ 


\section{A.7}

\section{Estação F2 - estação de medição fiscal}

Tabela A.19 - Matriz de planejamento experimental da EMED F2

\begin{tabular}{|c|c|c|c|c|c|c|c|}
\hline \multicolumn{7}{|c|}{ Matriz do planejamento } & $\begin{array}{c}\text { Incerteza da } \\
\text { vazão }\end{array}$ \\
\hline Exp & $\mathrm{x} 1$ & $\mathrm{x} 2$ & $\mathrm{x} 3$ & $\begin{array}{c}\mathrm{P} \\
{[\mathrm{kPa}]}\end{array}$ & $\mathrm{DP}[\mathrm{kPa}]$ & $\begin{array}{c}\mathrm{T} \\
{\left[{ }^{\circ} \mathrm{C}\right]}\end{array}$ & $\mathrm{y}(\%)$ \\
\hline 1 & -1 & -1 & -1 & $-6,8600$ & $-0,4982$ & $-1,0000$ & 12,58 \\
2 & 1 & -1 & -1 & 6,8600 & $-0,4982$ & $-1,0000$ & 12,58 \\
3 & -1 & 1 & -1 & $-6,8600$ & 0,4982 & $-1,0000$ & 12,58 \\
4 & 1 & 1 & -1 & 6,8600 & 0,4982 & $-1,0000$ & 12,58 \\
5 & -1 & -1 & 1 & $-6,8600$ & $-0,4982$ & 1,0000 & 12,58 \\
6 & 1 & -1 & 1 & 6,8600 & $-0,4982$ & 1,0000 & 12,58 \\
7 & -1 & 1 & 1 & $-6,8600$ & 0,4982 & 1,0000 & 12,58 \\
8 & 1 & 1 & 1 & 6,8600 & 0,4982 & 1,0000 & 12,58 \\
9 & $-1,682$ & 0 & 0 & $-11,5385$ & 0,0000 & 0,0000 & 3,15 \\
10 & 1,682 & 0 & 0 & 11,5385 & 0,0000 & 0,0000 & 3,15 \\
11 & 0 & $-1,682$ & 0 & 0,0000 & $-0,8380$ & 0,0000 & 20,98 \\
12 & 0 & 1,682 & 0 & 0,0000 & 0,8380 & 0,0000 & 20,98 \\
13 & 0 & 0 & $-1,682$ & 0,0000 & 0,0000 & $-1,6820$ & 1,40 \\
14 & 0 & 0 & 1,682 & 0,0000 & 0,0000 & 1,6820 & 1,40 \\
15 & 0 & 0 & 0 & 0,0000 & 0,0000 & 0,0000 & 1,21 \\
16 & 0 & 0 & 0 & 0,0448 & 0,0045 & 0,0015 & 1,21 \\
17 & 0 & 0 & 0 & 0,0034 & 0,0017 & 0,0131 & 1,21 \\
18 & 0 & 0 & 0 & 0,0198 & 0,0016 & 0,0081 & 1,21 \\
19 & 0 & 0 & 0 & 0,0159 & 0,0003 & 0,0424 & 1,21 \\
\hline
\end{tabular}

Tabela A.20 - Tabela de ANOVA do planejamento de experimentos da EMED F2

\begin{tabular}{|c|c|c|c|c|c|}
\hline \multirow{2}{*}{ Fonte de variação } & \multicolumn{5}{|c|}{ ANOVA; Var.:Y [\%]; $\mathrm{R}^{2}=, 95158 ; \mathrm{R}^{2}:$ : 90317} \\
& \multicolumn{5}{|c|}{3 fatores, 1 Bloco, 19 Experimentos; Média Quadrática Residual = } \\
& $\begin{array}{c}\text { Soma de } \\
\text { Quadrados }\end{array}$ & $\begin{array}{c}\text { Graus de } \\
\text { liberdade }\end{array}$ & $\begin{array}{c}\text { Quadrados } \\
\text { médios }\end{array}$ & Teste F & $\mathrm{p}$ \\
\hline$(1) \mathrm{u}(\mathrm{P})[\mathrm{kPa}](\mathrm{L})$ & 0,0000 & 1 & 0,0000 & 0,0000 & 0,999833 \\
\hline $\mathrm{u}(\mathrm{P})[\mathrm{kPa}](\mathrm{Q})$ & 29,0827 & 1 & 29,0827 & 6,2283 & 0,034104 \\
\hline$(2) \mathrm{u}(\mathrm{DP})[\mathrm{kPa}](\mathrm{L})$ & 0,0000 & 1 & 0,0000 & 0,0000 & 0,999777 \\
\hline $\mathrm{u}(\mathrm{DP})[\mathrm{kPa}](\mathrm{Q})$ & 822,8872 & 1 & 822,8872 & 176,2268 & 0,000000 \\
\hline$(3) \mathrm{u}(\mathrm{T})\left[{ }^{\circ} \mathrm{C}\right](\mathrm{L})$ & 0,0000 & 1 & 0,0000 & 0,0000 & 0,999122 \\
\hline $\mathrm{u}(\mathrm{T})\left[{ }^{\circ} \mathrm{C}\right](\mathrm{Q})$ & 9,6829 & 1 & 9,6829 & 2,0737 & 0,183725 \\
\hline $1 \mathrm{~L} \times 2 \mathrm{~L}$ & 0,0000 & 1 & 0,0000 & 0,0000 & 0,999999 \\
\hline $1 \mathrm{~L} \times 3 \mathrm{~L}$ & 0,0000 & 1 & 0,0000 & 0,0000 & 0,999998 \\
\hline $2 \mathrm{~L} \times 3 \mathrm{~L}$ & 0,0000 & 1 & 0,0000 & 0,0000 & 0,999998 \\
\hline Erro & 42,0253 & 9 & 4,6695 & & \\
\hline Total SQ & 867,9897 & 18 & & & \\
\hline
\end{tabular}


Gráfico de Pareto dos Efeitos; Variável: Y[\%] - EMED F2

3 fatores, 1 Bloc 0 , 19 Experimentos; Média Quadrática Residual $=4,669477$

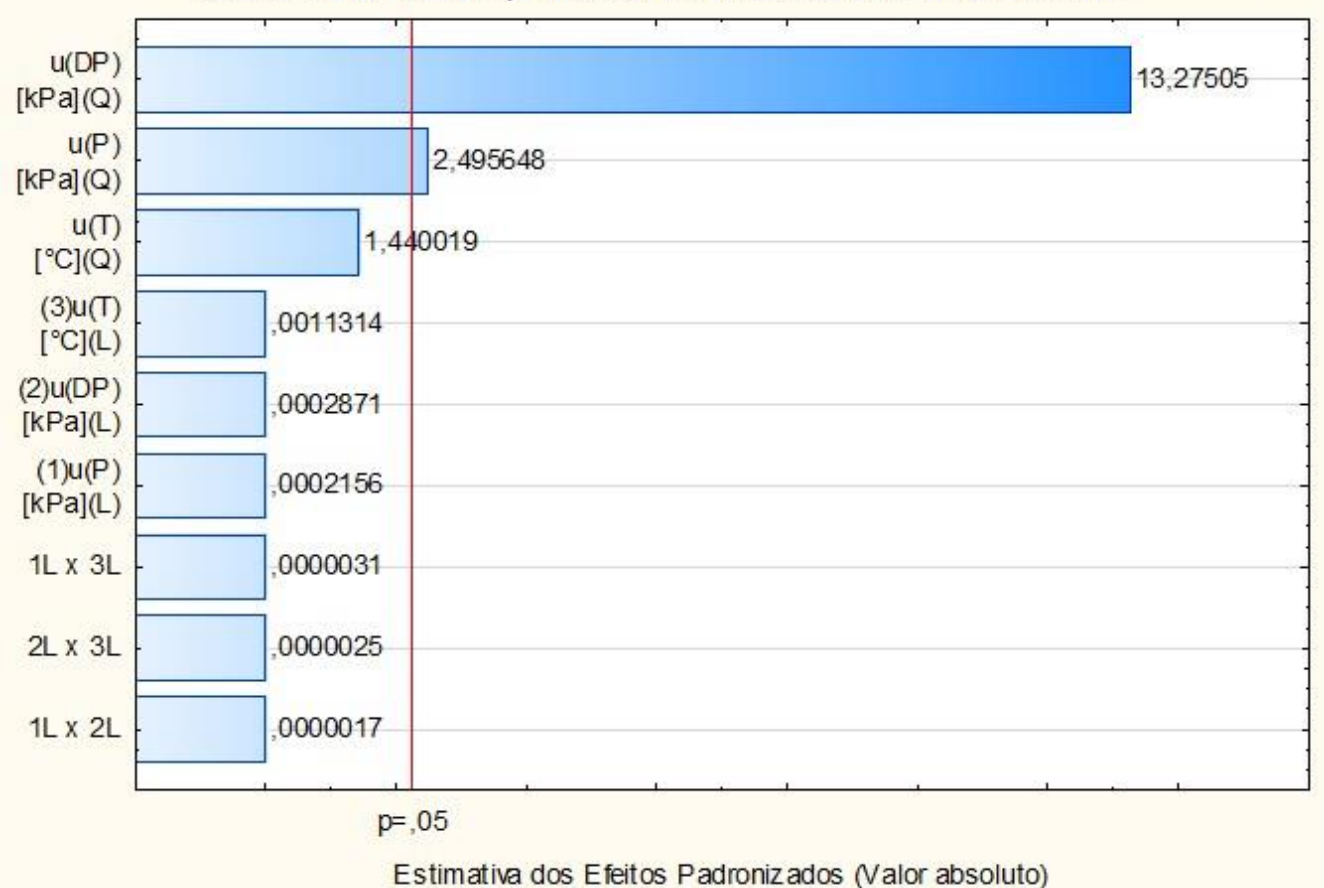

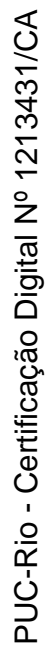

Valores Previstos vs. Valores Residuais - EMED F2 3 fatores, 1 Bloco, 19 Experimentos: Média Quadrática Residual $=4,669477$

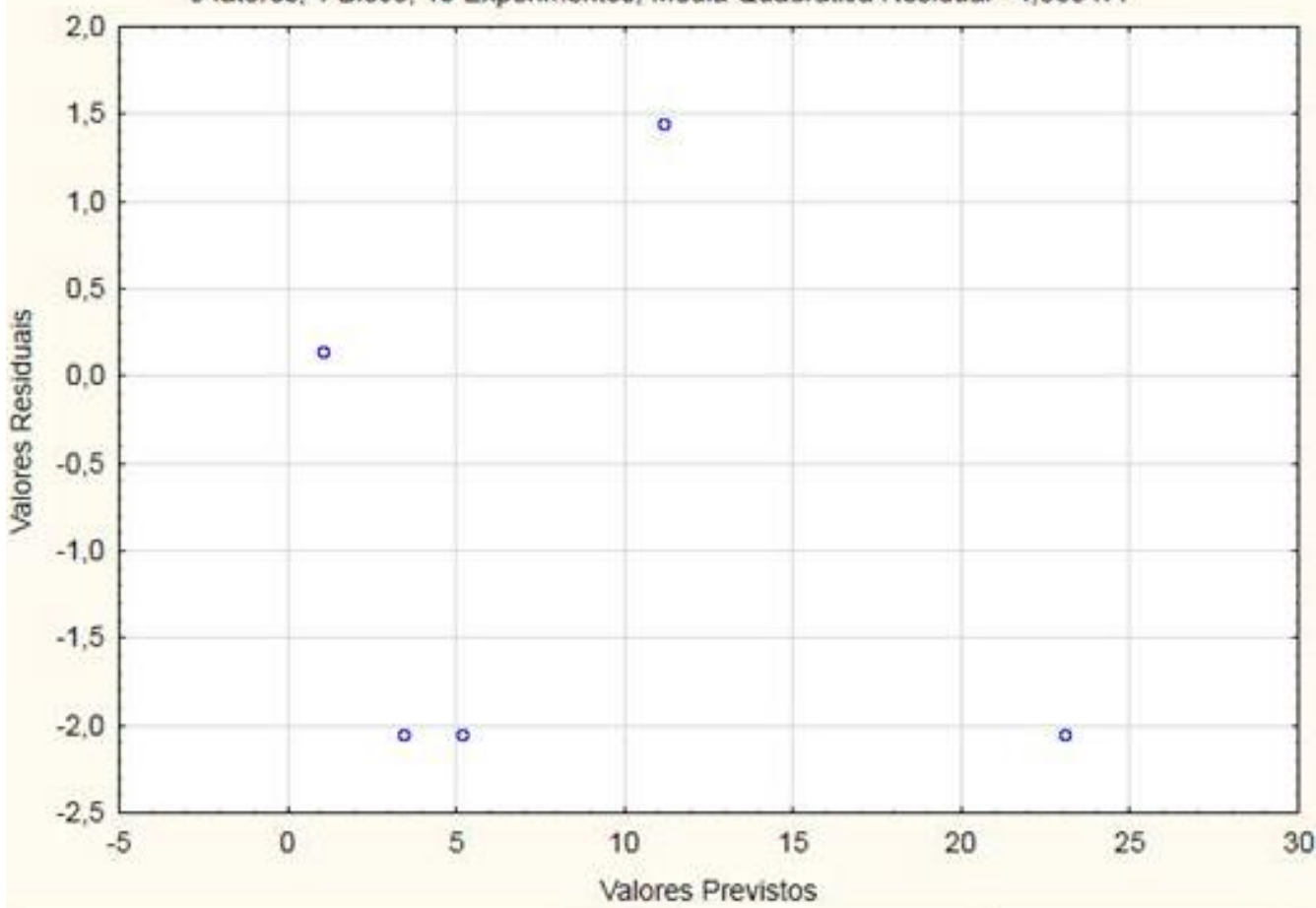

Figura A.50 - Resíduos versus estimativas de y (EMED F2 - nível: $1 \%$ f.e. e $1{ }^{\circ} \mathrm{C}$ ) 
Tabela A.21 - Matriz das incertezas estimadas da vazão (EMED F2)

(dado $x_{3}(T)$ igual a 1 e $x_{1}$ e $x_{2}$ variando do nível baixo ao nível alto)

\begin{tabular}{|c|c|c|c|c|c|c|c|c|c|c|c|}
\multicolumn{1}{c|}{} & -1 & $-0,8$ & $-0,6$ & $-0,4$ & $-0,2$ & 0 & 0,2 & 0,4 & 0,6 & 0,8 & 1 \\
\hline-1 & 11,13 & 10,61 & 10,20 & 9,91 & 9,73 & 9,67 & 9,73 & 9,91 & 10,20 & 10,61 & 11,13 \\
\hline$-0,8$ & 8,34 & 7,81 & 7,40 & 7,11 & 6,94 & 6,88 & 6,94 & 7,11 & 7,40 & 7,81 & 8,34 \\
\hline$-0,6$ & 6,16 & 5,64 & 5,23 & 4,94 & 4,76 & 4,70 & 4,76 & 4,94 & 5,23 & 5,64 & 6,16 \\
\hline$-0,4$ & 4,61 & 4,09 & 3,68 & 3,39 & 3,21 & 3,15 & 3,21 & 3,39 & 3,68 & 4,09 & 4,61 \\
\hline$-0,2$ & 3,68 & 3,15 & 2,75 & 2,45 & 2,28 & 2,22 & 2,28 & 2,45 & 2,75 & 3,15 & 3,68 \\
\hline 0 & 3,37 & 2,84 & 2,44 & 2,14 & 1,97 & 1,91 & 1,97 & 2,14 & 2,44 & 2,84 & 3,37 \\
\hline 0,2 & 3,68 & 3,15 & 2,75 & 2,45 & 2,28 & 2,22 & 2,28 & 2,45 & 2,75 & 3,15 & 3,68 \\
\hline 0,4 & 4,61 & 4,09 & 3,68 & 3,39 & 3,21 & 3,15 & 3,21 & 3,39 & 3,68 & 4,09 & 4,61 \\
\hline 0,6 & 6,16 & 5,64 & 5,23 & 4,94 & 4,76 & 4,70 & 4,76 & 4,94 & 5,23 & 5,64 & 6,16 \\
\hline 0,8 & 8,34 & 7,81 & 7,40 & 7,11 & 6,94 & 6,88 & 6,94 & 7,11 & 7,40 & 7,81 & 8,34 \\
\hline 1 & 11,13 & 10,61 & 10,20 & 9,91 & 9,73 & 9,67 & 9,73 & 9,91 & 10,20 & 10,61 & 11,13 \\
\hline
\end{tabular}

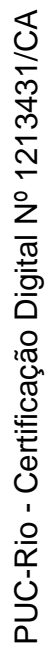

Superficie de Resposta; Variável: Y [\%] = uP x uDP - EMED F2

3 fatores, 1 Bloco, 19 Experimentos; Média Quadrática Residual $=4,669477$

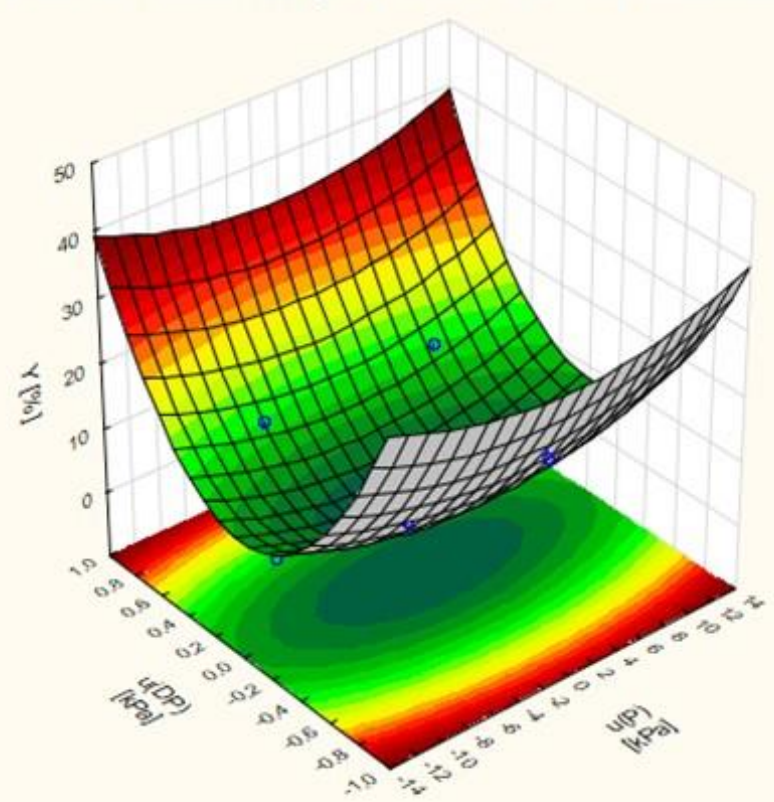

Figura A.51 - Superfície de resposta (EMED F2) dado uP e uDP (1\% f.e.) 
Curva de nível; Variável: Y [\%] = uP x uDP - EMED F2

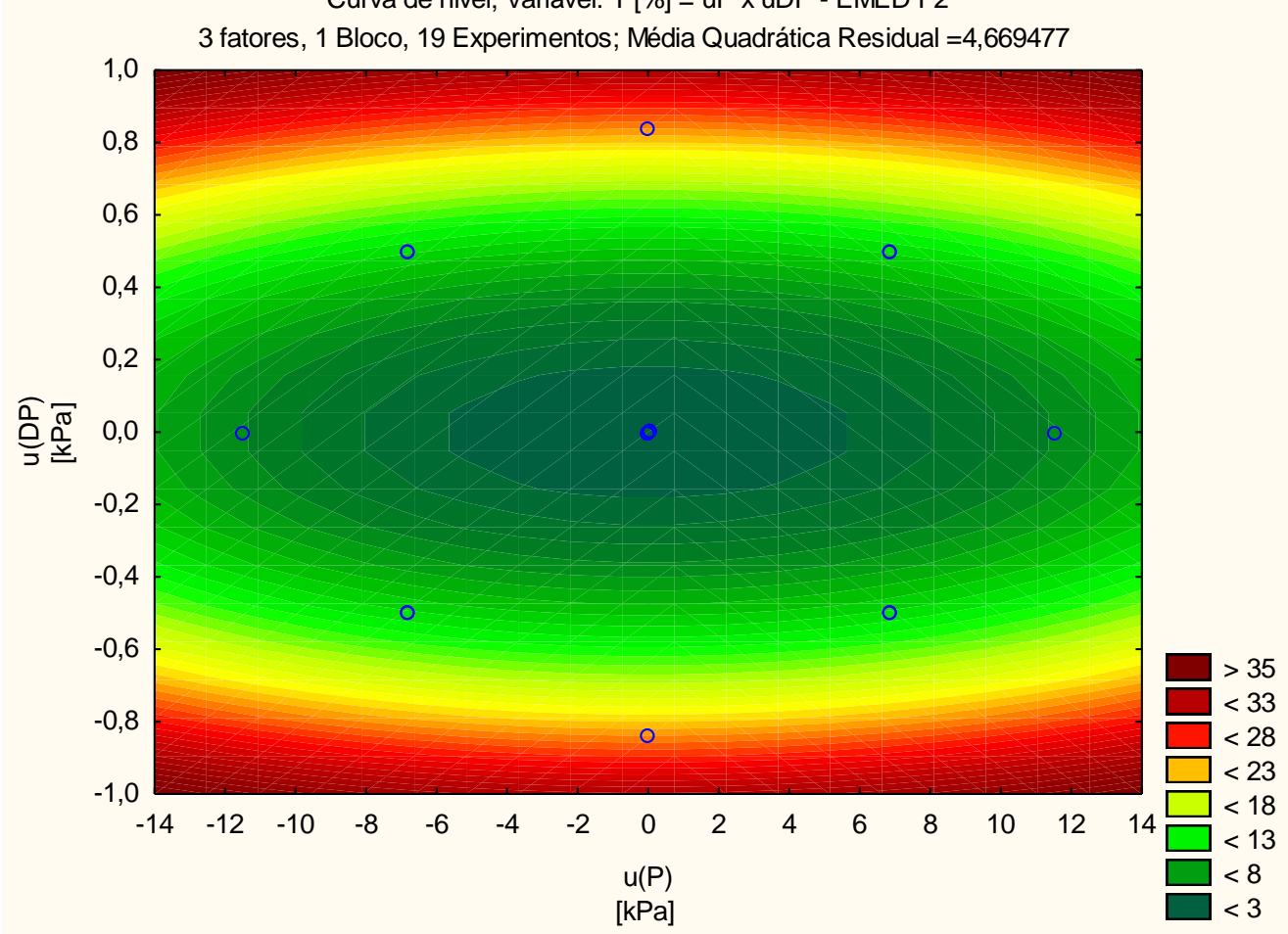

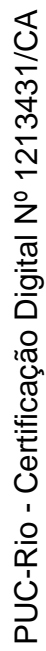

Figura A.52 - Curva de nível (EMED F2) dado uP e uDP (1 \% f.e.)

Superficie de Resposta; Variável: Y [\%] = uP x UT - EMED F2

3 fatores, 1 Bloco, 19 Experimentos; Média Quadrática Residual $=4,669477$
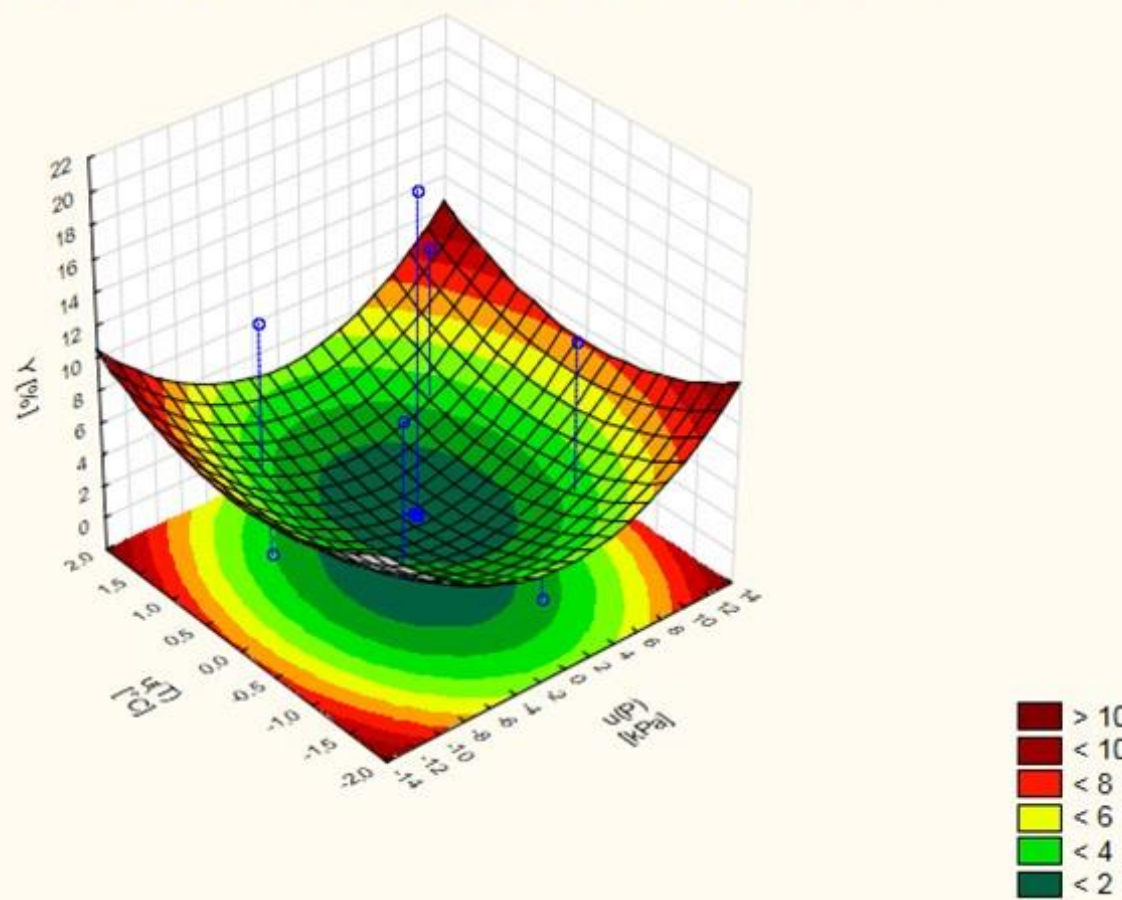

Figura A.53 - Superfície de resposta (EMED F2) dado uP ( $1 \%$ f.e.) e uT $\left( \pm 1{ }^{\circ} \mathrm{C}\right)$ 
Curva de nível; Variável: Y [\%] = uP x uT - EMED F2

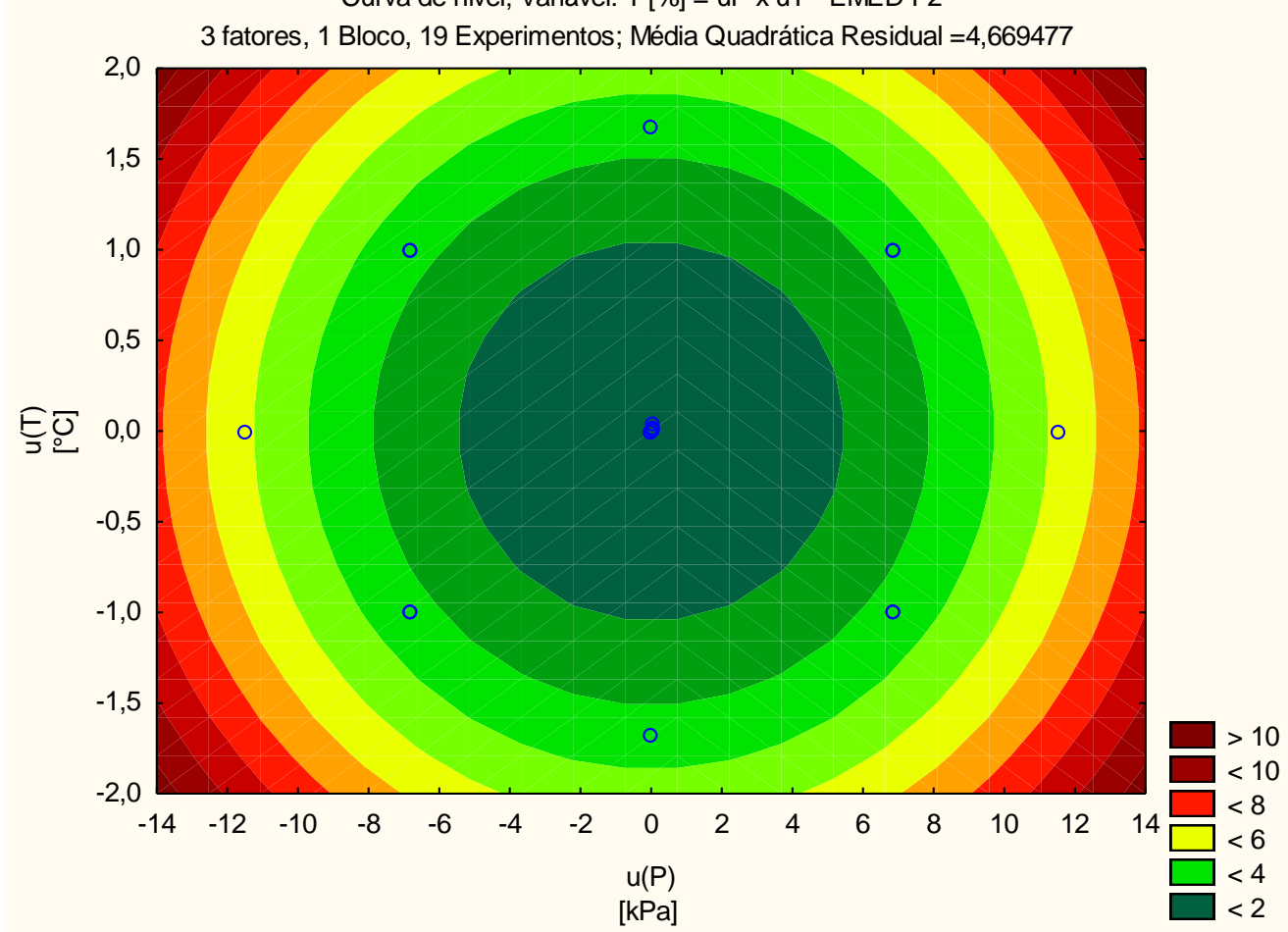

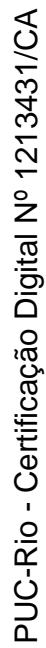

Figura A.54 - Curva de nível (EMED F2) dado uP ( $1 \%$ f.e. $)$ e uT $\left( \pm 1{ }^{\circ} \mathrm{C}\right)$

Superficie de Resposta; Variável: Y [\%] = uT x uDP - EMED F2

3 fatores, 1 Bloco, 19 Experimentos; Média Quadrática Residual $=4,669477$
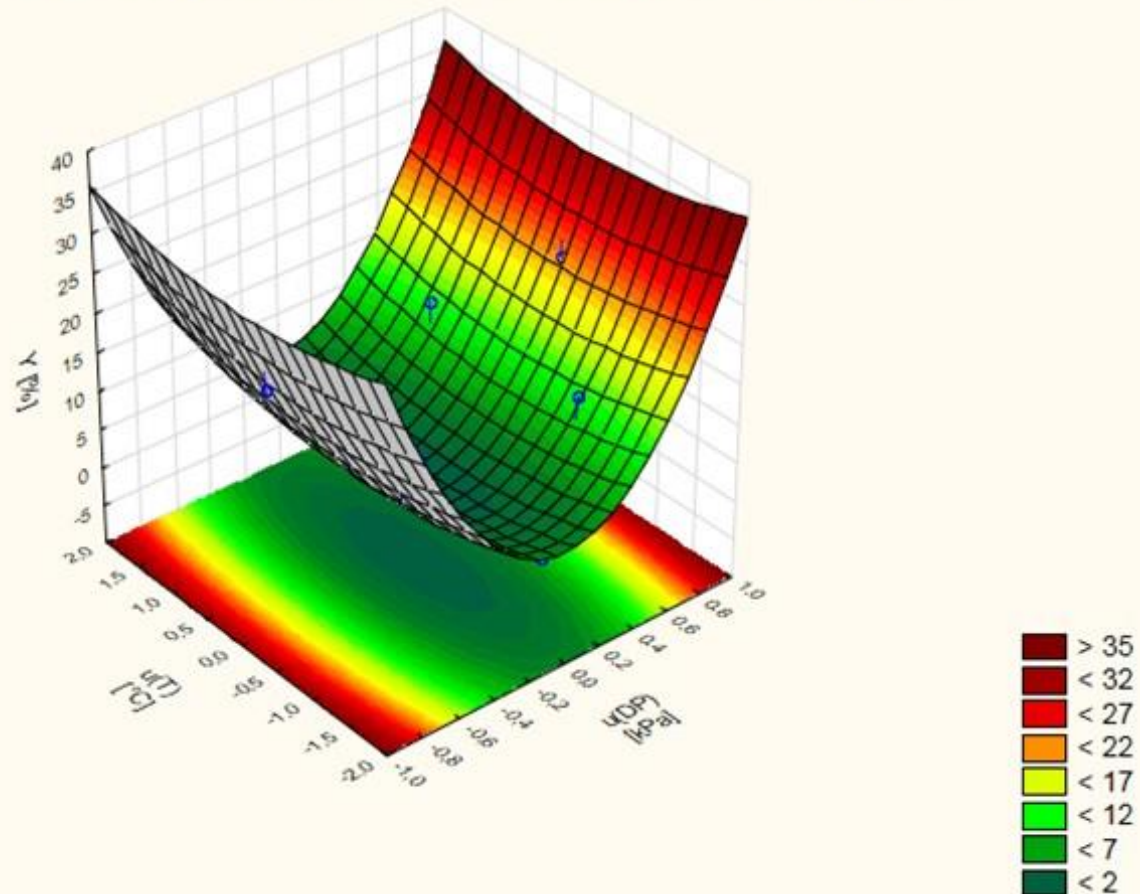

Figura A.55 - Superfície de resposta (EMED F2) dado uDP (1\% f.e.) e uT $\left( \pm 1{ }^{\circ} \mathrm{C}\right)$ 


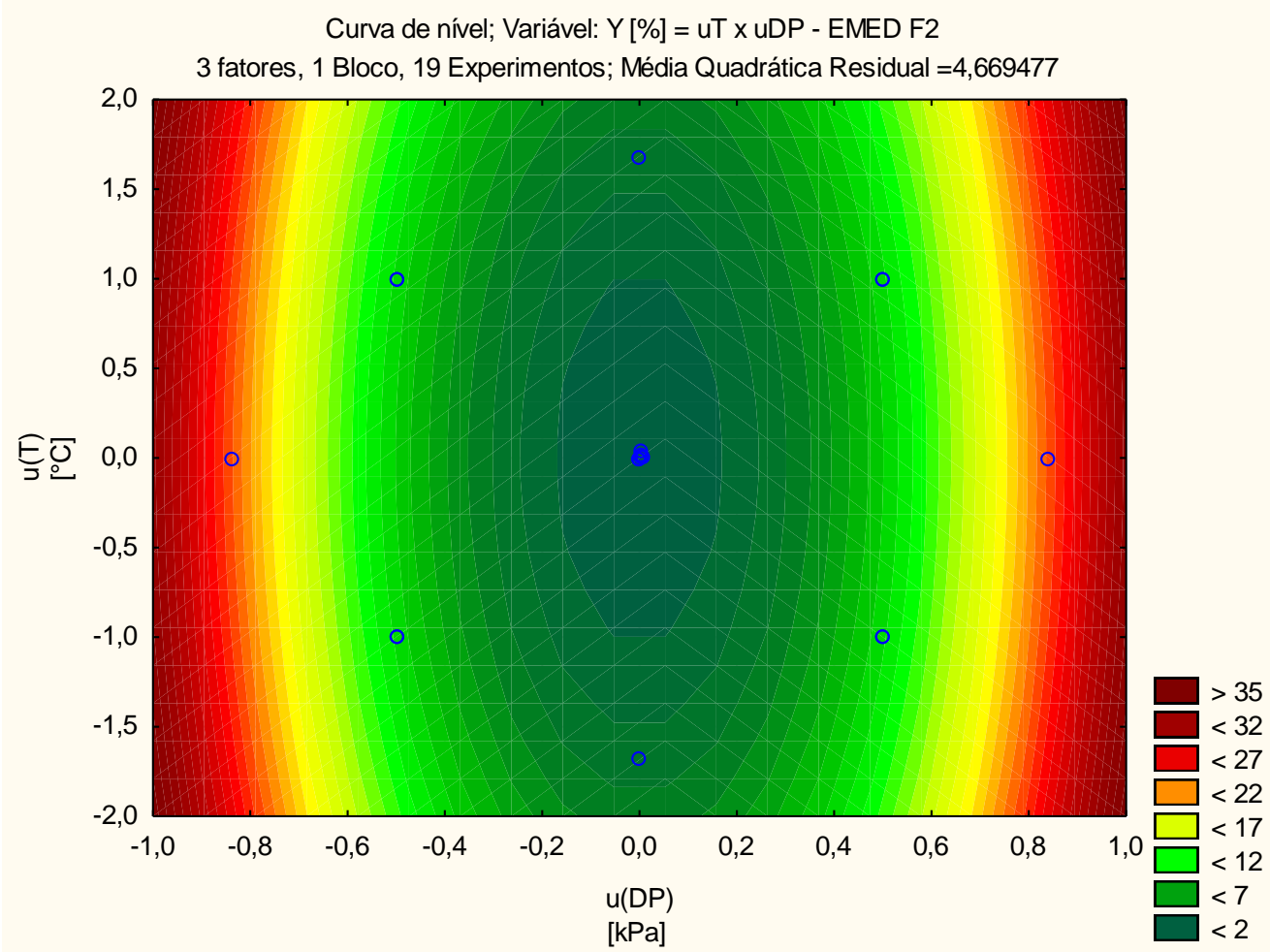

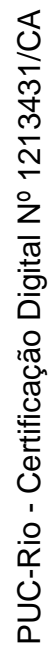

Figura A.56 - Curva de nível (EMED F2) dado uDP $(1 \%$ f.e. $)$ e uT $\left( \pm 1{ }^{\circ} \mathrm{C}\right)$

\section{A.8 \\ Estação G1 - estação de medição fiscal}

Tabela A.22 - Matriz de planejamento experimental da EMED G1

\begin{tabular}{|c|c|c|c|c|c|c|c|}
\hline \multicolumn{7}{|c|}{ Matriz do planejamento } & $\begin{array}{c}\text { Incerteza da } \\
\text { vazão }\end{array}$ \\
\hline Exp & $\mathrm{x} 1$ & $\mathrm{x} 2$ & $\mathrm{x} 3$ & $\begin{array}{c}\mathrm{P} \\
{[\mathrm{kPa}]}\end{array}$ & $\mathrm{DP}[\mathrm{kPa}]$ & $\begin{array}{c}\mathrm{T} \\
{\left[{ }^{\circ} \mathrm{C}\right]}\end{array}$ & $\mathrm{y}(\%)$ \\
\hline 1 & -1 & -1 & -1 & $-6,8600$ & $-0,2991$ & $-1,0000$ & 1,91 \\
2 & 1 & -1 & -1 & 6,8600 & $-0,2991$ & $-1,0000$ & 1,91 \\
3 & -1 & 1 & -1 & $-6,8600$ & 0,2991 & $-1,0000$ & 1,91 \\
4 & 1 & 1 & -1 & 6,8600 & 0,2991 & $-1,0000$ & 1,91 \\
5 & -1 & -1 & 1 & $-6,8600$ & $-0,2991$ & 1,0000 & 1,91 \\
6 & 1 & -1 & 1 & 6,8600 & $-0,2991$ & 1,0000 & 1,91 \\
7 & -1 & 1 & 1 & $-6,8600$ & 0,2991 & 1,0000 & 1,91 \\
8 & 1 & 1 & 1 & 6,8600 & 0,2991 & 1,0000 & 1,91 \\
9 & $-1,682$ & 0 & 0 & $-11,5385$ & 0,0000 & 0,0000 & 2,63 \\
10 & 1,682 & 0 & 0 & 11,5385 & 0,0000 & 0,0000 & 2,63 \\
11 & 0 & $-1,682$ & 0 & 0,0000 & $-0,5031$ & 0,0000 & 1,99 \\
12 & 0 & 1,682 & 0 & 0,0000 & 0,5031 & 0,0000 & 1,99 \\
13 & 0 & 0 & $-1,682$ & 0,0000 & 0,0000 & $-1,6820$ & 1,32 \\
14 & 0 & 0 & 1,682 & 0,0000 & 0,0000 & 1,6820 & 1,32 \\
15 & 0 & 0 & 0 & 0,0000 & 0,0000 & 0,0000 & 1,12 \\
16 & 0 & 0 & 0 & 0,0787 & 0,0007 & 0,0052 & 1,12 \\
17 & 0 & 0 & 0 & 0,0269 & 0,0018 & 0,0018 & 1,12 \\
18 & 0 & 0 & 0 & 0,0024 & 0,0005 & 0,0020 & 1,12 \\
19 & 0 & 0 & 0 & 0,0122 & 0,0032 & 0,0041 & 1,12 \\
\hline
\end{tabular}


Tabela A.23 - Tabela de ANOVA do planejamento de experimentos da EMED G1

\begin{tabular}{|c|c|c|c|c|c|}
\hline & \multicolumn{5}{|c|}{ ANOVA; Var.:Y [\%]; $\mathrm{R}^{2}=, 98778 ; \mathrm{R}_{\mathrm{a}}^{2}:, 97556$} \\
Fonte de variação & Q $\begin{array}{c}\text { Soma de } \\
\text { Quadrados }\end{array}$ & $\begin{array}{c}\text { Graus de } \\
\text { liberdade }\end{array}$ & $\begin{array}{c}\text { Quadrados } \\
\text { médios }\end{array}$ & Teste F & $\mathrm{p}$ \\
\cline { 2 - 6 }$(1) \mathrm{u}(\mathrm{P})[\mathrm{kPa}](\mathrm{L})$ & 0,000000 & 1 & 0,000000 & 0,0000 & 0,999760 \\
\hline $\mathrm{u}(\mathrm{P})[\mathrm{kPa}](\mathrm{Q})$ & 3,511910 & 1 & 3,511910 & 615,5815 & 0,000000 \\
\hline$(2) \mathrm{u}(\mathrm{DP})[\mathrm{kPa}](\mathrm{L})$ & 0,000000 & 1 & 0,000000 & 0,0000 & 0,999715 \\
\hline $\mathrm{u}(\mathrm{DP})[\mathrm{kPa}](\mathrm{Q})$ & 1,073927 & 1 & 1,073927 & 188,2422 & 0,000000 \\
\hline$(3) \mathrm{u}(\mathrm{T})\left[{ }^{\circ} \mathrm{C}\right](\mathrm{L})$ & 0,000000 & 1 & 0,000000 & 0,0000 & 0,999822 \\
\hline $\mathrm{u}(\mathrm{T})\left[{ }^{\circ} \mathrm{C}\right](\mathrm{Q})$ & 0,026229 & 1 & 0,026229 & 4,5975 & 0,060609 \\
\hline $1 \mathrm{~L} \times 2 \mathrm{~L}$ & 0,000000 & 1 & 0,000000 & 0,0000 & 0,999999 \\
\hline $1 \mathrm{~L} \times 3 \mathrm{~L}$ & 0,000000 & 1 & 0,000000 & 0,0000 & 0,999999 \\
\hline $2 \mathrm{~L} \times 3 \mathrm{~L}$ & 0,000000 & 1 & 0,000000 & 0,0000 & 0,999999 \\
\hline Erro & 0,051345 & 9 & 0,005705 & & \\
\hline Total SQ & 4,201188 & 18 & & & \\
\hline
\end{tabular}

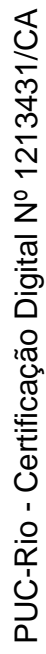

Gráfico de Pareto dos Efeitos; Variável: Y[\%] - EMED G1

3 fatores, 1 Bloco, 19 Experimentos; Média Quadrática Residual =,005705

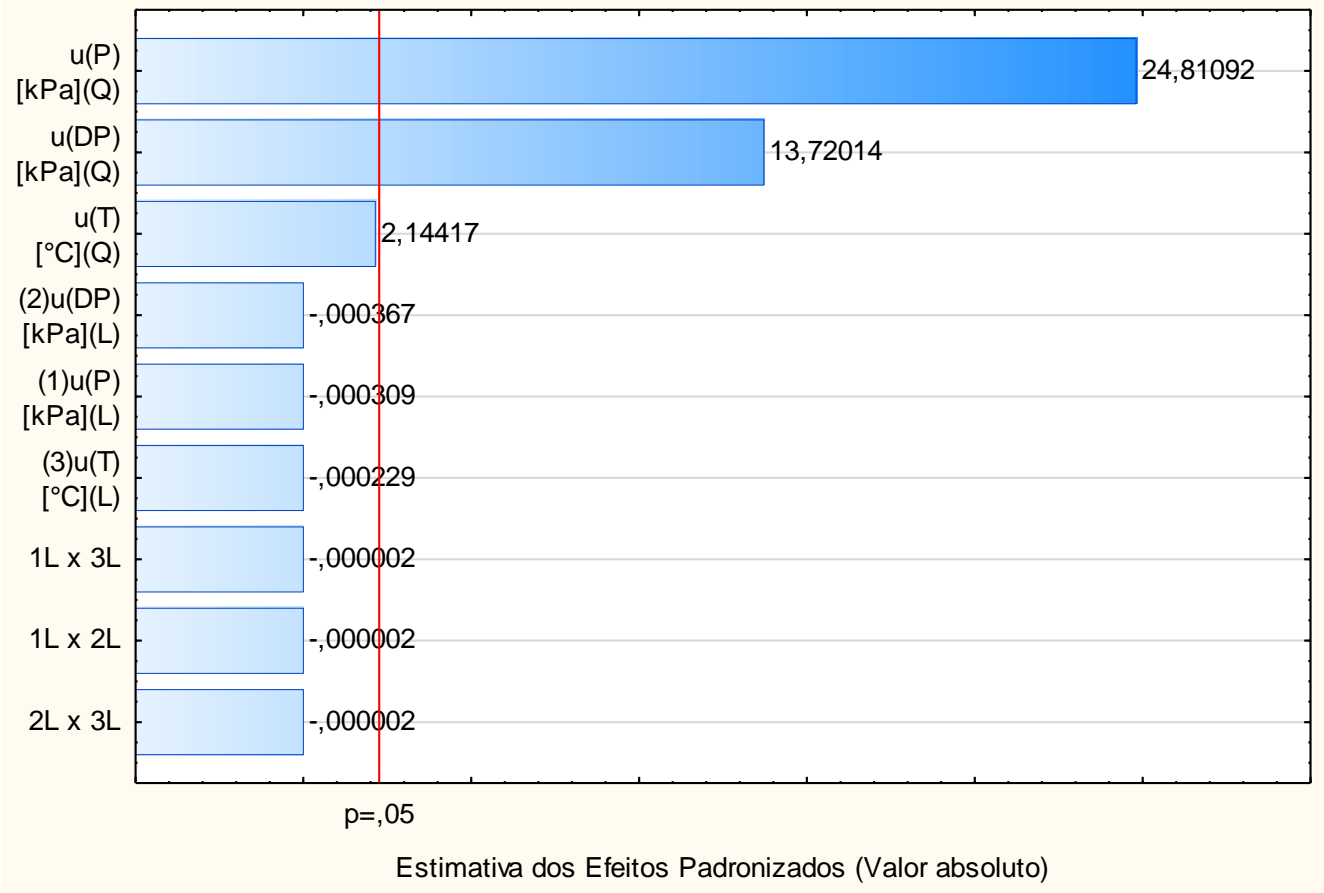

Figura A.57 - Gráfico de Pareto em função dos valores da estatística de teste t 
Valores Previstos vs. Valores Residuais - EMED G1

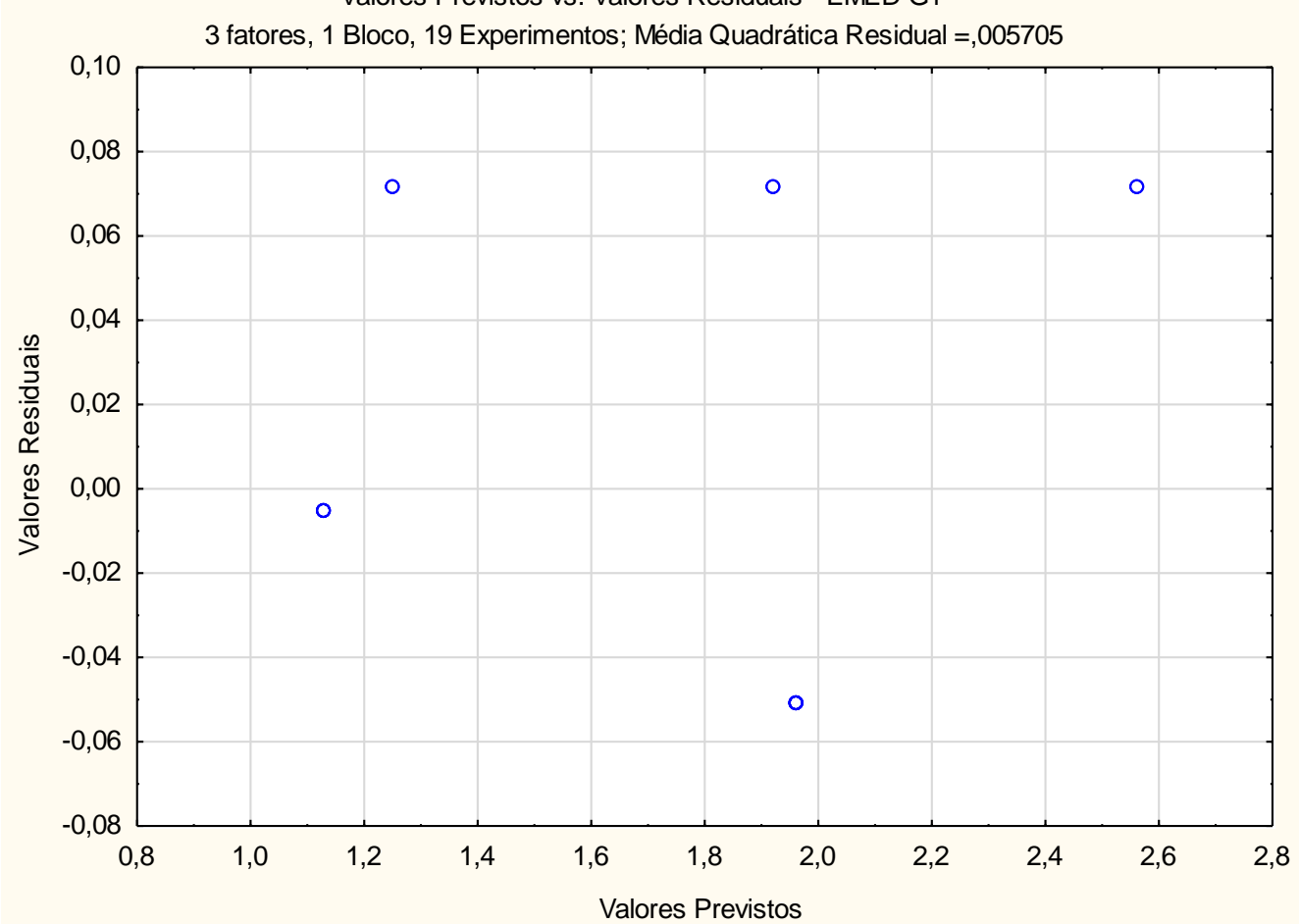

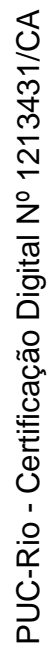

Tabela A.24 - Matriz das incertezas estimadas da vazão (EMED G1)

(dado $x_{3}(T)$ igual a 1 e $x_{1}$ e $x_{2}$ variando do nível baixo ao nível alto)

\begin{tabular}{|c|c|c|c|c|c|c|c|c|c|c|c|}
\multicolumn{1}{c|}{} & -1 & $-0,8$ & $-0,6$ & $-0,4$ & $-0,2$ & 0 & 0,2 & 0,4 & 0,6 & 0,8 & 1 \\
\hline-1 & 1,96 & 1,78 & 1,63 & 1,53 & $\mathbf{1 , 4 7}$ & 1,45 & $\mathbf{1 , 4 7}$ & 1,53 & 1,63 & 1,78 & 1,96 \\
\hline$-0,8$ & 1,86 & 1,68 & 1,53 & 1,43 & 1,37 & 1,35 & 1,37 & 1,43 & 1,53 & 1,68 & 1,86 \\
\hline$-0,6$ & 1,78 & 1,60 & 1,45 & 1,35 & 1,29 & 1,27 & 1,29 & 1,35 & 1,45 & 1,60 & 1,78 \\
\hline$-0,4$ & 1,72 & 1,54 & 1,40 & 1,30 & 1,24 & 1,22 & 1,24 & 1,30 & 1,40 & 1,54 & 1,72 \\
\hline$-0,2$ & 1,69 & 1,51 & 1,36 & 1,26 & 1,20 & 1,18 & 1,20 & 1,26 & 1,36 & 1,51 & 1,69 \\
\hline 0 & 1,68 & 1,50 & 1,35 & 1,25 & 1,19 & 1,17 & 1,19 & 1,25 & 1,35 & 1,50 & 1,68 \\
\hline 0,2 & 1,69 & 1,51 & 1,36 & 1,26 & 1,20 & 1,18 & 1,20 & 1,26 & 1,36 & 1,51 & 1,69 \\
\hline 0,4 & 1,72 & 1,54 & 1,40 & 1,30 & 1,24 & 1,22 & 1,24 & 1,30 & 1,40 & 1,54 & 1,72 \\
\hline 0,6 & 1,78 & 1,60 & 1,45 & 1,35 & 1,29 & 1,27 & 1,29 & 1,35 & 1,45 & 1,60 & 1,78 \\
\hline 0,8 & 1,86 & 1,68 & 1,53 & 1,43 & 1,37 & 1,35 & 1,37 & 1,43 & 1,53 & 1,68 & 1,86 \\
\hline 1 & 1,96 & 1,78 & 1,63 & 1,53 & $\mathbf{1 , 4 7}$ & 1,45 & $\mathbf{1 , 4 7}$ & 1,53 & 1,63 & 1,78 & 1,96 \\
\hline
\end{tabular}


Superficie de Resposta; Variável: Y [\%] = uP x uDP - EMED G1

3 fatores, 1 Bloco, 19 Experimentos; Média Quadrática Residual =,005705

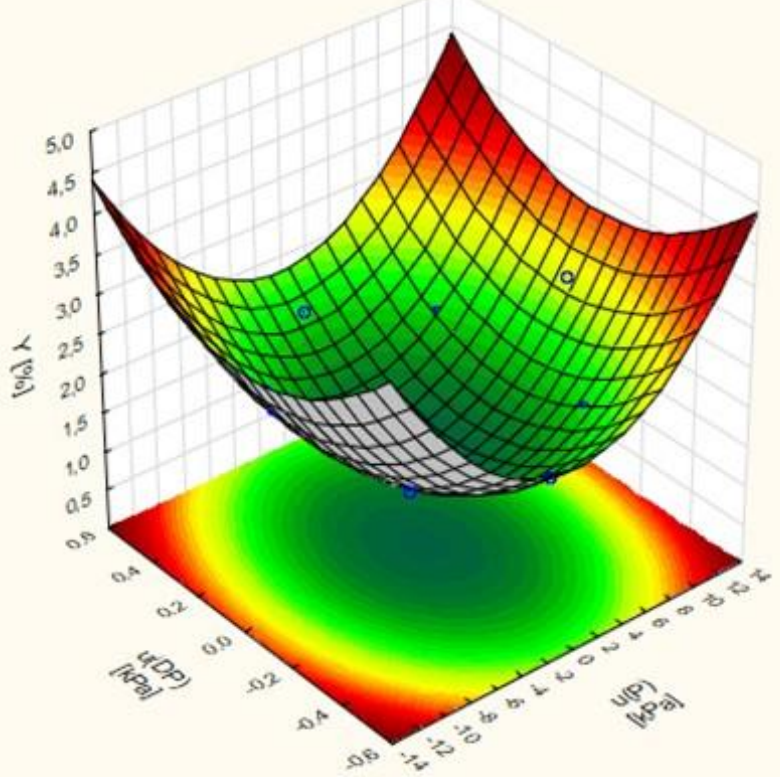

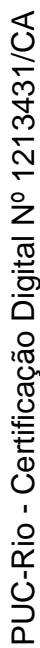

Figura A.59 - Superfície de resposta (EMED G1) dado uP e uDP (1\% f.e.)

Curva de nível; Variável: Y [\%] = uP x uDP - EMED G1

3 fatores, 1 Bloco, 19 Experimentos; Média Quadrática Residual =,005705

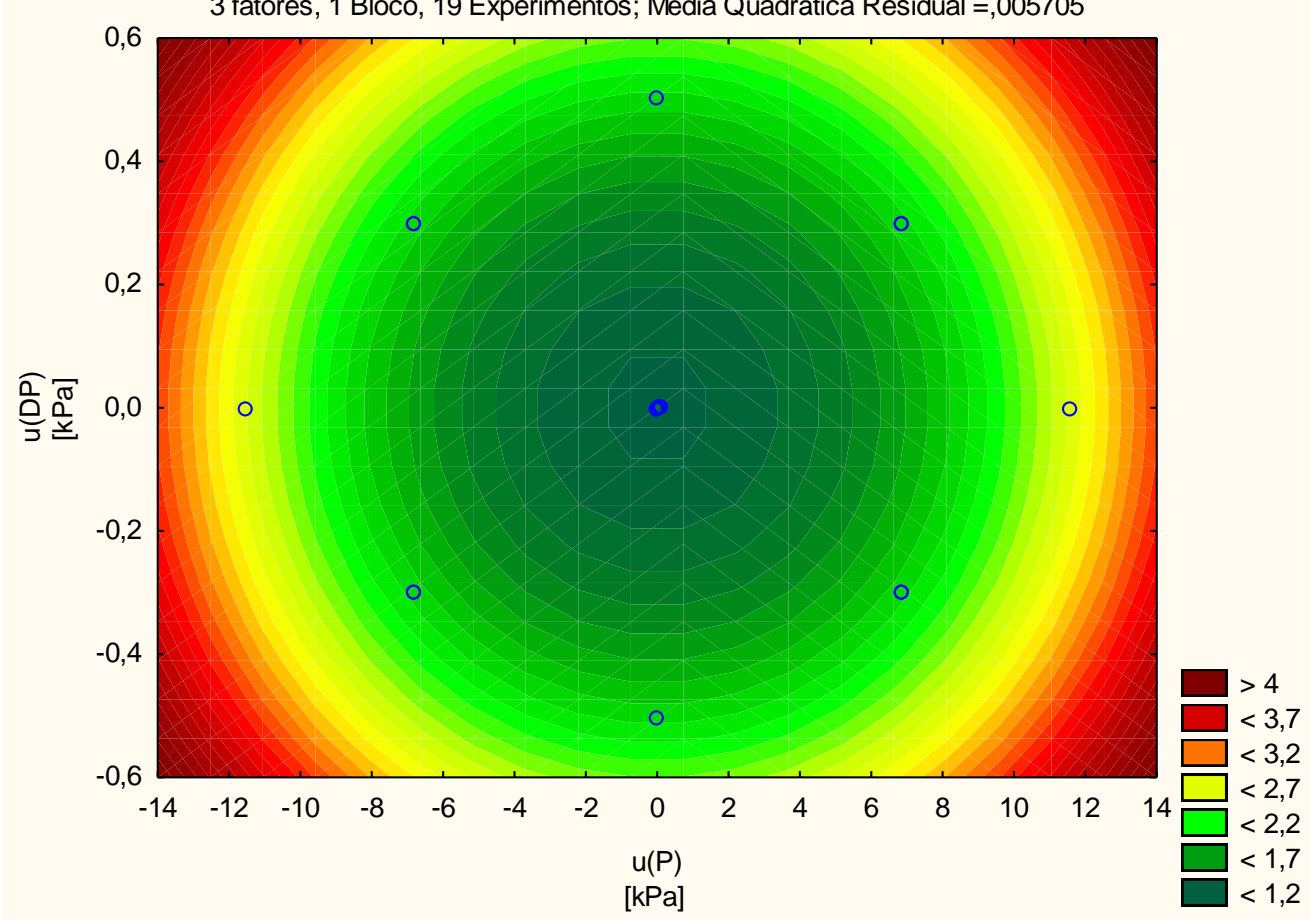

Figura A.60 - Curva de nível (EMED G1) dado uP e uDP (1 \% f.e.) 
Superficie de Resposta; Variável: $Y$ [\%] = uP x uT - EMED G1

3 fatores, 1 Bloco, 19 Experimentos; Média Quadrática Residual =, 005705

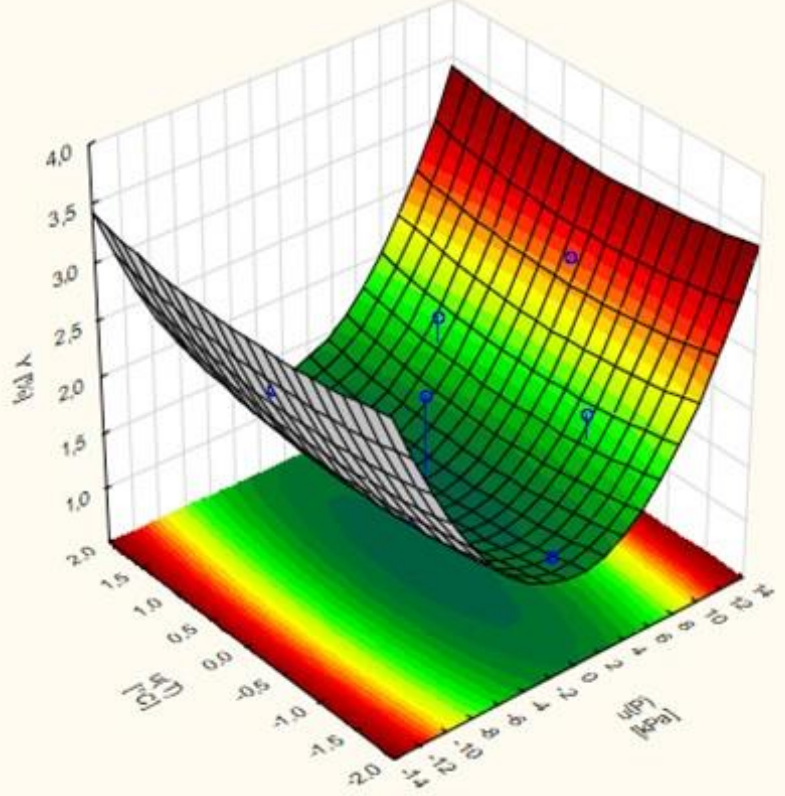

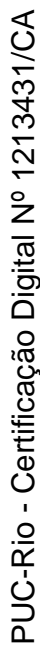

Figura A.61 - Superfície de resposta (EMED G1) dado uP (1\% f.e.) e uT $\left( \pm 1^{\circ} \mathrm{C}\right)$

Curva de nível; Variável: Y [\%] = uP x uT - EMED G1

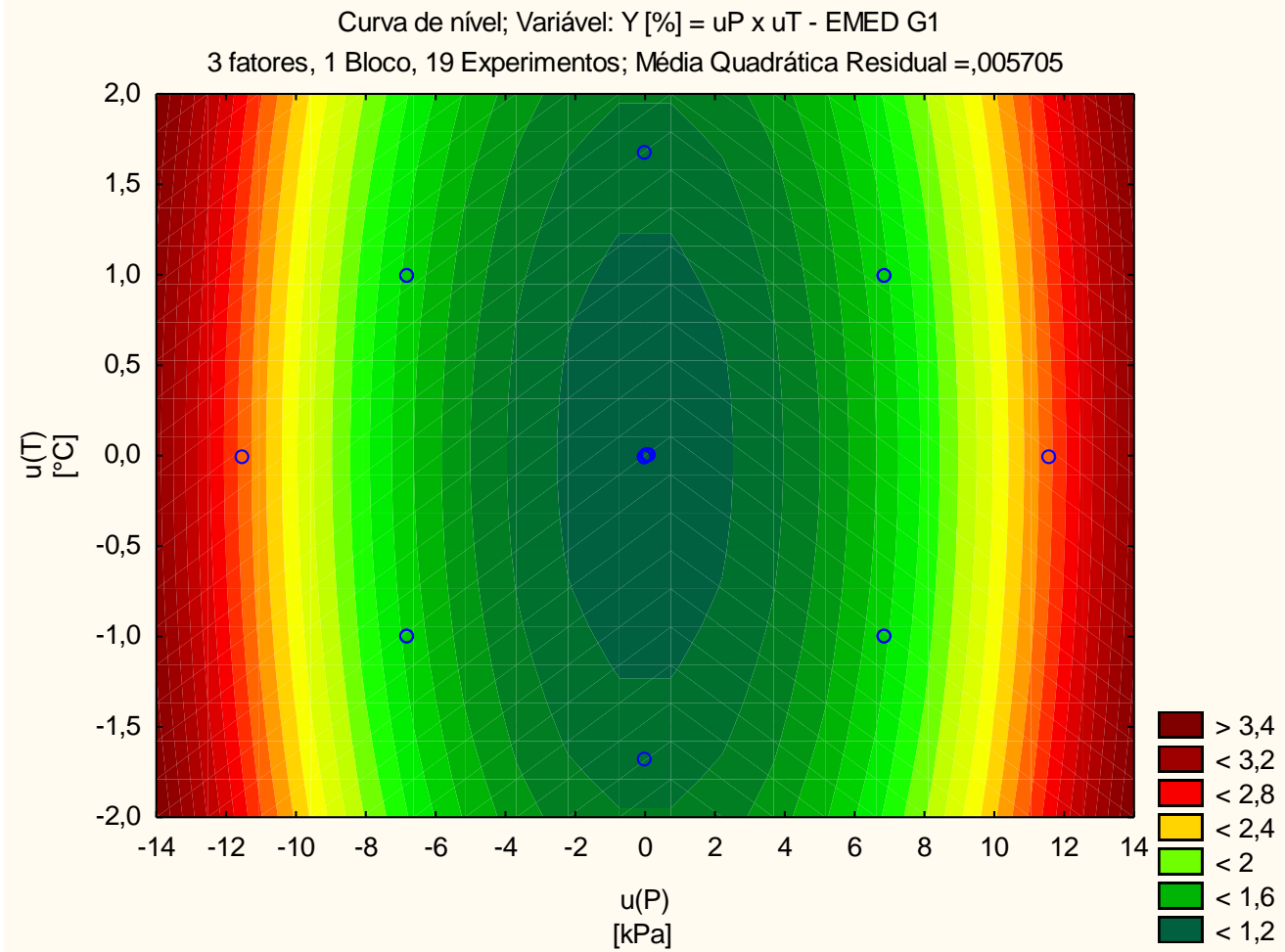

Figura A.62 - Curva de nível (EMED G1) dado uP (1\% f.e.) e uT $\left( \pm 1{ }^{\circ} \mathrm{C}\right)$ 
Superficie de Resposta; Variável: $Y$ [\%] = UT X UDP - EMED G1

3 fatores, 1 Bloco, 19 Experimentos; Média Quadrática Residual $=, 005705$
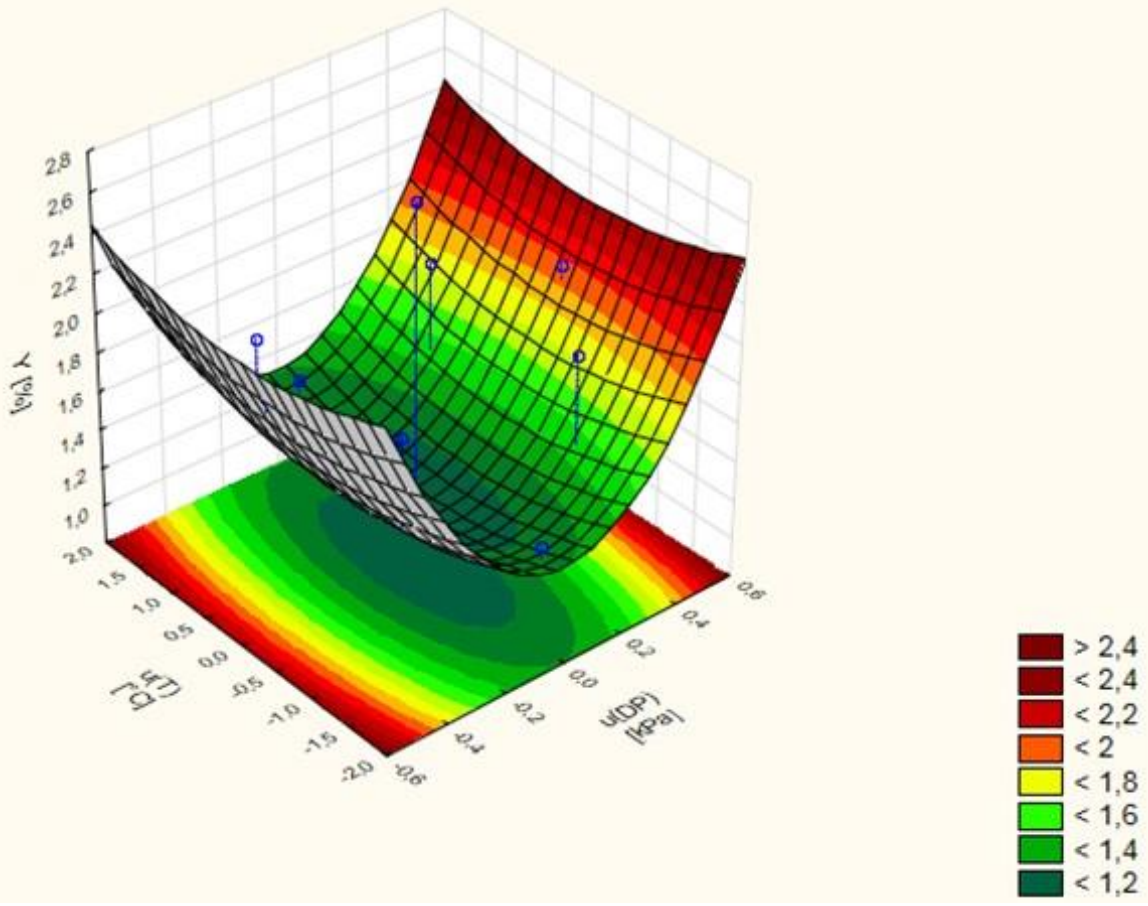

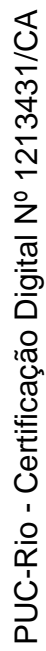

Figura A.63 - Superfície de resposta (EMED G1) dado uDP (1\% f.e.) e uT $\left( \pm 1^{\circ} \mathrm{C}\right)$

Curva de nível; Variável: Y [\%] = UT x UDP - EMED G1

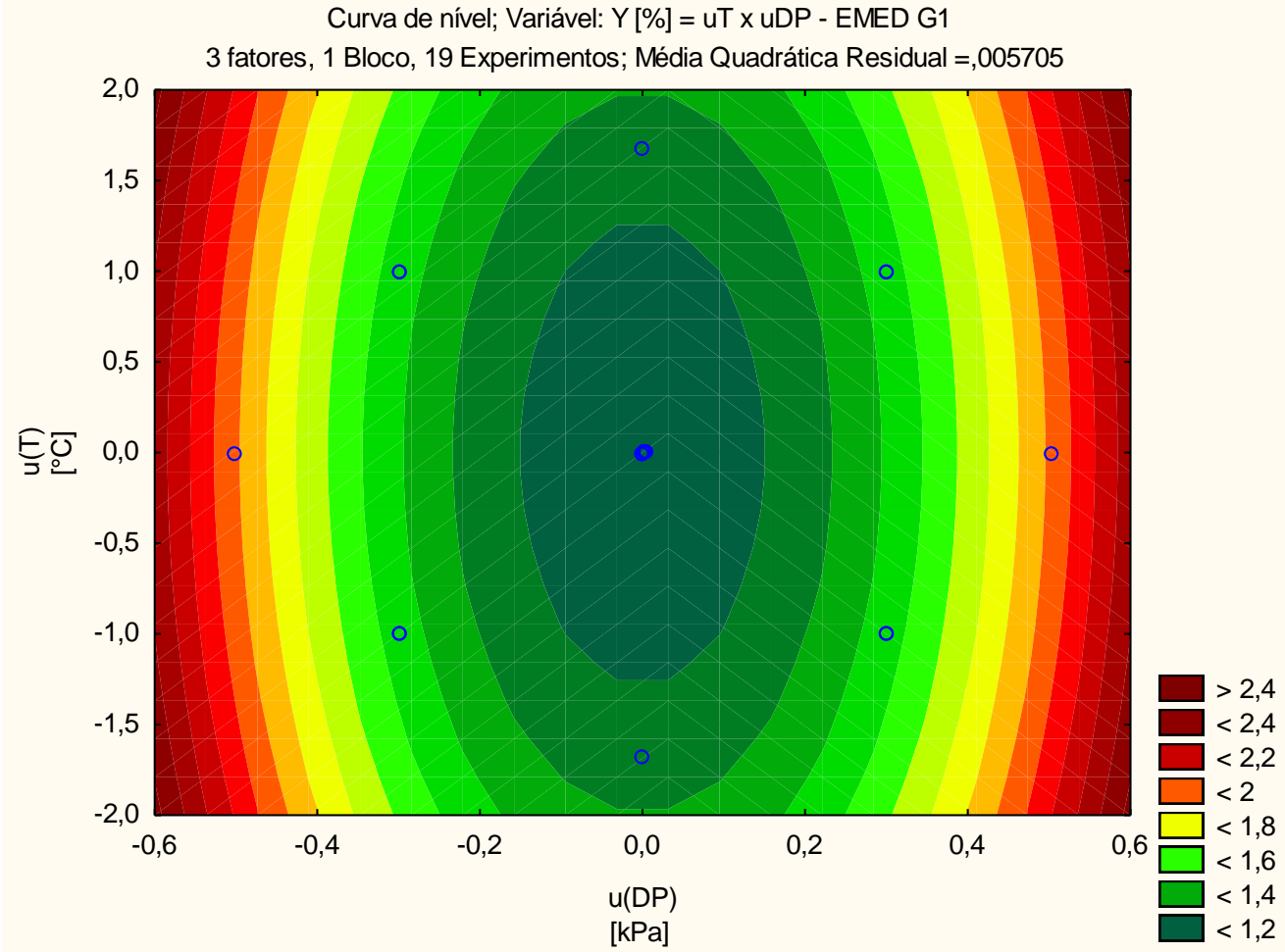

Figura A.64 - Curva de nível (EMED G1) dado uDP (1\% f.e.) e uT $\left( \pm 1{ }^{\circ} \mathrm{C}\right)$ 


\section{A.9}

\section{Estação G2 - estação de medição para apropriação}

Tabela A.25 - Matriz de planejamento experimental da EMED G2

\begin{tabular}{|c|c|c|c|c|c|c|c|}
\hline \multicolumn{7}{|c|}{ Matriz do planejamento } & $\begin{array}{c}\text { Incerteza da } \\
\text { vazão }\end{array}$ \\
\hline Exp & $\mathrm{x} 1$ & $\mathrm{x} 2$ & $\mathrm{x} 3$ & $\begin{array}{c}\mathrm{P} \\
{[\mathrm{kPa}]}\end{array}$ & $\mathrm{DP}[\mathrm{kPa}]$ & $\begin{array}{c}\mathrm{T} \\
{\left[{ }^{\circ} \mathrm{C}\right]}\end{array}$ & $\mathrm{y}(\%)$ \\
\hline 1 & -1 & -1 & -1 & $-6,8600$ & $-0,2991$ & $-1,0000$ & 4,61 \\
2 & 1 & -1 & -1 & 6,8600 & $-0,2991$ & $-1,0000$ & 4,61 \\
3 & -1 & 1 & -1 & $-6,8600$ & 0,2991 & $-1,0000$ & 4,61 \\
4 & 1 & 1 & -1 & 6,8600 & 0,2991 & $-1,0000$ & 4,61 \\
5 & -1 & -1 & 1 & $-6,8600$ & $-0,2991$ & 1,0000 & 4,61 \\
6 & 1 & -1 & 1 & 6,8600 & $-0,2991$ & 1,0000 & 4,61 \\
7 & -1 & 1 & 1 & $-6,8600$ & 0,2991 & 1,0000 & 4,61 \\
8 & 1 & 1 & 1 & 6,8600 & 0,2991 & 1,0000 & 4,61 \\
9 & $-1,682$ & 0 & 0 & $-11,5385$ & 0,0000 & 0,0000 & 2,63 \\
10 & 1,682 & 0 & 0 & 11,5385 & 0,0000 & 0,0000 & 2,63 \\
11 & 0 & $-1,682$ & 0 & 0,0000 & $-0,5031$ & 0,0000 & 7,39 \\
12 & 0 & 1,682 & 0 & 0,0000 & 0,5031 & 0,0000 & 7,39 \\
13 & 0 & 0 & $-1,682$ & 0,0000 & 0,0000 & $-1,6820$ & 1,32 \\
14 & 0 & 0 & 1,682 & 0,0000 & 0,0000 & 1,6820 & 1,32 \\
15 & 0 & 0 & 0 & 0,0000 & 0,0000 & 0,0000 & 1,12 \\
16 & 0 & 0 & 0 & 0,0552 & 0,0016 & 0,0186 & 1,12 \\
17 & 0 & 0 & 0 & 0,0578 & 0,0013 & 0,0112 & 1,12 \\
18 & 0 & 0 & 0 & 0,0321 & 0,0006 & 0,0135 & 1,12 \\
19 & 0 & 0 & 0 & 0,0349 & 0,0004 & 0,0098 & 1,12 \\
\hline
\end{tabular}

Tabela A.26 - Tabela de ANOVA do planejamento de experimentos da EMED G2

\begin{tabular}{|c|c|c|c|c|c|}
\hline \multirow[b]{2}{*}{ Fonte de variação } & \multicolumn{5}{|c|}{$\begin{array}{c}\text { ANOVA; Var.:Y [\%]; } \mathrm{R}^{2}=, 98182 ; \mathrm{R}_{\mathrm{a}}^{2}, 96364 \\
3 \text { fatores, } 1 \text { Bloco, } 19 \text { Experimentos; Média Quadrática Residual =,1604804 }\end{array}$} \\
\hline & $\begin{array}{c}\text { Soma de } \\
\text { Quadrados }\end{array}$ & $\begin{array}{l}\text { Graus de } \\
\text { liberdade }\end{array}$ & $\begin{array}{l}\text { Quadrados } \\
\text { médios }\end{array}$ & Teste F & $\mathrm{p}$ \\
\hline$(1) \mathrm{u}(\mathrm{P})[\mathrm{kPa}](\mathrm{L})$ & 0,00000 & 1 & 0,00000 & 0,0000 & 0,999644 \\
\hline $\mathrm{u}(\mathrm{P})[\mathrm{kPa}](\mathrm{Q})$ & 6,28121 & 1 & 6,28121 & 39,1401 & 0,000149 \\
\hline$(2) \mathrm{u}(\mathrm{DP})[\mathrm{kPa}](\mathrm{L})$ & 0,00000 & 1 & 0,00000 & 0,0000 & 0,999824 \\
\hline $\mathrm{u}(\mathrm{DP})[\mathrm{kPa}](\mathrm{Q})$ & 76,03268 & 1 & 76,03268 & 473,7817 & 0,000000 \\
\hline$(3) \mathrm{u}(\mathrm{T})\left[{ }^{\circ} \mathrm{C}\right](\mathrm{L})$ & 0,00000 & 1 & 0,00000 & 0,0000 & 0,999278 \\
\hline $\mathrm{u}(\mathrm{T})\left[{ }^{\circ} \mathrm{C}\right](\mathrm{Q})$ & 0,62695 & 1 & 0,62695 & 3,9067 & 0,079501 \\
\hline $1 \mathrm{~L} \times 2 \mathrm{~L}$ & 0,00000 & 1 & 0,00000 & 0,0000 & 0,999998 \\
\hline $1 \mathrm{~L} \times 3 \mathrm{~L}$ & 0,00000 & 1 & 0,00000 & 0,0000 & 0,999994 \\
\hline $2 \mathrm{~L} \times 3 \mathrm{~L}$ & 0,00000 & 1 & 0,00000 & 0,0000 & 0,999997 \\
\hline Erro & 1,44432 & 9 & 0,16048 & & \\
\hline Total SQ & 79,44589 & 18 & & & \\
\hline
\end{tabular}


Gráfico de Pareto dos Efeitos; Variável: Y[\%] - EMED G2

3 fatores, 1 Bloco, 19 Experimentos; Média Quadrática Residual =,1604804

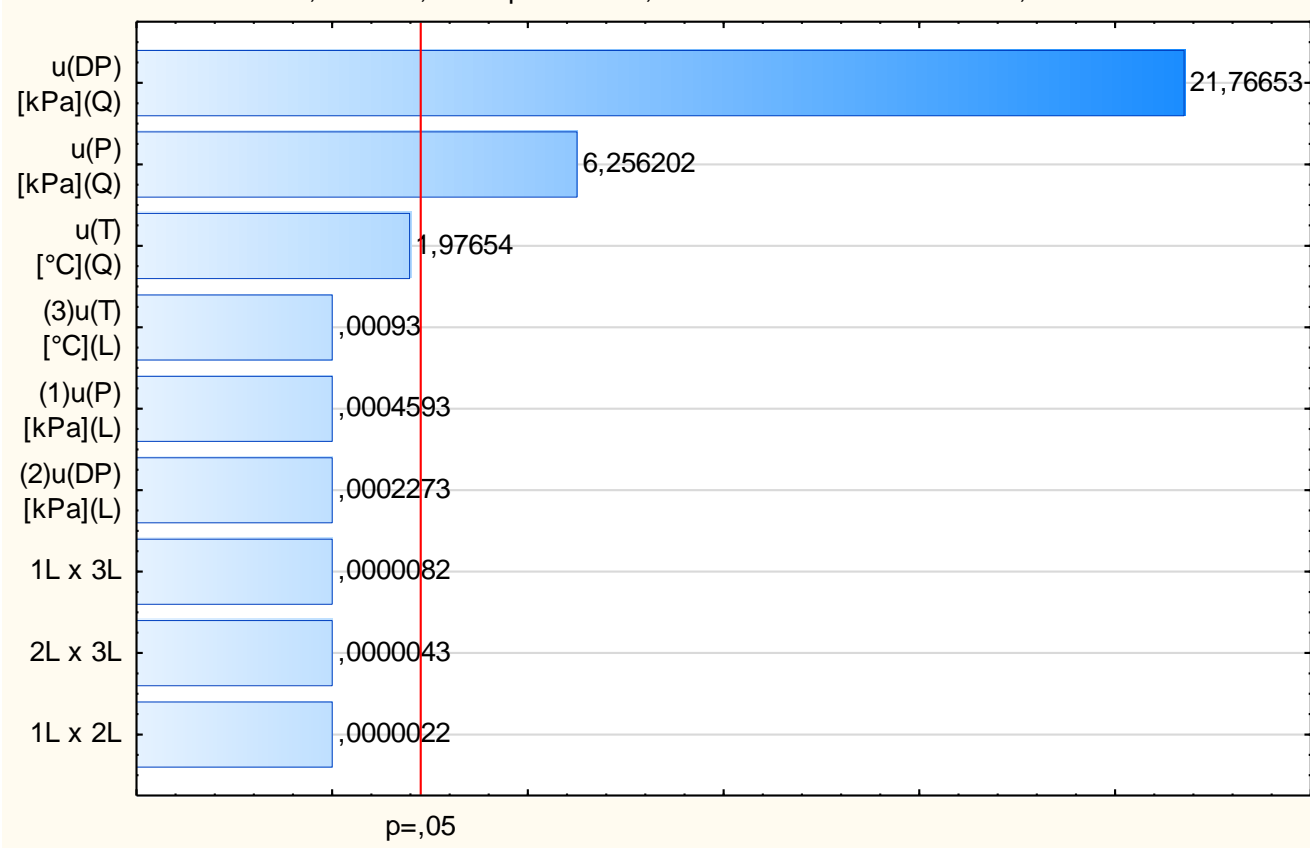

Estimativa dos Efeitos Padronizados (Valor absoluto)

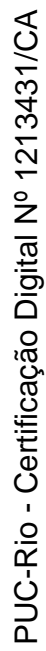

Figura A.65 - Gráfico de Pareto em função dos valores da estatística de teste t

Valores Previstos vs. Valores Residuais - EMED G2

3 factors, 1 Blocks, 19 Runs; MS Residual=,1604804

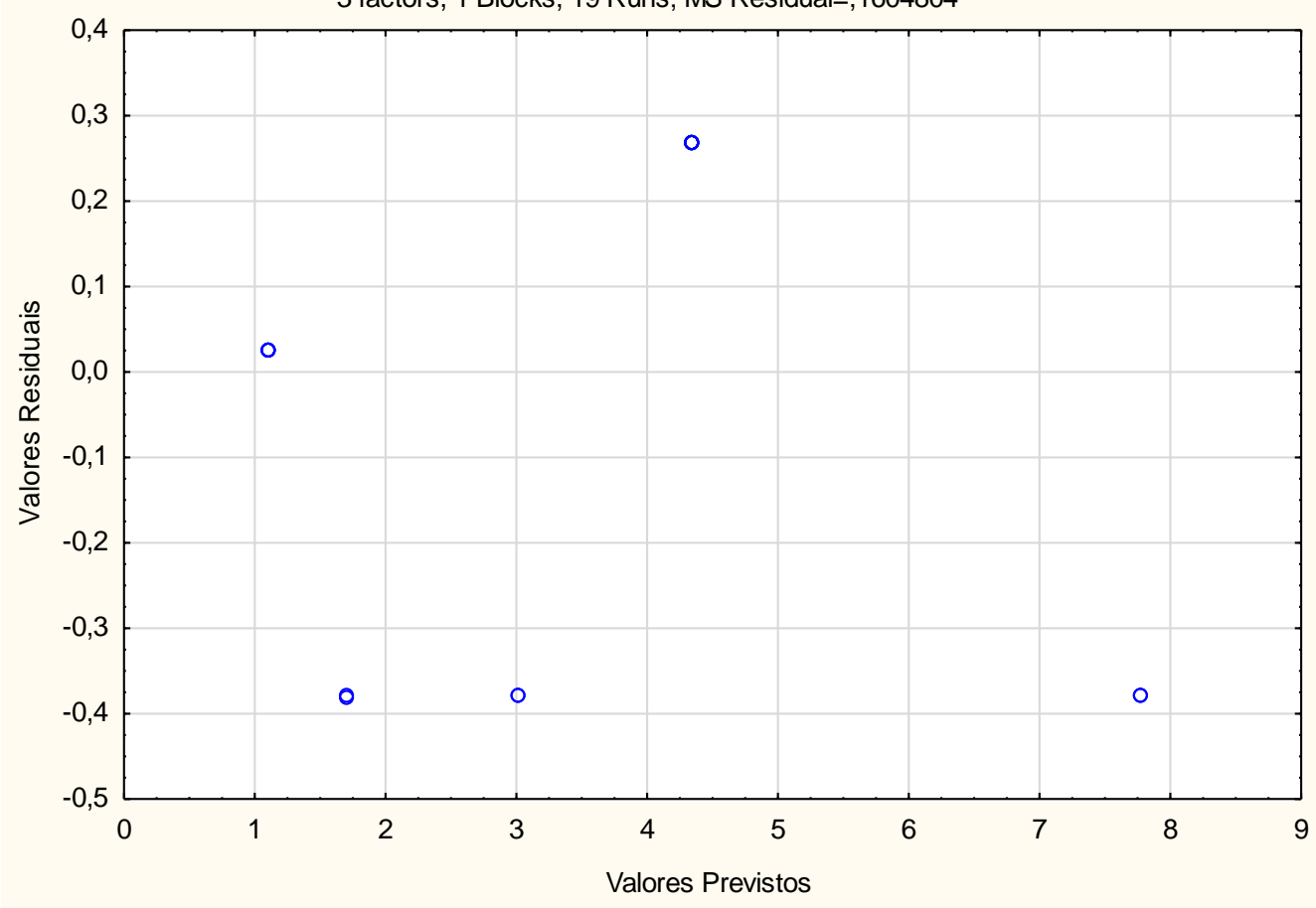

Figura A.66 - Resíduos versus estimativas de y (EMED G2 - nível: $1 \%$ f.e. e $1{ }^{\circ} \mathrm{C}$ ) 
Tabela A.27 - Matriz das incertezas estimadas da vazão (EMED G2)

(dado $x_{3}(T)$ igual a 1 e $x_{1}$ e $x_{2}$ variando do nível baixo ao nível alto)

\begin{tabular}{|c|c|c|c|c|c|c|c|c|c|c|c|}
\multicolumn{1}{c|}{} & \multicolumn{10}{c|}{$\mathbf{x}_{\mathbf{1}}$} \\
\cline { 2 - 14 } & -1 & $-0,8$ & $-0,6$ & $-0,4$ & $-0,2$ & 0 & 0,2 & 0,4 & 0,6 & 0,8 & 1 \\
\hline-1 & 4,35 & 4,10 & 3,91 & 3,78 & 3,70 & 3,67 & 3,70 & 3,78 & 3,91 & 4,10 & 4,35 \\
\hline$-0,8$ & 3,50 & 3,25 & 3,06 & 2,93 & 2,85 & 2,82 & 2,85 & 2,93 & 3,06 & 3,25 & 3,50 \\
\hline$-0,6$ & 2,84 & 2,59 & 2,40 & 2,27 & 2,19 & 2,16 & 2,19 & 2,27 & 2,40 & 2,59 & 2,84 \\
\hline$-0,4$ & 2,36 & 2,12 & 1,93 & 1,79 & 1,71 & 1,69 & 1,71 & 1,79 & 1,93 & 2,12 & 2,36 \\
\hline$-0,2$ & 2,08 & 1,84 & 1,65 & 1,51 & $\mathbf{1 , 4 3}$ & 1,40 & $\mathbf{1 , 4 3}$ & 1,51 & 1,65 & 1,84 & 2,08 \\
\hline 0 & 1,99 & 1,74 & 1,55 & 1,42 & 1,34 & 1,31 & 1,34 & 1,42 & 1,55 & 1,74 & 1,99 \\
\hline 0,2 & 2,08 & 1,84 & 1,65 & 1,51 & $\mathbf{1 , 4 3}$ & 1,40 & $\mathbf{1 , 4 3}$ & 1,51 & 1,65 & 1,84 & 2,08 \\
\hline 0,4 & 2,36 & 2,12 & 1,93 & 1,79 & 1,71 & 1,69 & 1,71 & 1,79 & 1,93 & 2,12 & 2,36 \\
\hline 0,6 & 2,84 & 2,59 & 2,40 & 2,27 & 2,19 & 2,16 & 2,19 & 2,27 & 2,40 & 2,59 & 2,84 \\
\hline 0,8 & 3,50 & 3,25 & 3,06 & 2,93 & 2,85 & 2,82 & 2,85 & 2,93 & 3,06 & 3,25 & 3,50 \\
\hline 1 & 4,35 & 4,10 & 3,91 & 3,78 & 3,70 & 3,67 & 3,70 & 3,78 & 3,91 & 4,10 & 4,35 \\
\hline
\end{tabular}

Superficie de Resposta; Variável: $Y$ [\%] = uP x uDP - EMED G2

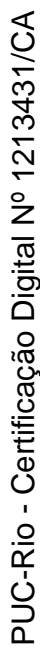
3 fatores, 1 Bloco, 19 Experimentos; Média Quadrática Residual =, 1604804

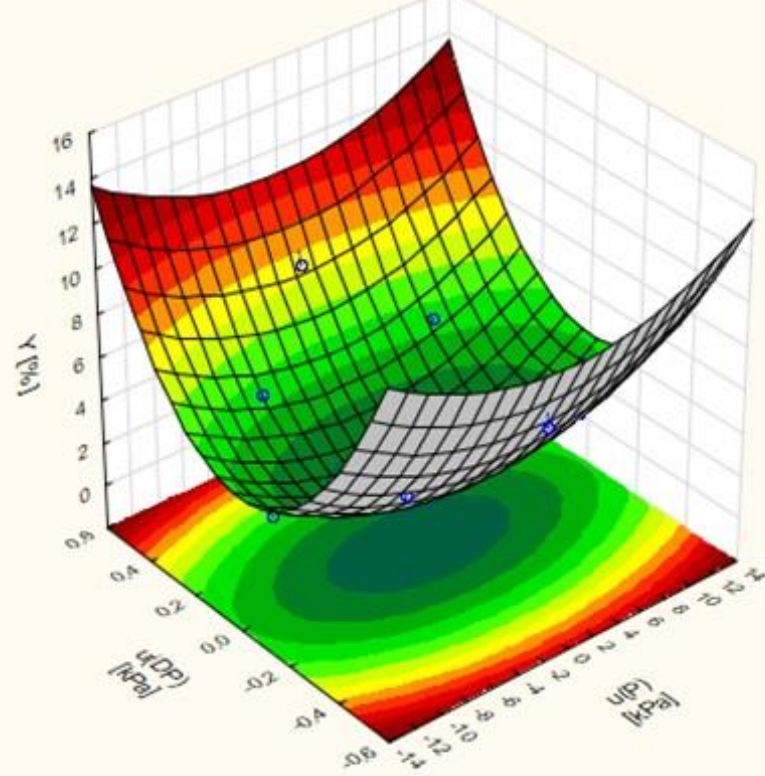

Figura A.67 - Superfície de resposta (EMED G2) dado uP e uDP (1 \% f.e.)

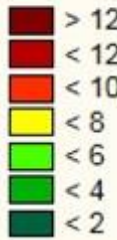


Curva de nível; Variável: Y [\%] = uP x uDP - EMED G2

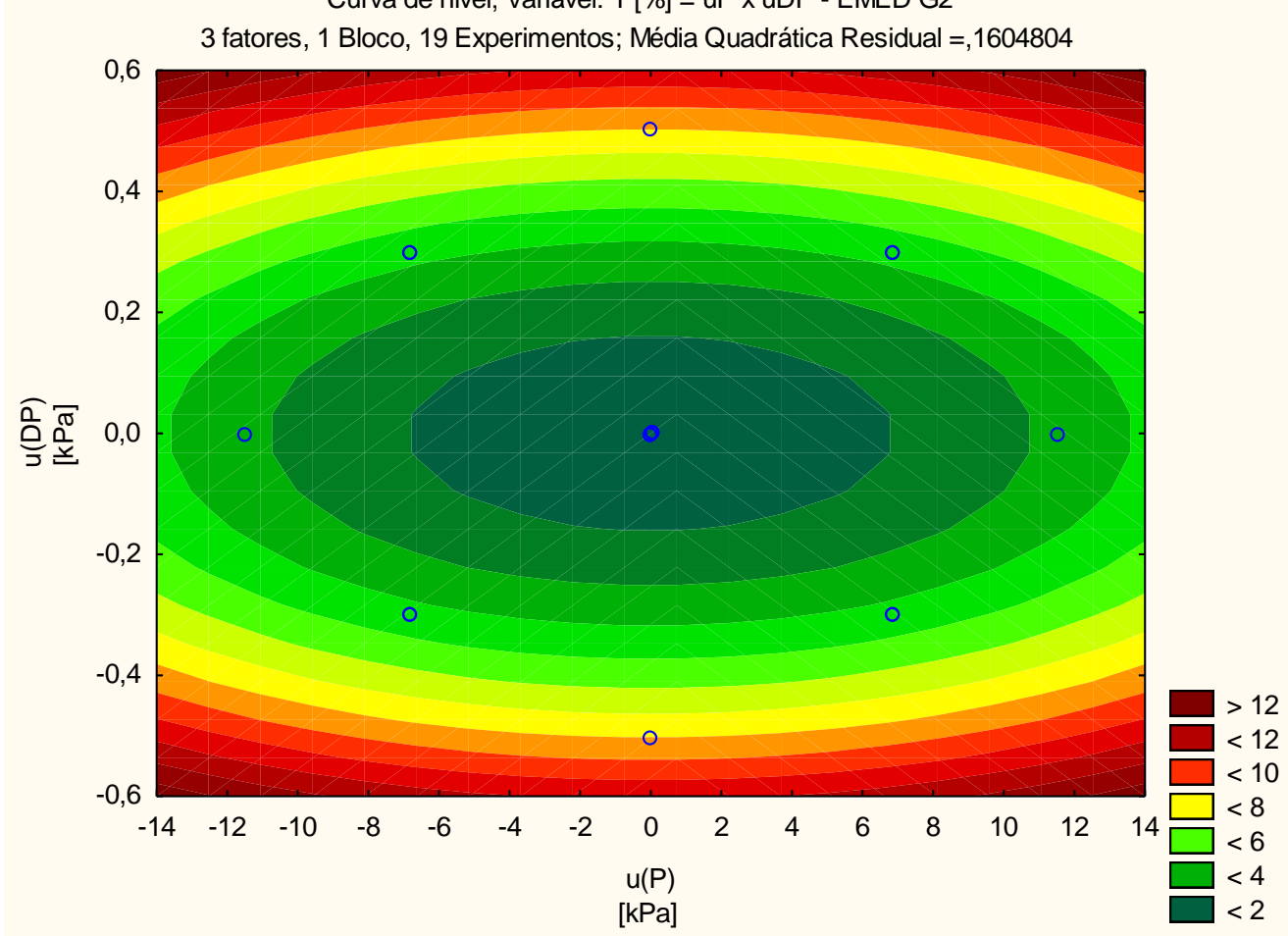

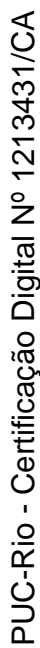

Figura A.68 - Curva de nível (EMED G2) dado uP e uDP ( $1 \%$ f.e.)

Superficie de Resposta; Variável: Y [\%] = UP x UT - EMED G2

3 fatores, 1 Bloco, 19 Experimentos; Média Quadrática Residual $=, 1604804$

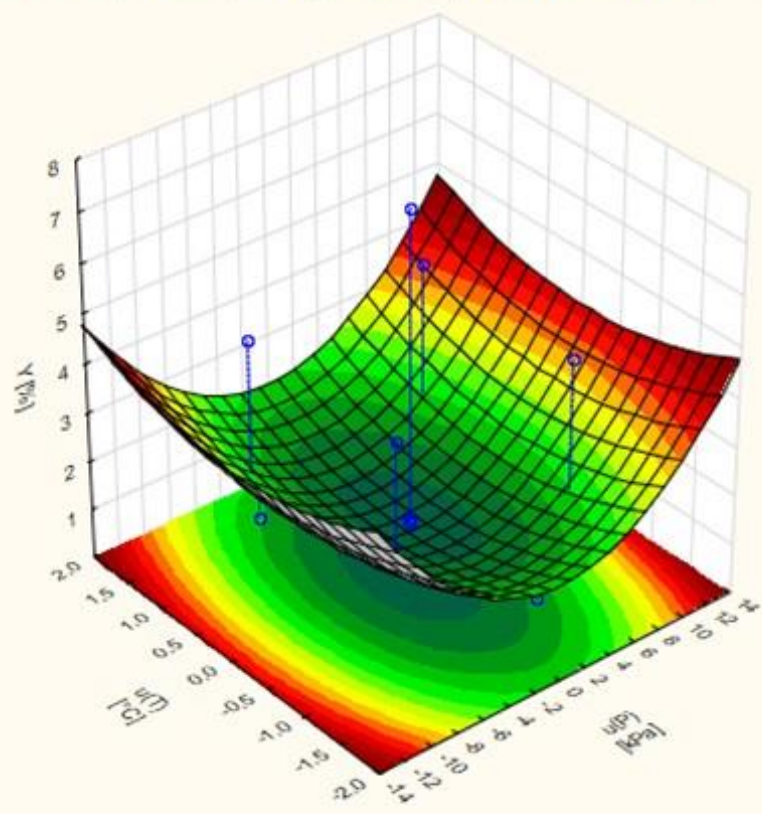

Figura A.69 - Superfície de resposta (EMED G2) dado uP (1\% f.e.) e uT $\left( \pm 1^{\circ} \mathrm{C}\right)$ 
Curva de nível; Variável: Y [\%] = uP x uT - EMED G2

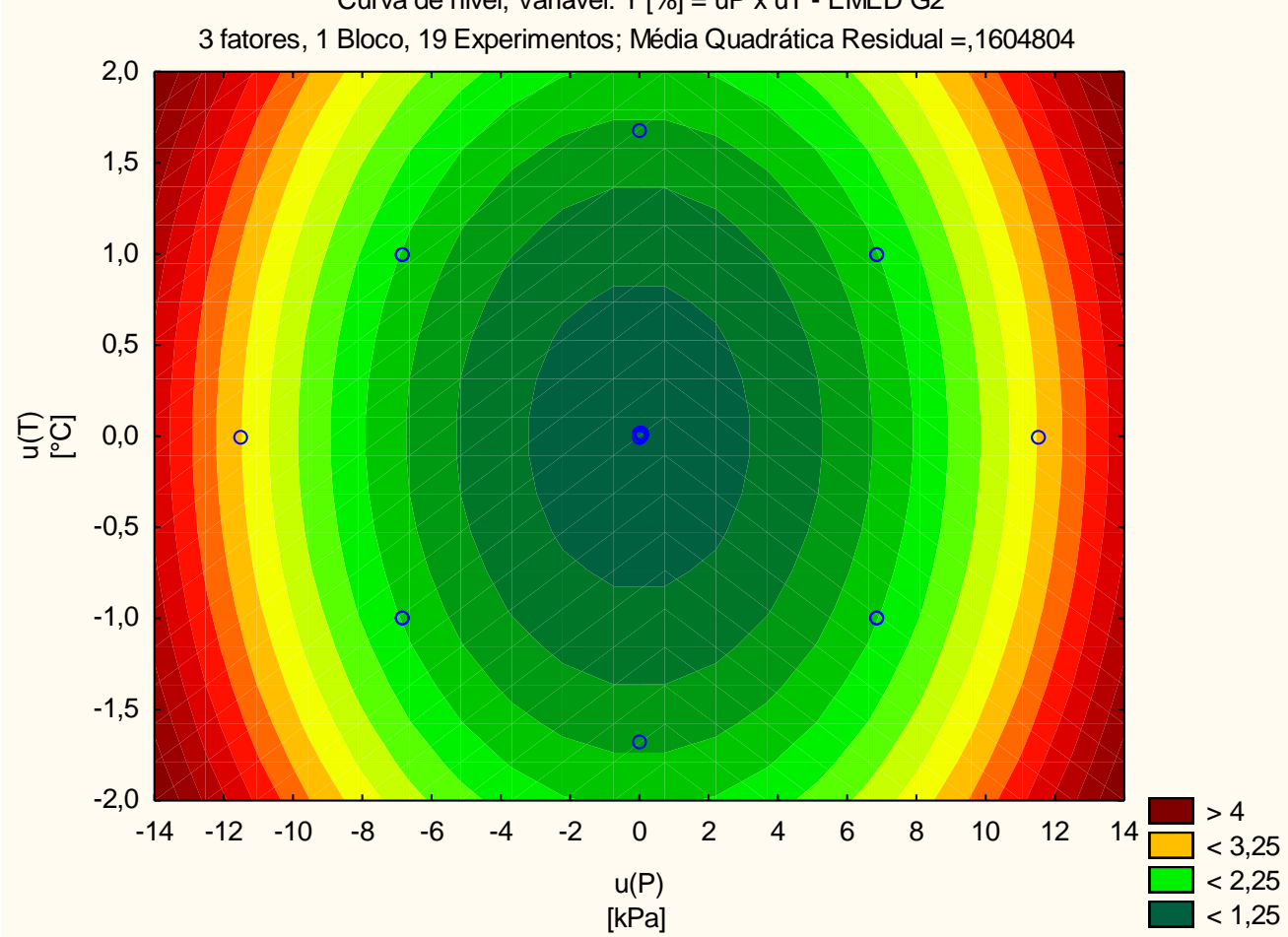

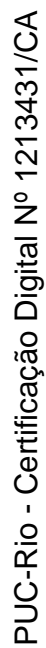

Figura A.70 - Curva de nível (EMED G2) dado uP ( $1 \%$ f.e. $)$ e uT $\left( \pm 1{ }^{\circ} \mathrm{C}\right)$

Superficie de Resposta; Variável: $Y$ [\%] = UT x uDP - EMED G2

3 fatores, 1 Bloco, 19 Experimentos; Média Quadrática Residual $=, 1604804$

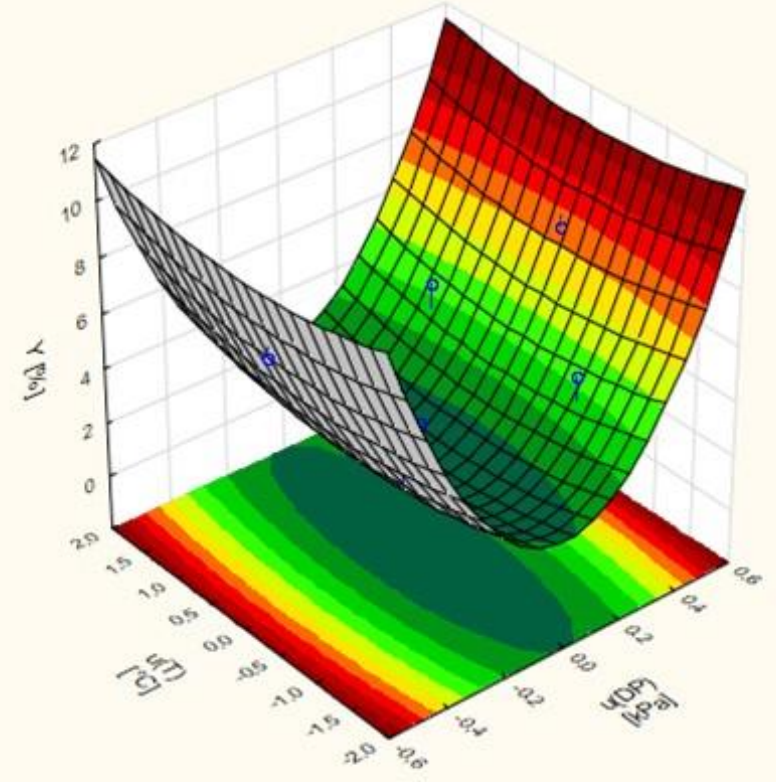

Figura A.71 - Superfície de resposta (EMED G2) dado uDP (1\% f.e.) e uT $\left( \pm 1^{\circ} \mathrm{C}\right)$ 


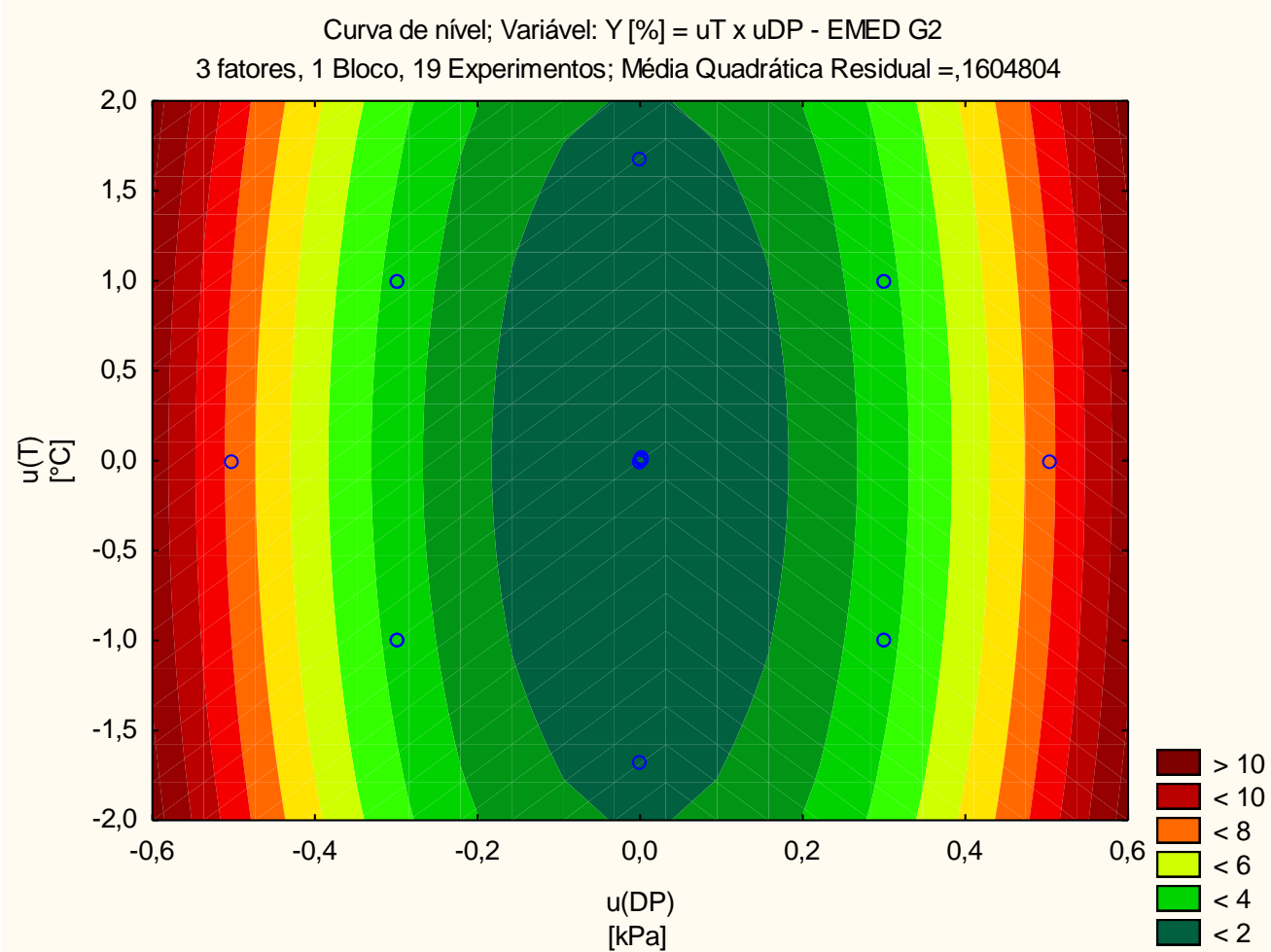

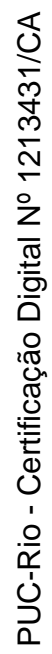

Figura A.72 - Curva de nível (EMED G2) dado uDP $\left(1 \%\right.$ f.e.) e uT $\left( \pm 1{ }^{\circ} \mathrm{C}\right)$

\section{A.10}

\section{Estação H - estação de medição fiscal}

Tabela A.28 - Matriz de planejamento experimental da EMED H

\begin{tabular}{|c|c|c|c|c|c|c|c|}
\hline \multicolumn{7}{|c|}{ Matriz do planejamento } & $\begin{array}{c}\text { Incerteza da } \\
\text { vazão }\end{array}$ \\
\hline Exp & $\mathrm{x} 1$ & $\mathrm{x} 2$ & $\mathrm{x} 3$ & $\begin{array}{c}\mathrm{P} \\
{[\mathrm{kPa}]}\end{array}$ & $\mathrm{DP}[\mathrm{kPa}]$ & $\begin{array}{c}\mathrm{T} \\
{\left[{ }^{\circ} \mathrm{C}\right]}\end{array}$ & $\mathrm{y}(\%)$ \\
\hline 1 & -1 & -1 & -1 & $-5,5800$ & $-0,4982$ & $-1,0000$ & 8,30 \\
2 & 1 & -1 & -1 & 5,5800 & $-0,4982$ & $-1,0000$ & 8,30 \\
3 & -1 & 1 & -1 & $-5,5800$ & 0,4982 & $-1,0000$ & 8,30 \\
4 & 1 & 1 & -1 & 5,5800 & 0,4982 & $-1,0000$ & 8,30 \\
5 & -1 & -1 & 1 & $-5,5800$ & $-0,4982$ & 1,0000 & 8,30 \\
6 & 1 & -1 & 1 & 5,5800 & $-0,4982$ & 1,0000 & 8,30 \\
7 & -1 & 1 & 1 & $-5,5800$ & 0,4982 & 1,0000 & 8,30 \\
8 & 1 & 1 & 1 & 5,5800 & 0,4982 & 1,0000 & 8,30 \\
9 & $-1,682$ & 0 & 0 & $-9,3856$ & 0,0000 & 0,0000 & 15,08 \\
10 & 1,68 & 0 & 0 & 9,3856 & 0,0000 & 0,0000 & 15,08 \\
11 & 0 & $-1,682$ & 0 & 0,0000 & $-0,8380$ & 0,0000 & 2,56 \\
12 & 0 & 1,682 & 0 & 0,0000 & 0,8380 & 0,0000 & 2,56 \\
13 & 0 & 0 & $-1,682$ & 0,0000 & 0,0000 & $-1,6820$ & 2,30 \\
14 & 0 & 0 & 1,682 & 0,0000 & 0,0000 & 1,6820 & 2,30 \\
15 & 0 & 0 & 0 & 0,0000 & 0,0000 & 0,0000 & 1,96 \\
16 & 0 & 0 & 0 & 0,0367 & 0,0276 & 0,0107 & 1,96 \\
17 & 0 & 0 & 0 & 0,1732 & 0,0227 & 0,0342 & 1,96 \\
18 & 0 & 0 & 0 & 0,0260 & 0,0419 & 0,0360 & 1,96 \\
19 & 0 & 0 & 0 & 0,1148 & 0,0616 & 0,0414 & 1,96 \\
\hline
\end{tabular}


Tabela A.29 - Tabela de ANOVA do planejamento de experimentos da EMED H

\begin{tabular}{|c|c|c|c|c|c|}
\hline & \multicolumn{5}{|c|}{ ANOVA; Var.:Y [\%]; $\mathrm{R}^{2}=, 98242 ; \mathrm{R}^{2}$ :,96483 } \\
Fonte de variação & $\begin{array}{c}\text { 3 fatores, 1 Bloco, 19 Experimentos; Média Quadrática Residual =,6637452 } \\
\text { Quadrados }\end{array}$ & $\begin{array}{c}\text { Graus de } \\
\text { liberdade }\end{array}$ & $\begin{array}{c}\text { Quadrados } \\
\text { médios }\end{array}$ & Teste F & $\mathrm{p}$ \\
\cline { 2 - 6 }$(1) \mathrm{u}(\mathrm{P})[\mathrm{kPa}](\mathrm{L})$ & 0,0000 & 1 & 0,0000 & 0,0000 & 0,999184 \\
\hline $\mathrm{u}(\mathrm{P})[\mathrm{kPa}](\mathrm{Q})$ & 331,7423 & 1 & 331,7423 & 499,8037 & 0,000000 \\
\hline$(2) \mathrm{u}(\mathrm{DP})[\mathrm{kPa}](\mathrm{L})$ & 0,0000 & 1 & 0,0000 & 0,0000 & 0,995958 \\
\hline $\mathrm{u}(\mathrm{DP})[\mathrm{kPa}](\mathrm{Q})$ & 3,5127 & 1 & 3,5127 & 5,2923 & 0,046961 \\
\hline$(3) \mathrm{u}(\mathrm{T})\left[{ }^{\circ} \mathrm{C}\right](\mathrm{L})$ & 0,0000 & 1 & 0,0000 & 0,0000 & 0,998402 \\
\hline $\mathrm{u}(\mathrm{T})\left[{ }^{\circ} \mathrm{C}\right](\mathrm{Q})$ & 2,3599 & 1 & 2,3599 & 3,5554 & 0,091985 \\
\hline $1 \mathrm{~L} \times 2 \mathrm{~L}$ & 0,0000 & 1 & 0,0000 & 0,0000 & 0,999922 \\
\hline $1 \mathrm{~L} \times 3 \mathrm{~L}$ & 0,0000 & 1 & 0,0000 & 0,0000 & 0,999964 \\
\hline $2 \mathrm{~L} \times 3 \mathrm{~L}$ & 0,0000 & 1 & 0,0000 & 0,0000 & 0,999827 \\
\hline Erro & 5,9737 & 9 & 0,6637 & & \\
\hline Total SQ & 339,7511 & 18 & & & \\
\hline
\end{tabular}

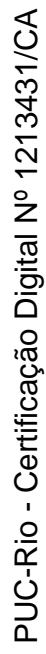

Gráfico de Pareto dos Efeitos; Variável: Y[\%] - EMED H

3 fatores, 1 Bloco, 19 Experimentos; Média Quadrática Residual =,6637452

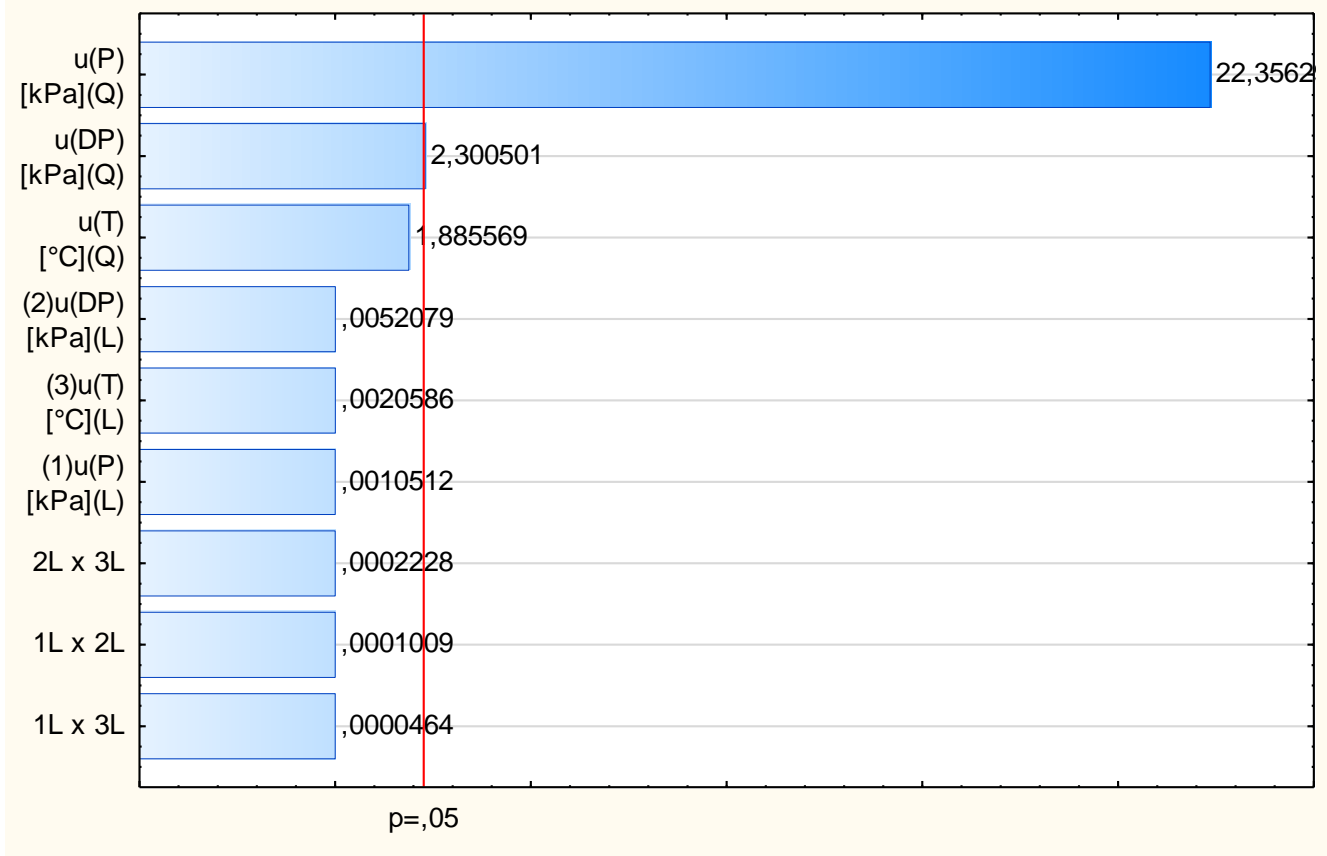

Estimativa dos Efeitos Padronizados (Valor absoluto)

Figura A.73 - Gráfico de Pareto em função dos valores da estatística de teste t 
Valores Previstos vs. Valores Residuais - EMED H

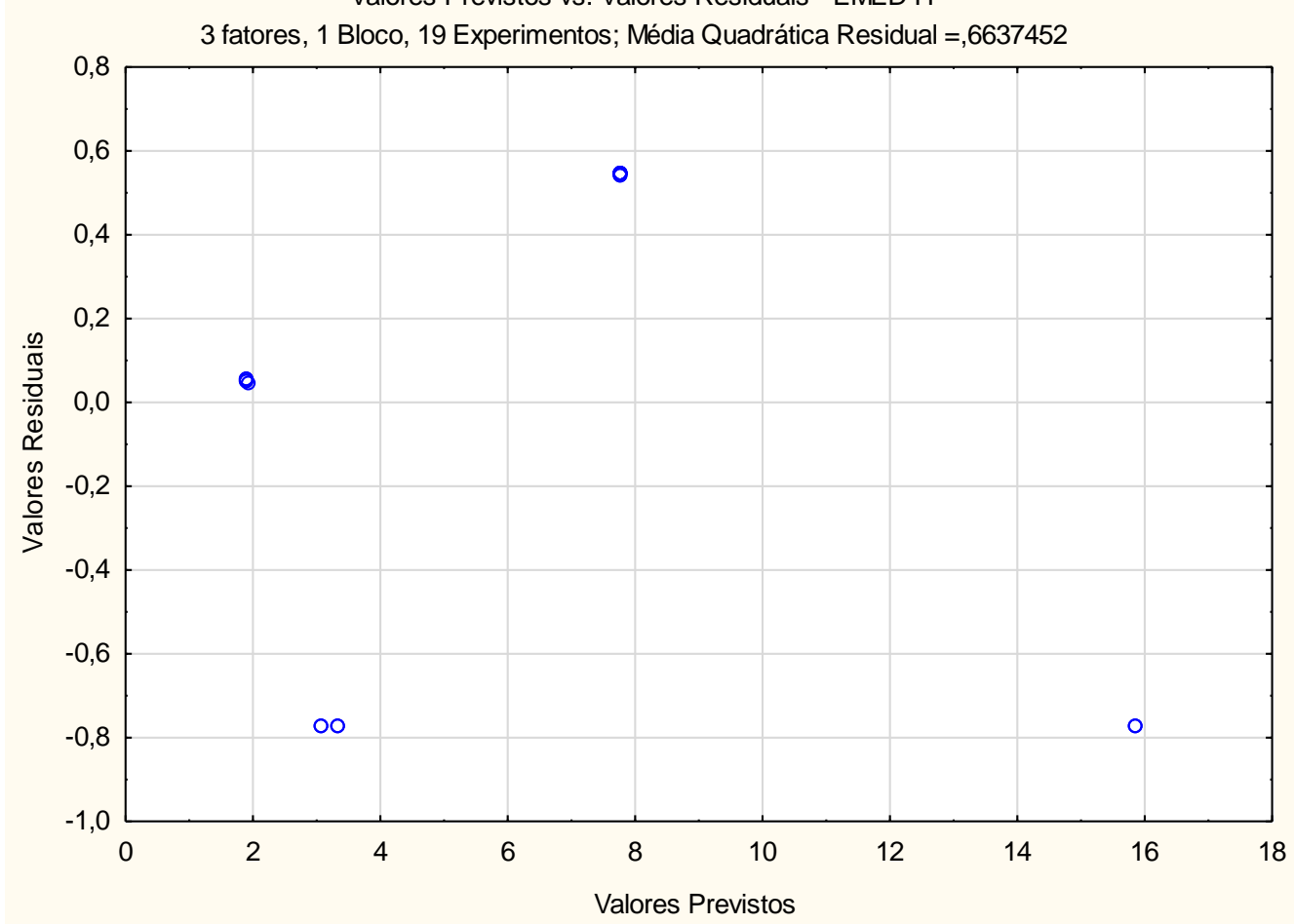

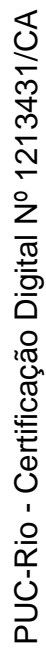

Figura A.74 - Resíduos versus estimativas de y (EMED H - nível: $1 \%$ f.e. e $1^{\circ} \mathrm{C}$ )

Tabela A.30 - Matriz das incertezas estimadas da vazão (EMED H) (dado $x_{3}(T)$ igual a 1 e $x_{1}$ e $x_{2}$ variando do nível baixo ao nível alto)

\begin{tabular}{|c|c|c|c|c|c|c|c|c|c|c|c|}
\multicolumn{1}{c|}{} \\
\cline { 2 - 13 } & -1 & $-0,8$ & $-0,6$ & $-0,4$ & $-0,2$ & 0 & 0,2 & 0,4 & 0,6 & 0,8 & 1 \\
\hline-1 & 7,75 & 5,98 & 4,60 & 3,61 & 3,02 & 2,82 & 3,02 & 3,61 & 4,60 & 5,98 & 7,75 \\
\hline$-0,8$ & 7,57 & 5,80 & 4,41 & 3,43 & 2,84 & 2,64 & 2,84 & 3,43 & 4,41 & 5,80 & 7,57 \\
\hline$-0,6$ & 7,43 & 5,65 & 4,27 & 3,29 & 2,69 & 2,50 & 2,69 & 3,29 & 4,27 & 5,65 & 7,43 \\
\hline$-0,4$ & 7,33 & 5,55 & 4,17 & 3,18 & 2,59 & 2,39 & 2,59 & 3,18 & 4,17 & 5,55 & 7,33 \\
\hline$-0,2$ & 7,27 & 5,49 & 4,11 & 3,12 & 2,53 & 2,33 & 2,53 & 3,12 & 4,11 & 5,49 & 7,27 \\
\hline 0 & 7,25 & 5,47 & 4,09 & 3,10 & 2,51 & 2,31 & 2,51 & 3,10 & 4,09 & 5,47 & 7,25 \\
\hline 0,2 & 7,27 & 5,49 & 4,11 & 3,12 & 2,53 & 2,33 & 2,53 & 3,12 & 4,11 & 5,49 & 7,27 \\
\hline 0,4 & 7,33 & 5,55 & 4,17 & 3,18 & 2,59 & 2,39 & 2,59 & 3,18 & 4,17 & 5,55 & 7,33 \\
\hline 0,6 & 7,43 & 5,65 & 4,27 & 3,29 & 2,69 & 2,50 & 2,69 & 3,29 & 4,27 & 5,65 & 7,43 \\
\hline 0,8 & 7,57 & 5,80 & 4,41 & 3,43 & 2,84 & 2,64 & 2,84 & 3,43 & 4,41 & 5,80 & 7,57 \\
\hline 1 & 7,75 & 5,98 & 4,60 & 3,61 & 3,02 & 2,82 & 3,02 & 3,61 & 4,60 & 5,98 & 7,75 \\
\hline
\end{tabular}


Superficie de Resposta; Variável: Y [\%] = uP x uDP - EMED H

3 fatores, 1 Bloco, 19 Experimentos; Média Quadrática Residual $=, 6637452$

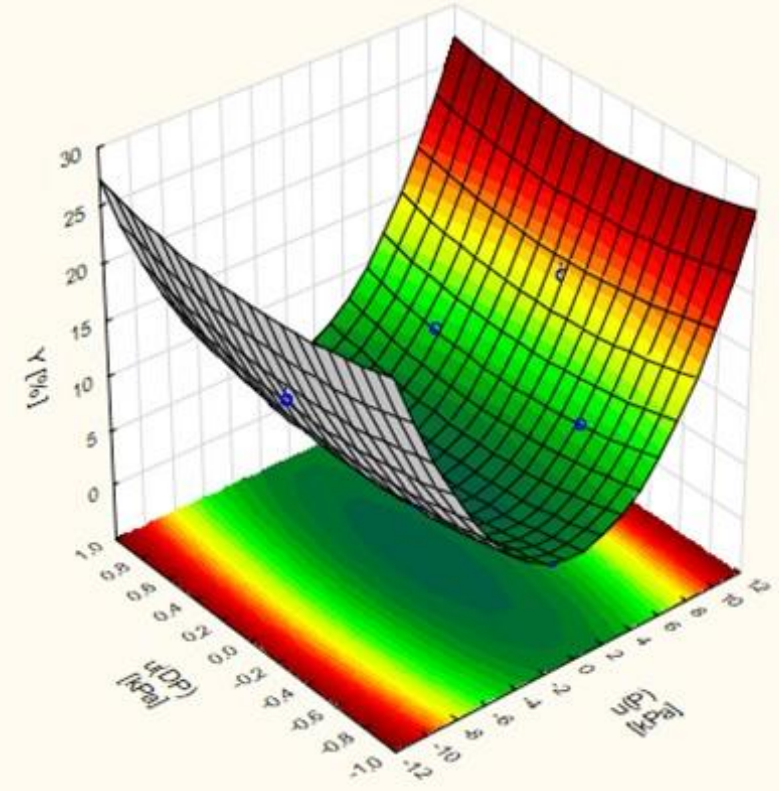

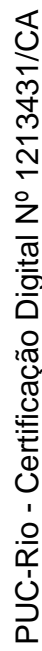

Figura A.75 - Superfície de resposta (EMED H) dado uP e uDP (1 \% f.e.)

Curva de nível; Variável: Y [\%] = uP x uDP - EMED H

3 fatores, 1 Bloco, 19 Experimentos; Média Quadrática Residual =,6637452

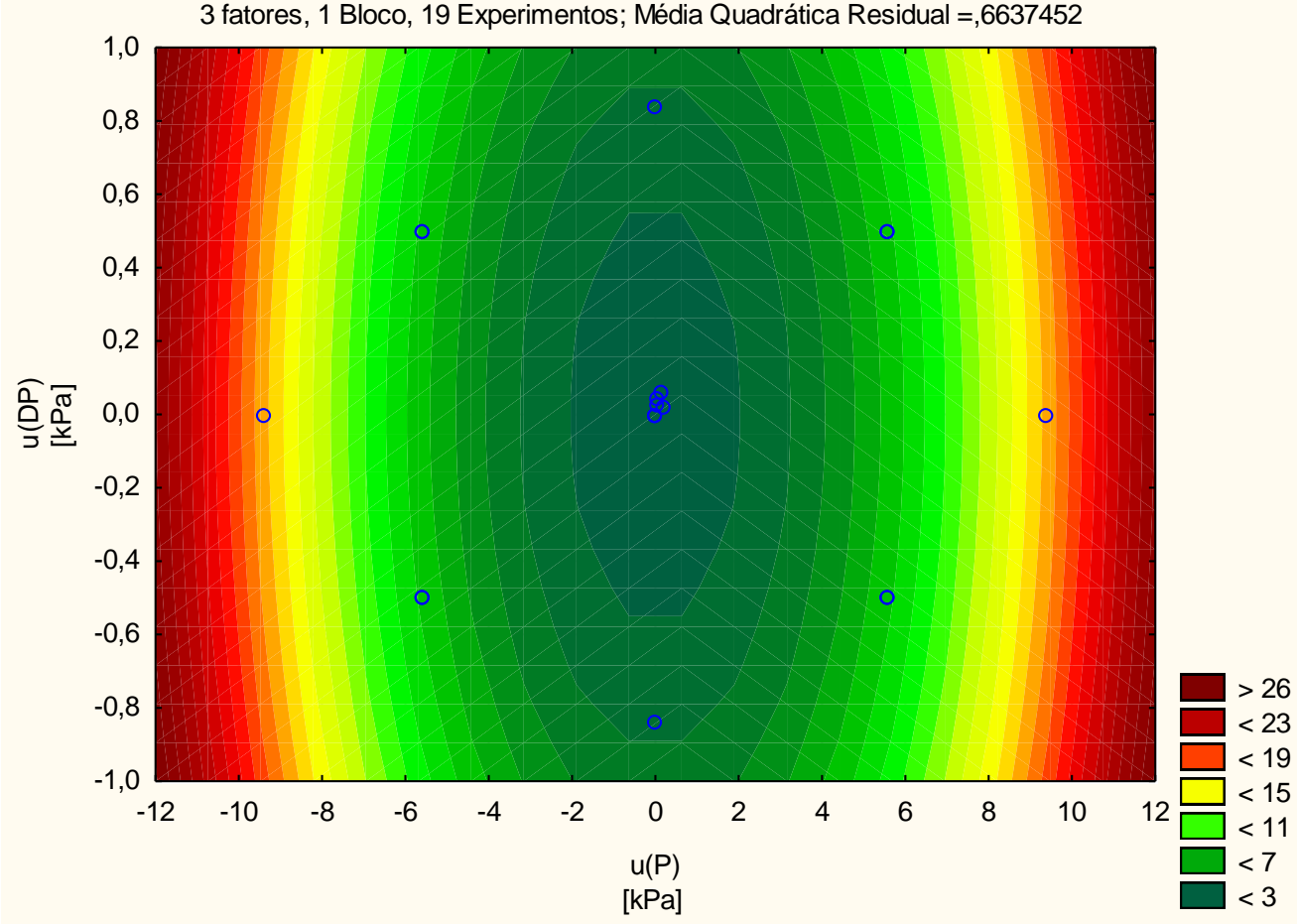

Figura A.76 - Curva de nível (EMED H) dado uP e uDP (1 \% f.e.) 
Superfície de Resposta; Variável: $Y$ [\%] = UP x UT - EMED H

3 fatores, 1 Bloco, 19 Experimentos; Média Quadrática Residual =,6637452

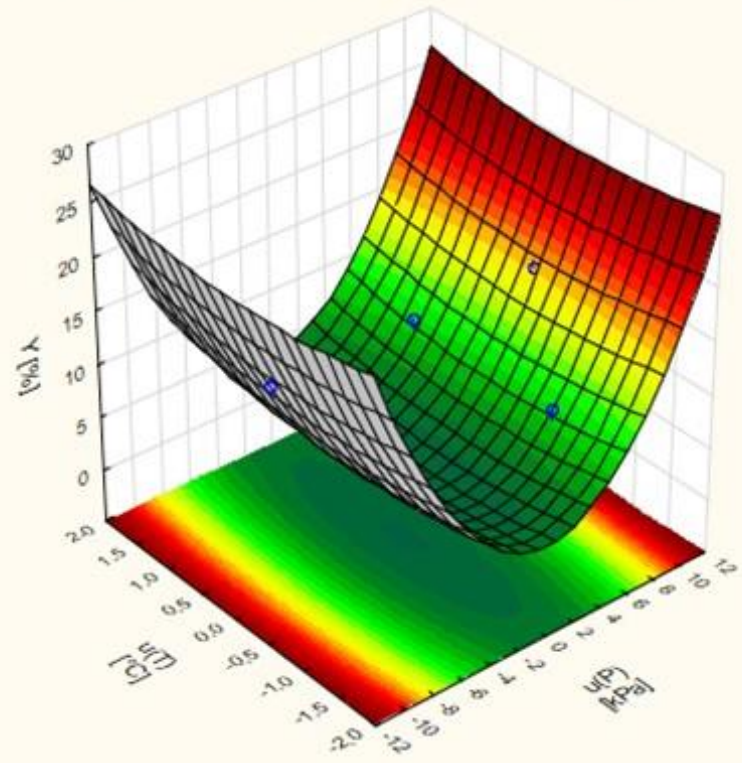

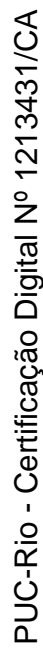

Figura A.77 - Superfície de resposta (EMED H) dado uP ( $1 \%$ f.e. $)$ e uT $\left( \pm 1^{\circ} \mathrm{C}\right)$

Curva de nível; Variável: $Y[\%]$ = uP x uT - EMED H

3 fatores, 1 Bloco, 19 Experimentos; Média Quadrática Residual =,6637452

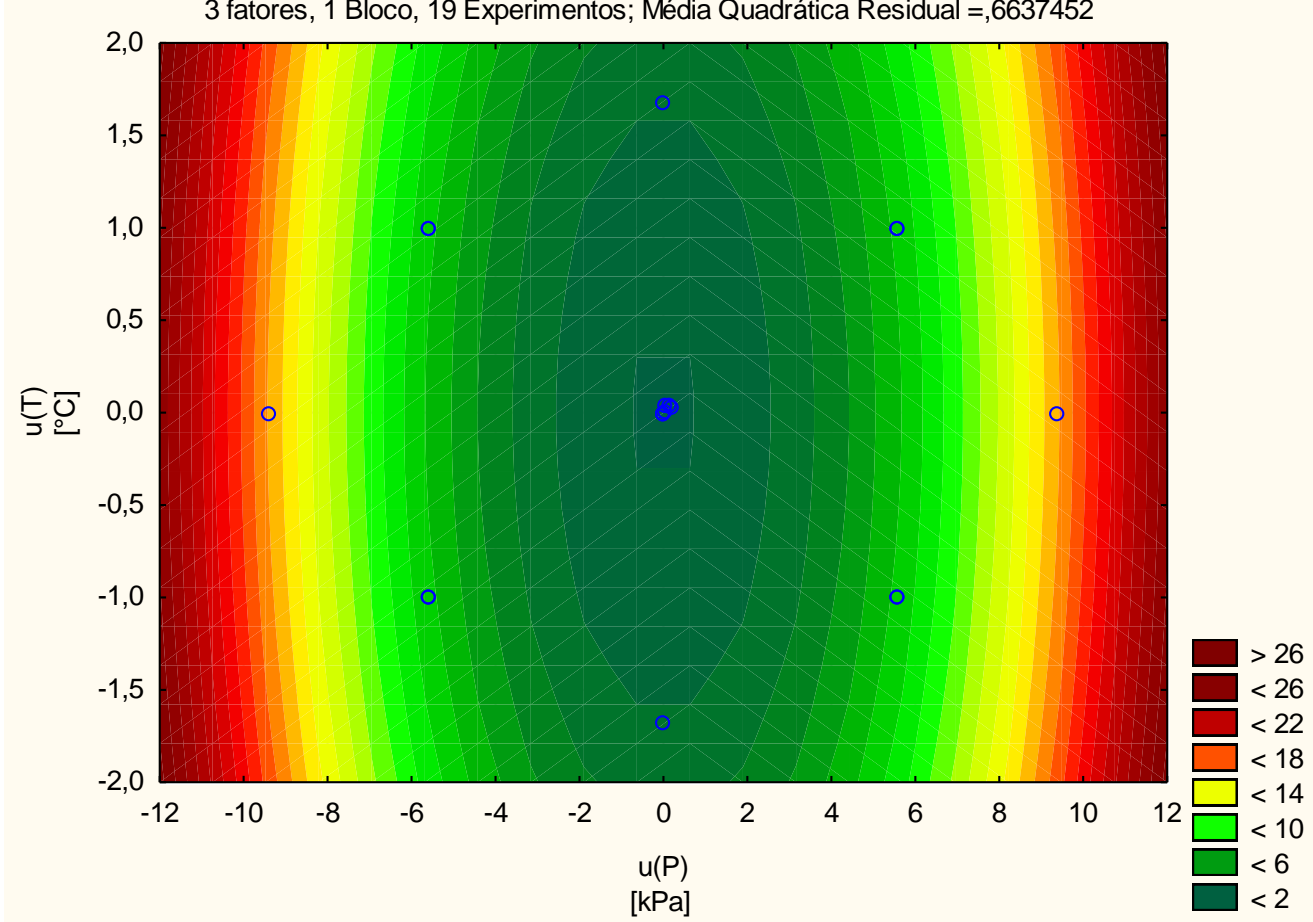

Figura A.78 - Curva de nível (EMED H) dado uP $(1 \%$ f.e. $)$ e uT $\left( \pm 1{ }^{\circ} \mathrm{C}\right)$ 
Superficie de Resposta; Variável: Y [\%] = UT x uDP - EMED H

3 fatores, 1 Bloco, 19 Experimentos; Média Quadrática Residual =,6637452

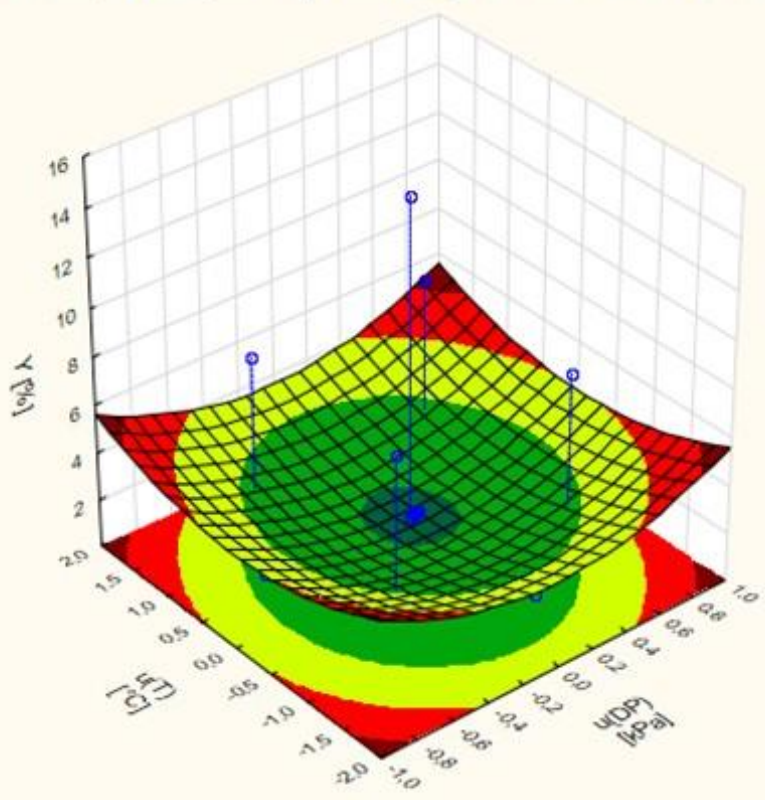

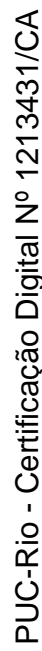

Figura A.79 - Superfície de resposta (EMED H) dado uDP (1\% f.e.) e uT ( $\left.\pm 1{ }^{\circ} \mathrm{C}\right)$

Curva de nível; Variável: $Y[\%]=$ UT $x$ uDP - EMED H

3 fatores, 1 Bloco, 19 Experimentos; Média Quadrática Residual =,6637452

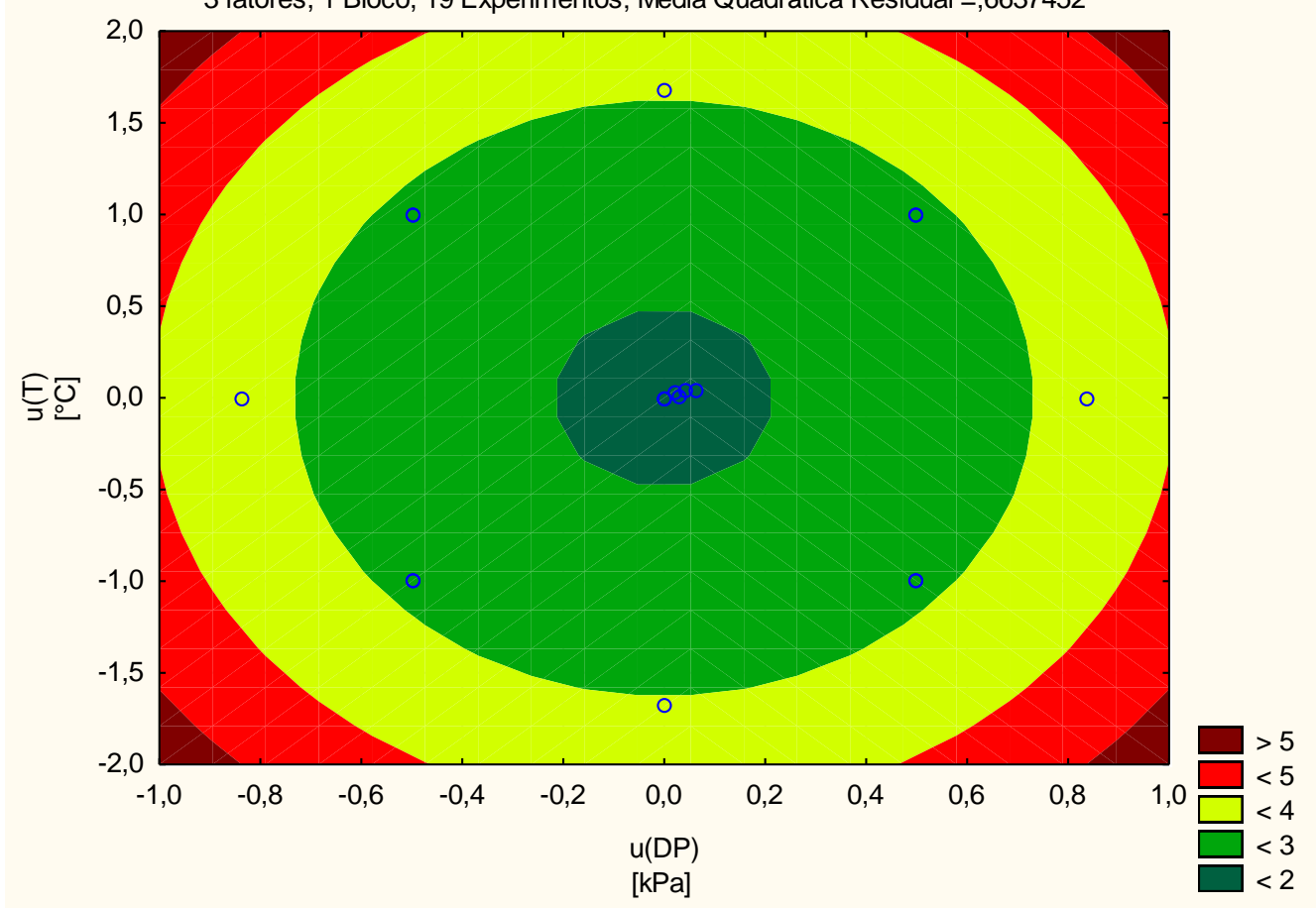

Figura A.80 - Curva de nível (EMED H) dado uDP (1\% f.e.) e uT $\left( \pm 1^{\circ} \mathrm{C}\right)$ 


\section{A.11}

\section{Estação I - estação de medição fiscal}

Tabela A.31 - Matriz de planejamento experimental da EMED I

\begin{tabular}{|c|c|c|c|c|c|c|c|}
\hline \multicolumn{7}{|c|}{ Matriz do planejamento } & $\begin{array}{c}\text { Incerteza da } \\
\text { vazão }\end{array}$ \\
\hline Exp & $\mathrm{x} 1$ & $\mathrm{x} 2$ & $\mathrm{x} 3$ & $\begin{array}{c}\mathrm{P} \\
{[\mathrm{kPa}]}\end{array}$ & $\mathrm{DP}[\mathrm{kPa}]$ & $\begin{array}{c}\mathrm{T} \\
{\left[{ }^{\circ} \mathrm{C}\right]}\end{array}$ & $\mathrm{y}(\%)$ \\
\hline 1 & -1 & -1 & -1 & $-5,5800$ & $-0,2490$ & $-1,0000$ & 3,16 \\
2 & 1 & -1 & -1 & 5,5800 & $-0,2490$ & $-1,0000$ & 3,16 \\
3 & -1 & 1 & -1 & $-5,5800$ & 0,2490 & $-1,0000$ & 3,16 \\
4 & 1 & 1 & -1 & 5,5800 & 0,2490 & $-1,0000$ & 3,16 \\
5 & -1 & -1 & 1 & $-5,5800$ & $-0,2490$ & 1,0000 & 3,16 \\
6 & 1 & -1 & 1 & 5,5800 & $-0,2490$ & 1,0000 & 3,16 \\
7 & -1 & 1 & 1 & $-5,5800$ & 0,2490 & 1,0000 & 3,16 \\
8 & 1 & 1 & 1 & 5,5800 & 0,2490 & 1,0000 & 3,16 \\
9 & $-1,682$ & 0 & 0 & $-9,3856$ & 0,0000 & 0,0000 & 4,39 \\
10 & 1,682 & 0 & 0 & 9,3856 & 0,0000 & 0,0000 & 4,39 \\
11 & 0 & $-1,682$ & 0 & 0,0000 & $-0,4188$ & 0,0000 & 3,81 \\
12 & 0 & 1,682 & 0 & 0,0000 & 0,4188 & 0,0000 & 3,81 \\
13 & 0 & 0 & $-1,682$ & 0,0000 & 0,0000 & $-1,6820$ & 1,44 \\
14 & 0 & 0 & 1,682 & 0,0000 & 0,0000 & 1,6820 & 1,44 \\
15 & 0 & 0 & 0 & 0,0000 & 0,0000 & 0,0000 & 1,21 \\
16 & 0 & 0 & 0 & 0,0490 & 0,0127 & 0,0023 & 1,21 \\
17 & 0 & 0 & 0 & 0,0607 & 0,0197 & 0,0101 & 1,22 \\
18 & 0 & 0 & 0 & 0,0308 & 0,0184 & 0,0011 & 1,22 \\
19 & 0 & 0 & 0 & 0,0844 & 0,0169 & 0,0177 & 1,22 \\
\hline
\end{tabular}

Tabela A.32 - Tabela de ANOVA do planejamento de experimentos da EMED I

\begin{tabular}{|c|c|c|c|c|c|}
\hline \multirow{2}{*}{ Fonte de variação } & \multicolumn{5}{|c|}{ ANOVA; Var.:Y [\%]; $\mathrm{R}^{2}=, 99591 ; \mathrm{R}_{\mathrm{a}}^{2}, 99182$} \\
\cline { 2 - 6 } & 3 fatores, 1 Bloco, 19 Experimentos; Média Quadrática Residual =, 0109098 \\
\hline$(1) \mathrm{u}(\mathrm{P})[\mathrm{kPa}](\mathrm{L})$ & 0,00000 & 1 & 0,00000 & 0,000 & 0,999505 \\
\hline $\mathrm{u}(\mathrm{P})[\mathrm{kPa}](\mathrm{Q})$ & 16,04798 & 1 & 16,04798 & 1470,968 & 0,000000 \\
\hline$(2) \mathrm{u}(\mathrm{DP})[\mathrm{kPa}](\mathrm{L})$ & 0,00000 & 1 & 0,00000 & 0,000 & 0,996983 \\
\hline $\mathrm{u}(\mathrm{DP})[\mathrm{kPa}](\mathrm{Q})$ & 10,58117 & 1 & 10,58117 & 969,877 & 0,000000 \\
\hline$(3) \mathrm{u}(\mathrm{T})\left[{ }^{\circ} \mathrm{C}\right](\mathrm{L})$ & 0,00000 & 1 & 0,00000 & 0,000 & 0,999624 \\
\hline $\mathrm{u}(\mathrm{T})\left[{ }^{\circ} \mathrm{C}\right](\mathrm{Q})$ & 0,02529 & 1 & 0,02529 & 2,318 & 0,162235 \\
\hline $1 \mathrm{~L} \times 2 \mathrm{~L}$ & 0,00000 & 1 & 0,00000 & 0,000 & 0,999958 \\
\hline $1 \mathrm{~L} \times 3 \mathrm{~L}$ & 0,00000 & 1 & 0,00000 & 0,000 & 0,999993 \\
\hline $2 \mathrm{~L} \times 3 \mathrm{~L}$ & 0,00000 & 1 & 0,00000 & 0,000 & 0,999966 \\
\hline Erro & 0,09819 & 9 & 0,01091 & & \\
\hline Total SQ & 24,00769 & 18 & & & \\
\hline
\end{tabular}


Gráfico de Pareto dos Efeitos; Variável: Y[\%] - EMED I

3 fatores, 1 Bloco, 19 Experimentos; Média Quadrática Residual =,0109098

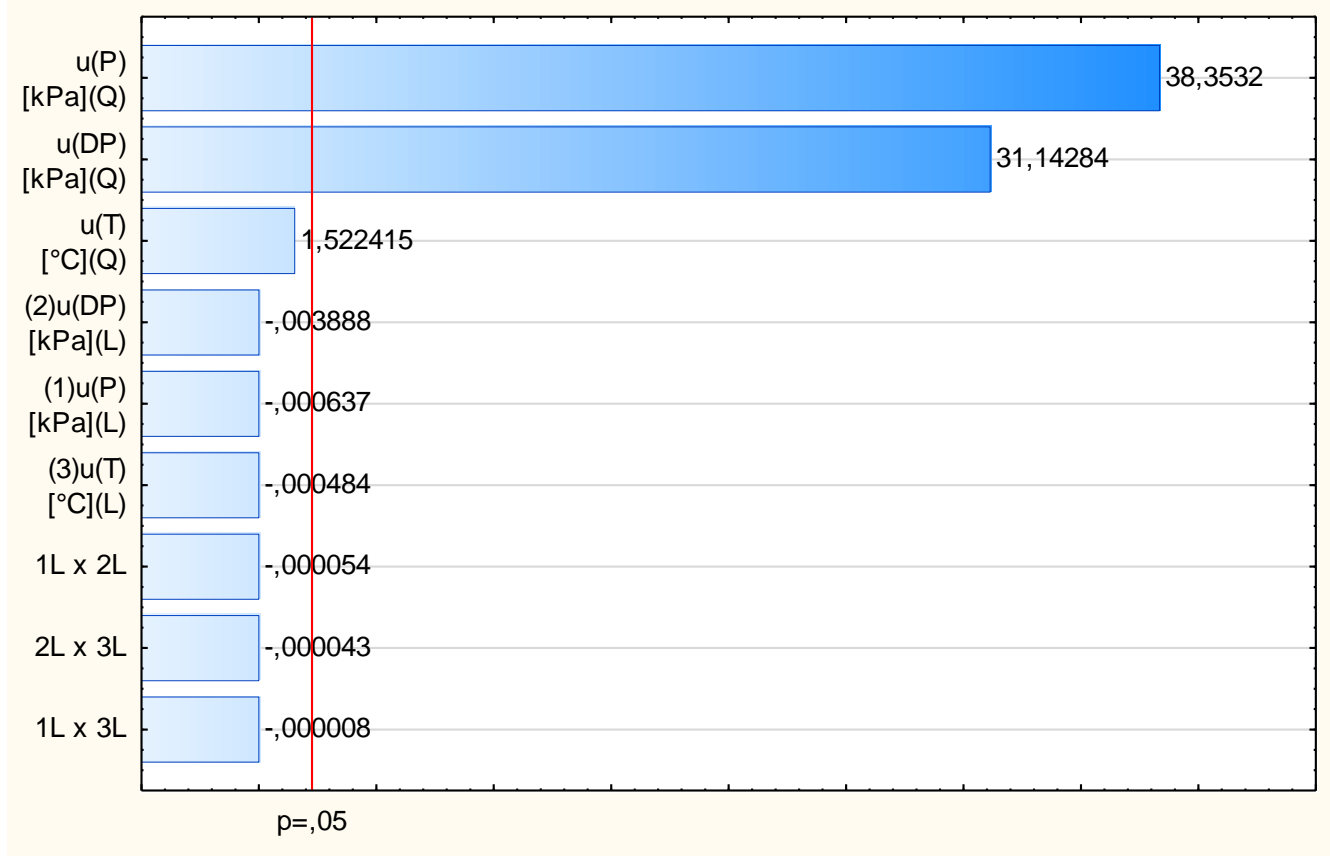

Estimativa dos Efeitos Padronizados (Valor absoluto)

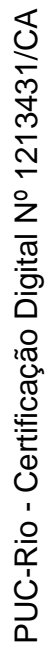

Figura A.81 - Gráfico de Pareto em função dos valores da estatística de teste t

Valores Previstos vs. Valores Residuais - EMED I

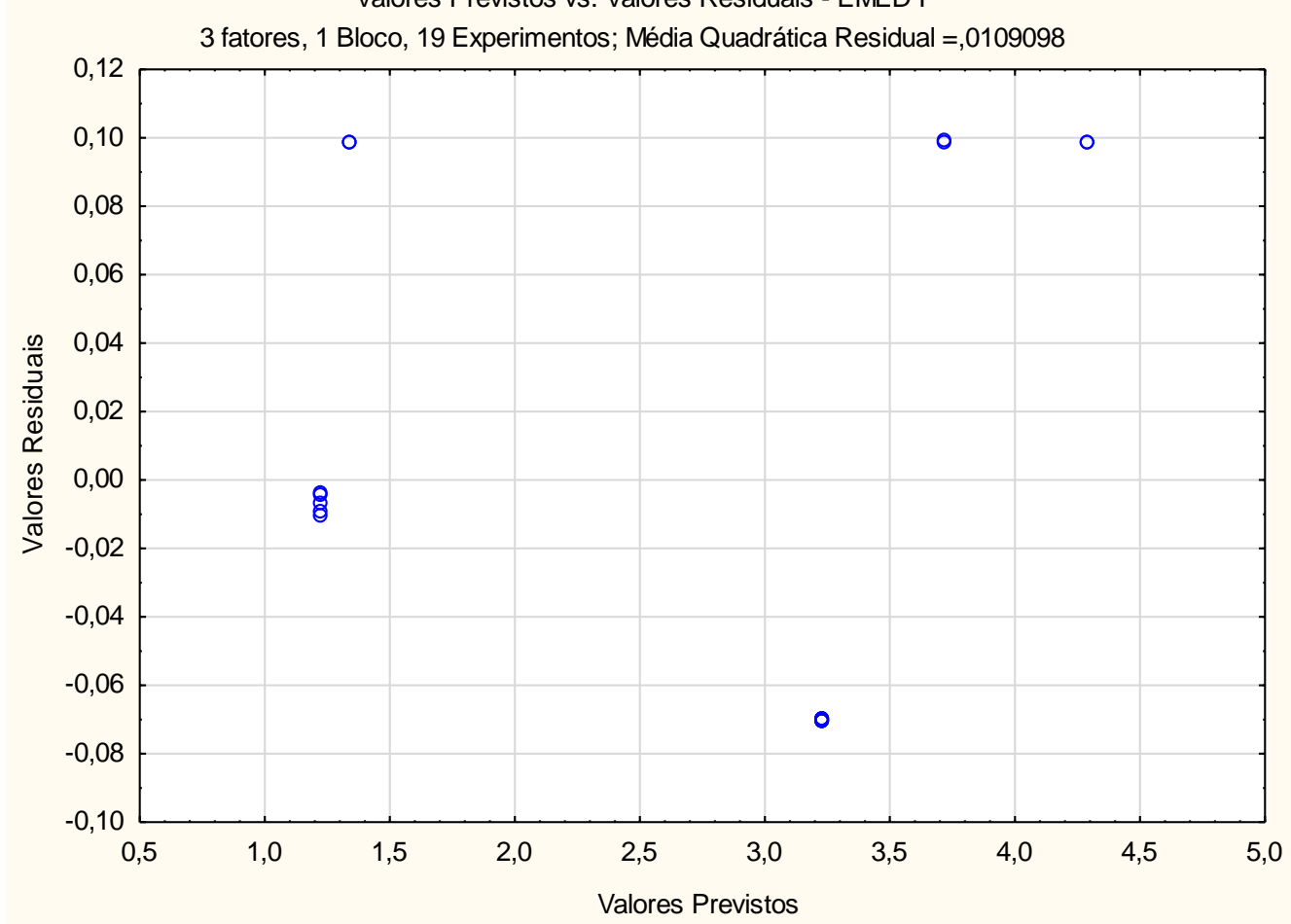

Figura A.82 - Resíduos versus estimativas de y (EMED I - nível: $1 \%$ f.e. e $1^{\circ} \mathrm{C}$ ) 
Tabela A.33 - Matriz das incertezas estimadas da vazão (EMED I)

(dado $x_{3}(\mathrm{~T})$ igual a 1 e $x_{1}$ e x2 variando do nível baixo ao nível alto)

\begin{tabular}{|c|c|c|c|c|c|c|c|c|c|c|c|c|}
\hline & \multicolumn{11}{|c|}{$\mathbf{x}_{1}$} \\
\hline & & -1 & $-0,8$ & $-0,6$ & $-0,4$ & $-0,2$ & 0 & 0,2 & 0,4 & 0,6 & 0,8 & 1 \\
\hline \multirow{10}{*}{$\mathbf{x}_{2}$} & -1 & 3,2 & 2,8 & 2,5 & 2,3 & 2,2 & 2,1 & 2,2 & 2,3 & 2,5 & 2,8 & 3,2 \\
\hline & $-0,8$ & 2,9 & 2,5 & 2,2 & 2,0 & 1,9 & 1,8 & 1,9 & 2,0 & 2,2 & 2,5 & 2,9 \\
\hline & $-0,6$ & 2,7 & 2,3 & 2,0 & 1,8 & 1,6 & 1,6 & 1,6 & 1,8 & 2,0 & 2,3 & 2,7 \\
\hline & $-0,4$ & 2,5 & 2,1 & 1,8 & 1,6 & 1,4 & 1,4 & 1,4 & 1,6 & 1,8 & 2,1 & 2,5 \\
\hline & $-0,2$ & 2,4 & 2,0 & 1,7 & 1,5 & 1,3 & 1,3 & 1,3 & 1,5 & 1,7 & 2,0 & 2,4 \\
\hline & 0 & 2,3 & 2,0 & 1,7 & 1,4 & 1,3 & 1,3 & 1,3 & 1,4 & 1,7 & 2,0 & 2,3 \\
\hline & 0,2 & 2,4 & 2,0 & 1,7 & 1,5 & 1,3 & 1,3 & 1,3 & 1,5 & 1,7 & 2,0 & 2,4 \\
\hline & 0,4 & 2,5 & 2,1 & 1,8 & 1,6 & 1,4 & 1,4 & 1,4 & 1,6 & 1,8 & 2,1 & 2,5 \\
\hline & 0,6 & 2,7 & 2,3 & 2,0 & 1,8 & 1,6 & 1,6 & 1,6 & 1,8 & 2,0 & 2,3 & 2,7 \\
\hline & 0,8 & 2,9 & 2,5 & 2,2 & 2,0 & 1,9 & 1,8 & 1,9 & 2,0 & 2,2 & 2,5 & 2,9 \\
\hline
\end{tabular}

Superficie de Resposta; Variável: Y [\%] = uP x UDP - EMED I

3 fatores, 1 Bloco, 19 Experimentos; Média Quadrática Residual $=, 0109098$

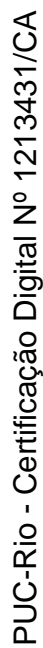

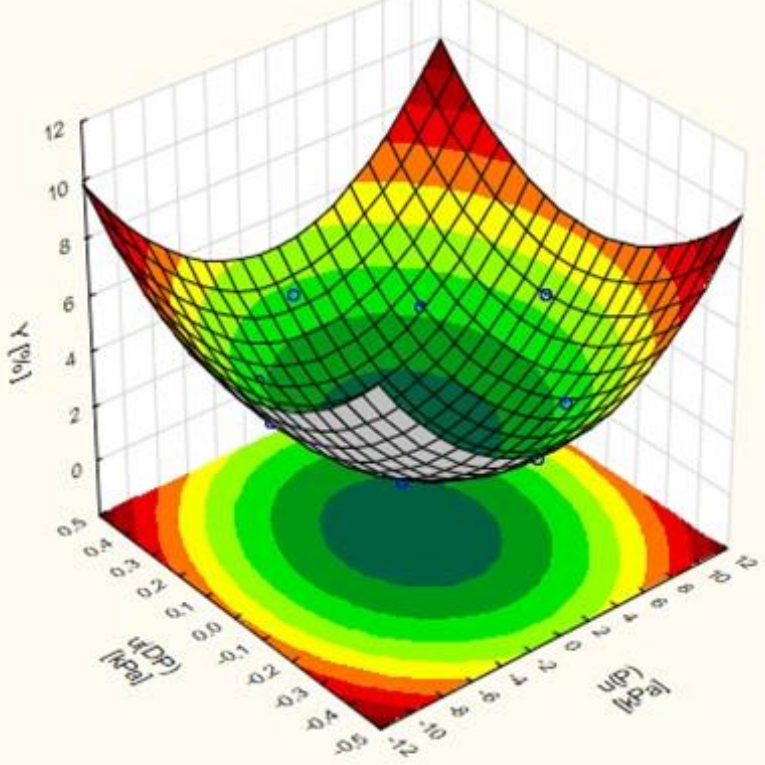

Figura A.83 - Superfície de resposta (EMED I) dado uP e uDP (1 \% f.e.) 
Curva de nível; Variável: Y [\%] = uP x uDP - EMED I

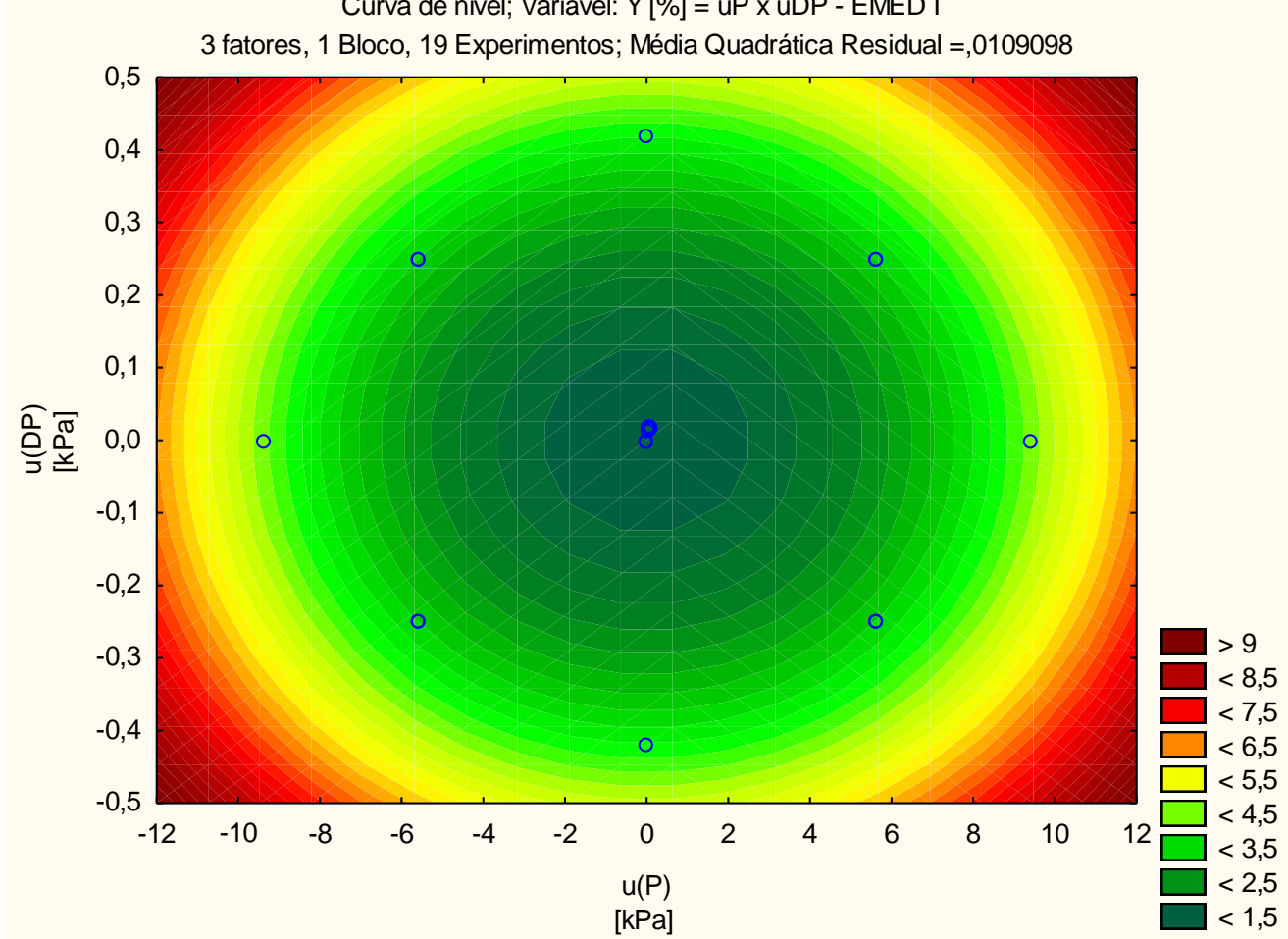

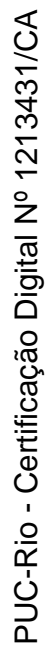

Figura A.84 - Curva de nível (EMED I) dado uP e uDP (1 \% f.e.)

Superficie de Resposta; Variável: Y [\%] = uP x UT - EMED I

3 fatores, 1 Bloco, 19 Experimentos; Média Quadrática Residual $=, 0109098$

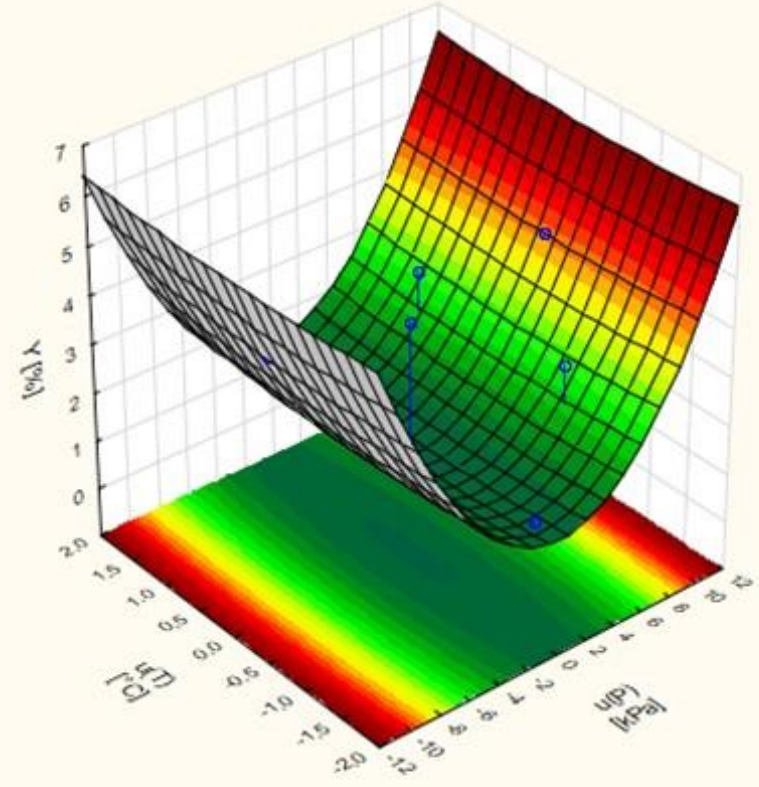

$>6$

Figura A.85 - Superfície de resposta (EMED I) dado uP $(1 \%$ f.e. $)$ e uT $\left( \pm 1{ }^{\circ} \mathrm{C}\right)$ 
Curva de nível; Variável: $Y$ [\%] = uP x uT - EMED I

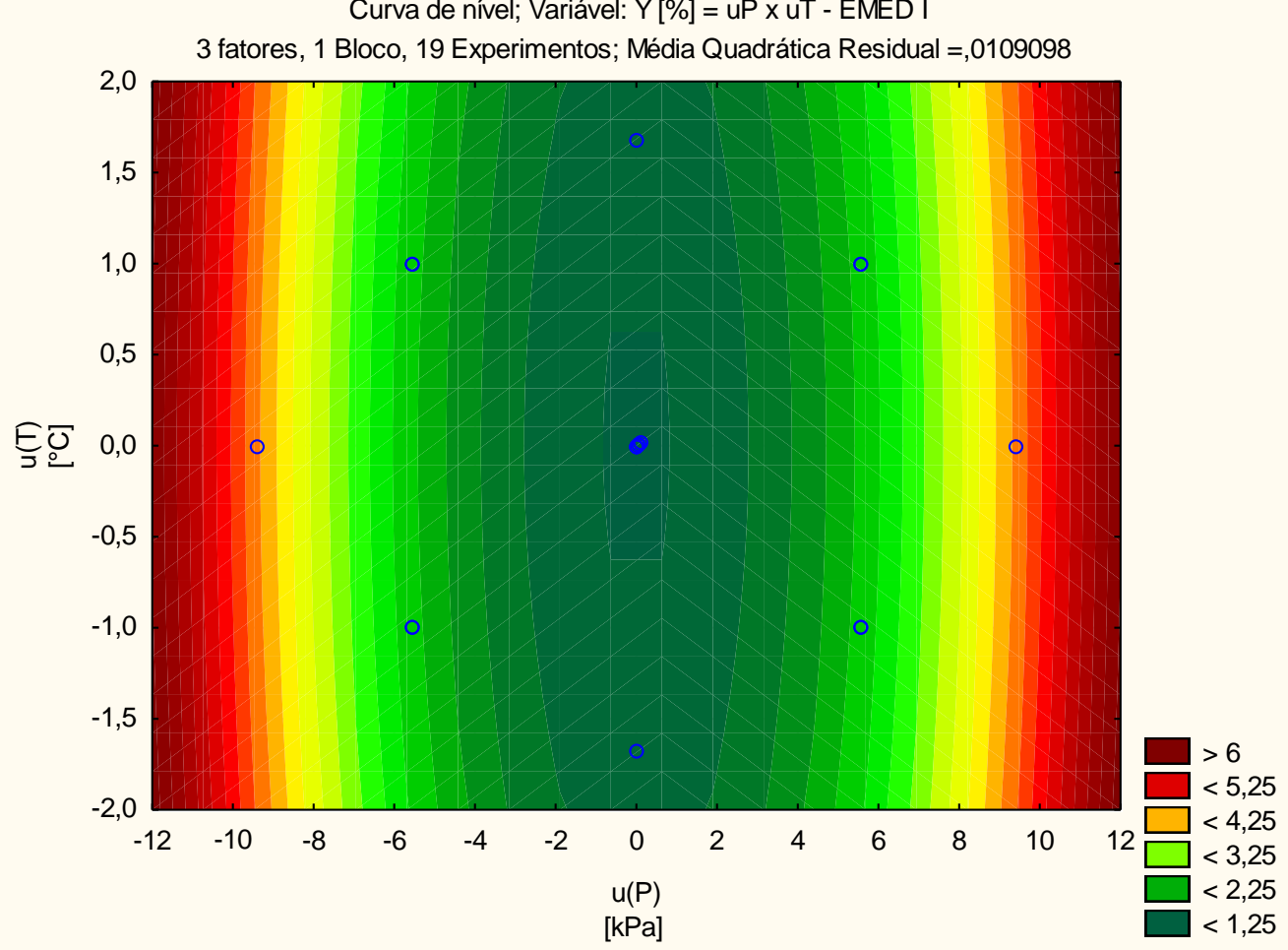

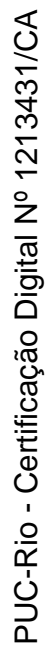

Figura A.86 - Curva de nível (EMED I) dado uP $(1 \%$ f.e. $)$ e uT $\left( \pm 1^{\circ} \mathrm{C}\right)$

Superfície de Resposta; Variável: $Y$ [\%] = UT x UDP - EMED I

3 fatores, 1 Bloco, 19 Experimentos; Média Quadrática Residual $=, 0109098$

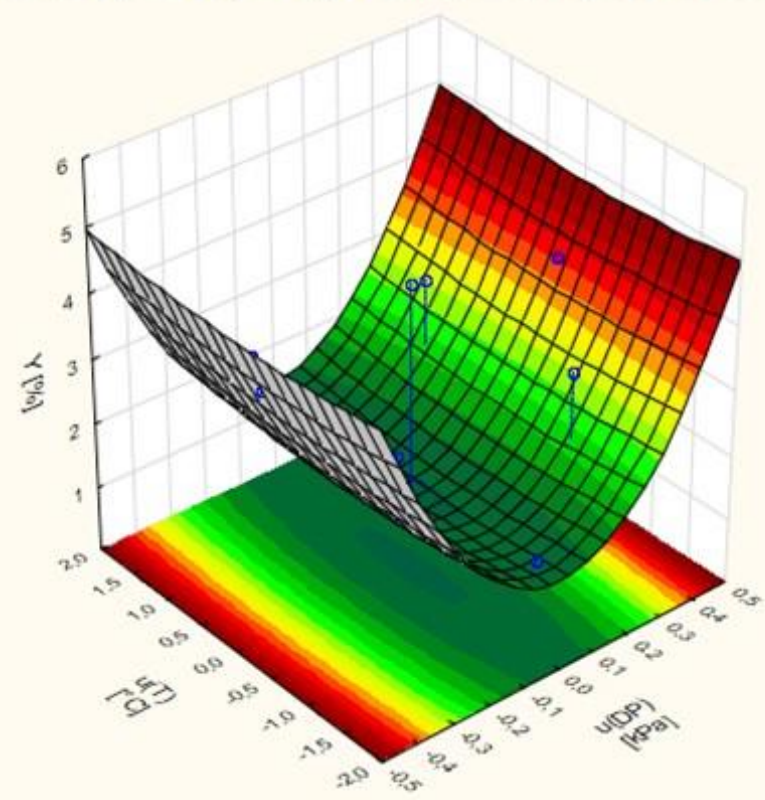

Figura A.87 - Superfície de resposta (EMED I) dado uDP ( $1 \%$ f.e.) e uT $\left( \pm 1{ }^{\circ} \mathrm{C}\right)$ 


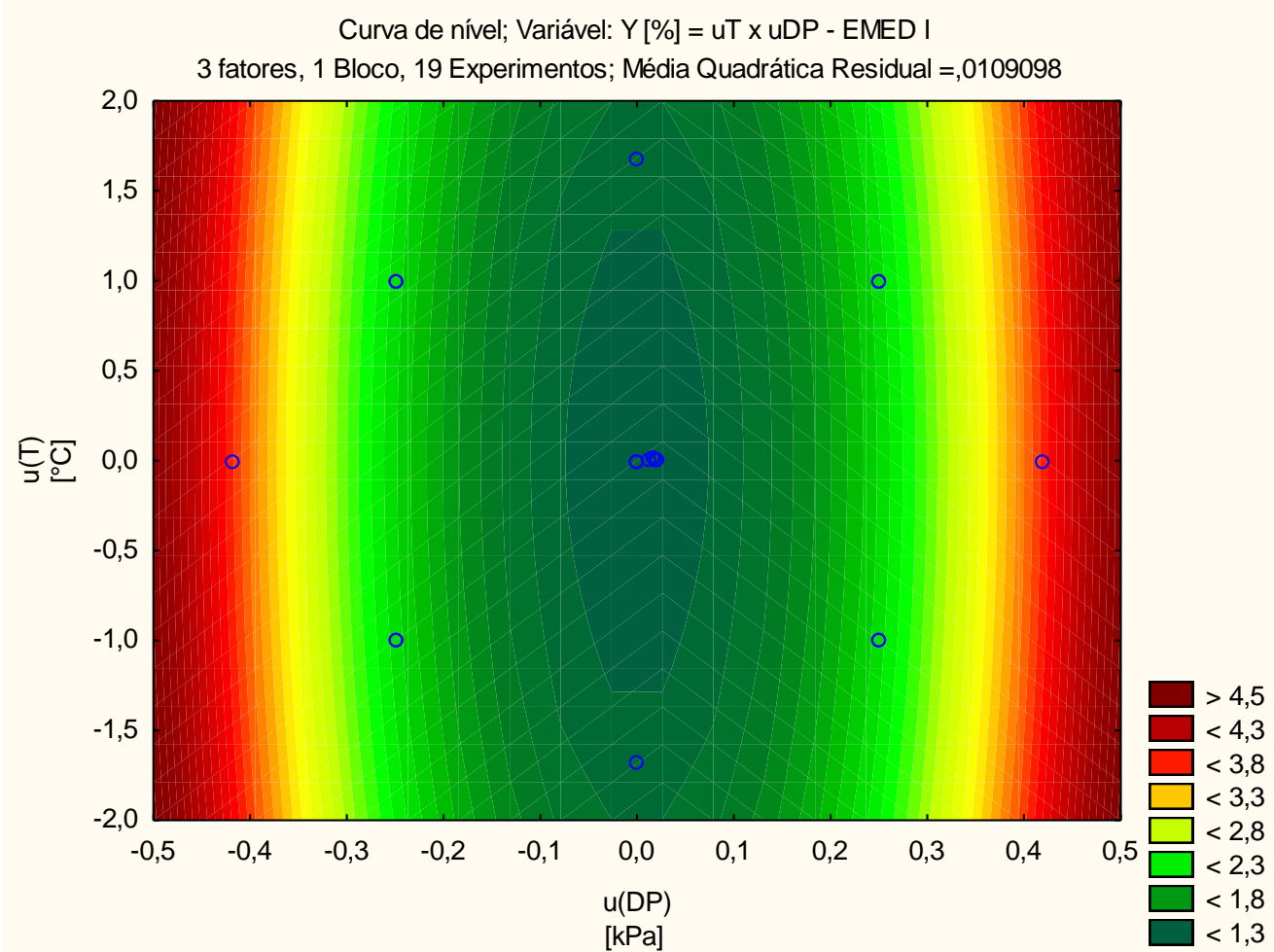

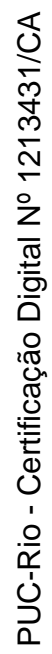

Figura A.88 - Curva de nível (EMED I) dado uDP $(1 \%$ f.e. $)$ e uT $\left( \pm 1^{\circ} \mathrm{C}\right)$

\section{A.12}

\section{Estação J1 - estação de medição fiscal}

Tabela A.34 - Matriz de planejamento experimental da EMED J1

\begin{tabular}{|c|c|c|c|c|c|c|c|}
\hline \multicolumn{7}{|c|}{ Matriz do planejamento } & $\begin{array}{c}\text { Incerteza da } \\
\text { vazão }\end{array}$ \\
\hline Exp & $\mathrm{x} 1$ & $\mathrm{x} 2$ & $\mathrm{x} 3$ & $\begin{array}{c}\mathrm{P} \\
{[\mathrm{kPa}]}\end{array}$ & $\mathrm{DP}[\mathrm{kPa}]$ & $\begin{array}{c}\mathrm{T} \\
{\left[{ }^{\circ} \mathrm{C}\right]}\end{array}$ & $\mathrm{y}(\%)$ \\
\hline 1 & -1 & -1 & -1 & $-5,5800$ & $-0,2490$ & $-1,0000$ & 2,51 \\
2 & 1 & -1 & -1 & 5,5800 & $-0,2490$ & $-1,0000$ & 2,51 \\
3 & -1 & 1 & -1 & $-5,5800$ & 0,2490 & $-1,0000$ & 2,51 \\
4 & 1 & 1 & -1 & 5,5800 & 0,2490 & $-1,0000$ & 2,51 \\
5 & -1 & -1 & 1 & $-5,5800$ & $-0,2490$ & 1,0000 & 2,51 \\
6 & 1 & -1 & 1 & 5,5800 & $-0,2490$ & 1,0000 & 2,51 \\
7 & -1 & 1 & 1 & $-5,5800$ & 0,2490 & 1,0000 & 2,51 \\
8 & 1 & 1 & 1 & 5,5800 & 0,2490 & 1,0000 & 2,51 \\
9 & $-1,682$ & 0 & 0 & $-9,3856$ & 0,0000 & 0,0000 & 4,09 \\
10 & 1,682 & 0 & 0 & 9,3856 & 0,0000 & 0,0000 & 4,09 \\
11 & 0 & $-1,682$ & 0 & 0,0000 & $-0,4188$ & 0,0000 & 2,04 \\
12 & 0 & 1,682 & 0 & 0,0000 & 0,4188 & 0,0000 & 2,04 \\
13 & 0 & 0 & $-1,682$ & 0,0000 & 0,0000 & $-1,6820$ & 1,43 \\
14 & 0 & 0 & 1,682 & 0,0000 & 0,0000 & 1,6820 & 1,43 \\
15 & 0 & 0 & 0 & 0,0000 & 0,0000 & 0,0000 & 1,20 \\
16 & 0 & 0 & 0 & 0,0896 & 0,0045 & 0,0015 & 1,20 \\
17 & 0 & 0 & 0 & 0,0003 & 0,0087 & 0,0013 & 1,20 \\
18 & 0 & 0 & 0 & 0,0991 & 0,0081 & 0,0008 & 1,20 \\
19 & 0 & 0 & 0 & 0,0796 & 0,0003 & 0,0008 & 1,20 \\
\hline
\end{tabular}


Tabela A.35 - Tabela de ANOVA do planejamento de experimentos da EMED J1

\begin{tabular}{|c|c|c|c|c|c|}
\hline \multirow[b]{2}{*}{ Fonte de variação } & \multicolumn{5}{|c|}{$\begin{array}{c}\text { ANOVA; Var.:Y [\%]; } \mathrm{R}^{2}=, 99831 ; \mathrm{R}^{2} \mathrm{a}:, 99663 \\
3 \text { fatores, 1 Bloco, 19 Experimentos; Média Quadrática Residual =,0026468 }\end{array}$} \\
\hline & $\begin{array}{c}\text { Soma de } \\
\text { Quadrados }\end{array}$ & $\begin{array}{l}\text { Graus de } \\
\text { liberdade }\end{array}$ & $\begin{array}{l}\text { Quadrados } \\
\text { médios }\end{array}$ & Teste F & $\mathrm{p}$ \\
\hline$(1) \mathrm{u}(\mathrm{P})[\mathrm{kPa}](\mathrm{L})$ & 0,00000 & 1 & 0,00000 & 0,000 & 0,999409 \\
\hline $\mathrm{u}(\mathrm{P})[\mathrm{kPa}](\mathrm{Q})$ & 13,72458 & 1 & 13,72458 & 5185,430 & 0,000000 \\
\hline$(2) \mathrm{u}(\mathrm{DP})[\mathrm{kPa}](\mathrm{L})$ & 0,00000 & 1 & 0,00000 & 0,000 & 0,998927 \\
\hline $\mathrm{u}(\mathrm{DP})[\mathrm{kPa}](\mathrm{Q})$ & 1,05009 & 1 & 1,05009 & 396,746 & 0,000000 \\
\hline$(3) \mathrm{u}(\mathrm{T})\left[{ }^{\circ} \mathrm{C}\right](\mathrm{L})$ & 0,00000 & 1 & 0,00000 & 0,000 & 0,999937 \\
\hline $\mathrm{u}(\mathrm{T})\left[{ }^{\circ} \mathrm{C}\right](\mathrm{Q})$ & 0,05283 & 1 & 0,05283 & 19,962 & 0,001559 \\
\hline $1 \mathrm{~L} \times 2 \mathrm{~L}$ & 0,00000 & 1 & 0,00000 & 0,000 & 0,999989 \\
\hline $1 \mathrm{~L} \times 3 \mathrm{~L}$ & 0,00000 & 1 & 0,00000 & 0,000 & 0,999999 \\
\hline $2 \mathrm{~L} \times 3 \mathrm{~L}$ & 0,00000 & 1 & 0,00000 & 0,000 & 0,999998 \\
\hline Erro & 0,02382 & 9 & 0,00265 & & \\
\hline Total SQ & 14,13128 & 18 & & & \\
\hline
\end{tabular}

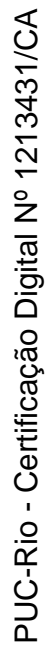

Gráfico de Pareto dos Efeitos; Variável: Y[\%] - EMED J1 3 fatores, 1 Bloco, 19 Experimentos; Média Quadrática Residual =,0026468

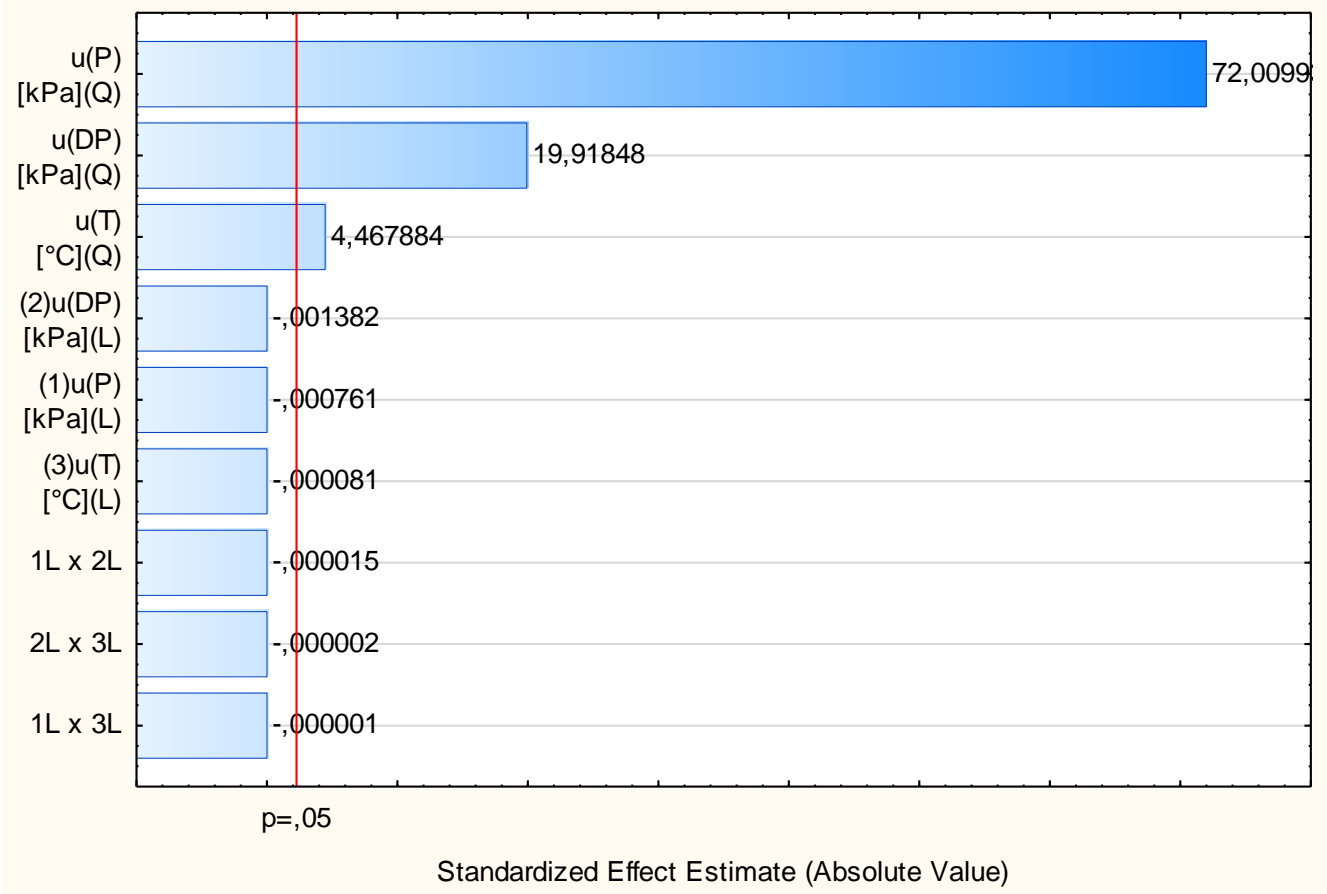

Figura A.89 - Gráfico de Pareto em função dos valores da estatística de teste t 
Valores Previstos vs. Valores Residuais - EMED J1

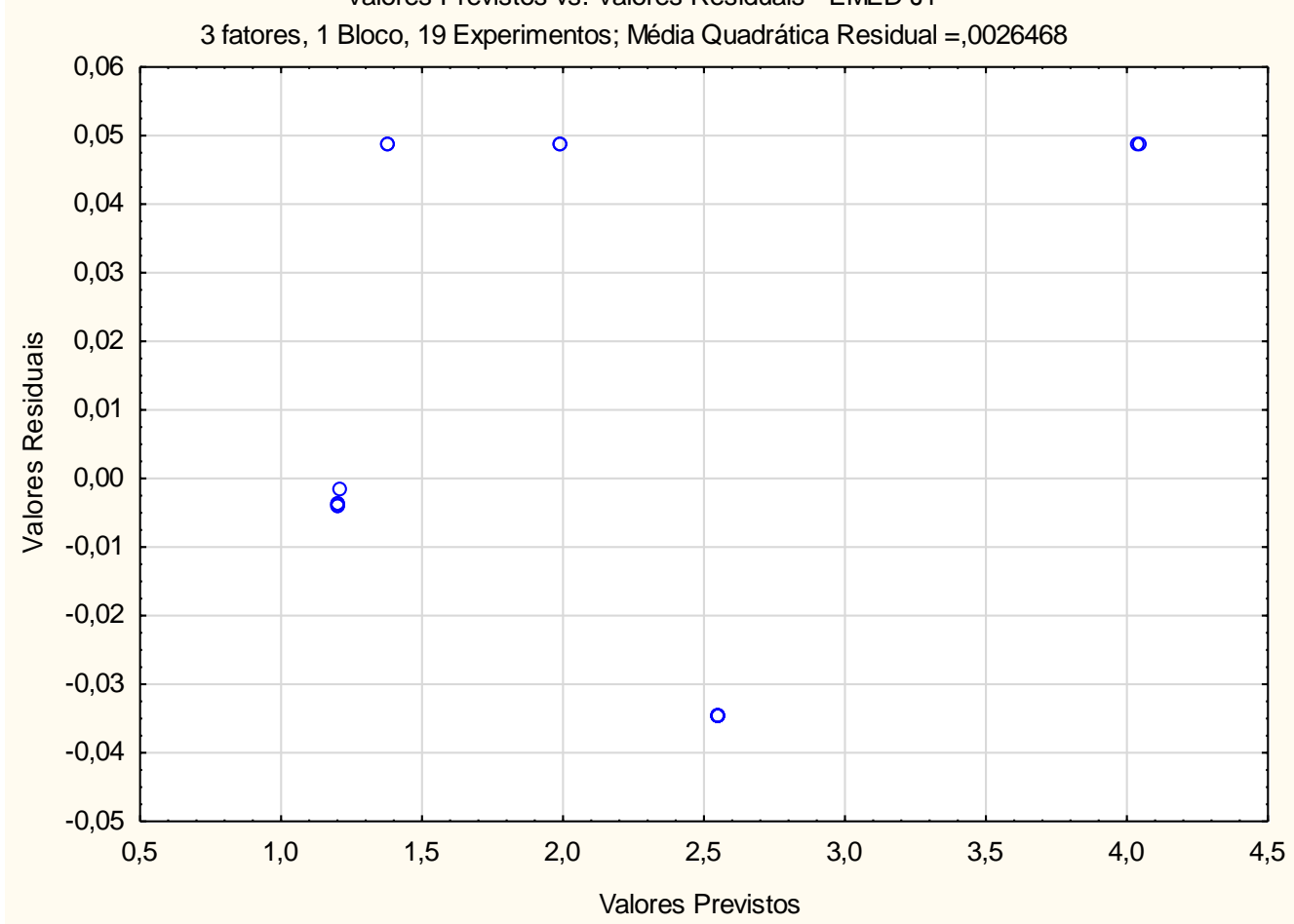

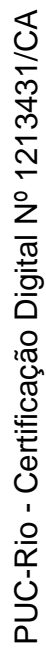

Figura A.90 - Resíduos versus estimativas de y (EMED J1 - nível: $1 \%$ f.e. e $1^{\circ} \mathrm{C}$ )

Tabela A.36 - Matriz das incertezas estimadas da vazão (EMED J1) (dado $x_{3}(T)$ igual a 1 e $x_{1}$ e $x_{2}$ variando do nível baixo ao nível alto)

\begin{tabular}{|c|c|c|c|c|c|c|c|c|c|c|c|c|}
\hline & \\
\hline & & -1 & $-0,8$ & $-0,6$ & $-0,4$ & $-0,2$ & 0 & 0,2 & 0,4 & 0,6 & 0,8 & 1 \\
\hline \multirow{11}{*}{$\mathbf{x}_{2}$} & -1 & 2,55 & 2,18 & 1,90 & 1,70 & 1,58 & 1,54 & 1,58 & 1,70 & 1,90 & 2,18 & 2,55 \\
\hline & $-0,8$ & 2,45 & 2,08 & 1,80 & 1,60 & 1,48 & 1,44 & 1,48 & 1,60 & 1,80 & 2,08 & 2,45 \\
\hline & $-0,6$ & 2,37 & 2,01 & 1,73 & 1,53 & 1,41 & 1,37 & 1,41 & 1,53 & 1,73 & 2,01 & 2,37 \\
\hline & $-0,4$ & 2,31 & 1,95 & 1,67 & 1,47 & 1,35 & 1,31 & 1,35 & 1,47 & 1,67 & 1,95 & 2,31 \\
\hline & $-0,2$ & 2,28 & 1,92 & 1,64 & 1,44 & 1,32 & 1,28 & 1,32 & 1,44 & 1,64 & 1,92 & 2,28 \\
\hline & 0 & 2,27 & 1,91 & 1,63 & 1,43 & 1,31 & 1,27 & 1,31 & 1,43 & 1,63 & 1,91 & 2,27 \\
\hline & 0,2 & 2,28 & 1,92 & 1,64 & 1,44 & 1,32 & 1,28 & 1,32 & 1,44 & 1,64 & 1,92 & 2,28 \\
\hline & 0,4 & 2,31 & 1,95 & 1,67 & 1,47 & 1,35 & 1,31 & 1,35 & 1,47 & 1,67 & 1,95 & 2,31 \\
\hline & 0,6 & 2,37 & 2,01 & 1,73 & 1,53 & 1,41 & 1,37 & 1,41 & 1,53 & 1,73 & 2,01 & 2,37 \\
\hline & 0,8 & 2,45 & 2,08 & 1,80 & 1,60 & 1,48 & 1,44 & 1,48 & 1,60 & 1,80 & 2,08 & 2,45 \\
\hline & 1 & 2,55 & 2,18 & 1,90 & 1,70 & 1,58 & 1,54 & 1,58 & 1,70 & 1,90 & 2,18 & 2,55 \\
\hline
\end{tabular}


Superficie de Resposta; Variável: $Y$ [\%] = uP x uDP - EMED J1

3 fatores, 1 Bloco, 19 Experimentos; Média Quadrática Residual $=, 0026468$

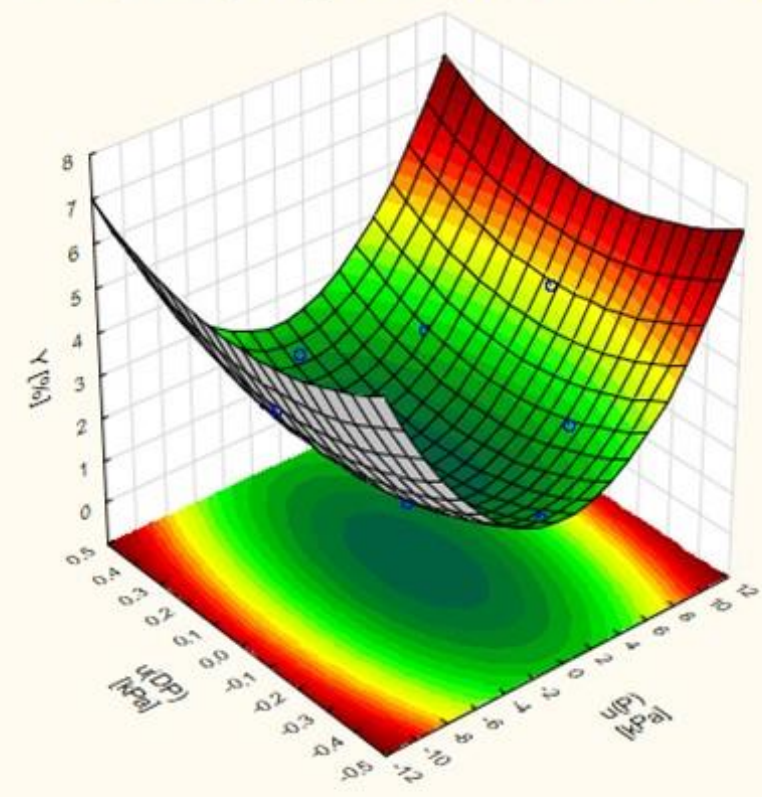

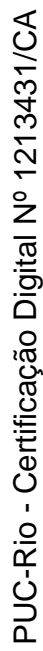

Figura A.91 - Superfície de resposta (EMED J1) dado uP e uDP (1\% f.e.)

Curva de nível; Variável: Y [\%] = uP x uDP - EMED J1

3 fatores, 1 Bloco, 19 Experimentos; Média Quadrática Residual =,0026468

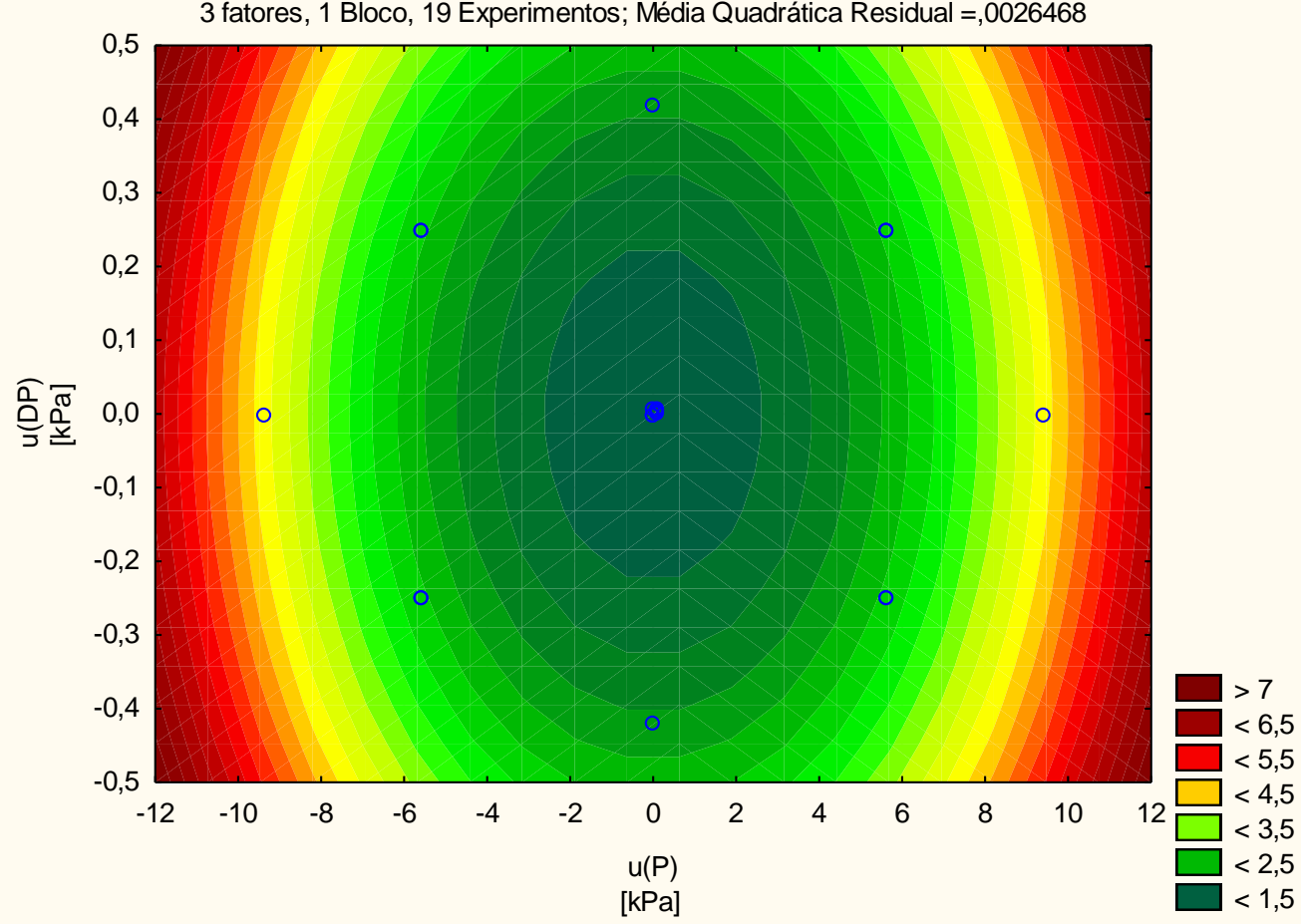

Figura A.92 - Curva de nível (EMED J1) dado uP e uDP (1 \% f.e.) 
Superfície de Resposta; Variável: Y [\%] = uP x UT - EMED J1

3 fatores, 1 Bloco, 19 Experimentos; Média Quadrática Residual=,0026468

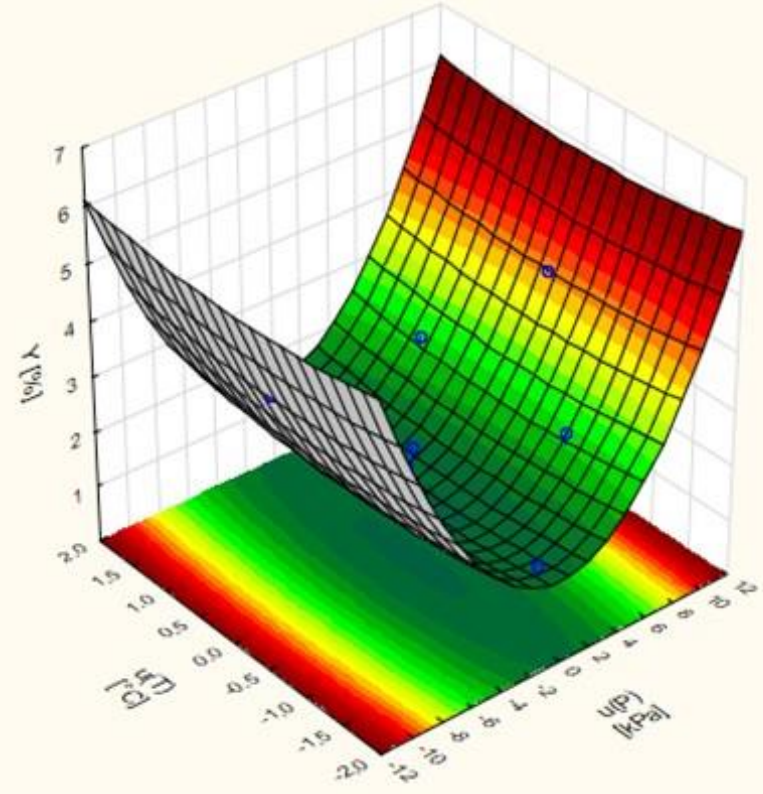

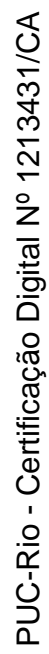

Figura A.93 - Superfície de resposta (EMED J1) dado uP (1\% f.e.) e uT $\left( \pm 1^{\circ} \mathrm{C}\right)$

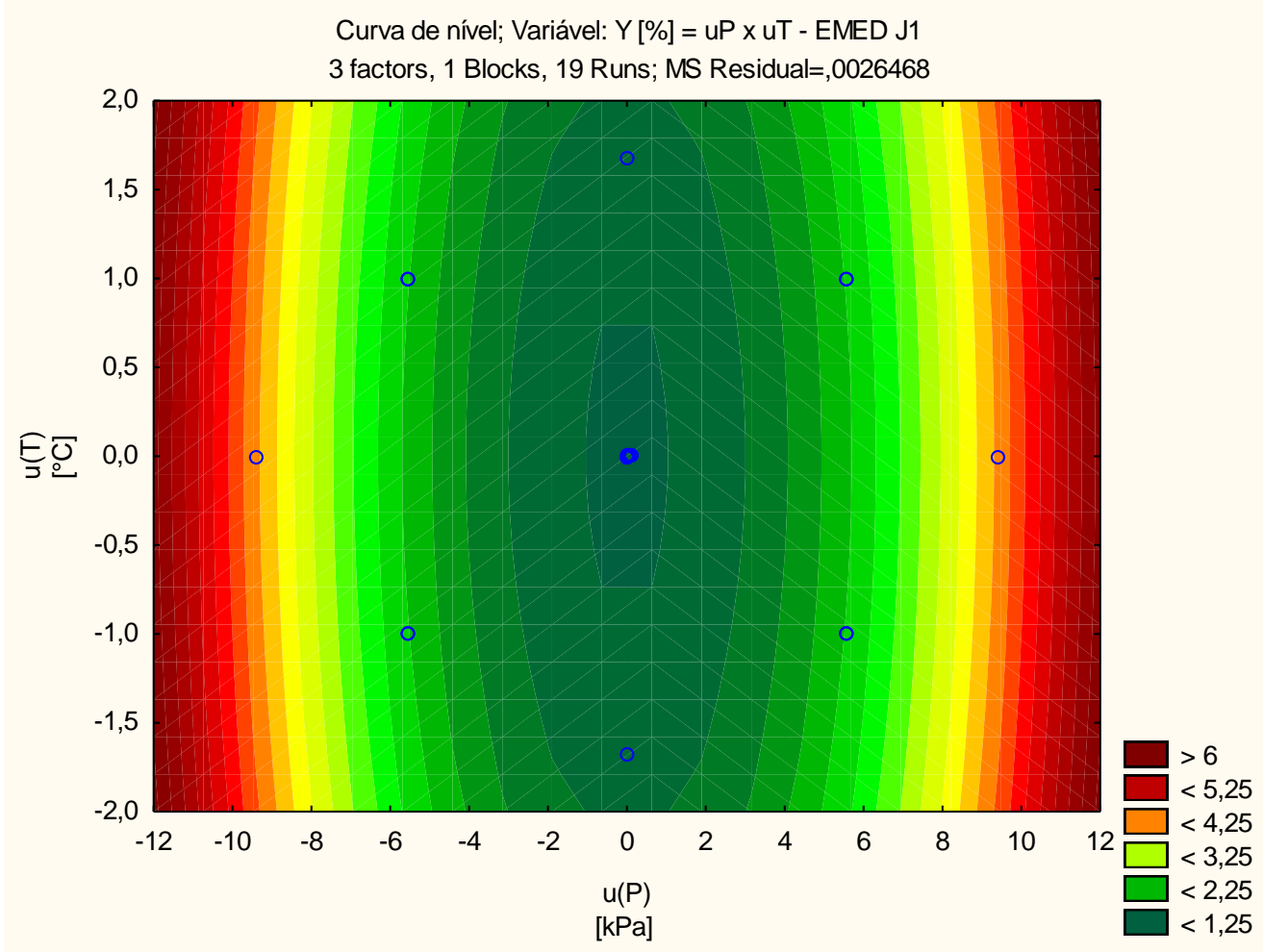

Figura A.94 - Curva de nível (EMED J1) dado uP (1\% f.e.) e uT $\left( \pm 1^{\circ} \mathrm{C}\right)$ 
Superficie de Resposta; Variável: $Y$ [\%] = UT X UDP - EMED J1

3 fatores, 1 Bloco, 19 Experimentos; Média Quadrática Residual $=, 0026468$

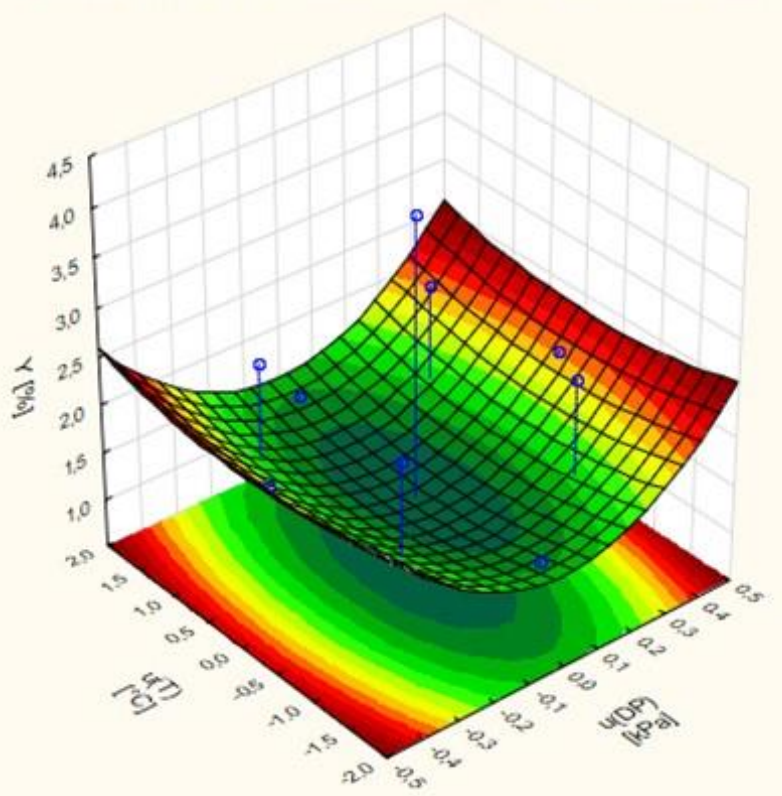

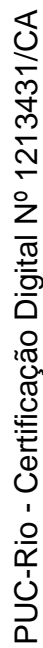

Figura A.95 - Superfície de resposta (EMED J1) dado uDP (1\% f.e.) e uT $\left( \pm 1^{\circ} \mathrm{C}\right)$

Curva de nível; Variável: Y [\%] = UT x UDP - EMED J1

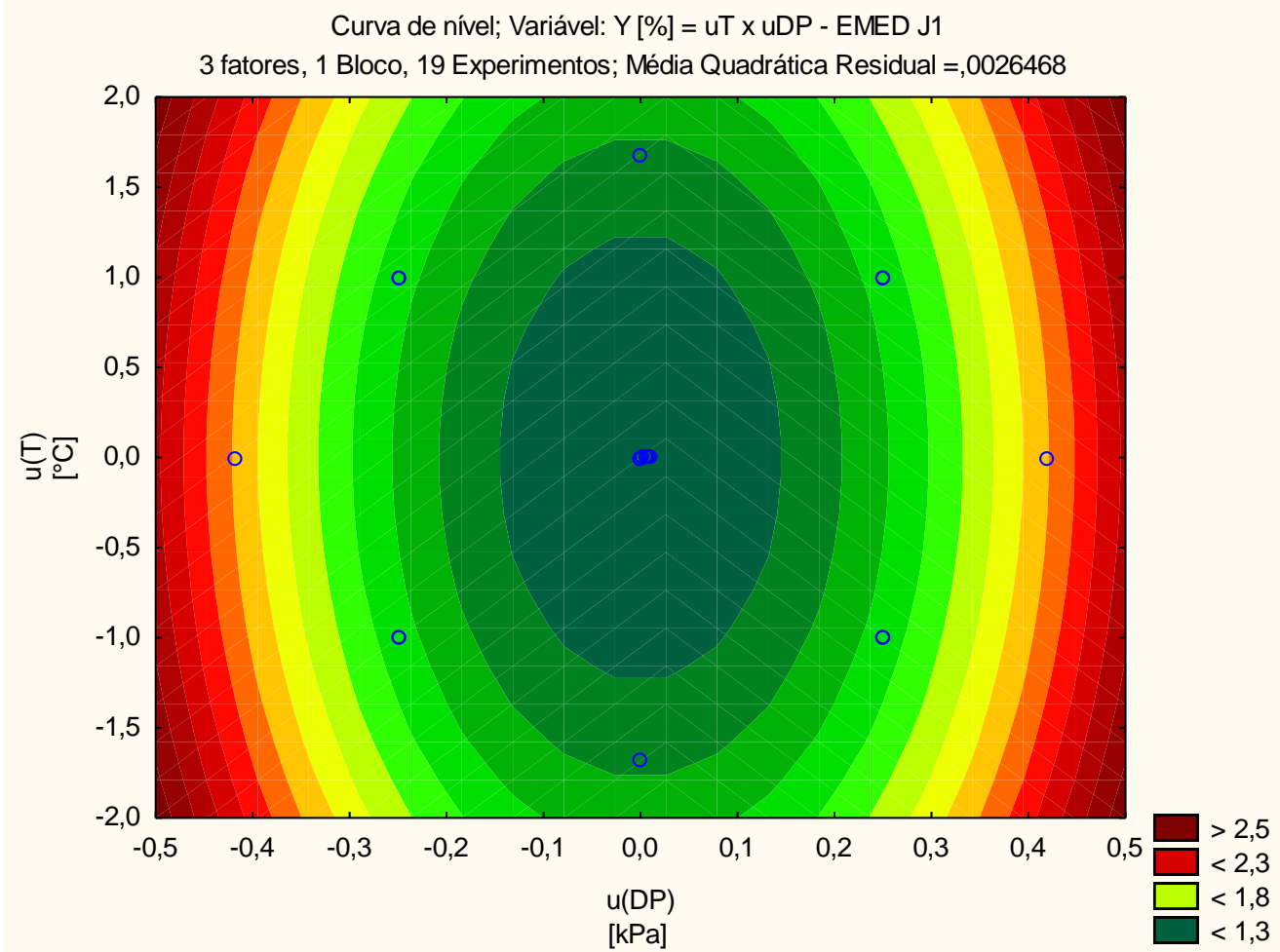

Figura A.96 - Curva de nível (EMED J1) dado uDP (1\% f.e.) e uT $\left( \pm 1{ }^{\circ} \mathrm{C}\right)$ 


\section{A.13}

\section{Estação J2 - estação de medição fiscal}

Tabela A.37 - Matriz de planejamento experimental da EMED J2

\begin{tabular}{|c|c|c|c|c|c|c|c|}
\hline \multicolumn{7}{|c|}{ Matriz do planejamento } & $\begin{array}{c}\text { Incerteza da } \\
\text { vazão }\end{array}$ \\
\hline Exp & $\mathrm{x} 1$ & $\mathrm{x} 2$ & $\mathrm{x} 3$ & $\begin{array}{c}\mathrm{P} \\
{[\mathrm{kPa}]}\end{array}$ & $\mathrm{DP}[\mathrm{kPa}]$ & $\begin{array}{c}\mathrm{T} \\
{\left[{ }^{\circ} \mathrm{C}\right]}\end{array}$ & $\mathrm{y}(\%)$ \\
\hline 1 & -1 & -1 & -1 & $-6,8600$ & $-0,2491$ & $-1,0000$ & 2,17 \\
2 & 1 & -1 & -1 & 6,8600 & $-0,2491$ & $-1,0000$ & 2,17 \\
3 & -1 & 1 & -1 & $-6,8600$ & 0,2491 & $-1,0000$ & 2,17 \\
4 & 1 & 1 & -1 & 6,8600 & 0,2491 & $-1,0000$ & 2,17 \\
5 & -1 & -1 & 1 & $-6,8600$ & $-0,2491$ & 1,0000 & 2,17 \\
6 & 1 & -1 & 1 & 6,8600 & $-0,2491$ & 1,0000 & 2,17 \\
7 & -1 & 1 & 1 & $-6,8600$ & 0,2491 & 1,0000 & 2,17 \\
8 & 1 & 1 & 1 & 6,8600 & 0,2491 & 1,0000 & 2,17 \\
9 & $-1,682$ & 0 & 0 & $-11,5385$ & 0,0000 & 0,0000 & 3,17 \\
10 & 1,682 & 0 & 0 & 11,5385 & 0,0000 & 0,0000 & 3,17 \\
11 & 0 & $-1,682$ & 0 & 0,0000 & $-0,4190$ & 0,0000 & 2,03 \\
12 & 0 & 1,682 & 0 & 0,0000 & 0,4190 & 0,0000 & 2,03 \\
13 & 0 & 0 & $-1,682$ & 0,0000 & 0,0000 & $-1,6820$ & 1,39 \\
14 & 0 & 0 & 1,682 & 0,0000 & 0,0000 & 1,6820 & 1,39 \\
15 & 0 & 0 & 0 & 0,0000 & 0,0000 & 0,0000 & 1,19 \\
16 & 0 & 0 & 0 & 0,0163 & 0,0029 & 0,0148 & 1,19 \\
17 & 0 & 0 & 0 & 0,0146 & 0,0000 & 0,0027 & 1,19 \\
18 & 0 & 0 & 0 & 0,0192 & 0,0016 & 0,0043 & 1,19 \\
19 & 0 & 0 & 0 & 0,0142 & 0,0003 & 0,0025 & 1,19 \\
\hline
\end{tabular}

Tabela A.38 - Tabela de ANOVA do planejamento de experimentos da EMED J2

\begin{tabular}{|c|c|c|c|c|c|}
\hline \multirow[b]{2}{*}{ Fonte de variação } & \multicolumn{5}{|c|}{$\begin{array}{c}\text { ANOVA; Var.:Y [\%]; } \mathrm{R}^{2}=, 99135 ; \mathrm{R}_{\mathrm{a}}^{2}:, 98271 \\
3 \text { fatores, 1 Bloco, } 19 \text { Experimentos; Média Quadrática Residual =,0260231 }\end{array}$} \\
\hline & $\begin{array}{c}\text { Soma de } \\
\text { Quadrados }\end{array}$ & $\begin{array}{l}\text { Graus de } \\
\text { liberdade }\end{array}$ & Quadrados médios & Teste F & $\mathrm{p}$ \\
\hline$(1) \mathrm{u}(\mathrm{P})[\mathrm{kPa}](\mathrm{L})$ & 0,00000 & 1 & 0,00000 & 0,0000 & 0,994653 \\
\hline $\mathrm{u}(\mathrm{P})[\mathrm{kPa}](\mathrm{Q})$ & 16,30272 & 1 & 16,30272 & 626,4707 & 0,000000 \\
\hline$(2) \mathrm{u}(\mathrm{DP})[\mathrm{kPa}](\mathrm{L})$ & 0,00000 & 1 & 0,00000 & 0,0002 & 0,990333 \\
\hline $\mathrm{u}(\mathrm{DP})[\mathrm{kPa}](\mathrm{Q})$ & 14,26241 & 1 & 14,26241 & 548,0670 & 0,000000 \\
\hline$(3) \mathrm{u}(\mathrm{T})\left[{ }^{\circ} \mathrm{C}\right](\mathrm{L})$ & 0,00000 & 1 & 0,00000 & 0,0000 & 0,999504 \\
\hline $\mathrm{u}(\mathrm{T})\left[{ }^{\circ} \mathrm{C}\right](\mathrm{Q})$ & 0,31421 & 1 & 0,31421 & 12,0744 & 0,006995 \\
\hline $1 \mathrm{~L} \times 2 \mathrm{~L}$ & 0,00000 & 1 & 0,00000 & 0,0000 & 0,999871 \\
\hline $1 \mathrm{~L} \times 3 \mathrm{~L}$ & 0,00000 & 1 & 0,00000 & 0,0000 & 0,999993 \\
\hline $2 \mathrm{~L} \times 3 \mathrm{~L}$ & 0,00000 & 1 & 0,00000 & 0,0000 & 0,999985 \\
\hline Erro & 0,23421 & 9 & 0,02602 & & \\
\hline Total SQ & 27,09167 & 18 & & & \\
\hline
\end{tabular}


Gráfico de Pareto dos Efeitos; Variável: Y[\%] - EMED J2

3 fatores, 1 Bloco, 19 Experimentos; Média Quadrática Residual =,0260231

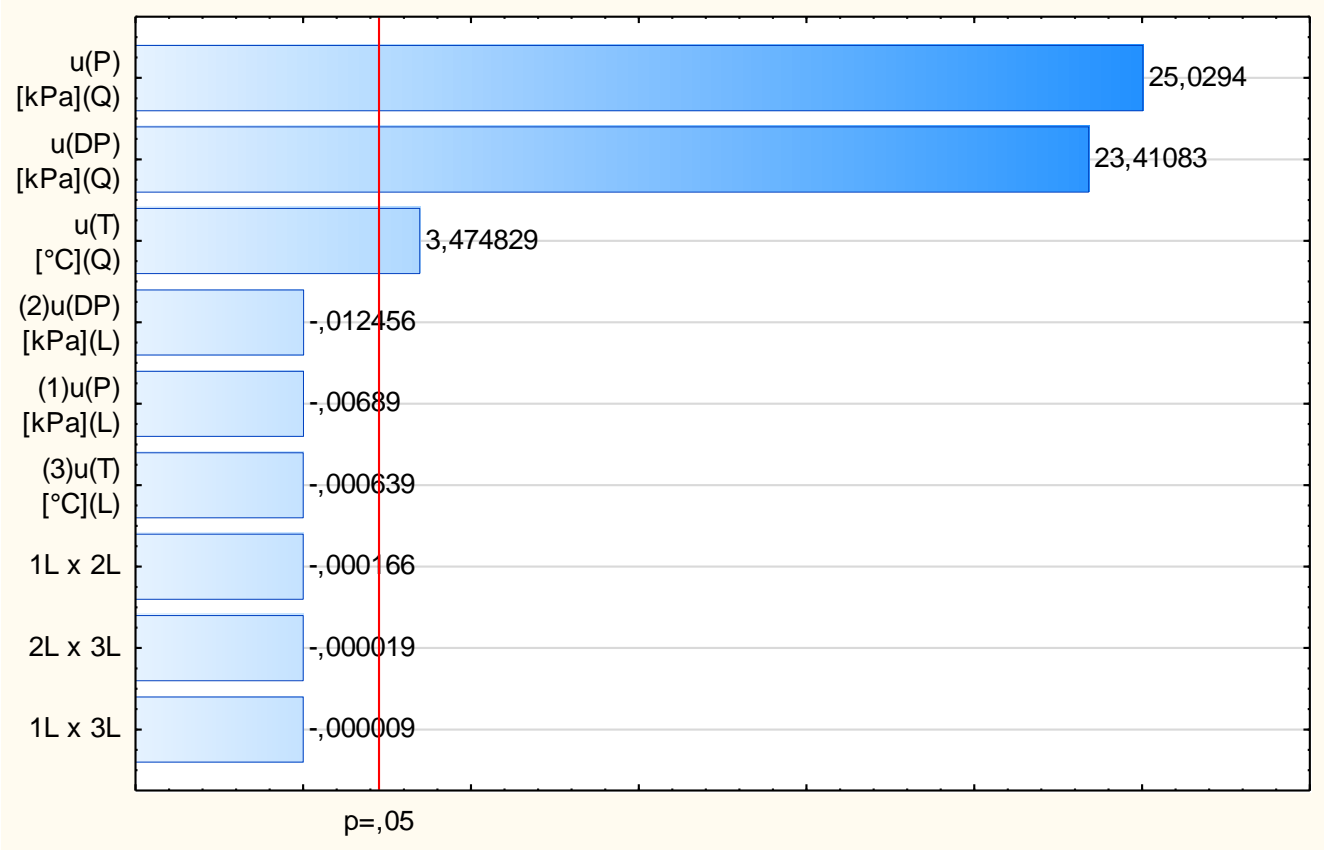

Estimativa dos Efeitos Padronizados (Valor absoluto)

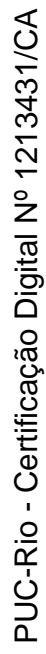

Figura A.97 - Gráfico de Pareto em função dos valores da estatística de teste t

Valores Previstos vs. Valores Residuais - EMED J2

3 fatores, 1 Bloco, 19 Experimentos; Média Quadrática Residual =,0260231

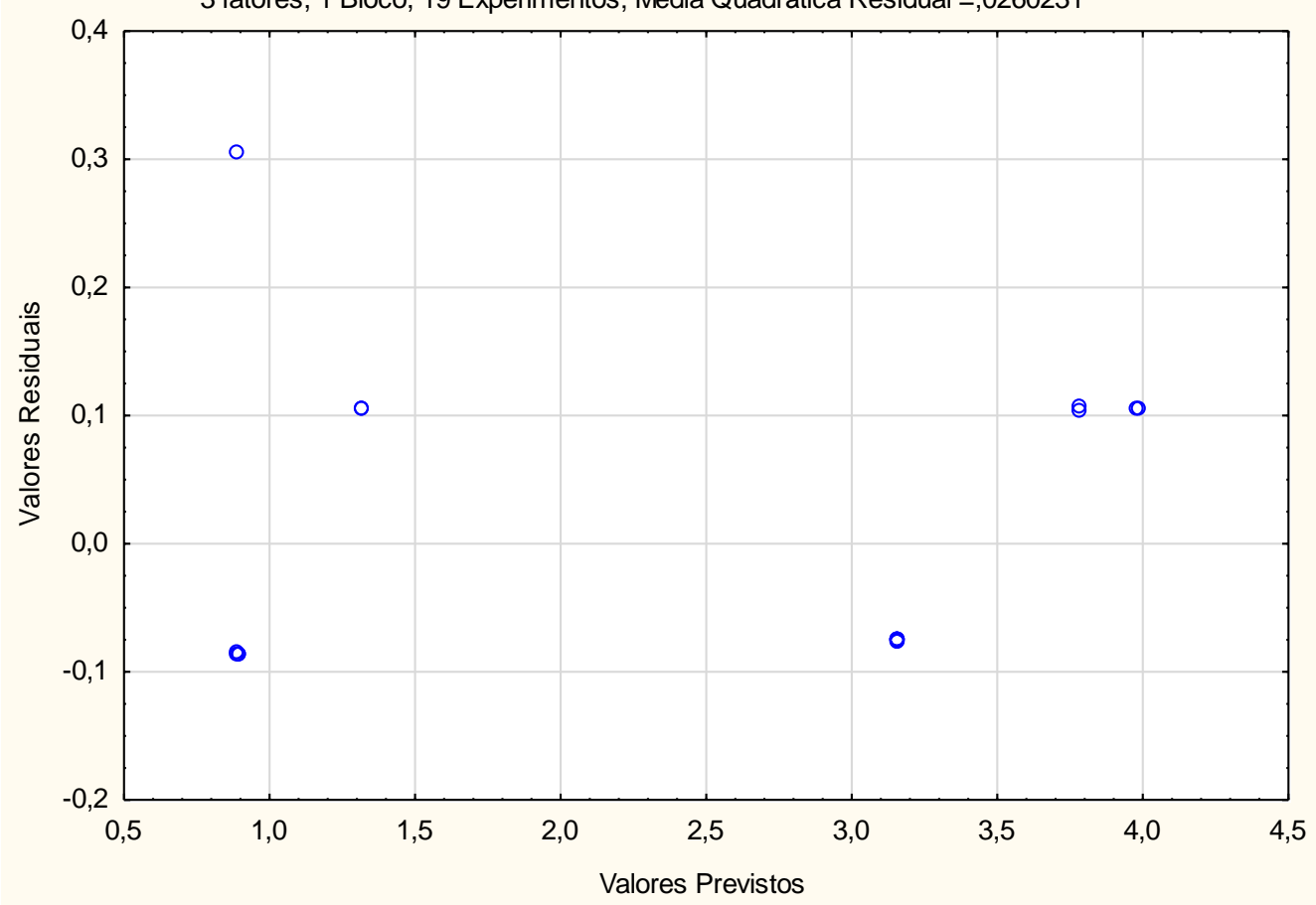

Figura A.98 - Resíduos versus estimativas de y (EMED J2 - nível: $1 \%$ f.e. e $1^{\circ} \mathrm{C}$ ) 
Tabela A.39 - Matriz das incertezas estimadas da vazão (EMED J2)

(dado $x_{3}(T)$ igual a 1 e $x_{1}$ e $x_{2}$ variando do nível baixo ao nível alto)

\begin{tabular}{|c|c|c|c|c|c|c|c|c|c|c|c|}
\multicolumn{1}{c|}{} & \multicolumn{10}{c|}{$\mathbf{x}_{\mathbf{1}}$} \\
\cline { 2 - 14 } & -1 & $-0,8$ & $-0,6$ & $-0,4$ & $-0,2$ & 0 & 0,2 & 0,4 & 0,6 & 0,8 & 1 \\
\hline-1 & 3,16 & 2,76 & 2,46 & 2,24 & 2,11 & 2,06 & 2,11 & 2,24 & 2,46 & 2,76 & 3,16 \\
\hline$-0,8$ & 2,79 & 2,39 & 2,09 & 1,87 & 1,74 & 1,69 & 1,74 & 1,87 & 2,09 & 2,39 & 2,79 \\
\hline$-0,6$ & 2,50 & 2,11 & 1,80 & 1,58 & 1,45 & 1,41 & 1,45 & 1,58 & 1,80 & 2,11 & 2,50 \\
\hline$-0,4$ & 2,30 & 1,90 & 1,60 & 1,38 & 1,25 & 1,20 & 1,25 & 1,38 & 1,60 & 1,90 & 2,30 \\
\hline$-0,2$ & 2,17 & 1,78 & 1,47 & 1,26 & 1,13 & 1,08 & 1,13 & 1,26 & 1,47 & 1,78 & 2,17 \\
\hline 0 & 2,13 & 1,74 & 1,43 & 1,22 & 1,08 & 1,04 & 1,08 & 1,22 & 1,43 & 1,74 & 2,13 \\
\hline 0,2 & 2,17 & 1,78 & 1,47 & 1,26 & 1,13 & 1,08 & 1,13 & 1,26 & 1,47 & 1,78 & 2,17 \\
\hline 0,4 & 2,30 & 1,90 & 1,60 & 1,38 & 1,25 & 1,20 & 1,25 & 1,38 & 1,60 & 1,90 & 2,30 \\
\hline 0,6 & 2,50 & 2,11 & 1,80 & 1,58 & 1,45 & 1,41 & 1,45 & 1,58 & 1,80 & 2,11 & 2,50 \\
\hline 0,8 & 2,79 & 2,39 & 2,09 & 1,87 & 1,74 & 1,69 & 1,74 & 1,87 & 2,09 & 2,39 & 2,79 \\
\hline 1 & 3,16 & 2,76 & 2,46 & 2,24 & 2,11 & 2,06 & 2,11 & 2,24 & 2,46 & 2,76 & 3,16 \\
\hline
\end{tabular}

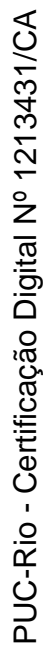

Superficie de Resposta; Variável: $Y$ [\%] = uP $x$ uDP - EMED J2

3 fatores, 1 Bloco, 19 Experimentos; Média Quadrática Residual $=, 0260231$

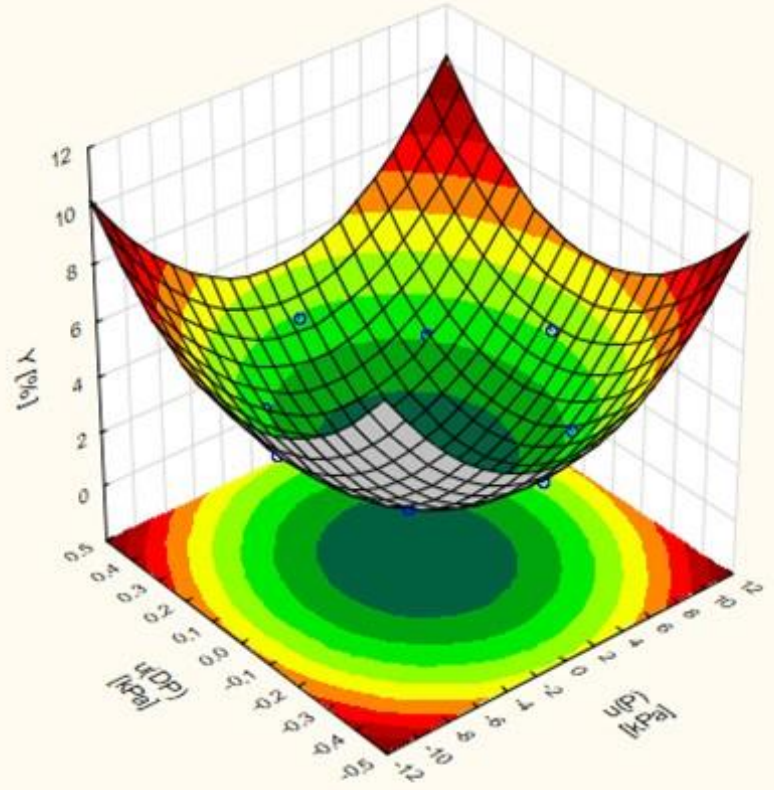

Figura A.99 - Superfície de resposta (EMED J2) dado uP e uDP (1 \% f.e.) 
Curva de nível; Variável: Y [\%] = uP x uDP - EMED J2

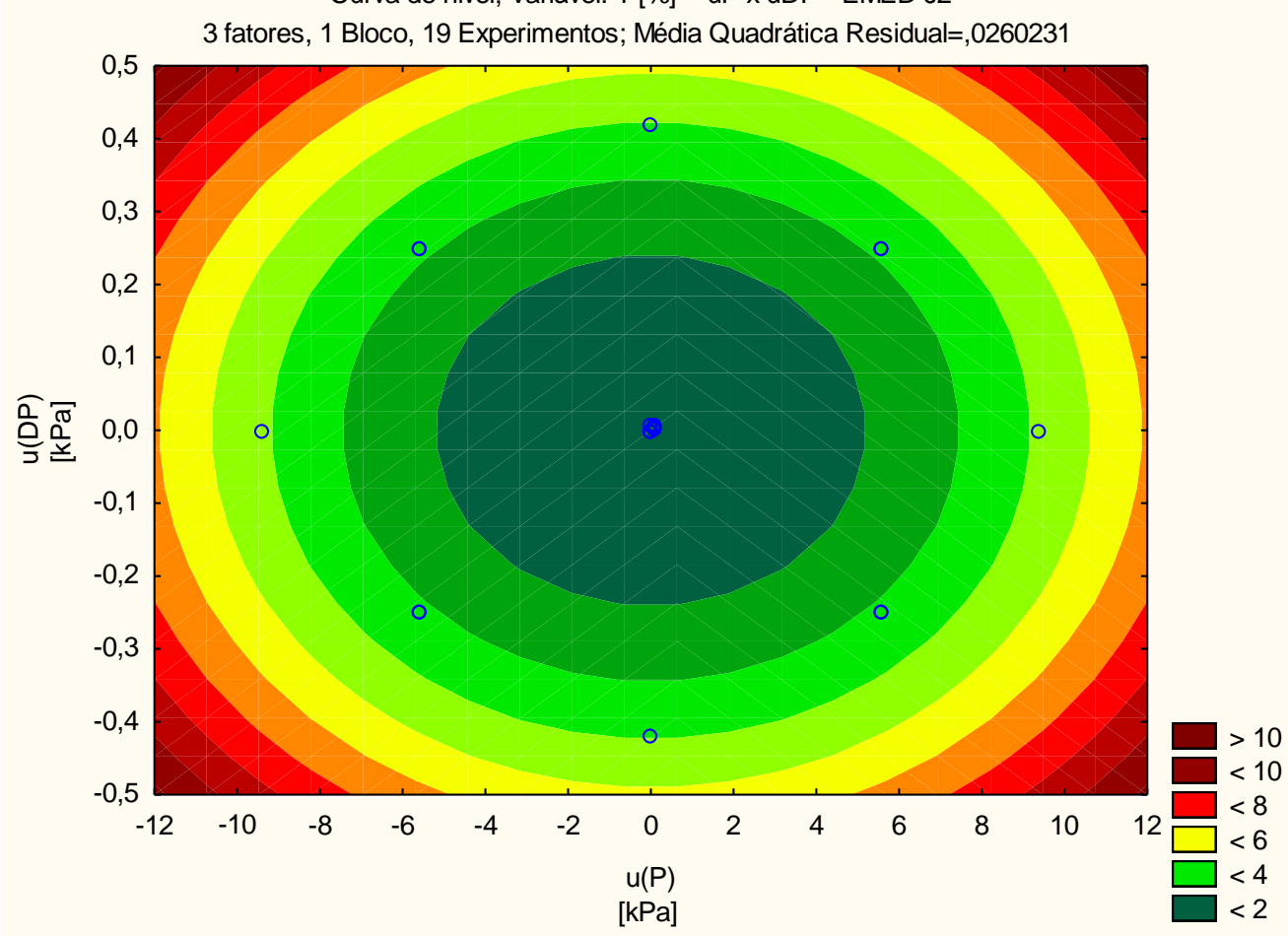

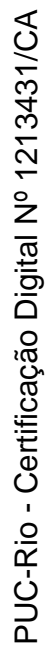

Figura A.100 - Curva de nível (EMED J2) dado uP e uDP (1 \% f.e.)

Superficie de Resposta; Variável: Y [\%] = uP x UT - EMED J2 3 fatores, 1 Bloco, 19 Experimentos; Média Quadrática Residual $=, 0260231$

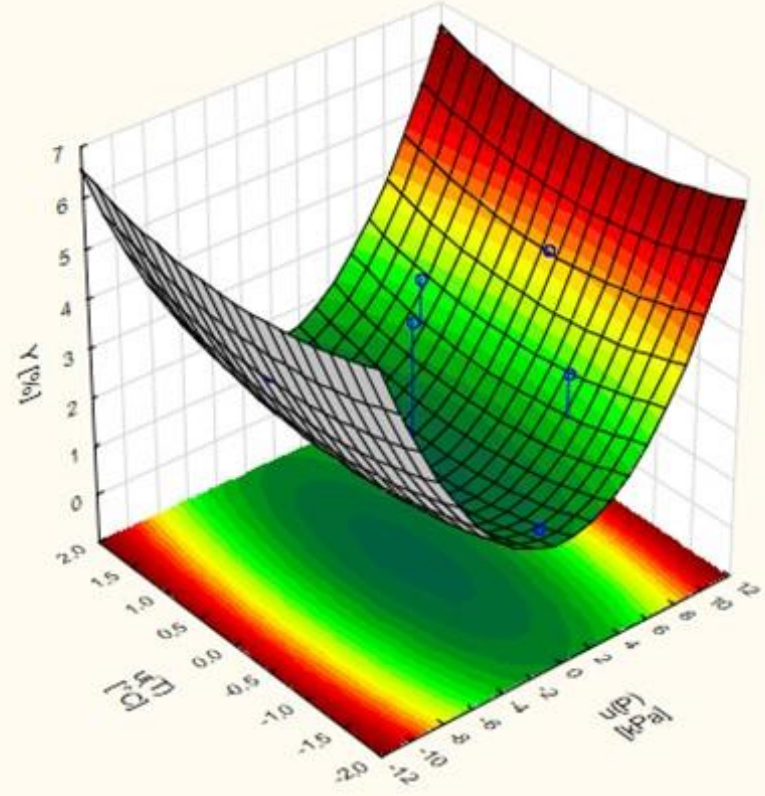

Figura A.101 - Superfície de resposta (EMED J2) dado uP (1\% f.e.) e uT $\left( \pm 1{ }^{\circ} \mathrm{C}\right)$ 
Curva de nível; Variável: Y [\%] = uP x uT - EMED J2

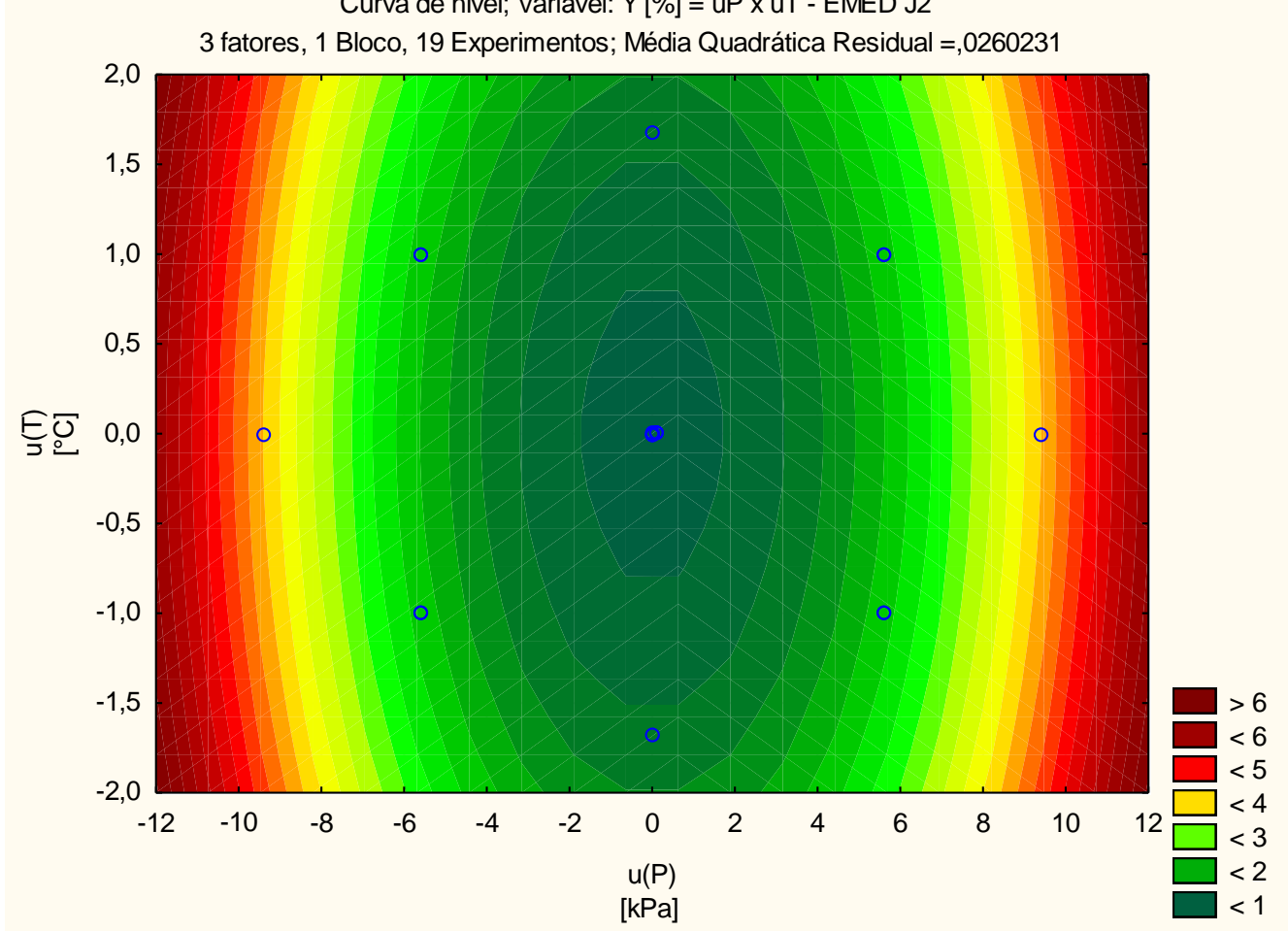

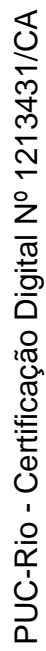

Figura A.102 - Curva de nível (EMED J2) dado uP (1 \% f.e.) e uT $\left( \pm 1^{\circ} \mathrm{C}\right)$

Superfície de Resposta; Variável: $Y$ [\%] = UT X uDP - EMED J2

3 fatores, 1 Bloco, 19 Experimentos; Média Quadrática Residual $=, 0260231$

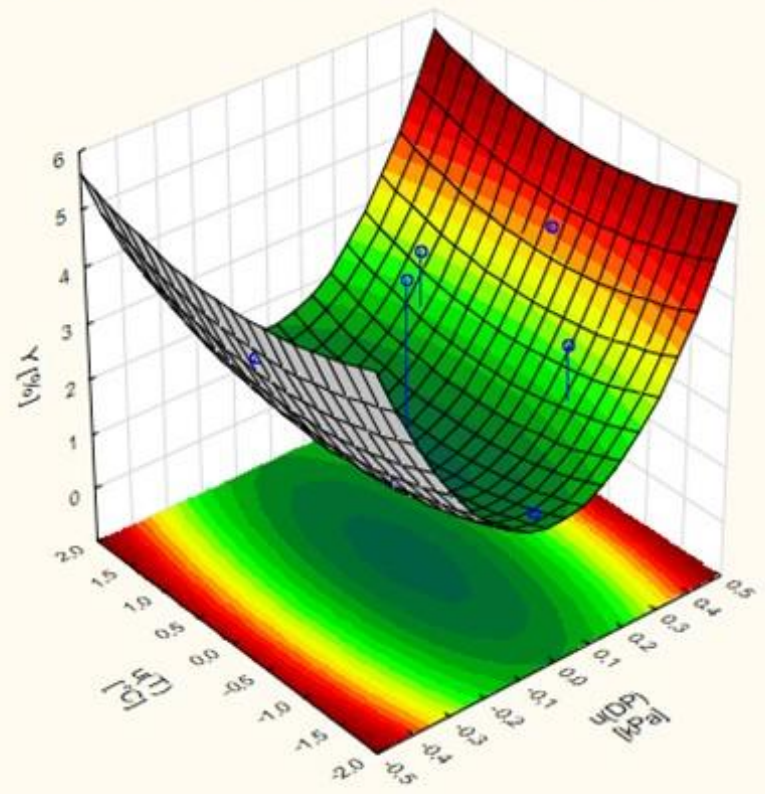

Figura A.103 - Superfície de resposta (EMED J2) dado uDP (1\% f.e.) e uT $\left( \pm 1^{\circ} \mathrm{C}\right)$ 
Curva de nível; Variável: Y [\%] = UT x uDP - EMED J2

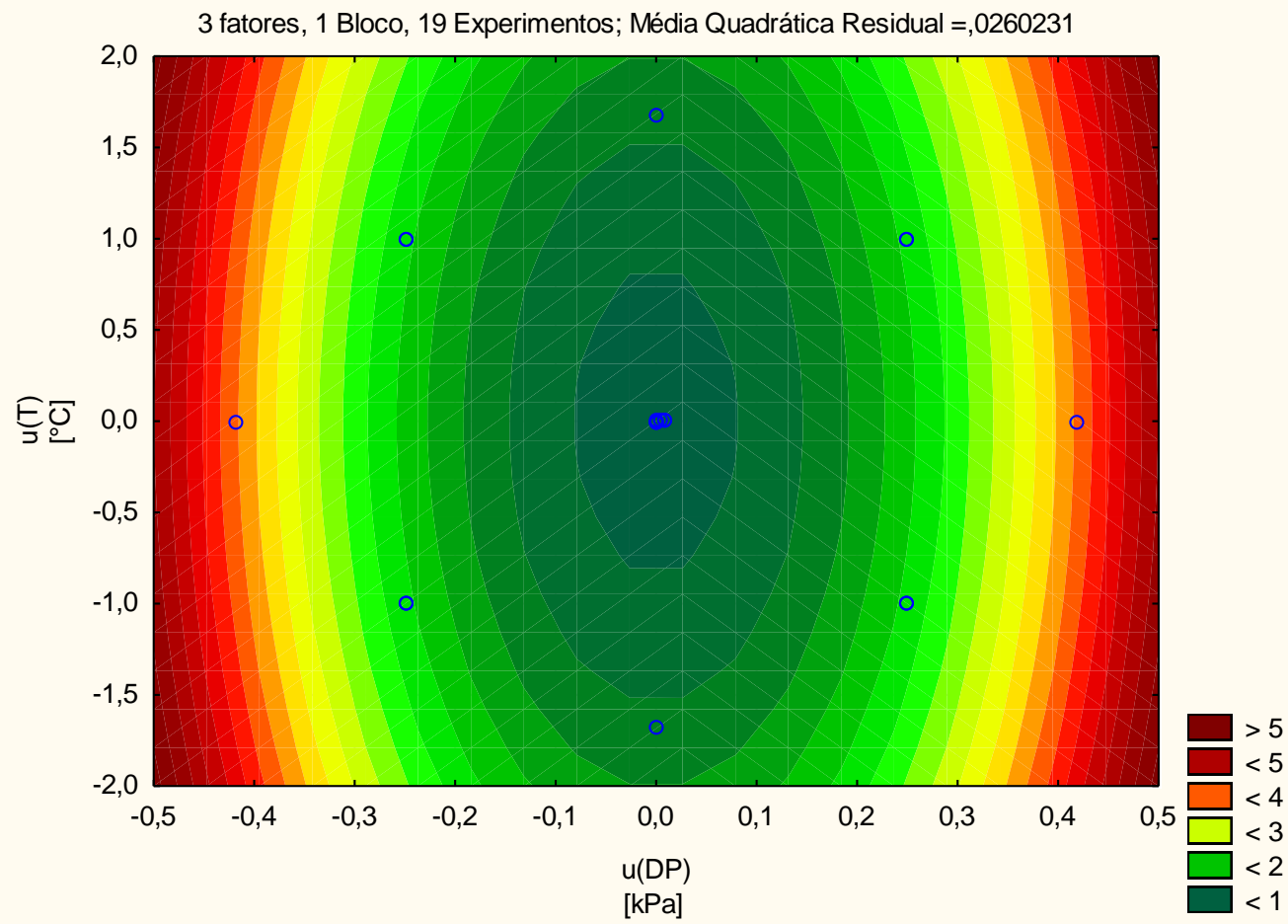

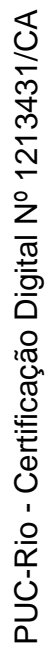

Figura A.104 - Curva de nível (EMED J2) dado uDP $\left(1 \%\right.$ f.e.) e uT $\left( \pm 1{ }^{\circ} \mathrm{C}\right)$ 